\title{
Madurez institucional
}

\section{995-20I 8}

El presente
capítulo

está estructurado en seis acápites. En el primero de ellos se ofrece un contexto global y nacional de las transformaciones sufridas por la educación superior desde la década de 1990 y que vienen determinando el desarrollo del sector hasta nuestros días. Los cinco acápites restantes coinciden con las administraciones de los cinco rectores generales que ha tenido la USTA desde I995 hasta nuestros días. En estos acápites sustantivos se sintetizan los elementos más destacables de las respectivas administraciones rectorales con subacápites especiales para las sedes, seccionales y la VUAD.

\section{CAMBIOS EN LA UNIVERSIDAD DESDE LA DÉCADA DE I990}

El fin de la rectoría de fray Álvaro Galvis se dio en un periodo de transformaciones del sistema universitario en general y de la educación superior católica en particular. En 1990, la Constitución Apostólica para las universidades católicas, Ex Corde Ecclesiae, del papa Juan Pablo II, definió naturaleza, misión e identidad de las universidades católicas a nivel mundial a través de una multiplicidad de elementos como la catolicidad de los planteles, su relación con la Iglesia, lineamientos generales de pastoral, etc.

Desde su promulgación, esta Constitución ha servido de faro para todas las instituciones universitarias católicas en el mundo y ha coadyuvado a afianzar la comunidad universitaria católica global. En cierto sentido, Ex Corde Ecclesiae reafirmó la misión y valores que la Universidad Santo Tomás había puesto en funcionamiento desde su restauración en 1965 y que hemos analizado ya en el primer capítulo. Así, por ejemplo, en el numeral 7 de la Constitución, sobre el contexto tecnológico contemporáneo, se afirma:

En el mundo de hoy, caracterizado por unos progresos tan rápidos en la ciencia y en la tecnología, las tareas de la universidad católica asumen una importancia y una urgencia cada vez mayores. De hecho, los descubrimientos científicos y tecnológicos, si por una parte conllevan un enorme crecimiento económico e industrial, por otra imponen ineludiblemente la necesaria y correspondiente búsqueda del significado, con el fin de garantizar que los nuevos descubrimientos sean usados para el auténtico bien de cada persona y del conjunto de la sociedad humana. Si es responsabilidad de toda universidad buscar este significado, la universidad católica está llamada de modo especial a responder a esta exigencia; su inspiración cristiana le permite incluir en su búsqueda la dimensión moral, espiritual y religiosa, y valorar las conquistas de la ciencia y de la tecnología en la perspectiva total de la persona humana ${ }^{\mathrm{I}}$.

La reflexión sobre la educación superior católica coincidió con reformas del sistema universitario alrededor del mundo. Claudio Rama ha establecido tres grandes momentos de reforma a la educación superior latinoamericana en el siglo Xx. El primero se corresponde con las demandas del movimiento de Córdoba y sus repercusiones en las décadas subsiguientes. El segundo podría caracterizarse como reforma neoliberal, llevada a cabo entre las décadas de I980 y I990. La tercera y última habría surgido, según Rama, desde mediados 


\title{
I 66
}

\author{
Madurez institucional 1995-2018
}

de la década de 1990 a partir de las inconsistencias de la segunda y como causa de fenómenos mundiales como la revolución tecnológica y la globalización ${ }^{2}$.

Lo que para Rama son dos fenómenos diferenciados, a saber la segunda y tercera reformas, los tomaremos para nuestros efectos como una serie conjunta de transformaciones acaecidas a la educación superior en las últimas tres décadas y que están atadas a procesos mundiales como la globalización, el vertiginoso desarrollo de las comunicaciones y el triunfo de la ideología de mercado. En este sentido, hay que decir que desde la década de 1980 en América Latina, y en Colombia desde los noventa, la educación superior ha atravesado por procesos de mercantilización, privatización, internacionalización, diversificación, tecnificación, entre otras que han llevado a una resignificación de la experiencia del conocimiento académico y de la vida universitaria ${ }^{3}$.

Así, se han generado sistemas de educación superior complejos y segmentados en que, por poner un ejemplo, la tradicional universidad con un campus en una ciudad ha devenido en universidad "multicampus". La universidad privada, además, ha confirmado su dominio en el mercado en buena parte de los sistemas latinoamericanos, las iniciativas investigativas se han complejizado, tecnificado e internacionalizado y la población estudiantil se ha masificado ${ }^{4}$. Cabe aclarar que estos procesos son, desde cierto punto de vista, una intensificación de tendencias que se venían dando desde la segunda posguerra, tal como vimos en el primer capítulo.

Desde la década de I980, sin embargo, el mundo entero ha estado signado por fuertes impulsos de globalización y mercantilización. La ideología del libre mercado se ha impuesto en las sociedades humanas por el incontenible ímpetu del capital financiero que busca la apropiación y explotación de recursos para alimentar la insaciable necesidad de consumo del mundo moderno. Al asediar las barreras comerciales y arancelarias, el capital financiero ha contribuido a la dilución de las fronteras y la emergencia de la llamada "aldea global", una experiencia planetaria marcada por la interconexión, la facilidad de comunicación, la aceleración del ritmo de vida, entre otras.

La globalización también está asociada al vertiginoso desarrollo de las tecnologías de la comunicación que aportan nuevas experiencias espacio-temporales y contribuyen a la creación de nuevos lenguajes. Así, el avance y popularización de la telefonía celular desde las últimas décadas del siglo xx y la masificación del uso del Internet en los últimos veinte años han alterado por completo la experiencia de la modernidad en incontables formas y hasta en los más recónditos parajes del globo.

Las tecnologías de la información han transformado a su vez la experiencia del conocimiento, de la academia y de la universidad, esferas humanas cuyas prácticas consisten precisamente en un conjunto de acciones informativas y comunicativas. Los hábitos de lectura y escritura se han digitalizado, los ritmos de trabajo se han acelerado, nuevos métodos han aparecido, los escenarios de producción se han diversificado, los espacios de enseñanza y aprendizaje se han reformulado, muchas barreras disciplinarias se han desvanecido, las iniciativas se han internacionalizado, los mercados educativo y científico se han ampliado. Además, nuevos paradigmas científicos en todas las áreas del conocimiento han acompañado estos procesos.

Como manifestación de la emergencia de una "aldea global universitaria”, vale la pena señalar la celebración de diversas conferencias sobre educación superior, regionales y mundiales en los que representantes de buena parte de los estados nacionales, así como de la academia y de la comunidad universitaria, se reúnen para debatir los problemas globales y establecer derroteros y lineamientos generales a largo plazo. Mencionemos apenas de paso las dos conferencias mundiales sobre educación superior celebradas en París en 1998 y 2009 y las dos conferencias regionales latinoamericanas celebradas en La Habana en 1996 y Cartagena de Indias en 2008.

Teniendo en cuenta el carácter neoliberal de las reformas universitarias latinoamericanas desde la década de i980, no sorprende que el fenómeno haya dado inicio muy tempranamente en Chile, primer país del continente en que se institucionalizó la doctrina del libre mercado bajo la dictadura de Augusto Pinochet (1973-1990)5. De ahí para adelante se sucedieron las reformas neoliberales en el resto del continente - excepto en casos especiales como $\mathrm{Cuba}-$ auspiciadas por los organismos de cooperación e integración internacional, tal como había sucedido con las reformas desarrollistas de las décadas de 1950 y $1960^{6}$ :

Los cinco países [Chile, Colombia, México, Argentina y Brasil] reformaron sus políticas hacia un marco parecido: estímulo a la educación privada, constitución de un marco regulatorio común válido para los sectores educativos público y privado, y creación de instituciones específicas para la orientación, el control y la vigilancia (acreditación y evaluación) de las instituciones de educación superior. Este 


\section{7}

\section{Madurez institucional 1995-20I8}

esquema debe permitir al Estado, por medio de un sistema de incitación financiera basada en indicadores de desempeño y de resultados, modificar los comportamientos de las instituciones educativas hacia la realización de ciertos objetivos generales de política pública7.

Instituciones de educación superior (IES) de diversa índole se multiplicaron, mientras que las públicas se vieron forzadas a buscar nuevas fuentes de financiamiento y a mercantilizarse para sobrevivir ${ }^{8}$. Con el tiempo, el elemento "privatizador" de la reforma se radicalizaría al entrar en escena las universidades corporativas y con ánimo de lucro que sirven directamente al sector empresarial y financiero. Martínez Boom coincide con Roth en su apreciación de la reforma de la década de 1990 como un fenómeno neoliberal. Para él, la educación en la última década del siglo XX se convirtió en herramienta del capital en la medida en que comenzó a ser atravesada por los valores empresariales como la "competencia". Las lógicas mercantiles de lo "eficaz", lo "eficiente" y lo "pertinente" se convirtieron en los vectores fundamentales de la educación ${ }^{9}$.

La educación se convierte así en un campo altamente competitivo en que se asocia la calidad al precio y las universidades se ven volcadas a una administración cada vez más gerencial con una primacía del marketing y la publicidad. Bajo esta lógica los estudiantes pasaron a ser percibidos como consumidores

\section{libres de seleccionar lo más conveniente de la oferta educacional para maximizar su potencial compe- titivo en la sociedad, mientras que los proveedores privados estuvieron en condiciones de aprovechar la posibilidad de atender un prometedor espacio de demanda en el cual materializar utilidades prove- nientes de la movilización de recursos adicionales por parte de los usuarios y sus familiares ${ }^{\mathrm{I}}$.}

Sobre el fenómeno de la privatización, nos dice Germán Rama, aún en términos de "segunda reforma":

La segunda reforma se caracterizó por la instauración de un complejo modelo binario — público y privado; de alta y baja calidad; universitario y no universitario- como resultado del contexto mercantil y heterogéneo, y que promovió modelos de calidad, de precios, de financiamiento diferenciados. Ello facilitó la significativa expansión del sector privado, medido en términos de cobertura, matrícula e instituciones, sobre la base, en general, de un pequeño sector de calidad y otro mayor orientado a la absorción de la demanda insatisfecha y con menores exigencias de calidad. Tan notable expansión privada diferenciada estuvo además asociada en sus inicios a la ausencia de mecanismos de regulación de la calidad de la educación superior y creó un desajuste estructural en el marco de un sistema totalmente heterogéneo, incontrolado y repetitivo ${ }^{\mathrm{II}}$.

Este es precisamente el escenario que se presentó en Colombia durante la década de i99o hasta que a fines de la década se emplearon políticas estatales para limitar el crecimiento irresponsable del sistema. Pero, en general, el Estado ha empequeñecido su rol en la esfera de la educación superior; en su retirada ha pasado de ser agente docente a regulador. En Colombia, como en América Latina, surgió entonces un sistema regulativo conformado por organismos de vigilancia y control que emplean mecanismos altamente tecnificados de evaluación institucional, jerarquización del conocimiento, de sus actores, etc. —se definieron por ejemplo los indicadores de evaluación por publicación en revistas indexadas y patentes-, que aportan indicadores al servicio de los ideales de productividad:

Bajo la inspiración y el apoyo técnico-financiero de organismos multilaterales, se observa a partir de los años 1980-1990 un despliegue de evaluaciones estandarizadas, de mediciones de la calidad comúnmente externas y cuantitativas para, así, facilitar comparaciones a escala nacional e internacional, con amplia utilización de procedimientos estadísticos. Por otro lado, también se reconoce el esfuerzo de una importante corriente de académicos para asegurar procesos evaluativos que, sobre todo, respeten los valores universitarios del conocimiento como elemento de realización humana, de la formación científica y socialmente relevante, de las aptitudes de respeto a la diversidad, cooperación, libertad y justicia, sin propósito de clasificación y rankings ${ }^{12}$.

Dias Sobrinho no solo señala las nuevas características de la función estatal, sino que a su vez apunta a la emergencia de sistemas transnacionales de evaluación y acreditación altamente tecnificados que usan lenguajes universales de medición. Este ha sido un factor fundamental para la internacionalización puesto que lenguajes universales ( $v . g r$., el de créditos académicos) permiten la convalidación, la homologación, en últimas la movilidad académica, tan característica de 


\section{68}

Madurez institucional I995-20I8

los últimos años. Un escenario en donde la internacionalización ha sido central es el de los posgrados, que ha tenido un crecimiento considerable.

El fenómeno de la internacionalización ha sido alentado por las tecnologías de la información y la comunicación (TIC), por la apertura de las sociedades comunistas asiáticas, pero es también una política global como lo demuestra la aparición, desde la década de I990, de diversos organismos de integración educativa universitaria ${ }^{\mathrm{r} 3}$. Alianzas educativas e investigativas bilaterales o multilaterales, afianzamiento de sistemas internacionales de becas y ayudas financieras, iniciativas docentes e investigativas multilaterales, internacionalización de currículos de instituciones y de programas académicos hacen parte de este proceso de internacionalización educativa.

Hoy en día, las bases de datos científicas y motores de búsqueda que se han convertido en pieza central de la investigación científica y el desarrollo de redes de conocimiento transfronterizas, que promueven la renovación permanente del mismo, han ayudado a conformar una comunidad universitaria global. Dentro de esta ha ido ganando espacio en los últimos años la enseñanza virtual que por medio de la tecnología ofrece educación a larga distancia. En Colombia, el despegue de la educación virtual se dio en los años 2004-2005 $5^{14}$.

La diversificación ha sido pieza central de toda esta transformación educativa. Estudiantes y profesores alimentan una comunidad universitaria tan diversa como no lo había sido a lo largo de ochocientos años de historia de una patriarcal, blanca y eurocéntrica universidad. La amplia cobertura social y regional ha beneficiado particularmente a las mujeres y a los habitantes de regiones apartadas de países como Colombia.

El escenario estudiantil universitario actual está marcado por las diversidades social, étnica, regional, laboral, política, etc. Aun así, estas diversidades no dejan de esconder nuevas inequidades asociadas a brechas de calidad y de capacidad de pago de los consumidores $^{15}$. Si la diversificación poblacional ha sido radical, la institucional no lo ha sido menos. Hoy en día, el panorama incluye institutos universitarios, corporaciones, escuelas técnicas y tecnológicas, universidades virtuales que brindan servicios educativos variopintos en modalidad, alcance, calidad y filosofía institucional ${ }^{\mathrm{I} 6}$.

Además, la departamentalización, el sistema de créditos académicos y la semestralización de los ciclos se han perfeccionado y estandarizado. A su vez, ha habido acortamiento de carreras, flexibilización de currículos, aceleración de procesos de revisión y actualización curricular, adopción de modelos de construcción colectiva del conocimiento y autoaprendizaje, entre otros. Se fue masificando además una idea de educación permanente que se contrapone a la idea del estudio universitario como un evento definitivo que se termina con la otorgación del título universitario para pasar completamente a la vida laboral. La cada vez más acelerada obsolescencia de los conocimientos contribuye en gran medida a afianzar todos estos cambios y a conferirles una naturaleza siempre transitoria.

Una expresión de la necesidad de transformaciones en el campo de la educación superior en Colombia son las misiones educativas que se llevaron a cabo en la década de 1990. A la Misión de Ciencia y Tecnología (I989-I99I) le siguió la Misión de Ciencias, Educación y Desarrollo (I993-I994), popularmente denominada "grupo de sabios". Esta última señaló problemas graves de cobertura, altas tasas de analfabetismo y baja calidad de la educación básica y media con serias repercusiones para la educación superior, además de otros graves problemas de infraestructura y preparación pedagógica de los docentes. Luego siguieron la Misión Nacional para la Modernización de la Universidad Pública (I994-I995) y la Misión Presidencial para el Desarrollo de la Educación Superior (I996).

Estas misiones reflexionaron y propusieron estrategias para el desarrollo tecnológico, la investigación y la educación dejando como conclusión, de acuerdo con Duque y Lucio, dos aspectos fundamentales: en primer lugar, la falta de voluntad política en la aplicación de los análisis y las propuestas que arrojan estas misiones y, en segundo lugar, el corto alcance de las políticas, que se limita en general al periodo del Gobierno Nacional que propone los planes de desarrollo ${ }^{17}$.

Colombia tuvo que enfrentarse a los cambios globales en la educación superior desde su situación muy particular de un país en guerra. A finales de la década de I980, en el marco del fortalecimiento de las guerrillas, la emergencia de los grupos paramilitares y la arremetida del narcoterrorismo, como estrategia para redireccionar políticamente al país frente a los desafíos del fin del milenio, sectores representativos se abocaron a un proceso de redefinición del Estadonación que culminó con la Constitución de i99i. Para la educación, la nueva carta política fue el preámbulo de la reforma. En el artículo sobre la educación superior, la Constitución reza: 


\section{69}

Madurez institucional 1995-2018

Artículo 69. Se garantiza la autonomía universitaria. Las universidades podrán darse sus directivas y regirse por sus propios estatutos, de acuerdo con la ley.

La ley establecerá un régimen especial para las universidades del Estado.

E1 Estado fortalecerá la investigación científica en las universidades oficiales y privadas y ofrecerá las condiciones especiales para su desarrollo.

E1 Estado facilitará mecanismos financieros que hagan posible el acceso de todas las personas aptas a la educación superior.

Pero no sería sino hasta la promulgación de la Ley 30 de 1992 que la historia contemporánea de la educación en Colombia dio realmente inicio. Como se puede apreciar en el citado artículo de la Constitución Nacional, la autonomía universitaria es un valor central del sentido mismo del sistema. La Ley 30 concretiza que la autonomía de las instituciones de educación superior es para darse y modificar sus estatutos, designar sus autoridades, crear y desarrollar programas académicos, expedir títulos, definir sus labores, arbitrar y aplicar sus recursos. Para las instituciones de educación superior privadas, esta autonomía así entendida sirvió como herramienta para ampliar su cobertura y suplir la creciente demand $\mathrm{a}^{\mathrm{I} 8}$.

En este contexto, el mantenimiento de la calidad de los programas y de los planteles se convirtió en un problema de Estado. La excesiva libertad del mercado implicó la proliferación de instituciones - pero principalmente de modalidades y programas académicosde sospechosa calidad, lo que tuvo como consecuencia una crisis generalizada de la educación superior ${ }^{19}$. Para las universidades privadas ya consolidadas como la Universidad Santo Tomás, esta situación ha constituido un enorme desafío.

La Ley 30 también preconstituyó el Sistema Nacional de Acreditación para regular la calidad educativa. Se previó que las instituciones de educación superior se acogerían voluntariamente al sistema a través de la autoevaluación para poder disfrutar de las prerrogativas de la acreditación que a su vez se estableció como un reconocimiento oficial temporal, lo que en la práctica confiere un carácter permanente a los procesos de autoevaluación y acreditación dentro de las universidades ${ }^{20}$.

E1 sistema quedó a cargo del Consejo Nacional de Educación Superior (CESU), del Consejo Nacional de Acreditación (CNA), dependiente de aquel, y del Icfes. La ley también creó una plataforma oficial de información sobre instituciones y programas de educación superior, el Sistema Nacional de Información de la Educación Superior (Snies). Además, para el fomento de la educación superior la ley ordenó la creación del Fondo para el Desarrollo de la Educación Superior (Fodesep) y el fortalecimiento del Instituto Colombiano de Crédito Educativo y Estudios Técnicos en el Exterior (Icetex). El sistema empezó a tomar forma en 1993 con la creación efectiva de estos organismos oficiales y con la reglamentación de su funcionamiento y criterios ${ }^{21}$.

Otras reformas enmarcadas en el espíritu de los noventa tomarían algunos años. Tal es el caso del establecimiento del crédito académico como mecanismo de cuantificación de la educación recibida por los estudiantes universitarios. En abril de 2002 el Gobierno Nacional estableció por decreto el sistema de créditos que remplazó definitivamente al sistema de Unidades de Labor Académica (ULAs) que había sido introducido en el país en la década de $1980^{22}$. La adopción del sistema de créditos había sido una tendencia global por varios años por sus facilidades para la movilidad académica. Para cuando fue oficializado en Colombia, el sistema de créditos ya había sido implantado en la Unión Europea, Estados Unidos y la mayoría de los países asiáticos.

\section{La Universidad debe sacudirse}

y renovarse moral e intelectualmente, vincularse a la sociedad y ser factor de transformación. 


\section{70}

\section{Madurez institucional 1995-20I8}

Los gobiernos de los últimos veinticinco años han sido fieles a las tendencias mundiales y continentales que hemos señalado anteriormente; la formulación de las políticas y los esfuerzos para llevarlas a cabo obedecen a las lógicas cuantitativas propias del lenguaje universal y estandarizado de los organismos de cooperación internacional, como tasas de cobertura, de mortalidad estudiantil, etc. Hay que decir que esto aplica sobre todo para los niveles educativos primario y secundario, que son el principal foco del esfuerzo administrativo estatal. Por cuenta de la autonomía del sistema universitario, el desarrollo de este obedece más a tendencias globales que a políticas públicas que consisten principalmente en estímulos económicos de carácter subsidiario y crediticio más que en reformas de fondo.

Así, en la década de r99o las políticas de educación superior de las tres administraciones presidenciales se centraron en programas de becas para estudios en el exterior ${ }^{23}$, incentivo al desarrollo tecnológico, estímulo a la creación de programas de posgrado, créditos, subsidios, etc. ${ }^{24}$. En lo que va corrido del presente siglo, la política educativa solo ha tendido a profundizar la filosofía instaurada en la década de I990. En una invitación del Ministerio de Educación Nacional al seminario internacional "Pertinencia de la Educación: la educación para la competitividad" que tuvo lugar en octubre de 2007, el Gobierno Nacional recordaba los lineamientos de su "Visión 2019", propuesta de desarrollo social en el marco del bicentenario de la Independencia:

Con este marco se definió la política para la competitividad de Colombia que toma la educación como estrategia transversal para el logro de las metas trazadas. En respuesta a esta política, el Ministerio de Educación viene adelantando acciones para fomentar un sistema educativo pertinente, en el cual la formación del recurso humano responda a las necesidades demandadas por los sectores productivos estratégicos para el país. Con esto se busca, por un lado, disminuir tiempos y costos en la selección de personal, así como reducir costos de adecuación y capacitación de la fuerza laboral por parte de las empresas $^{25}$.

De esta manera se invitaba al sector educativo a cumplir una misión fabril. La disminución de los tiempos de producción y el abaratamiento de los costos son expresión de una intensificación ideológica de la visión neoliberal de la educación, y particularmente de la universidad, como un medio de producción de capital humano al servicio de la empresa privada. Los valores de la competitividad y productividad se ven, pues, como necesarios para la atracción de la inversión extranjera ${ }^{26}$. En ese sentido, se ha estado fomentando una educación superior pertinente para el sector productivo en la cual la educación técnica y tecnológica ha sido fundamental ${ }^{27}$.

En 2011 se dio un intento por reformar la Ley 30 de 1992. Pese a que no fue finalmente ejecutado por cuenta de la amplia movilización civil en su contra, las características del proyecto gubernamental de reforma dan cuenta de la direccionalidad del modelo educativo colombiano. El proyecto pretendía mayor flexibilización laboral y académica para mejorar los indicadores de calidad y una serie de medidas para atraer la inversión privada, incluyendo la apertura a instituciones de educación superior con fines de lucro, y así lograr mejores índices de cobertura. En particular, el tema de las universidades con ánimo de lucro preocupó incluso a los planteles educativos privados, con lo que la movilización estudiantil alcanzó más fuerza y el proyecto fue finalmente retirado.

En el marco de un Estado cuya participación en la educación superior se reduce principalmente a labores regulativas, las políticas educativas desde la década de I990 han seguido los lineamientos y pautas del sistema mundial. En respuesta a un mercado global cada vez más competitivo y tecnificado, el Estado colombiano ha querido hacer partícipe a las universidades del impulso al desarrollo tecnológico y la innovación con fines de producción. Para ello se trazan continuamente metas de cobertura, se estimula el sistema a través del crédito educativo, se apoya la creación de programas de posgrados, entre otras. Así analizaba en el Informe de su gestión rectoral el rector fray Eduardo González Gil, O. P., una década de políticas educativas:

A pesar de las normas establecidas por la Ley 30 de 1992 , sus decretos reglamentarios y del Sistema Nacional de Acreditación, que fijan el marco conceptual y normativo para el cambio de nuestro sistema de educación superior, los adelantos hechos en el país son aún precarios porque la eficiencia y eficacia que se buscan en los procesos académicos y administrativos continúan afectadas por factores sociales, humanos, económicos, administrativos y por prácticas añejas ${ }^{28}$. 
I 7 I

Madurez institucional 1995-20I8

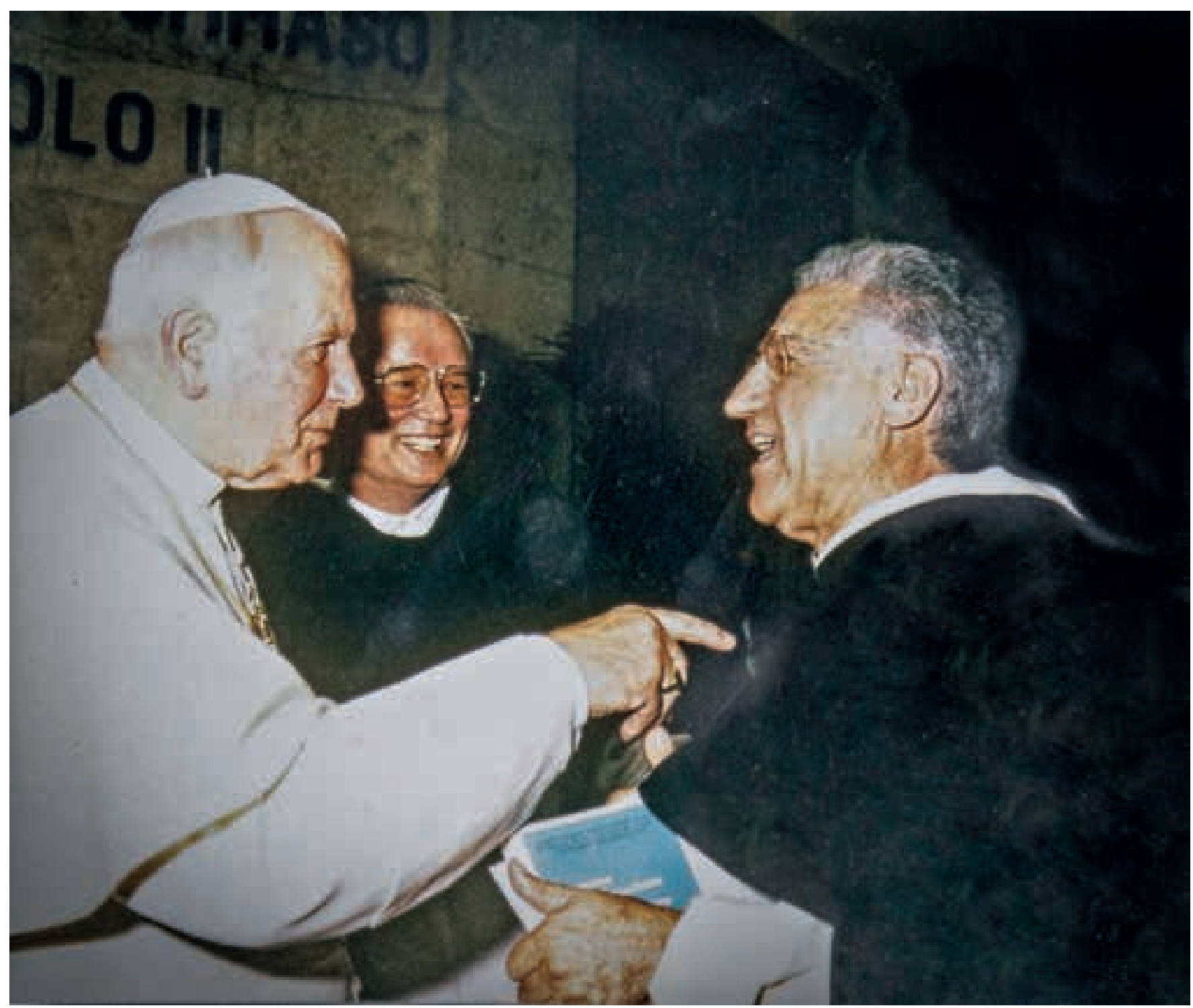

El papa Juan Pablo II durante su visita a Chiquinquirá en 1986. Lo acompañan fray Tito Murcia Florián, O.P. (atrás), y el Maestro de la Orden Damian Byrne, O.P. 


\section{72}

Madurez institucional $1995^{-2018}$

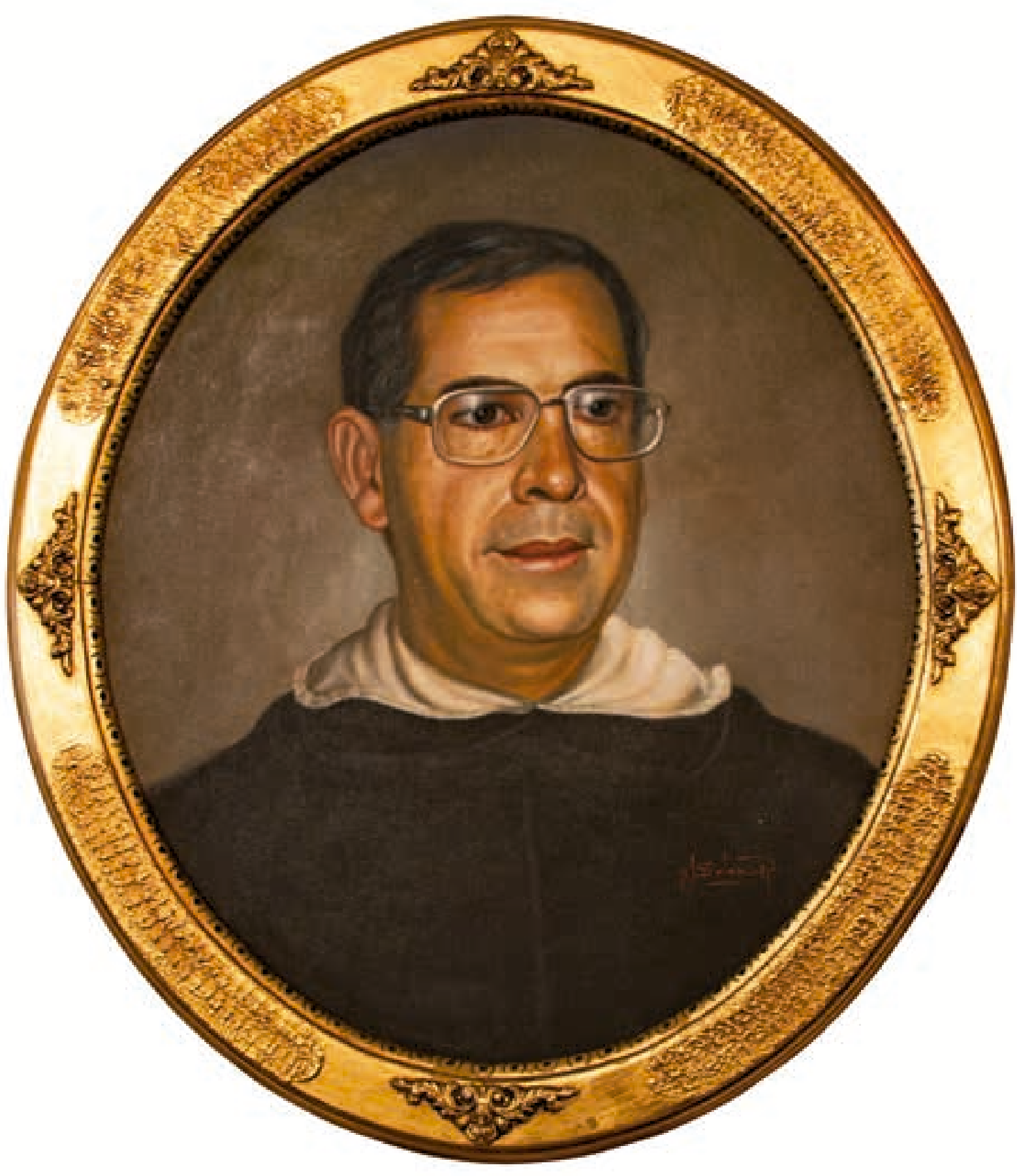

Fray Jaime de Jesús Valencia García,

O. P., rector general 1995-1999 


\section{73}

Madurez institucional 1995-2018

\section{FRAY JAIME DE JESÚS VALENCIA GARCÍA, O.P., RECTOR GENERAL I995-I999}

Le correspondió a fray Jaime de Jesús Valencia García, O.P., rector general desde julio de I995, dirigir la Universidad durante los primeros años de su readecuación a los retos del fin de milenio. Fray Jaime Valencia nació el I9 de septiembre de I94I en Medellín. Llegó en 1953 al Colegio Santo Tomás de Bogotá a terminar estudios básicos y pasó luego al Seminario Apostólico Dominicano Jordán de Sajonia en I954, donde se graduó de bachiller cuatro años más tarde. Hizo profesión religiosa en 1959 y al año siguiente inició estudios en el Studium Generale Sancti Alberti Magni. Fray Jaime Valencia hizo profesión solemne en noviembre de 1962 , se ordenó como sacerdote en noviembre de $1967^{29}$, fue acreditado como catedrático en el Studium Generale con el título de Lector Theologiae en 1968 y obtuvo doctorado en el Institute Supérieur de Philosophie de la Université Catholique de Lovaina en 1974.

Entre 1973 y 1976 fray Jaime Valencia fue promotor provincial de Estudios y más adelante prior del Convento de Cristo Rey de Bucaramanga. Desde 1975 desempeñó diversas funciones en la Universidad Santo Tomás en Bogotá y Bucaramanga como docente, vicerrector administrativo-financiero, subdirector del Centro de Investigaciones, decano de Contaduría Pública, Ingeniería Civil, Economía, Sociología, Odontología y Laboratorio Dental, director del Centro Regional de Cali y finalmente rector de la Seccional Bucaramanga entre 1989 y 1994. Después de su rectoría general (I995-I999), fray Jaime Valencia continuó con su vida académica y administrativa desempeñándose, entre otras, como rector del Colegio Jordán de Sajonia entre los años 2003 y $2006^{30}$.

En los primeros meses de la administración del rector Valencia se llevaron adelante procesos de regulación fiscal y contable ${ }^{3 \mathrm{I}} \mathrm{y}$ de puesta al día en obligaciones institucionales con el Icfes y otras entidades. Además de esto, durante este tiempo se suscitó una importante reflexión al interior de la comunidad dominicana sobre su relación con la Universidad ${ }^{32}$, lo que fue de la mano con un afianzamiento del Consejo de Fundadores como máximo organismo de dirección de la USTA ${ }^{33}$.

E1 I3 de noviembre de 1996, el nuevo rector celebró un encuentro en Paipa (Boyacá) con frailes que empezaron a participar de la dirección de la Universidad ${ }^{34}$, para discutir sobre los criterios a tener en cuenta para la reforma del Estatuto Orgánico vigente desde 1980.

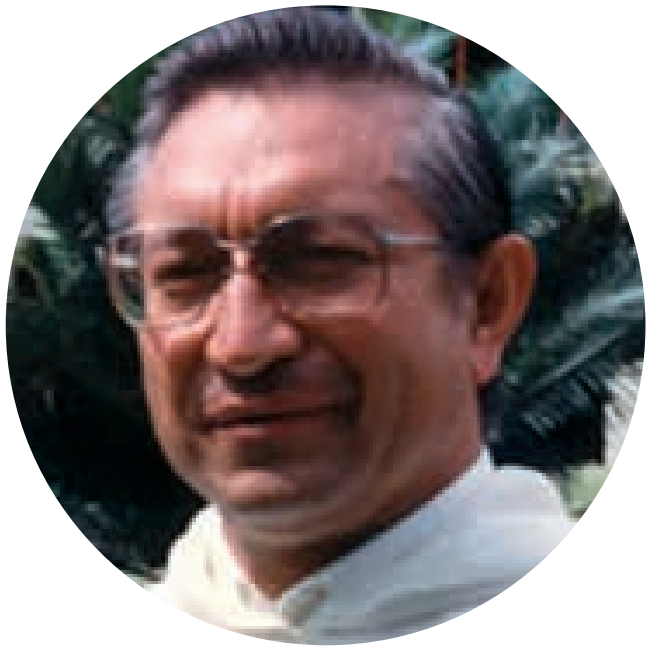

Fray Tito Belisario Murcia Florián, O. P., prior provincial durante la rectoría de fray Jaime Valencia, O.P.

E1 rector, en la introducción del evento, sentenció: "La universidad debe sacudirse y renovarse moral e intelectualmente, vincularse a la sociedad y ser factor de transformación. Nuestro Estatuto se enmarca en la Misión Institucional tomasina, respetando principios constitucionales y legales, y atendiendo a los principios de unidad y eficiencia" 35 .

En la misma reunión, el rector enumeró algunos principios generales que deben ser guía para la vida académica de la Universidad, que hoy siguen teniendo vigencia:

Centro de cultura y ciencia con responsabilidad ante la sociedad; búsqueda continua de nuevos conocimientos con sentido humanístico y sentido universal; preocupación por la identidad nacional y la ecoética; centro de controversia que favorezca la libertad de aprendizaje, investigación y cátedra; garantía de igualdad y responsabilidad social con los más necesitados; afirmación de la autonomía y respeto a la normatividad; fomento de la convivencia, el respeto mutuo, la tolerancia, la civilidad; búsqueda de la excelencia académica y procura de la acreditación; vínculo estrecho entre investigación y docencia (esta fruto de la primera); intención permanente de extensión y apertura, a 


\section{74}

Madurez institucional 1995-2018

fin de garantizar la interrelación con la sociedad; autoevaluación periódica para confirmar fortalezas y superar debilidades; cooperación interinstitucional e intercomunicación; fomento a la participación en la vida institucional, garantizando el derecho de asociación; derecho de petición, respeto al debido proceso; planeación micro y macro; propiciar la descentralización y la desconcentración (pues somos aun celosos del poder); buscar criterios y mecanismos para funcionar dentro de la unidad; regionalización: hacer presencia en la diversidad regional; economía: la Orden se ha desprendido de unos bienes que no se pueden malgastar y que es preciso conservar y aumentar para utilidad común; prevalencia y respeto a los principios ${ }^{36}$.

La reunión terminó con importantes conclusiones que demarcarán el derrotero de la Universidad en los siguientes años, se destacan:
- Todo el accionar pedagógico debe girar en torno al concepto de persona.

- Enfatizar en la formación integral: tanto en lo intelectual como en lo sensitivo.

- Disposición constante en la búsqueda de la verdad.

- El tomismo debe aplicarse en la práctica y afirmarse en el discurso.

- El ser como miembros de la Orden de Predicadores debemos trabajarlo como universitarios, pero especialmente en el área de humanidades.

- Continuar con la capacitación a los frailes para las labores administrativas de la Universidad.

- Es mejor buscar la desconcentración del poder en las seccionales con autonomía y no en la descentralización, por el peligro de la secesión y el federalismo.

- Los máximos órganos de autoridad son el Consejo de Fundadores, el Consejo Superior y el rector general.

- Sobre la educación a distancia, se determinó mantener la División de la Universidad Abierta y a Distancia

A lo largo de su historia, la Universidad se ha caracterizado por brindar espacios de bienestar para la Comunidad Educativa

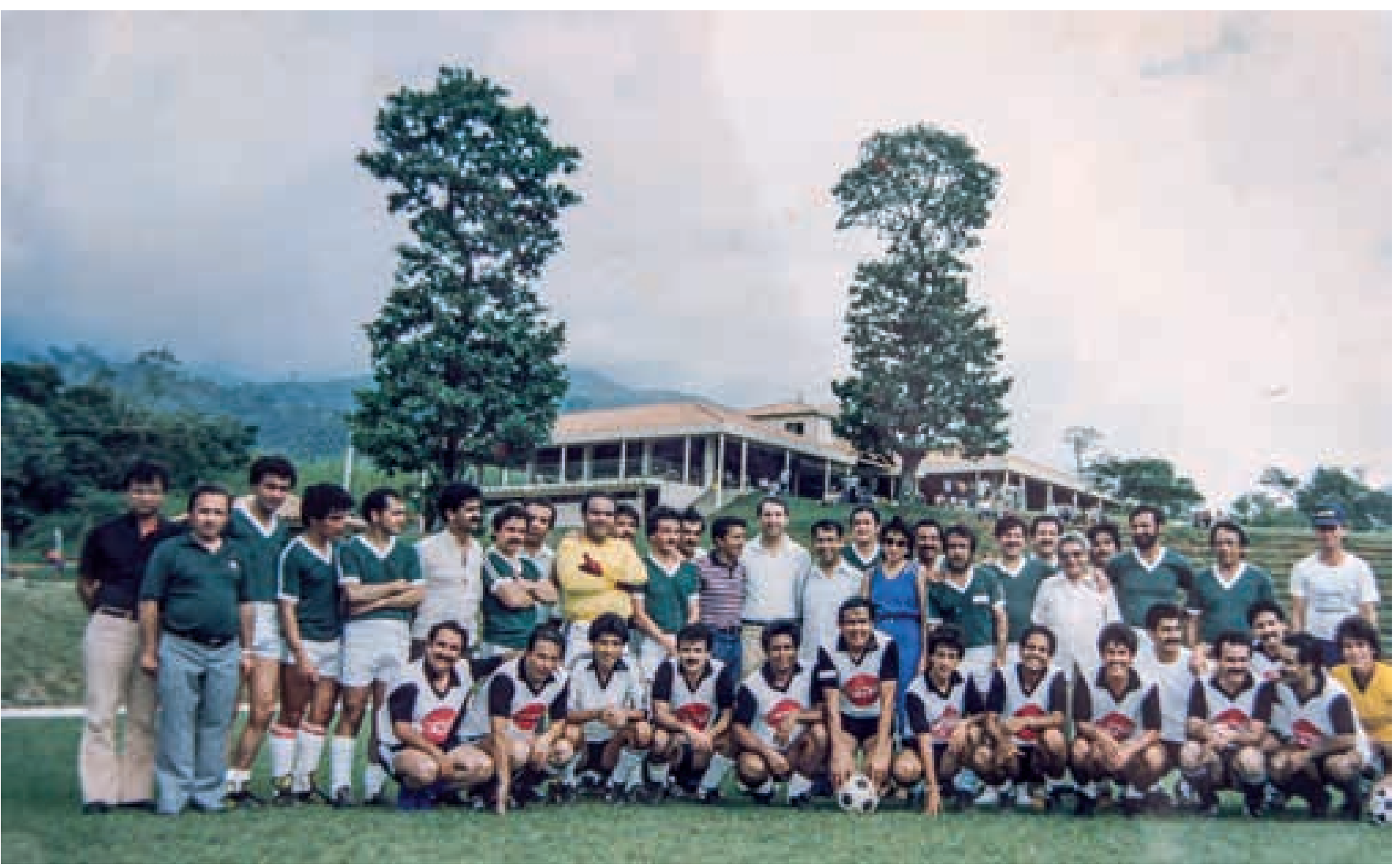


Madurez institucional 1995-2018

pero con el objetivo de crear la Vicerrectoría de la Universidad Abierta y a Distancia; pasar de División (tramitador) a Vicerrectoría (autonomía).

- Trabajar incansablemente para tener el nuevo Estatuto Orgánico lo más pronto posible.

- Se aclaró la diferencia entre Corporación (universitas personarum) y Fundación (universitas bonorum). E1 primero es un "nosotros" con misión compartida; el segundo es un capital que cumple una "misión" con un personal sirviente que fácilmente se vuelve mercenario. La USTA es una Fundación y el Consejo de Fundadores debe ser el puente entre la Corporación (Orden de Predicadores) y la universitas bonorum con dos grandes lealtades: al proyecto dominicano y a la conservación de los bienes.

Pero los encuentros continuaron con el fin de consolidar el nuevo Estatuto Orgánico. El lugar elegido fue
Kualamaná (Melgar), en septiembre de 1997, donde, dada la falta de consenso en los debates por la actualización, el Maestro de la Orden se vio en la necesidad de intervenir y proponer una comisión encargada de concluirla. Esta estuvo integrada por los frailes Generoso Gutiérrez, Faustino Corchuelo y Pedro José Díaz, quien la presidió.

Así mismo, la Universidad se repensó administrativamente y como primera medida se reajustaron las funciones de sus unidades administrativas y órganos directivos. Sindicatura fue reestructurada completamente ${ }^{37}$ y en noviembre de 1996 se crearon la Oficina de Presupuesto y el Departamento de Planta Física ${ }^{38}$. Sobre esto afirmaba el rector en su Informe general del periodo I995-1999:

Por vez primera y con todas las dificultades iniciales, la Universidad proyectó y ejecutó un presupuesto. A partir de esa fecha se han venido ejecutando presupuestos anuales que le señalan el rumbo en cuanto

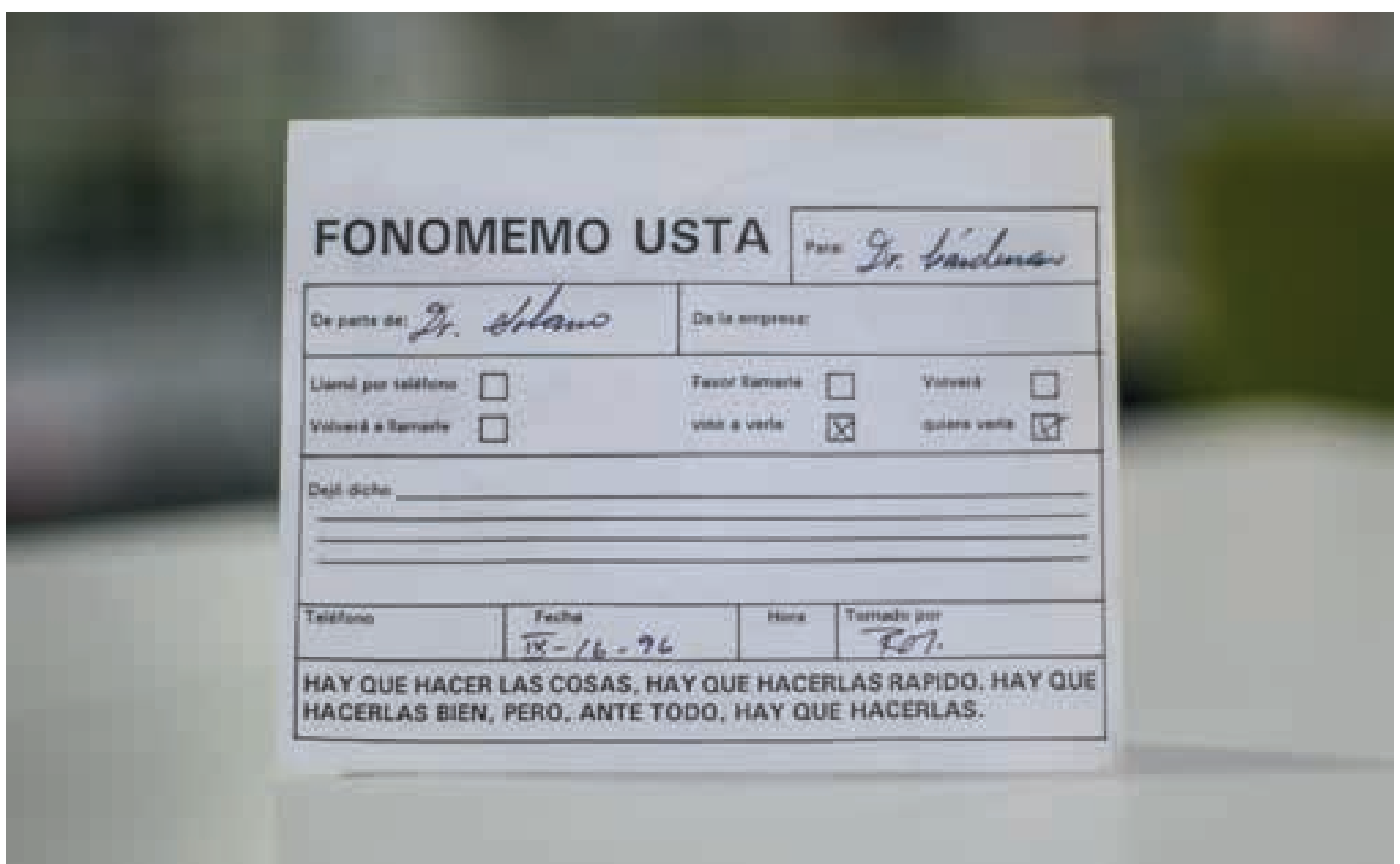




\section{78}

Madurez institucional 1995-2018

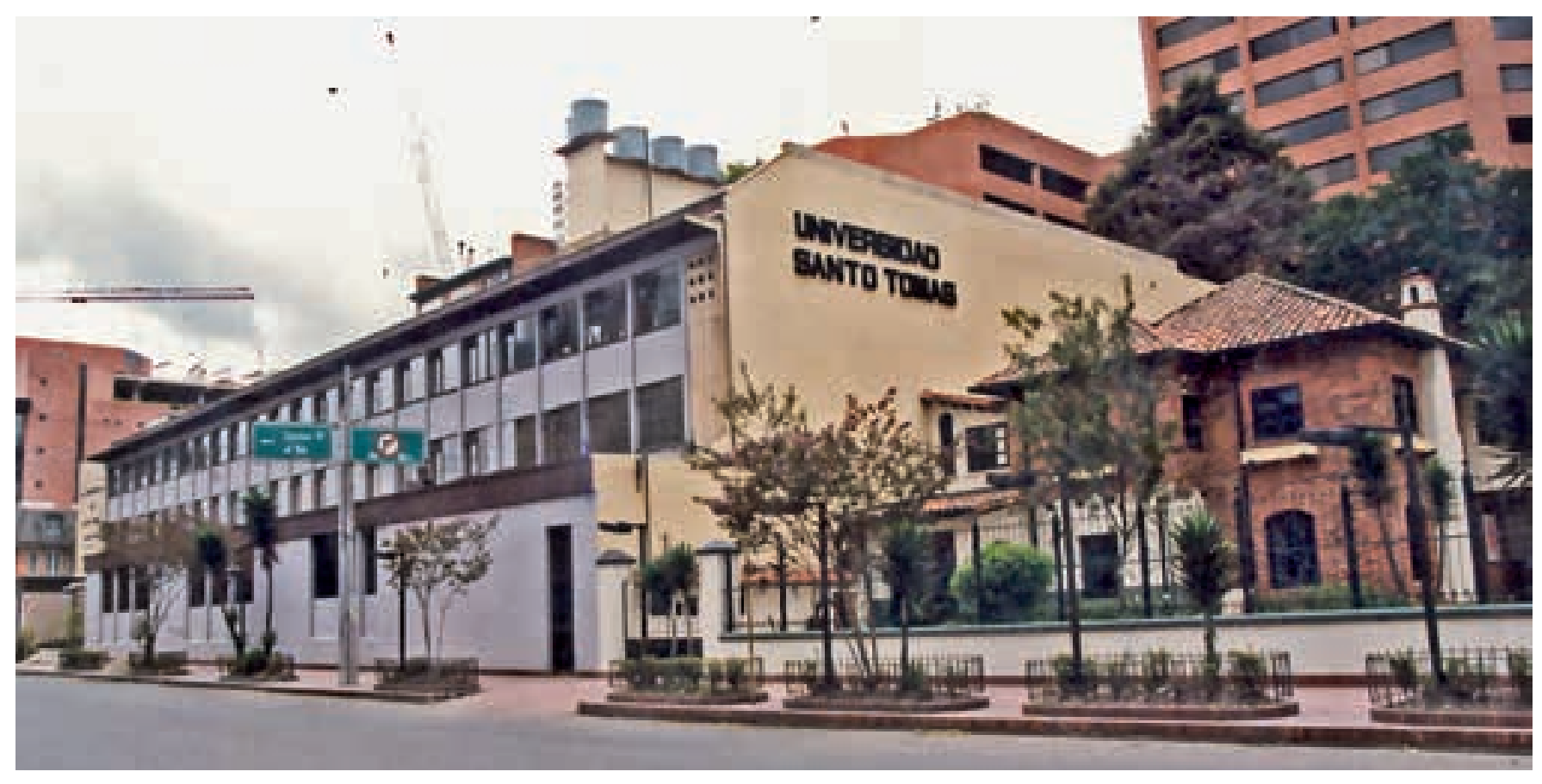

Primera sede del Centro de Enseñanza

Desescolarizada junto a las facultades de Derecho y

Filosofía, hoy edificio Doctor Angélico

$(\text { VUAD })^{43}$ en 1997 con un reglamento propio aprobado en noviembre de ese año ${ }^{44}$.

El año siguiente fue, para la recién creada VUAD, un periodo de consolidación. Empezó a funcionar con planta física y departamentos propios, se consolidaron las unidades, se hicieron los nombramientos respectivos y se llevó a cabo una adecuación, integración y reestructuración en lo académico y administrativo, sobre todo en la Facultad de Educación para atender a las nuevas exigencias de ley en cuestión de calidad ${ }^{45}$. En 1999 la VUAD contaba con 28 programas de pos y pregrado, alrededor de 13 ooo estudiantes, y 37 centros regionales distribuidos en II4 municipios ${ }^{46}$. Para la evolución de la población estudiantil entre los años I99I-I998, véase la tabla I6, "Población estudiantil Universidad a Distancia I99I/I-I998/I”.

Además, la USTA se propuso restaurar la Facultad de Medicina. Se encargó al doctor Carlos Iván Rodríguez Melo (médico egresado de la Uis y doctor en Administración de la Pontificia Universidad Católica Argentina Santa María de los Buenos Aires) realizar un análisis DoFA sobre la viabilidad del proyecto, cuyas conclusiones fueron favorables para su reapertura. En mayo de 1999 el Consejo de Fundadores, sobre esa base, aprobó el arrendamiento de las instalaciones con todos los equipos de la Clínica Fray Bartolomé de Las Casas, al tiempo que el Consejo Superior aprobaba un empréstito hasta por \$4000 000 000 para tal fin.

El Consejo Administrativo y Financiero de la Universidad realizó una amplia evaluación del proyecto y conceptuó que era favorable, aun en un escenario conservador: con solo el $40 \%$ de ocupación de la clínica, la Universidad tendría el retorno de la inversión en dos años.

Para febrero del 2000, bajo la rectoría de Eduardo González Gil, fray Carlos Arturo Díaz seguía realizando las gestiones pertinentes ante el Concejo Distrital de Bogotá en torno al arriendo de la clínica, a pesar de la existencia de un informe en el que se decía que la estructura física de la clínica estaba cercana a desplomarse. Tal vez fue la razón para que la USTA desistiera de reabir la Facultad de Medicina, a pesar de que el alcalde de Bogotá, Enrique Peñalosa, les comunicaba que el Distrito asumiría la remodelación de la clínica.

Por otro lado, la Seccional Bucaramanga, que se había consolidado hacía ya varios años, vio un importante crecimiento en la segunda mitad de la década. En 


\section{79}

Madurez institucional 1995-2018

I995 la Seccional contaba con nueve pregrados, a saber: Arquitectura, Administración de Empresas Agropecuarias, Contaduría Pública, Comercio Exterior ${ }^{47}$, Derecho y Ciencias Políticas, Economía y Administración de Empresas, Laboratorio Dental, Odontología y Optometría De estos, los de más reciente creación habían sido Administración de Empresas Agropecuarias y Comercio Exterior, que iniciaron en el primer y segundo semestre de 1993 respectivamente, y Optometría, que comenzó en el primer semestre de $1995^{48}$.

En posgrados, Bucaramanga contaba con dos maestrías, en Administración de Empresas y en Evaluación en Educación, además de ocho especializaciones ${ }^{49}$, la mayoría de las cuales habían sido creadas en los primeros años del decenio bajo la vicerrectoría académica de fray José Antonio Balaguera y la rectoría seccional de fray Jaime Valencia ${ }^{50}$. En el primer semestre de 1995 Bucaramanga tenía 4825 estudiantes de pregrado y 4874 en el segundo ${ }^{51}$. Por esta época, algunas de las políticas institucionales incluyeron actualización y modernización de programas curriculares, ampliación de la oferta en pregrado y posgrado, capacitación de directivos y docentes, impulso a la investigación y a programas de extensión e inicio de procesos de acreditación ${ }^{52}$.

Entre 1994 y 1996, ya con fray José Antonio Balaguera como rector seccional, se continuaron las labores de mejoramiento y ampliación de la infraestructura en Floridablanca y se continuó el crecimiento académico con programas como Optometría, ya mencionado, y Cultura Física, Deporte y Recreación, lanzado en $1996^{53}$. En el periodo I996-I998 Bucaramanga dio inicio a los procesos de autoevaluación para la acreditación de sus programas ${ }^{54}$ y amplió su oferta e infraestructura académica. Se llegaron a ofertar quince posgrados, se creó el Departamento de Idiomas y con la incorporación de Ingeniería de Telecomunicaciones se llegó a once facultades presenciales. Ingeniería de Telecomunicaciones en particular tuvo un rápido crecimiento en su población estudiantil, pues inició en el primer semestre de 1997 con 73 estudiantes y a fines de ese mismo año ya atendía a $147^{55}$. En I998 la Seccional contaba con sedes presenciales en Bucaramanga, Floridablanca y Piedecuesta ${ }^{56}$.

Entre diciembre de 1997 y marzo de 1999 la USTA Bucaramanga realizó varios actos académicos, científicos, culturales, religiosos, deportivos, artísticos y sociales, para celebrar sus bodas de plata. En el marco de las celebraciones, la Seccional lanzó su primer programa de doctorado, en Ingeniería de Telecomunicación en febrero de $1999^{57}$, y en el segundo semestre se inauguró el programa de Ingeniería Mecatrónica, con el que la Seccional llegó a los doce programas de pregrado ${ }^{5}$.

La USTA se expande a Tunja, Medellín y Chiquinquirá

A pesar del enorme esfuerzo que implica la adaptación al sistema de educación superior, la rectoría de fray Jaime Valencia se caracterizó por una importante expansión de la modalidad presencial en las regiones. Esta era una política tanto de la Provincia como de la Universidad a mediados de la década de I99059. Durante esa época la comunidad dominicana y las directivas de la Universidad consideraron alternativas de expansión regional sobre la base de la presencia de la comunidad dominicana en casas y conventos, pero, principalmente, sobre la presencia de la Universidad Abierta y a Distancia. Por ello, dentro de las alternativas que se consideraron entre los años I995 y 1997 se cuentan Cali ${ }^{60}$ y Cartagena ${ }^{6 r}$, pero después de analizar las condiciones de la demanda educativa, las posibilidades de infraestructura, entre otras cuestiones, la USTA terminó extendiéndose solo a Tunja y Medellín, y por breve tiempo a Chiquinquirá.

\section{Es mejor buscar la desconcentración del poder con autonomía y no la descentralización, por el peligro de la secesión y el federalismo en las sedes y seccionales.}




\section{80}

Madurez institucional 1995-2018

Un factor de larga duración para contextualizar la llegada de la modalidad presencial de la UsTA a Boyacá es la histórica conexión de la Orden de Predicadores con esa región, que se remonta al siglo $\mathrm{XVI}^{62}$. Para mediados de la década de I990, la USTA hacía presencia a través de la modalidad a distancia en Duitama, Guateque, La Uvita, Chiquinquirá y Sogamoso, una red educativa que facilitó establecer contacto con el poder público al tiempo que llevar a cabo un proceso de planificación concienzudo que incluyó estudios de factibilidad y diagnósticos de la situación regional de la educación superior ${ }^{63}$. Lo que las directivas encontraron en el departamento fue una demanda importante por servicios de educación superior a consecuencia tanto de la poca oferta como de la baja calidad de algunos de los programas existentes en aquel momento.

La idea de establecer una sede en Tunja se empezó a socializar en I995; sus promotores eran fray Luis Alberto Orozco Arcila, O. P., el doctor Pedro Reyes Zambrano y algunos frailes del Convento de Santo Domingo de Tunja, como Adalberto Cardona, O. P. ${ }^{64}$. En septiembre de I995, a solicitud del rector Valencia, fray Luis Alberto Orozco, entonces director regional del ceD en Boyacá, y Reyes Zambrano, entonces coordinador de la USTA en Duitama, elaboraron una primera propuesta "Seccional usTA Boyacá", en la que señalaron las favorables condiciones para el proyecto y la hoja de ruta ${ }^{65}$.

En octubre fray Luis Alberto Orozco, ahora como director del proyecto y Reyes Zambrano como asesor, propusieron usar el Cread de Tunja como punto de partida de las operaciones. En ese momento la Universidad y la comunidad dominicana iniciaron diálogos y gestiones con el gobernador del departamento, estudiantes y representantes de la sociedad civil, quienes expresaron su apoyo al proyecto; además, como este se empezara a conocer en los medios de comunicación regionales, la sociedad civil comenzó a mostrar notorio interés.

El 22 de noviembre siguiente, el Consejo Superior acordó la creación de la Sede ${ }^{66}$. Al mismo tiempo se empezaron a hacer inscripciones para los programas de pregrado en Derecho \& Ciencias Políticas y Arquitectura, que serían ofrecidos como extensiones de la Sede Bogotá y la Seccional Bucaramanga respectivamente, así como para especializaciones en derecho penal, derecho administrativo y educación a mbiental. Se tomó en arriendo a la comunidad dominicana de Tunja el edificio contiguo a la casa de Santo Domingo - en donde funcionaron el Liceo Santo Domingo y la Corporación Universitaria de Boyacá-, se iniciaron labores de adecuación, se seleccionó el personal y se compraron elementos de oficina ${ }^{67}$.

En febrero de 1996 fray José Antonio Balaguera fue nombrado primer decano de División encargado de los programas presenciales y a distancia del departamento de Boyacá. En marzo dieron inicio las labores académicas en Derecho y Arquitectura con 63 y 82 estudiantes respectivamente, lo que demuestra la buena recepción que tuvo la USTA en Tunja desde su génesis ${ }^{68}$. Las especializaciones, ofrecidas por la Unidad de Posgrados, fueron también muy apreciadas entre docentes y abogados, a quienes iban especialmente dirigidos ${ }^{69}$.

Para la selección de los programas académicos se tuvo en cuenta que estos fuesen programas bandera de la Universidad, como era en efecto el caso de Derecho en Bogotá y Arquitectura en Bucaramanga, y que la dotación con que se contaba fuese suficiente para garantizar la excelencia académica. Además, se tuvo en cuenta la importante tradición regional en el ejercicio de estas dos profesiones ${ }^{70}$. Más tarde, en 1998 se empezaron a ofrecer los programas de Ingeniería Civil e Ingeniería Electrónica, extensiones de la Sede Principal $^{7 \mathrm{I}}$.

La historia y el presente de la Sede Tunja de la USTA en el convento de los frailes dominicos

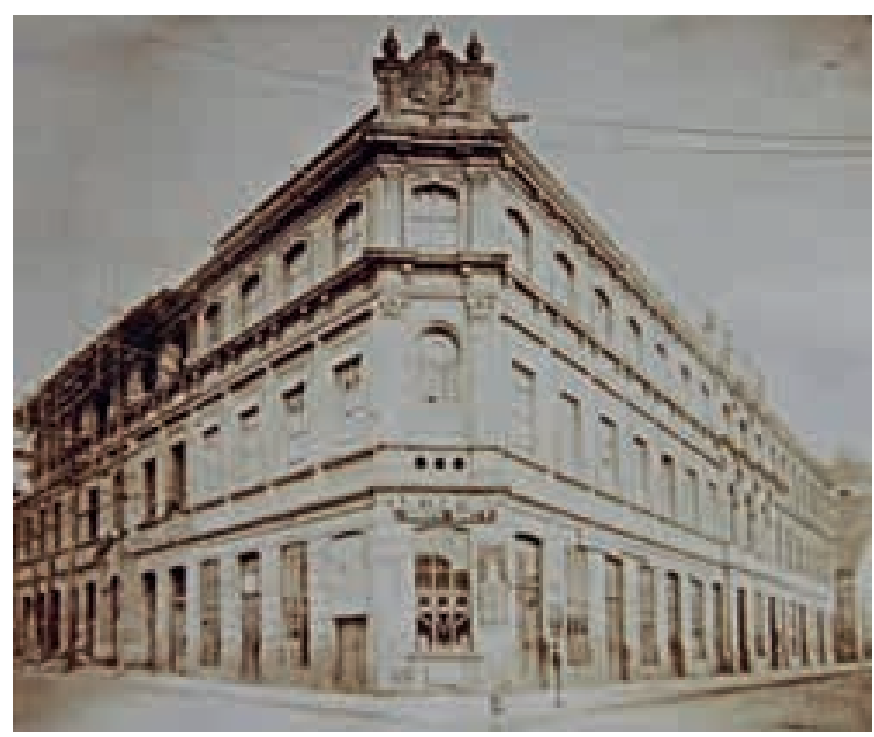




\section{82}

Madurez institucional 1995-2018

Durante sus primeros años, la UsTA Tunja vivió un crecimiento exponencial de su población estudiantil que se puede apreciar en la tabla 2I, "Población estudiantil pregrado, Tunja I997-2002”, y en la gráfica 5, "Población estudiantil pregrado, Tunja I997-2002". Los principales factores que determinaron este importante éxito de la Universidad fueron su buena imagen y prestigio entre la población boyacense, esfuerzos importantes en publicidad y presencia institucional, así como el uso estratégico de la planeación y los estudios de factibilidad y mercadeo como determinantes para la oferta de servicios ${ }^{72}$.

Por otro lado, es notable que desde su inicio la USTA Tunja haya contado con un Centro de Investigación Institucional (Ciusta) que impulsó tempranamente los procesos investigativos. Con el tiempo se irían creando, de acuerdo con las necesidades, organismos como el Departamento de Contabilidad, Comité de Planta Física, Departamento de Bienestar Universitario, Biblioteca, Departamento de Sistemas, Coordinación de Proyectos Institucionales, Departamento de Comunicaciones y Mercadeo, Pastoral Universitaria, Recursos Humanos, entre otros ${ }^{73}$.

A la creación de la Sede Tunja le sucedió, en mayo de I998, la de la sede presencial en Medellín, en donde la Provincia Dominicana contaba con una casa desde I97I que fue erigida en convento en $1999^{74}$. En cuanto a la Santo Tomás, esta hacía presencia a través del CED desde 1979 con tres programas de filosofía ${ }^{75}$. En los últimos años los encargados de la administración

La USTA Medellín en su modalidad presencial inició en el segundo semestre de 1998 con catorce estudiantes y siete profesores en Ingeniería de Telecomunicaciones y diez estudiantes y cinco profesores en Arquitectura

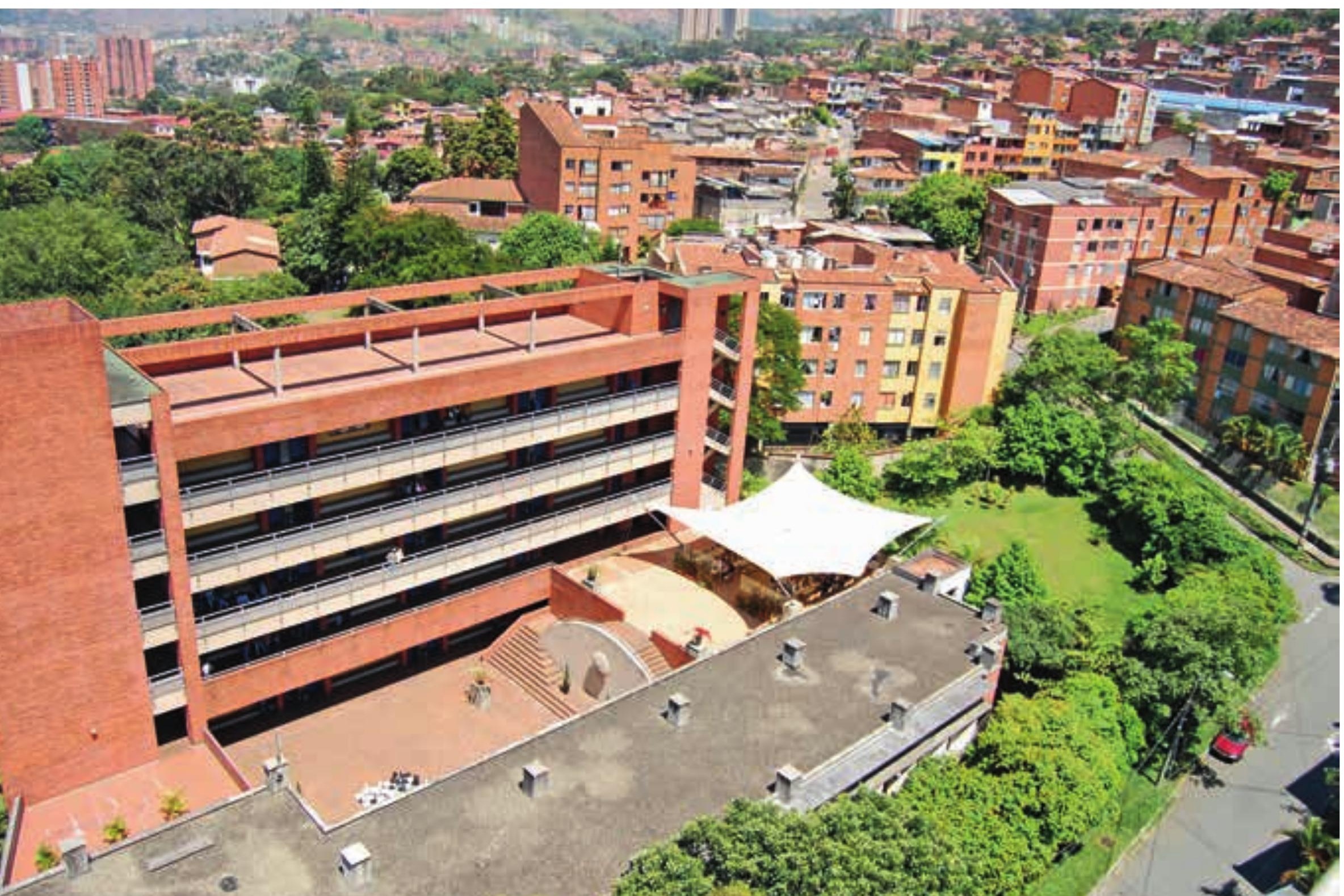




\section{83}

Madurez institucional I995-20I8

en Medellín venían proponiendo la construcción de la sede como respuesta al incremento de la población estudiantil (véase tabla I2, "Población estudiantil usTa Medellín I995-I998”). Se argumentaba la necesidad de centralizar las actividades administrativas y académicas, puesto que estas se venían adelantando en lugares diferentes que hacían necesarios largos desplazamientos.

Así mismo, en la década de los noventa la administración de la USTA en Medellín se venía complejizando por cuenta de la diversificación de los servicios académicos. A partir de 1990 se empezaron a ofrecer tecnologías, en 1996 carreras profesionales y desde I997 posgrados. Por otro lado, en 1996 se empezaron a adquirir propiedades en Medellín y a adelantar gestiones para el levantamiento de la sede que fue finalmente inaugurada el 15 de mayo de $1998^{76}$.

La UsTa Medellín en su modalidad presencial inició en el segundo semestre de 1998 con catorce estudiantes y siete profesores en Ingeniería de Telecomunicaciones y diez estudiantes y cinco profesores en Arquitectura ${ }^{77}$. En la tabla 13, "Población estudiantil de pregrados presenciales en Medellín I998-2002", se aprecia que la evolución de la población estudiantil en pregrado en la modalidad presencial en sus primeros cuatro años fue de un crecimiento más bien discreto.

Hubo extensión de programas presenciales en la ciudad boyacense de Chiquinquirá, cuya importancia histórica para la Orden de Predicadores es invaluable. Fue allí donde los dominicos se reagruparon después del exilio a los Llanos en I86r y se convirtió en su refugio durante décadas por la regencia dominicana de la devoción a la Virgen de Chiquinquirá, principal advocación nacional católica. En Chiquinquirá, el experimento puso en marcha en el segundo semestre de 1997 , constituyéndose en una decanatura de división que funcionó durante dos años en los cuales se ofertaron los pregrados en Psicología y Economía \& Administración de Empresas ${ }^{78}$. La oferta de pregrados presenciales no obstante fue cancelada a fines de 1999 cuando los servicios se siguieron prestando únicamente a los estudiantes antiguos.

\section{Crecimiento académico, material y egresados}

En cuanto al crecimiento académico en Bogotá durante la rectoría de fray Jaime Valencia, vale la pena señalar la apertura de las facultades de Ingeniería de Telecomunicaciones, de Comunicación Social79 y de Cultura Física, Deporte y Recreación ${ }^{80}$. Además, se reabrió el Departamento de Idiomas y el Instituto de Cooperativismo (Instituto de Educación e Investigación
Cooperativa, Icousta) $)^{8 \mathrm{r}}$ y el pregrado de Sociología en I998, catorce años después de haberse cerrado su oferta ${ }^{82}$.

La reapertura de Idiomas es un avance importante hacia la consolidación de la educación por cátedras en la Universidad que vino a fortalecer el trabajo llevado a cabo desde el Departamento de Filosofía y Cultura Teológica. También vale la pena señalar que la Facultad de Comunicación Social, con énfasis en la paz, fue creada con el objetivo de formar comunicadores sociales que afrontaran la situación del país y aportaran como agentes mediadores a la resolución de conflictos y al mejoramiento de la calidad de vida ${ }^{8_{3}}$.

En esto hay una clara intención por parte de la Universidad de responder a problemas concretos y urgentes del país, como la violencia. Aunque en un ámbito muy diferente, fue con el mismo enfoque hacia los problemas y las transformaciones históricas que se creó la Facultad de Ingeniería de Telecomunicaciones, teniendo en cuenta los rápidos avances en la tecnología de la comunicación de las últimas décadas ${ }^{84}$.

Otro ejemplo de desarrollo curricular tomasino determinado por la pertinencia social fue la implementación en estos años de una modalidad de grado en la Facultad de Ingeniería Civil que, acogiendo la línea de proyección social, permitió a los estudiantes llevar a cabo proyectos profesionales en sectores de bajos recursos como opción de grado. Esta modalidad se convirtió rápidamente en la favorita de los ingenieros tomasinos frente a las otras opciones disponibles ${ }^{85}$. En cuanto a los posgrados, en 1999 la Universidad llegó a la cifra de 44, entre ellos seis maestrías y un doctorado en convenio con una universidad extranjera ${ }^{86}$. Sobre el comportamiento de la población estudiantil durante la rectoría del rector Valencia, este se puede apreciar en la tabla I4, "Evolución de la población estudiantil en pregrado y posgrado I994-1999”.

Durante la rectoría de fray Jaime Valencia, la USTA tuvo un importante crecimiento material a través de adquisición de propiedades, remodelaciones y construcción de nuevos edificios en un proceso vinculado a la expansión tanto regional, como ya hemos visto, como de la Sede Bogotá. Entre 1995 y 1996 la Sede se expandió a la manzana comprendida entre las calles 5I y $5^{2}$ y carreras séptima y novena, incluyendo el edificio Sugamuxi ubicado en la esquina de la séptima con 52 y rebautizado por la Universidad como edificio Santo Domingo ${ }^{87}$. Sobre los edificios adquiridos se iniciaron obras de adecuación para aulas y oficinas relacionadas con programas y actividades de posgrados. Así mismo, la Universidad desarrolló un plan 


\section{84}

Madurez institucional 1995-2018

de desarrollo arquitectónico en toda la manzana y al final del periodo Valencia se había adquirido ya un $70 \%$ del total de los predios proyectados ${ }^{88}$.

Esta expansión de la Sede Principal coincidió con el desarrollo de problemas de entorno urbano, debido al surgimiento de bares y discotecas ${ }^{89}$. Estos inconvenientes han seguido siendo tema de preocupación recurrente durante lo que va corrido del siglo XXI no solo en lo que se refiere al expendio de licor, sino también al microtráfico de estupefacientes en las inmediaciones de la Sede ${ }^{\circ}$. Por ello, la Universidad ha sido vocal en el debate público local y nacional sobre las regulaciones del expendio de licor y contaminación auditiva alrededor de centros educativos, así como sobre las políticas de prevención del consumo de drogas y alcohol entre los jóvenes ${ }^{91}$.

Vale la pena mencionar como un logro de la administración de fray Jaime Valencia la creación de la Asociación Nacional de Profesionales Tomasinos (Prousta) en 1995, preocupación constante del anterior rector, un parteaguas de las relaciones entre la Universidad y sus egresados, siendo la economista Eva Flye Quintero su primera y actual directora. Esto se dio en el marco del nuevo sistema de educación superior surgido en la década de 1990, atravesado por valores de eficiencia para los cuales es fundamental la medición de los resultados. Además de incentivar la asociación e integración entre egresados y entre estos y su alma mater, Prousta permite consolidar las fuentes de información sobre la huella tomasina en diferentes áreas económicas y del saber.

El 2I de mayo de 1998 Prousta se constituyó legalmente como una corporación sin ánimo de lucro integrada por las asociaciones de profesionales tomasinos de las diferentes facultades y programas académicos. Entre el ir y el i3 de junio de 1999 se llevó a cabo el Primer Congreso de Profesionales Tomasinos "La Universidad Santo Tomás en Colombia Unida por la Paz", realizado en Bucaramanga ${ }^{92}$.

\section{Acreditación, PEI y Plan 2020}

El desarrollo de los diversos instrumentos y estrategias para garantizar la calidad y asegurar la acreditación de los programas y de la Universidad por parte del Estado fue un proceso que se echó a andar también durante la rectoría de fray Jaime Valencia. Para ello se hizo necesario, en primer lugar, informar a los miembros de la comunidad tomasina y familiarizarlos con los distintos procesos técnicos propios de la acreditación. Esta tarea se dio en

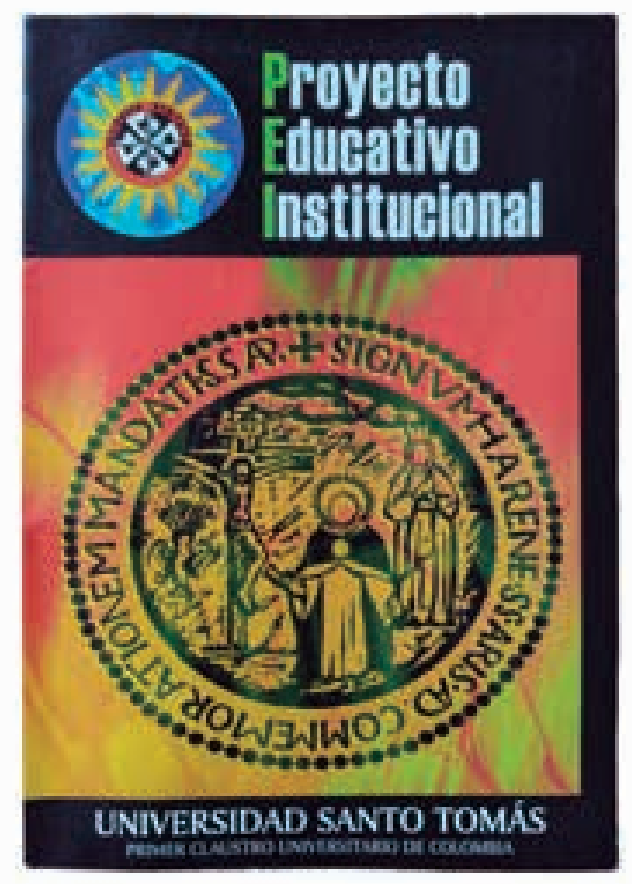

Con el Proyecto Educativo Institucional la rectoría quiso responder a las exigencias del Ministerio de Educación Nacional en materia de organización administrativa y académica

forma de encuentros y seminarios organizados por la Vicerrectoría Académica General, inicialmente a cargo de fray Jorge Murcia Florián93.

Además, en las distintas facultades se hicieron ejercicios conducentes al fortalecimiento de la gestión investigativa y académica a partir de los lineamientos del Centro de Investigaciones y Acreditación, creado para apoyar los procesos de investigación y acreditación ${ }^{94}$. En este contexto se construyó un primer Modelo de Investigación Institucional en $1995^{95}$ y se avanzó hacia la creación de un proyecto dominicano de universidad ajustado al contexto histórico ${ }^{96}$. Así se llegó al primer Proyecto Educativo Institucional de la Universidad (PEI), elaborado en 1996 y reformado en 1999 y $2004^{97}$. Las dos figuras definitivas detrás de la construcción del PEI son, sin lugar a dudas, los profesores e intelectuales tomasinos Alberto Cárdenas Patiño y Eudoro Rodríguez.

Detengámonos por ahora en el PEI de 1999, que tuvo una vigencia de cinco años y cuya formulación estuvo en relación orgánica con el Plan Prospectivo del que trataremos en breve. El documento fue formulado 


\section{85}

Madurez institucional 1995-2018

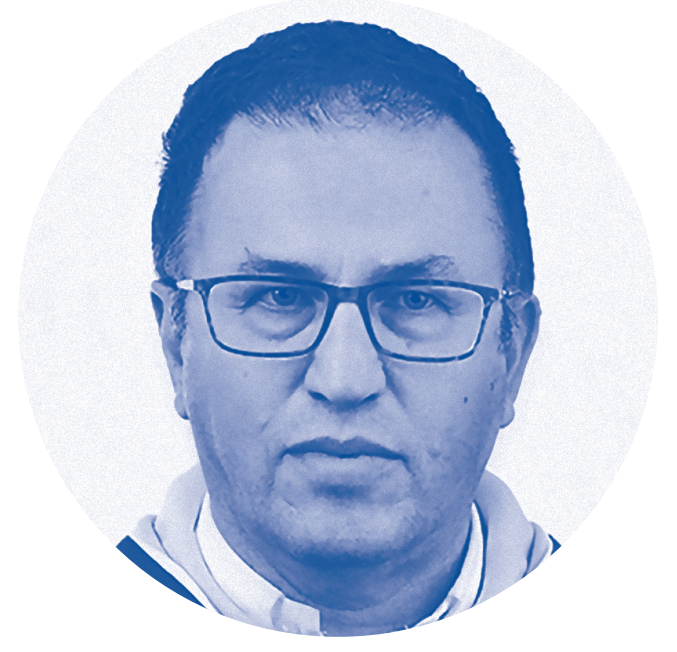

Fray José Bernardo Vallejo Molina, O. P., uno de los vicerrectores administrativos generales durante a rectoría de fray Jaime Valencia, $O . P$.

en el marco de una comprensión del tiempo histórico en que la USTA repasa su largo pasado hasta la supresión de I86I, su situación presente desde la restauración de I965 y el siglo XXI que se entrevé en la década de r990:

Apertura a la globalización del conocimiento, conexión con centros académicos y productores de conocimiento, regionalización, cubrimiento, asimilación de la tecnología de las comunicaciones, asunción de la cibercultura, sistematización de procesos, investigación disciplinaria-interdisciplinaria-transdisciplinaria, generación de nuevo conocimiento (por lo menos de utilidad institucional y social), servicio social y comunitario, impulso a la ética civil, ecumenismo, ética mundial, protagonismo femenino, multipolarismo internacional, integración latinoamericana, democracia participativa, Estado social de derecho, derechos humanos, derechos de la humanidad, cuidado del medioambiente, justicia protectiva, justicia distributiva, paz, crítica al modelo neoliberal, desarrollo solidario sostenible, autodiagnóstico-autoevaluación-autocomprensión, reestructuración (reforma estatutaria) ${ }^{98}$.

Por otro lado, la identidad de la Institución continúa conformándose a partir de cinco elementos fundamentales: I) carácter de Estudio General, 2) personería jurídica de derecho eclesiástico, 3) pertenencia a la Orden de Predicadores, 4) orientación tomista y 5) personería jurídica de derecho privado, sin ánimo de lucro, para la utilidad común de los colombianos y ceñimiento a las leyes y normas que rigen la educación superior en el país. De estos cinco elementos, solo el último había sufrido cambios importantes en los últimos años a raíz de los cambios en el sistema educativo colombiano.

Mientras que la identidad institucional en general se reafirma en consonancia con los lineamientos de la ley, del espíritu científico y de la filosofía tomasina, la misión situacional, aquella que surge del análisis de corto y largo plazo en los contextos colombiano, latinoamericano y mundial, presenta importantes innovaciones. Para la misión se tienen en cuenta la creciente desigualdad entre países ricos y pobres, la emergencia del mundo multipolar, la consolidación de la ideología neoliberal, de la política norteamericana, la llegada de propuestas ideológicas y filosóficas fundamentalistas, milenaristas y esotéricas, así como las necesidades específicas del país en cuanto a justicia social, derechos humanos y democracia participativa ${ }^{99}$.

A partir de ahí, la USTA se compromete con la sociedad a: I) seguir contribuyendo al avance científico-tecnológico que el desarrollo del país requiere, 2) contribuir al proceso de democratización y la realización efectiva de la Constitución de I99I, 3) asumir críticamente el multiculturalismo aprovechándose de su inserción regional y mediante el trabajo del Centro de Investigaciones, 4) ayudar a repensar los problemas básicos de la realidad como totalidad, 5) continuar y fortalecer la tradición formadora en la búsqueda de modelos alternativos de desarrollo integral, justicia social y convivencia pacífica, 6) adelantar planes concretos de ayuda social y comunitaria, 7) encauzar, sin exclusivismo, la orientación latinoamericana, 8) crear una escuela de líderes cristianos, 9) potenciar el liderazgo femenino mediante la reflexión, la investigación y la práctica, Io) reafirmar la presencia multirregional a través de proyectos modernos de comunicación, II) fomentar la racionalidad en el manejo del medioambiente y crear espacios de reflexión sobre los problemas de la relación entre el hombre y la naturaleza, I2) abrir 


\section{86}

Madurez institucional 1995-20I8

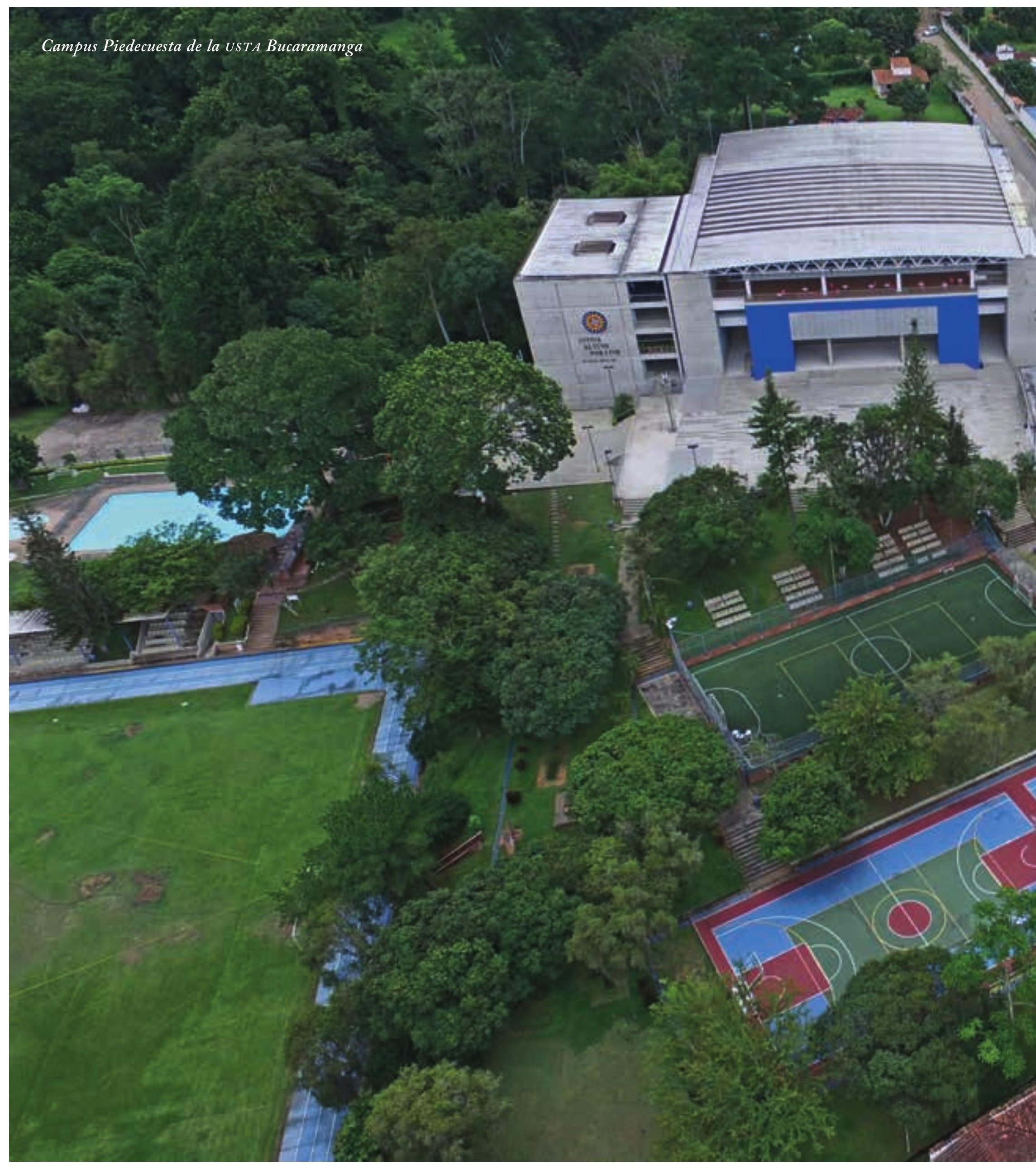




\section{88}

Madurez institucional 1995-2018

espacios para la creación y la expresión estética, I3) recuperar la tradición pedagógica dominicana y renovar la doctrina educativa tomista, y I4) fomentar la reflexión crítica sobre modelos económicos y las relaciones entre economía y humanismo. En el cumplimiento de estos compromisos institucionales se verían involucrados los diferentes estamentos de la Universidad y se crearían varias cátedras sobre temas particulares, como veremos más adelante.

En el marco de estos compromisos, la UsTa definió cuatro propósitos sustantivos a ser cumplidos por etapas: I) científico-investigativos, 2) ideológico-culturales, 3) en el ámbito de la comunicación social y 4) pedagógicos. Los propósitos científico-investigativos suponían potenciar la posición privilegiada de la Universidad Abierta y a Distancia para vincular la USTA a las comunidades, descentralizar la investigación, crear un Centro de Investigaciones Disciplinarias e

\section{E1 propósito}

\section{fundamental de la}

\section{USTA es aportary}

contribuir a la búsqueda

de alternativas a

la crisis actual del

país, suscitando una

cultura científica con

perspectiva humanística,

abierta a los valores

cristianos, que permita

el logro de un desarrollo

integral a través del

conocimiento creativo y

crítico. incrementar cuantitativa y cualitativamente las publicaciones científicas.

Los propósitos ideológico-culturales implicaban desarrollar el pensamiento tomista y la historia de las ideas, dinamizar la dimensión cultural del país, difundir el pensamiento social católico y crear espacios de información social con participación de otras entidades y grupos. En cuanto a los propósitos en el ámbito de la comunicación social, se pretendía tecnificar el servicio de la Universidad Abierta y a Distancia, crear la emisora Tomás de Aquino y construir pequeños centros culturales en áreas rurales a ejemplo de experiencias como Radio Sutatenza. Finalmente, los propósitos pedagógicos se lograrían a través de la investigación y de una orientación de los programas de licenciatura y posgrados en educación hacia una vinculación de los diferentes niveles educativos, desde preescolar hasta la educación universitaria:

En síntesis, el propósito fundamental de la USTA es aportar y contribuir a la búsqueda de alternativas a la crisis actual del pais, suscitando una cultura científica con perspectiva humanística, abierta a los valores cristianos, que permita el logro de un desarrollo integral a través del conocimiento creativo y crítico como compete a una institución universitaria ${ }^{100}$.

Además de esto, el PEI de 1999 redefinió para los años venideros el sentido de la comunidad, de la estructura organizacional, de los objetivos de la formación integral, del bienestar institucional, de la administración, de la gestión académica, de la docencia, de la investigación, de la proyección social, de la interacción con el medio externo, de los criterios para el manejo de los recursos y del seguimiento a las políticas de gestión.

A partir de todo lo anterior, la USTA se proyectó hacia el año 2020 como una institución dinámica, conectada entre sus diferentes organismos y con la realidad exterior, tecnificada, sistematizada, investigativa, interdisciplinaria, diversa en sus diferentes niveles de educación, participante de la cultura democrática de la nación, posicionada editorialmente, recreativa y con liderazgo femenino, entre otros elementos. Esta proyección se dio también como parte del proceso de ajuste a las políticas regulativas de la década de I990; la Universidad dio entonces un significativo giro hacia la planificación en sus políticas 


\section{89}

Madurez institucional 1995-2018

administrativas y académicas a partir de la participación y discusión en las facultades:

\begin{abstract}
Así las cosas, la Universidad el siglo XXI debe ser el resultado de los fundamentos institucionales y el de las herramientas operativas, donde se garantiza la eficiencia en el manejo de los recursos y efectividad de los mismos frente a la gerencia que demandará el siglo venidero, por lo tanto, la permanencia del pensamiento Tomista será una realidad en el año 2020. Ese es el "escenario al que la UsTA le ha apostado al año 2020 ” y alrededor del cual viene presentándose el consenso de las personas conocedoras, bien llamados expertos, de las necesidades y retos de la institución para el nuevo sigloror.
\end{abstract}

El momento fundamental de institucionalización del espíritu de planeación fue I999, año en que se lanzó el Plan Prospectivo USTA 2020, construido a través de talleres de expertos, profesores, administrativos, etc., entre marzo y julio de ese mismo año. Desde su lanzamiento, USTA 2020 fue la piedra angular de los posteriores planes generales de desarrollo de la Universidad ${ }^{\mathrm{ro2}}$. El Plan partía de la premisa de que para ser más competitivos en el presente y en el futuro había que pensar en escenarios posibles, contingencias y tendencias.

Así, al anticipar las tendencias mundiales que se anunciaban desde mediados de la década de r980, se podría elegir el mejor camino posible para transitar durante dos décadas valiéndose de estrategias particulares. De esas tendencias mundiales hemos hablado anteriormente: globalización, competitividad, debilitamiento del Estado con el consecuente relevo de sus funciones por parte de intereses privados ${ }^{103}$.

El plan fue construido a partir de una ambiciosa elaboración filosófica que estaba a su vez informa$\mathrm{da}$ por los enormes retos que se presentaban en la década de I990 y que estaban configurando la sociedad a mediano plazo; así, por ejemplo, conceptos como "sociedad del conocimiento", "revolución de la inteligencia", "realidad postindustrial" y "competitividad" definieron esa nueva realidad con la cual la USTA tendría que interactuar durante al menos dos décadas ${ }^{104}$.

Claramente, la USTA institucionalizaba su participación en las lógicas que en los noventa resignificaban la misión de las universidades: "Si quisiéramos describir el concepto de conocimiento, tendríamos que asociarlo con la ciencia y con su manifestación que es la tecnología. Ambas constituyen la divisa más

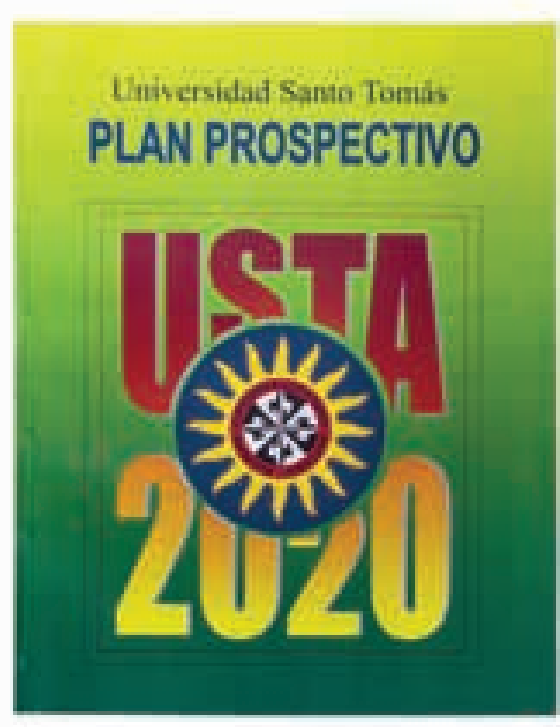

Con el Plan Prospectivo USTA 2020 la Universidad inició la planeación administrativa y académica a largo plazo

importante de la economía actual y el elemento primordial de la era posindustrial. Sirviéndonos de una metáfora, las podríamos denominar 'la moneda del siglo XXI" "'05.

Lógicamente, para la elaboración del Plan se tuvo en cuenta también la posición, desde el punto de vista de la competencia, de la región latinoamericana en que la USTA se inscribe; es decir, el desempeño competitivo regional a través de indicadores como producción académica, número de investigadores, número de patentes, etc. Frente al oscuro diagnóstico resultante, se identificaron dos grandes causas: por un lado, la precariedad de la financiación de la investigación y de la educación, y por otro, la ineficacia de los modelos pedagógicos ${ }^{\mathrm{I0} 6}$.

Este segundo factor, el de modelos de educación memorísticos, inflexibles y que restringen la creatividad, genera en USTA 2020 una propuesta de renovación curricular cuyo objetivo es el fomento de la innovación a través de la interdisciplinariedad y modelos pedagógicos más dinámicos, flexibles, intertextuales y virtuales. Al mismo tiempo, se propone un viraje hacia las áreas de mayor proyección actual, fundamentalmente las nuevas tecnologías ${ }^{107}$. 


\title{
I 90
}

\author{
Madurez institucional 1995-2018
}

El Plan Prospectivo significó también una reafirmación de los pilares fundamentales de la doctrina tomista, que es el rasgo esencial del espíritu universitario de la USTA. Por ello, se llama la atención sobre la "crisis de sentido" de los tiempos finiseculares como consecuencia de algunos rasgos del pensamiento actual como el nihilismo, el eclecticismo, el cientificismo, el relativismo, el materialismo, entre otros ${ }^{\text {108 }}$.

El Plan Prospectivo propuso 21 factores de cambio que, con distintas variaciones de importancia y urgencia, constituirían los campos en los cuales se aplicarían distintas estrategias para la sobrevivencia, el desarrollo y el efectivo cumplimiento de la Misión de la Usta durante dos décadas: I) posicionamiento, 2) modelo y políticas organizativas, 3 ) identidad institucional, 4) informática, 5) espacio físico, 6) impacto social, 7) calidad académica, 8) equidad del conocimiento, 9) enfoque educativo, Io) comunidad educativa, II) posgrados e investigación, I2) recursos, I3) continuidad del sistema educativo, I4) calidad de docentes y estudiantes, 15 ) articulación con el sector privado y el Estado, I6) interdisciplinariedad, I7) humanización de la tecnología, I8) educación a distancia, I9) educación permanente, 20) formación para la previsión y 2I) apertura ${ }^{109}$.

A la luz de los años, se aprecia que en los factores de cambio identificados en 1999 algunos estaban directamente relacionados con las necesidades corporativas que se anunciaban como fundamentales en los años noventa (posicionamiento, articulación con la empresa y el Estado, apertura), mientras que otros pertenecen directamente a la identidad filosófica y pedagógica de la Universidad (impacto social, educación a distancia). De acuerdo con el espíritu del Plan, se debía avanzar integralmente en todos estos factores, puesto que el objetivo fundamental es alcanzar una solidez en dos áreas consolidadas: la base institucional, doctrinal y misional, por un lado, y el campo operativo-administrativo, por el otro.

Ya en el campo de las estrategias prácticas para construir la Universidad del 2020, el Plan proponía acciones directas en tres grandes áreas: I) estructuración de las bases institucionales, 2) desarrollo tecnológico en todas sus modalidades articulado a la investigación, la educación, la administración y la comunicación y 3) administración y finanzas.

En la primera gran área, las estrategias incluían configurar una unidad educativa, hacer reestructuración en áreas como la dirección pastoral y la investigación, y fortalecer la dimensión comunitaria, la solidaridad, la justicia social y el área de Bienestar Universitario. En la segunda, las estrategias estaban destinadas al desarrollo tecnológico en varios campos y al progreso de la educación virtual. En la tercera gran área, las estrategias se orientaron a una mejor organización, definición de competencias, mayor rigor en los procesos, implementación de soporte tecnológico, manejo estratégico de los recursos, diversificación de servicios y una mayor proyección de mercado.

Así, con un PEI y un Plan Prospectivo a dos décadas, al finalizar la década de I99o la Universidad había hecho importantes avances para hacer frente a las tareas del nuevo milenio con una institucionalidad consolidada y como un plantel orientado por la planeación y el pensamiento a largo plazo, este a su vez basado en la conciencia histórica proyectada en el PEI.

E1 Plan Prospectivo marca claramente un antes y un después en la historia administrativa de la USTA al inaugurar, gracias al proceso de transformación que se venía dando desde mediados de la década, el periodo moderno de administración planificada y tecnificada del claustro. De ahí en adelante, la administración rectoral empezó a obedecer a planes generales de desarrollo construidos colectivamente, junto a sus respectivos planes de acción en cada una de las sedes, seccionales y VUAD.

Terminada la rectoría de fray Jaime Valencia, el prior provincial y presidente del Consejo de Fundadores, fray Carlos Mario Alzate, en carta del I4 de $1999^{\mathrm{II}}$, le agradece su gestión y reconoce varios aspectos positivos: posicionamiento de la USTA en el concierto de las instituciones del país; crecimiento y desarrollo de la Universidad con la apertura y extensión de nuevos programas en distintas ciudades; progreso en la atención pastoral a la comunidad universitaria mediante la evangelización de la cultura y proyección apostólica; mejoramiento de la planta física: nuevas construcciones y adquisición de predios; crecimiento patrimonial; impulso y apoyo a la presencia dominicana en el claustro universitario; iniciación del proceso de acreditación de los programas académi$\cos ^{\mathrm{II}}$; elaboración del proyecto educativo institucional -PEI- y del proyecto de desarrollo USTA 2020; creación e impulso de Prousta; planeación de proyectos con presupuesto; generación de recursos para cubrir las necesidades laborales de los trabajadores; mejor estructuración de la Universidad Abierta y a Distancia; incremento en el número de estudiantes de posgrados y en la VUAD, entre otros. 


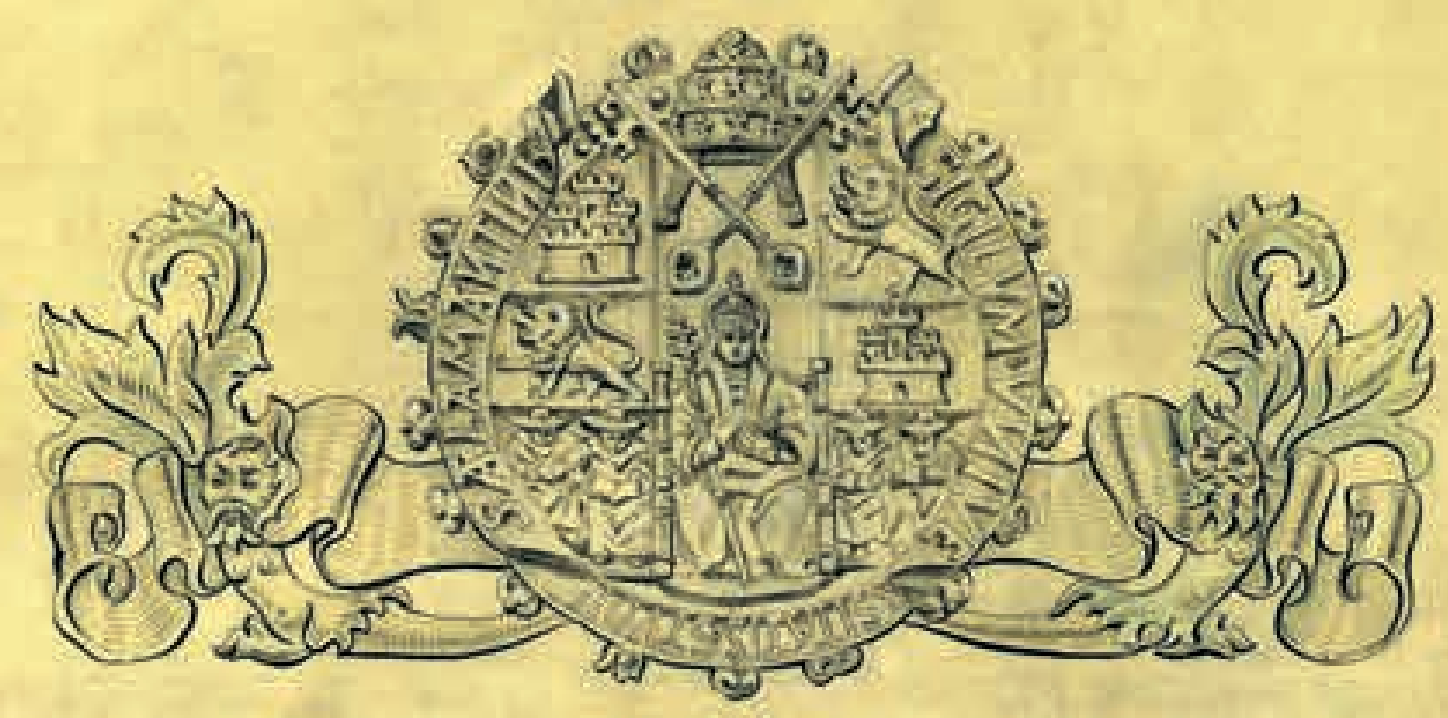

EL. RECTOR DE LAVNIVERSIDAD DE SALAMANCA AL DE LAVNIVERSIDAD DE SANTO TOMAS, DE BOGOTA तes 19. IPROPIOES DE VNAMADRE AMAR A TODAS SVS kijas, justo es también que lenga predilección por aquéllas que mayores dificultades encontraron cu su vida. Por eso,nuestra Vniversidad que, como madre, se gloría de haberos servido de modelo y haberos trásmilido sus tradicionesy privilegios, segoza hoy, conparticular ale. gría, en esta celebración del IV Centenario, al que habéis tenido la gentileza de invitarnos. No nos atrevcmos a decir que nos unimos a vue stro gozo, pues lo tenemos por nuestro, como por nuestres tuvimos vuestras dificuliades Aceptad, por tanto, este mensaje en el que van nuestro amor, nuestra gratifud y nuestro aliento para futuras y más allas empresas, como las que sin duda acometeréis en el quinto siglo que koy comienza de vuestra kistoria.

En Salamanca, en las casas de esta Insigne Vuiversidad, a 15 de Junio del año del Señor 1980, IV Centenario de la bula "Romanus Pontifex"

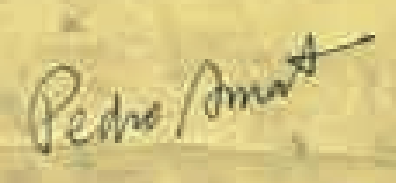

Pedro Ainat Muñoz 


\section{92}

Madurez institucional 1995-2018

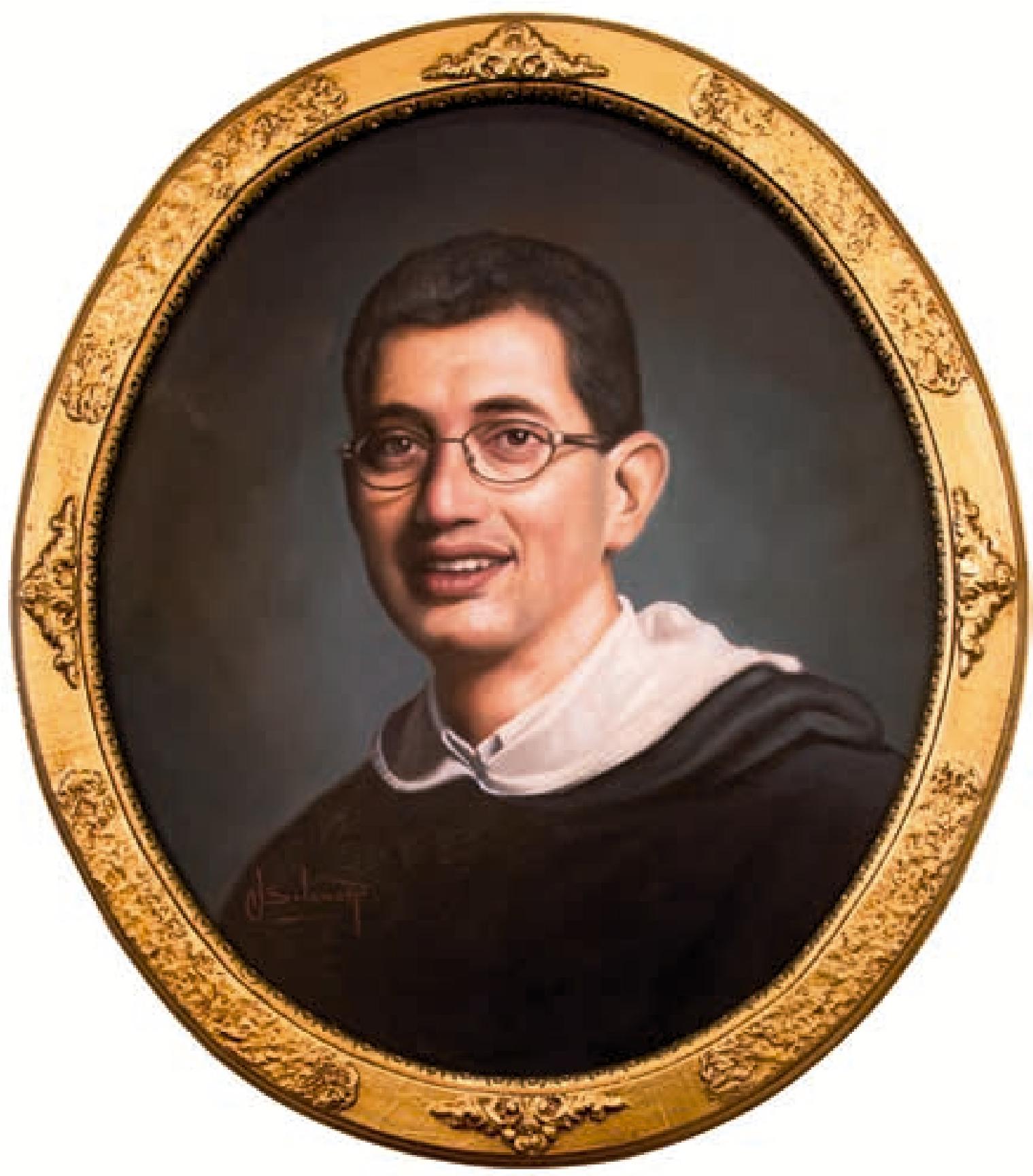

Fray Eduardo González Gil, O.P., rector general 1999-2003 


\section{93}

Madurez institucional 1995-20I8

\section{FRAY EDUARDO GONZÁLEZ GIL, O. P., RECTOR GENERAL 1999-2003}

En junio de 1999, el Consejo de Fundadores eligió al a fray Eduardo González Gil, O. P., como rector para el cuatrienio $1999-2003^{\text {II }}$. Fray Eduardo nació el 27 de febrero de 1963 en Guadalupe, Santander. Adelantó el prenoviciado y el noviciado en 1988 , hizo profesión religiosa el r. ${ }^{\circ}$ de julio de 1989 y profesión solemne el r. ${ }^{\circ}$ de julio de r994. Fue ordenado diácono el 7 de octubre de 1995 y presbítero el 3 de agosto de 1996.

A1 llegar a la rectoría, fray Eduardo era ingeniero industrial por la Universidad Industrial de Santander (1988), licenciado en Filosofía (1994) y especialista en Docencia Universitaria por la USTA (1996). Después de su rectoría aun se especializó en Gerencia de Instituciones de Educación Superior por la USTA (2004), se licenció en Teología (20II), obtuvo un magíster en Educación (20II) y una especialización en Evaluación-Planeación Universitaria (2012), esta última en la Universidad Autónoma de Yucatán, en Mérida. Actualmente, se encuentra cursando el Doctorado en Administración de Empresas en la Universidad Católica de Santa María de Buenos Aires (UCA), en Argentina, y su trabajo de investigación trata sobre el gobierno corporativo en las universidades, una mirada desde la teoría de la agencia. Así mismo, es subprior del Convento en Chiquinquirá.

Antes de la rectoría, fray Eduardo enseñó Matemáticas en el Jordán de Sajonia entre 1990 y 1994, fue docente y director de Pastoral Universitaria en la USTA Bogotá entre 1994 y 1995, y docente de Humanidades en la USTA Tunja y Chiquinquirá entre 1996 y 1999. También ha desempeñado diversas funciones docentes y administrativas en conventos de Bogotá y Boyacá. Después de su rectoría fue vicerrector académico general en el periodo 20I0-2015 y rector de la Seccional Tunja entre 2015 y $2016^{115}$.

La administración de fray Eduardo González dio continuidad a los procesos de mejoramiento de la calidad académica con miras a la acreditación, así como a la implantación de una cultura de planeación, enfocándose además en la internacionalización de la Universidad, la promoción de la investigación y el impulso a las nuevas tecnologías ${ }^{116}$. Por otro lado, mientras que durante la segunda mitad de la década de 1990 la Universidad había vivido un periodo de expansión por medio de la oferta presencial en las regiones, para el cambio de siglo el enfoque fue hacia el fortalecimiento de las sedes y seccionales existentes e iniciar la construcción de una sola USTA a

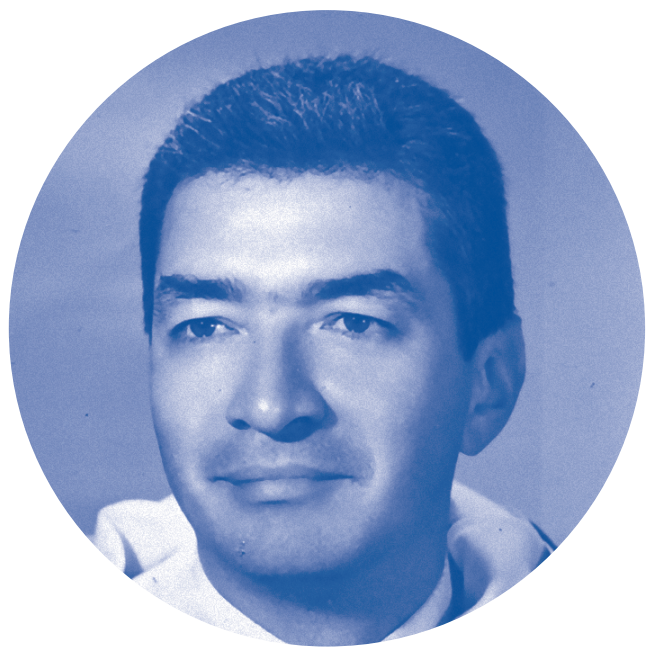

Fray Carlos Mario Alzate Montes, O.P., prior provincial durante los años 1998-2002

nivel nacional ${ }^{117}$. En ese sentido, se hicieron los primeros esfuerzos por unificar y fortalecer la imagen institucional alrededor de la cultura administrativa y de programas académicos fuertes y comunes a nivel nacional ${ }^{118}$.

Se iniciaba así con la unificación de programas académicos a nivel nacional, la construcción de una sola USTA con presencia en varias regiones del país. La unidad desde la diversidad regional. Pero será necesario superar muchos obstáculos y problemas para alcanzar la realidad multicampus dos décadas más tarde.

Puede decirse que la administración del rector Eduardo González fue la primera en trabajar bajo los lineamientos de un Plan General de Desarrollo, que fue aprobado en noviembre de 1999 por el Consejo de Fundadores y destinado a guiar a la Universidad, en todas sus sedes y seccionales, en el periodo $2000-$ 2003 como continuidad y aplicación del PEI de $1999^{\text {III }}$. En consonancia con las nuevas tendencias en educación superior en el cambio de siglo, el Plan General de Desarrollo 1999-2003 contemplaba una función 


\section{94}

Madurez institucional I995-20I8 $^{-20}$

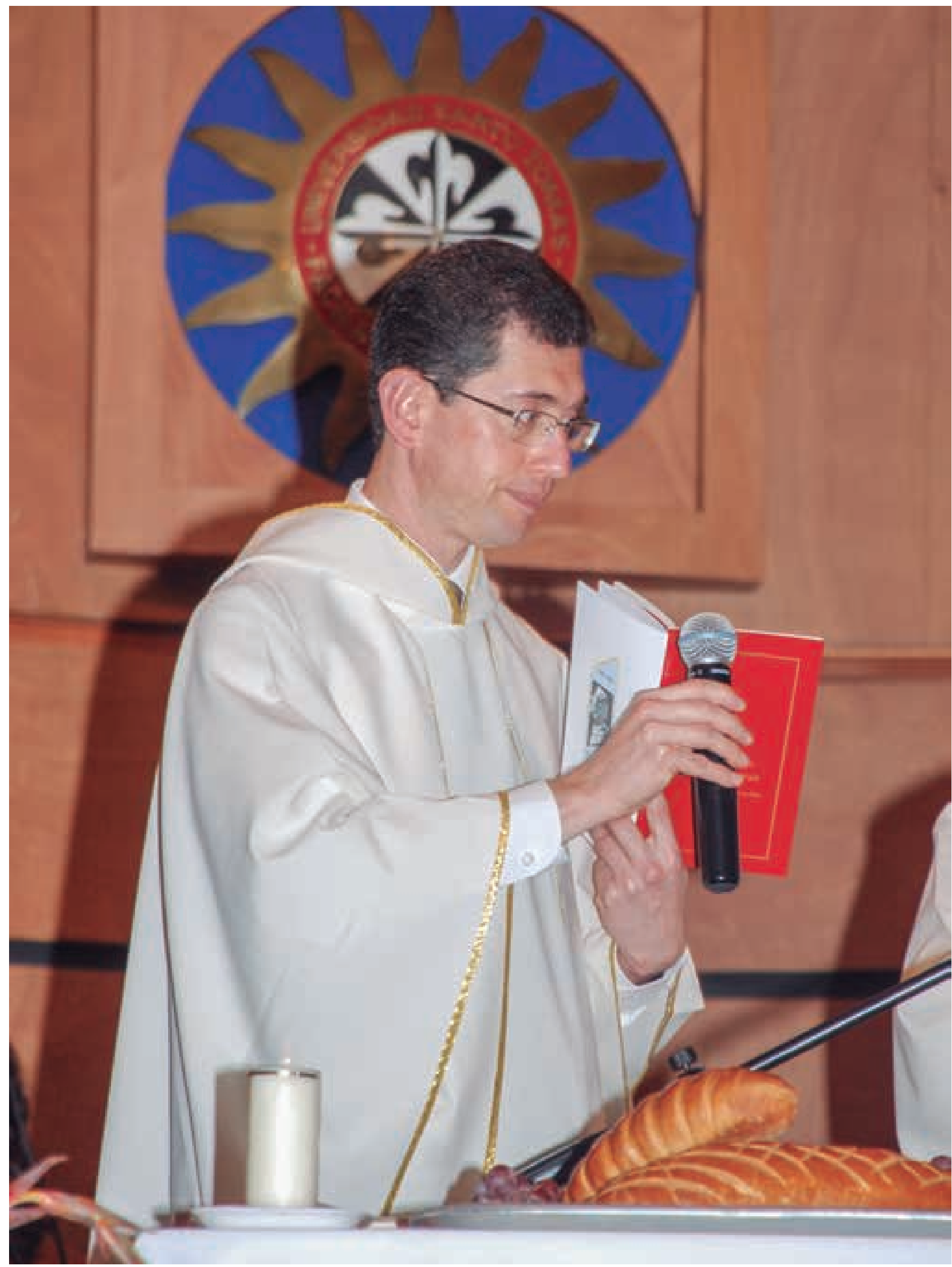

Durante la rectoría de fray Eduardo González Gil, se crearon las unidades de apoyo a los procesos académicos, investigativos, de calidad y estudiantiles 


\section{Durante la segunda mitad de la década de 1990, la} Universidad había vivido un periodo de expansión por medio de la oferta presencial en las regiones, para el cambio de siglo. Con fray Eduardo como rector, el enfoque fue el fortalecimiento de las sedes y seccionales existentes e iniciar la construcción de una sola USTA a nivel nacional.

“más pragmática” para la Universidad, en lugar de una idea del "conocimiento por el conocimiento" En este marco, la pertinencia aparece como un valor fundamental para el accionar de la Universidad. $\mathrm{Su}$ filosofía administrativa se puede resumir de la siguiente manera:

Es evidente que toda empresa humana de cierta envergadura requiere una sana y racional administración de sus diferentes recursos para que puedan ser objeto de uso o aprovechamiento óptimo y funcional, de modo que pueda asegurar así la mejor realización de sus múltiples y variados objetivos. En este punto la Universidad Santo Tomás requiere modernas estrategias, en cuyo diseño puede intervenir el área académica mediante una estrecha y eficiente relación con el sector administrativo, a efecto de lograr una optimización de sus recursos y la adopción de políticas que surtan la máxima eficacia en su manejo ${ }^{\mathrm{I2} I}$.

Un eje central del Plan fue la concreción y articulación orgánica de tres áreas de acción en las que se consuman los objetivos misionales de la Universidad, y que hoy en día se conocen como "funciones sustantivas", a saber docencia, investigación y proyección social ${ }^{122}$. La articulación se dio de maneras reconocibles a través de la sincronización entre los planes de estudio y las líneas de investigación, la promoción de la "pertinencia” de los programas académicos, la participación de la comunidad tomasina en las actividades propias de proyección social y, en términos generales, una mayor coordinación de las actividades institucionales.

En el plano científico-académico, el Plan contemplaba la continuación del proceso de actualización de métodos pedagógicos introduciendo nuevas metodologías hasta llegar a un modelo institucional de pregrados y posgrados flexibles e interdisciplinarios en los que tuvieran cabida no solo la formación, sino también la investigación y la proyección social. Frente a las urgentes necesidades de la Universidad en el área de investigación, se propiciarían los espacios y recursos para ello a través de la política de publicación de trabajos de grado sobresalientes, tesis, etc., y de la consolidación de líneas de investigación ${ }^{123}$.

Por otro lado, la rectoría de fray Eduardo González habría de continuar con el proceso de autoevaluación y acreditación fijando políticas institucionales al respecto y logrando la acreditación de los primeros programas académicos ${ }^{124}$, como se verá más adelante.

Al final de la rectoría de fray Jaime Valencia se habían culminado los procesos de registros calificados de varios programas académicos de la Universidad en el contexto de la acreditación voluntaria que el gobierno había promulgado. Las facultades de Filosofía, Contaduría Pública y Derecho, así como varios programas a distancia, dieron el salto cualtitativo para presentarse al examen del Consejo Nacional de Acreditación para obtener la acreditación voluntaria $^{125}$. La reacción fue en cadena. Otros programas de la Sede Central (Bogotá) como de la Seccional de Bucaramanga también iniciaron sus procesos de revisión documental y autoevaluación, con los mismos fines. Además, para afianzar la proyección y el posicionamiento institucional, fruto de los primeros resultados de la autoevaluación, se propuso una modernización de los centros regionales, la decisión 


\section{6}

\section{Madurez institucional 1995-20I8}

irreversible de culminar los procesos de acreditación y homologación de títulos y la continuación de la política de seguimiento a egresados para la evaluación del impacto educativo ${ }^{\mathrm{I} 26}$.

Para cumplir todo esto era imprescindible continuar con la reestructuración administrativa que se venía adelantando por la anterior rectoría. Por ello, fray Eduardo González continuó con la política de unificación de criterios administrativos, de coordinación entre los diferentes órganos, de incorporación de la planeación como función determinante de la gestión, de mejoramiento de las comunicaciones y de la imagen universitaria. A esto se le sumaron políticas de ampliación del alcance de Bienestar Universitario y de diversificación de fuentes de financiación ${ }^{127}$. Era la aplicación de su profesión (ingeniería industrial) al servicio de la USTA en todos sus frentes.

Entre las estrategias transversales a las políticas académicas, administrativas y de evaluación y regulación, se incluyeron la capacitación y perfeccionamiento docente y administrativo, la renovación de estatutos y manuales de funciones y de procedimientos, organigramas, se realizaron importantes inversiones en ciencia y tecnología, se avanzó significativamente en la sistematización de la información, en convenios, asesorías y otros modos de cooperación con el sector productivo distrital y nacional, con otras instituciones educativas nacionales e internacionales, etc. Todas estas estrategias se agruparon de la siguiente manera: I) para la proyección social, 2) para el fortalecimiento de la comunidad universitaria, 3) para el avance investigativo y científico y 4) para el mejoramiento de los procesos administrativos ${ }^{\mathrm{I2}}$.

La rectoría de fray Eduardo González Gil inició en medio de una sensible disminución de la población estudiantil, fenómeno observable desde el primer semestre de 1998 y que tuvo que ser encarado con prontitud. En la tabla I5, "Población estudiantil, pregrado, consolidado nacional I997-2002", y en el gráfico 3, "Población estudiantil, pregrado, consolidado nacional 1997-2002", se aprecia un momento crítico de baja en la población estudiantil de pregrado en el segundo semestre de 1998 con una recuperación importante en el semestre inmediatamente siguiente y un descenso constante de la población de ahí en adelante. Al respecto, fray Eduardo señala:

A partir del primer período de 1998 , el proceso de matrícula de la población estudiantil permitió observar una tendencia general hacia la disminución. Las inscripciones, la matrícula de neotomasinos y el total de matriculados en Bogotá, VUAD, Bucaramanga y Chiquinquirá presentan cifras con bajas de población en pequeños porcentajes, con recuperaciones cíclicas en Bogotá y Bucaramanga. La seccional Tunja y la Sede de Medellín, por tener programas académicos de reciente creación, aumentan su población en forma progresiva, pero no porcentajes altamente significativos. Para los segundos períodos académicos se observa un cumplimiento, ya histórico, de una población inscrita y matriculada menor en todos los cursos. [...] Gracias a distintos tipos de análisis, es ya conocida la explicación atribuida a la baja demanda de cupos para la educación superior, más que todo por razón de las particulares condiciones económicas y políticas que el país viene viviendo en la última década. En la Universidad Santo Tomás este fenómeno se manifiesta, no tanto en los inscritos o matriculados, sino en la deserción temprana ${ }^{\mathrm{r} 29}$.

Como apunta el rector González en su Informe de Gestión, el fenómeno fue generalizado en todo el país por cuenta de la crisis económica. En la tabla II, "Población universitaria nacional I997-2000", se puede apreciar el comportamiento de solicitudes, estudiantes nuevos y total de matriculados en la educación superior colombiana entre los años 1997 y 2000. Se observa sobre todo un descenso en las solicitudes en 1998 que se agudiza en 1999 y una recuperación ya en el año 2000.

Para sortear esta situación, la Universidad implementó políticas de corto y largo plazo. Entre las primeras se cuentan principalmente los incentivos financieros y las facilidades de pago a los estudiantes para prevenir la mortalidad académica de causas económicas ${ }^{130}$. Como respuesta a más largo plazo se creó el subsistema de información académica SAC, en Bogotá (más adelante en las otras sedes y seccionales), que permitió consolidar información y hacer seguimiento a los comportamientos de la Universidad en admisiones, matrícula, rendimiento académico, etc. ${ }^{\text {I3 }}$. En la tabla 24, "Población estudiantil y docente 2000-2004", se aprecia la evolución de la población estudiantil y del personal docente en el periodo 2000-2004.

VUAD, sedes y seccionales

Aunque por causas diferentes, en la VUAD en particular la población estudiantil sufrió una sensible disminución en los años finales de la década de 1990 e inicios de la siguiente. En la tabla I7, "Población 


\section{97}

Madurez institucional 1995-2018

estudiantil VUAD I998-2 a 200I-I", es posible apreciar cómo la disminución se dio sobre todo en la Facultad de Educación y muy particularmente en sus posgrados.

Por otro lado, los números de la tabla I8, "Población pregrado VUAD I997-I a 2002-2", que muestra las cifras para pregrado hasta el año 2002, indica una baja histórica en el segundo semestre de 1998; a pesar de la recuperación importante del semestre posterior, la disminución continuó sostenida durante el fin del periodo tenido en cuenta hasta llegar a la situación del segundo semestre del 2002 en que se tenía una población estudiantil cercana al 51.5\% de la del primer semestre de 1997 .

Finalmente, en la tabla i9, "Población posgrado VUAD, I999-2002”, se aísla el comportamiento de la población estudiantil de posgrado de la modalidad, que fue la que tuvo un comportamiento de mayor disminución ${ }^{\mathrm{I} 32}$. De hecho, durante la segunda mitad de la década de I990, el crecimiento de la oferta académica en la VUAD se había centrado principalmente en posgrados, que empezaron a llegar más consistentemente a las diferentes regiones del país ${ }^{\mathrm{I} 33}$.

Lamentablemente, llegada la hora a varios de los programas de la VUAD, principalmente de su Facultad de Educación, les fue negada la acreditación, lo que obligó a la Universidad a sacar del mercado a varios de ellos con una consecuente baja sensible en las matrículas. Ello explica que mientras del segundo semestre de 1999 al primero de 2001 la Facultad de Ciencias y Tecnologías pasó de 3790 estudiantes matriculados a 4376, durante ese mismo lapso la Facultad de Educación pasó de 7230 a 3584; es decir, una disminución del 49.5\%: "Este comportamiento en la matrícula coincide con el proceso de acreditación obligatoria para los programas de educación, cuyo resultado es conocido en la Universidad, lo cual puede ser una de las causas de tan alta deserción en un periodo relativamente corto" ${ }^{134}$.

Esto tuvo como consecuencia una profundización de problemas económicos que venían aquejando a la VUAD $^{135}$. Las causas de estas crisis son una serie de factores que se fueron acumulando durante varios años. El problema fundamental yacía en que a pesar de los cambios administrativos que llevaron a la creación de la Vicerrectoría Administrativo-Académica Nacional en 1997, al menos desde el Plan Integrado de la década de 1980 en la Universidad Abierta y a Distancia no se había creado un modelo académico adaptado a las nuevas tendencias y lineamientos nacionales e internacionales sobre modalidad a distancia ni al marco filosófico de la Universidad.
Es decir que la VUAD tampoco había adaptado su quehacer ni al PEI ni al Plan General de Desarrollo $2000-2003^{136}$. En contra del espíritu de unidad institucional del Plan, había una falta de diálogo curricular entre las modalidades presencial y a distancia; esto demostraba que la creación de la Vicerrectoría, más que conferir autonomía a la modalidad a distancia, había creado desarticulación ${ }^{137}$. Así mismo, al interior de la VUAD se evidenciaba una falta de relación orgánica entre sus dos facultades ${ }^{138}$.

Por otro lado, y también a despecho tanto del espíritu orgánico del Plan de Desarrollo como de los objetivos que se había planteado la Universidad con la creación de la Vicerrectoría, se presentaban problemas en el diálogo entre los centros regionales y la administración central de la VUAD en Bogotá que estaban impidiendo la conformación de una comunidad académica ${ }^{\mathrm{r} 39}$. Las dificultades provenían de una excesiva centralización administrativa que generaba malestar en las regiones desde donde estudiantes, docentes y coordinadores elevaban quejas frecuentes en este sentido. A esto se sumaba la práctica ausencia de Bienestar Universitario en los centros regionales ${ }^{\mathrm{I} 4 \mathrm{O}}$.

Los materiales pedagógicos, elementos fundamentales de la modalidad a distancia, eran un tema de preocupación constante. La fortaleza editorial de la modalidad había tenido una baja sustancial y se evidenciaba incumplimiento en el suministro de los materiales que llevaba a atrasos en las programaciones académicas. Además, desde las regiones se criticaban los criterios pedagógicos emanados desde Bogotá como inapropiados, desactualizados y descontextualizados ${ }^{\mathrm{I} 4 \mathrm{I}}$.

Además, no había políticas definidas sobre inducción a directivos y docentes a las estrategias pedagógicas propias de la modalidad a distancia. El excesivo centralismo restaba autonomía a los tutores regionales y el mejoramiento docente tanto como la investigación provenían de iniciativas aisladas y no de estrategias sistemáticas ${ }^{142}$. Se evidenciaba también una grave falta de convenios regionales y locales para el apoyo a los estudiantes en sus prácticas ${ }^{\mathrm{I} 43}$. Todo esto motivó la grave crisis que enfrentó la VUAD en el cambio de siglo.

Frente a estos problemas, la Vicerrectoría Académica llevó adelante una serie de medidas de choque como reducción de personal, recuperación de la cartera morosa, disminución de gastos, campaña publicitaria, promoción de eventos académicos, reducción de becas, entre otros ${ }^{144}$. Sin embargo, pronto el Consejo de Fundadores asumió las riendas de la situación después de estimar la necesidad de un proceso completo de reingeniería en la VUAD. Se planteó, en primer lugar, 


\section{99}

Madurez institucional I995-20I8

Mientras tanto Tunja, que venía funcionando administrativamente como una Decanatura de División ${ }^{152}$, fue asimilada como una seccional por orden del Consejo de Fundadores en 1999 con el objetivo de "asegurar un orden organizacional coherente con la índole estatutaria y conducir a resultados académicos y administrativos de alta calidad". De esta manera, el decano de División de Tunja, fray José Antonio Balaguera en aquel momento, pasó a ser rector seccional y se constituyeron las entidades necesarias para el funcionamiento administrativo de la seccional ${ }^{153}$.

Tres años después, en febrero de 2002, Tunja fue reconocida como seccional por el Icfes, dando fin a un proceso burocrático que había iniciado a fines de $1996^{154}$. Con este reconocimiento se oficializaron todos los cargos administrativos regidos por el Estatuto Orgánico que se promulgó ese mismo año: rectoría seccional, vicerrectorías académica y administrativa-financiera, departamentos de planeación y desarrollo, de comunicaciones y mercadeo, de sistemas, de recursos humanos, sindicatura, contabilidad, bienestar universitario, pastoral universitaria, planta física, biblioteca y archivo ${ }^{155}$.

Por otro lado, ya desde fines de la década de 1990 Tunja dio inicio a un periodo de crecimiento en infraestructura material con tres nuevos edificios ${ }^{156}$. En 1999 se le había comprado al Convento Santo Domingo de Guzmán un terreno parte del inmueble del antiguo Liceo Santo Domingo de Guzmán que fue luego remodelado ${ }^{157}$. En el año 2000 se adquirió otro de $47000 \mathrm{~m}^{2}$ donde se comenzó a construir el campus $^{158}$. En marzo del 200 r se inauguró el edificio San Alberto Magno ${ }^{\mathrm{I} 9}$. Más adelante, entre el 2002 y el 2003 se empezó un proyecto de construcción que incluyó la restauración del antiguo Convento de Santo Domingo de Guzmán y la construcción del Campus Universitario y del edificio Giordano Bruno ${ }^{\mathrm{I} 60}$.

En cuanto a la Sede Medellín, durante la rectoría de fray Eduardo González, mantuvo los dos programas académicos de pregrado con que había iniciado, Arquitectura e Ingeniería de Telecomunicaciones, extensiones de Bucaramanga y Bogotát ${ }^{16 r}$. E1 crecimiento de la población estudiantil se puede apreciar en la tabla 22, "Población estudiantes Medellín 2000-I a 2002-I". En 2002 Medellín había hecho una reestructuración administrativa eliminando la figura de vicedecanos proveyéndose a las facultades de decanos académicos ${ }^{162}$.

Durante estos años, la USTA evaluó algunas posibilidades de reubicación de la Sede Medellín ${ }^{163}$. En el año 2002 la Sede inauguró el edificio San Alberto Magno para ampliar la cobertura de servicios a la comunidad académica y posicionar la Institución ${ }^{164}$. Ese mismo año la Universidad inició gestiones para extender a Medellín los programas de Comercio Exterior y Derecho ${ }^{165}$.

Creación de las unidades, currículo, docencia, internacionalización, espacios culturales y proyección social

Quizá el hecho administrativo más importante y significativo de este periodo rectoral fue la reforma a la Vicerrectoría Académica General, contemplada en el Plan General de Desarrollo y su Plan de Acción. Surgieron así cuatro organismos administrativos dentro de la estructura de la misma Vicerrectoría ${ }^{166}$, que hoy siguen teniendo vigencia.

La Unidad de Planeación Académica y Perfeccionamiento Docente, bajo la dirección de la licenciada Carmen Lucía Gordillo Guerrero, fue creada para apoyar políticas académicas y pedagógicas del vicerrector académico general y asesorar a las facultades en la construcción de sus modelos pedagógicos, la planeación curricular y la capacitación docente ${ }^{167}$.

La Unidad de Investigación y Posgrados, con su director Ómar Parra Rozo, buscaba desarrollar, consolidar y promover la investigación articulándola con la docencia y la proyección social y, al mismo tiempo, coordinar la política institucional de investigación en posgrados ${ }^{168}$.

La Unidad de Proyección Social y Extensión Universitaria, con su primer director, el filósofo Luis Ernesto Solano Gutiérrez, fue creada con el propósito de coordinar las áreas de educación continuada, servicios, centros multimodales, etc. ${ }^{169}$.

Finalmente, la Unidad de Evaluación y Regulación Académica, con su directora licenciada Nidia Díaz Díaz, fue encargada de la planificación, coordinación y gestión de los proyectos de promoción de la evaluación y la regulación académica de los programas con fines de acreditación, así como de la unificación de criterios para la autoevaluación ${ }^{\mathrm{1} 70}$. La creación de esta última constituyó un impulso importante hacia la generación de una cultura de la evaluación y la calidad en los procesos de la Universidad ${ }^{171}$.

A lo largo de los años estas unidades se han conformado como espacios multidisciplinares que coordinan el trabajo, proporcionan recursos logísticos y sistematizan los trabajos que son llevados a cabo por iniciativa de las facultades y de los departamentos académicos. Como veremos más adelante, con los años estos organismos se desdoblarían y reorganizarían hasta adquirir su conformación actual. 


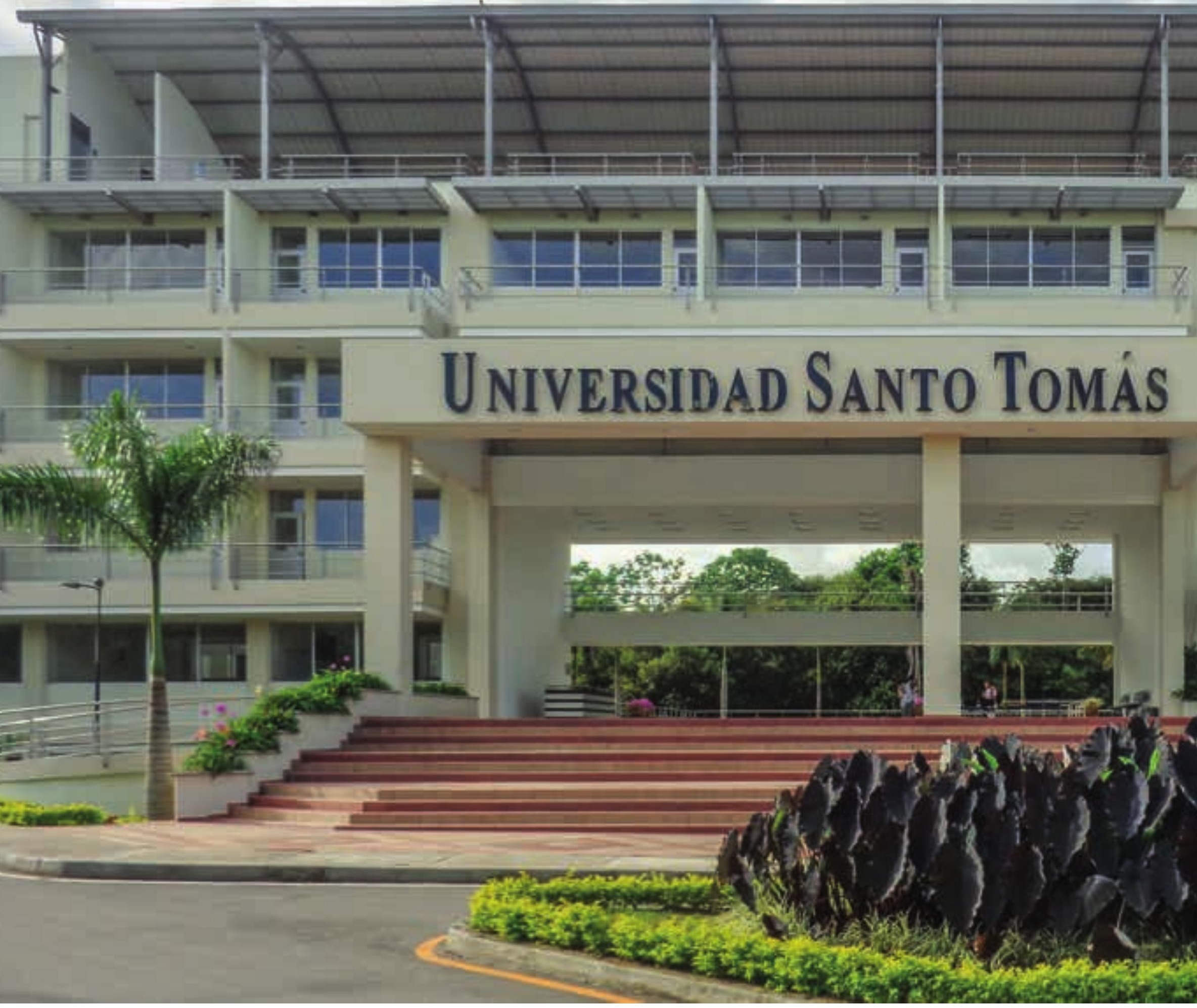

La creación de la Unidad de Investigación, ya referida, marcó un antes y un después en la investigación tomasina al centralizar sus políticas y articularlas con la docencia y la proyección social, así como al facilitar el apoyo a los centros de investigación existentes en las facultades ${ }^{772}$. En este contexto se empezó a trabajar en la construcción, a partir de las experiencias del Centro Interdisciplinario de Investigación (CIDI) y el Centro de Investigaciones de Enseñanza Desescolarizada (Ciced), de un modelo investigativo institucional ${ }^{173}$.

En el segundo semestre de 2000 se presentó a la VUAD un documento llamado "Caracterización, estructura, funcionamiento y lineamientos básicos orientados hacia el desarrollo de los Posgrados y la Investigación en la Universidad Santo Tomás", ajustado al Plan General de Desarrollo 2000-2003, en el que se plantean los lineamientos, tareas y objetivos que la Unidad persigue. Del documento se derivaron los tres proyectos "macro" de responsabilidad directa de la Unidad: I) reorganización de los programas de posgrado, 2) estructuración, articulación y reorganización de los procesos investigativos en la USTA y 3) reorganización de los procesos editoriales y de producción del conocimiento ${ }^{174}$.

Esto dio como resultado, en el 2000, el documento "Proyecto Investigativo Institucional (Proin)", que sintetiza el contexto investigativo y curricular, políticas, principios, criterios, visión, misión, modelo investigativo, modelo organizacional y estrategias para la investigación ${ }^{175}$. Al Proin le siguió en 2002 el documento "Protocolo de Investigación en la Universidad Santo Tomás", realizado por el investigador William Mantilla Cárdenas, al que se le sumará en el 2010 el 


\section{$20 I$}

Madurez institucional $1995^{-2018}$

Dada la gran acogida de la Universidad en los Llanos Orientales, se proyectó la ampliación de la USTA Villavicencio en la zona de Aguas Claras

documento "Fundamentación teórica de las Líneas Medulares de Investigación” presentado por los docentes del Departamento de Humanidades y Formación Integral, Javier Francisco Yate Rodríguez y Ómar Asdrúbal León Carreño.

E1 Proin fue pensado en el marco del Plan General de Desarrollo de fray Eduardo González, por lo que su horizonte estratégico fue el año $2003^{176}$. En septiembre del 2000 se divulgó en la Institución este documento, en el que se planteó el contexto, las políticas institucionales, el modelo investigativo institucional y la organización de la investigación en la Universidad, unificándose el lenguaje académico-administrativo ${ }^{\mathrm{I} 77}$. Por ello, para los distintos proyectos se establecieron:

La hipótesis, el cuestionamiento, la pregunta y el problema como los puntos de partida del modelo y de la situación investigativa que dan cabida a los proyectos. Estos últimos representan el campo problémico; la agrupación de los proyectos dentro de temas o líneas o perspectivas específicas representan las líneas. Siendo así, las líneas de investigación van siendo más generales y apuntan hacia el campo objetual que es materia del programa. El programa cobija las líneas, las líneas cobijan los proyectos, los proyectos cobijan los problemas. En resumen se puede hablar de que cada uno de estos términos apunta a dimensiones de lo objetual como programa, del campo temático como línea y del campo problémico como proyecto ${ }^{\mathrm{T} 78}$.

El enfoque problémico de la investigación en la USTA quedaba así institucionalizado. Por otro lado, vale la pena agregar que las líneas fueron pensadas aquí como susceptibles de permanente reconstrucción. Planteadas 


\section{2}

Madurez institucional 1995-2018

inter y transdisciplinariamente, se convirtieron en el motor de la investigación, así como en el punto de referencia y de respuesta a las necesidades, programas y propuestas de la Institución ${ }^{179}$. Se empezó a hablar de Líneas Medulares de Investigación (LMI) y de Líneas Activas de Investigación (LAI), primera gran unificación del lenguaje. En cuanto a las primeras, se propusieron varias, expresadas desde la filosofía institucional y desde la relación de las disciplinas de conocimiento de los programas con dicha filosofía ${ }^{\mathrm{180}}$.

Con la publicación del libro Proyecto Investigativo Institucional PROIN. Un enfoque para la concepción y el desarrollo de la investigación, en el 2005, quedan instituidas las políticas y líneas investigativas, convirtiéndose en el documento guía sobre el tema.

En continuidad con el proceso de adaptación a las regulaciones educativas que la década de 1990 había traído, durante la rectoría de fray Eduardo González se llevó a cabo una renovación curricular que siguió los lineamientos de la Ley 30 de I992, la Ley II5 de I994 ${ }^{\text {18I }}$, el Decreto 808 de $2002^{182}$, así como del Estatuto Orgánico de la Usta, del PEi y del Plan General de Desarrollo $2000-2003^{\mathrm{r} 83}$. Así, en el año 2000 la Universidad inició la revisión y autoevaluación de todos sus programas de pregrado y posgrado a nivel nacional, poniéndose especial interés en las maestrías, lo que llevó a inscribirlas en la Comisión Nacional de Doctorados y Maestrías ${ }^{184}$, con el apoyo de la unidad respectiva.

Al comenzar el nuevo milenio, la Sede de Bogotá contaba con treinta y siete programas de pregrado organizados en once facultades ${ }^{185}$. Así mismo y atendiendo al PEI, también se iniciaron las siguientes cátedras opcionales institucionales (COI) a cargo del Departamento de Humanidades y Formación Integral: Santa Catalina de Siena (tema: género), Francisco de Vitoria (tema: derechos humanos y derecho internacional), Bartolomé de las Casas (tema: multiculturalismo) y Alberto Magno (tema: ciencia, ecología y tecnología), que se sumaron a las obligatorias ya existentes: Tomismo o Cátedra Institucional, Antropología, Epistemología, Filosofía Política y Ética ${ }^{186}$. Cuatro años más tarde, el Departamento ya contaba con un total de catorce COI sobre los temas más importantes de la sociedad actual ${ }^{187}$. Estos cambios eran parte de una transformación general en la que se buscaba que el nuevo departamento adquiriera mayor autonomía frente a la Facultad de Filosofía ${ }^{\text {188 }}$, que desde I965 dirigía las cátedras institucionales. Se sumó también la creación del Departamento de Ciencias Básicas. Estas nuevas dependencias académicas iniciarán su proceso de consolidación y delimitación administrativa durante los siguientes cuatro años ${ }^{189}$.

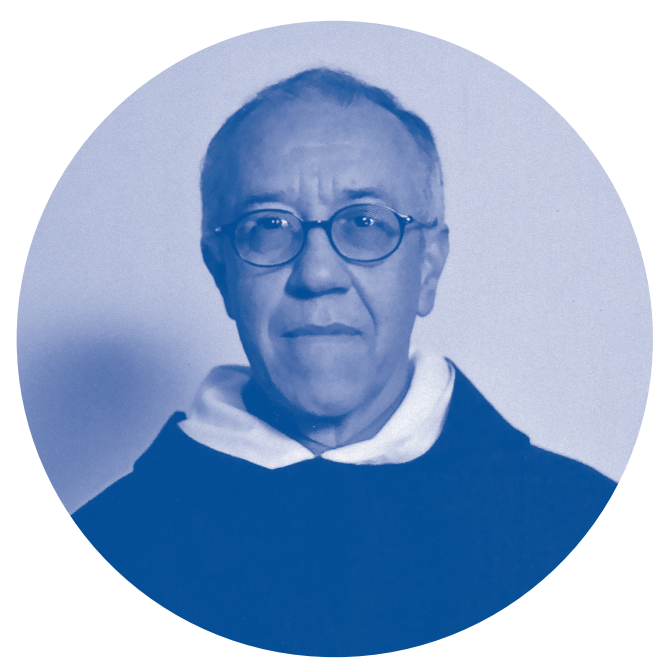

Fray Faustino Corchuelo Alfaro, O. P., vicerrector académico durante la rectoría de fray Eduardo González Gil, O.P.

En este sentido, también vale la pena mencionar la creación, en estos años, del Centro de Estudios en Economía y Humanismo Louis Joseph Lebret, O. P. La idea de crear un Centro Lebret surgió del Congreso de Economía, Ética y Valores realizado por la Facultad de Economía y Administración en octubre de 1998, institucionalizado por el Capítulo Provincial de este mismo año. La propuesta era generar un espacio en que se articulasen proyección social e investigación y que sirviese de intermediario con asociaciones externas precisamente para adelantar procesos de proyección social ${ }^{190}$.

Desde junio del 2000 se empezó a reunir el grupo de profesores y frailes especialistas en el pensamiento de Lebret que serían el origen del Centro que se planteaba como una organización no gubernamental (ONG) que involucraría a toda la comunidad dominicana de Colombia, incluyendo frailes, profesores, egresados, religiosas, etc. ${ }^{191}$. El Centro de Estudios fue tomando forma lentamente. En 2002, con fray Luis Alberto Orozco Arcila como director, los miembros del grupo visitaron el Centro de Economía y Humanismo en Lyon, así como el Centro Lebret de París para estudiar sus funcionamientos, identidad y concretar posibilidades de convenios ${ }^{192}$. En marzo de 2003, el Consejo Superior finalmente creó el Centro de Estudios de Economía y Humanismo Louis Joseph Lebret, adscrito a la Vicerrectoría Académica ${ }^{193}$ y estructurado bajo un 


\section{3}

Madurez institucional 1995-20I8

director y un coordinador. Más adelante, en febrero de 2004 el Centro Lebret fue adscrito a la Facultad de Economía de la Sede Principal ${ }^{194}$.

Otro de los hitos administrativo-académicos de la rectoría de fray Eduardo González fue la creación en julio del 2002 de la Oficina de Relaciones Internacionales e Interinstitucionales (ORII), que fue otro organismo tendiente hacia la organicidad de los procesos que previamente se trabajaban de manera completamente independiente por las facultades ${ }^{195}$. Por otro lado, en estos años de cambio de siglo aparecieron espacios de acción cultural y de integración social mucho más definidos en relación con los años anteriores; jornadas de poesía semanales, cine foro, conciertos quincenales, cuentería semanal, exposiciones de arte, días de la secretaria y de la mujer y fiesta de fin de año para personal administrativo, entre otros ${ }^{196}$.

Por cuenta de la globalización, desde la década de I990 ha tomado cuerpo una preocupación cada vez más institucionalizada y un consenso cada vez más generalizado sobre la necesidad de la proyección de las instituciones de educación superior sobre los contextos socioeconómicos y culturales en que se encuentran. El consenso gira en torno a la necesidad de que las instituciones de educación superior, incluyendo por supuesto a las universidades, entiendan la realidad en que se encuentran insertas y apunten hacia una interacción con su entorno que promueva la solución de problemas reales, prácticos y urgentes.

En la USTA, el desarrollo comunitario, la creación de infraestructura, el socorro de las comunidades menos favorecidas y la promoción de una cultura de paz han sido objeto de acción social recurrente, algunos de ellos con una tradición institucional que inició en los primeros años de vida del plantel. No obstante, los primeros esbozos de lo que sería la proyección social tomasina, institucional y sistemática, se remontan a los procesos reformativos llevados a cabo en la década de I980 por cuenta de los decretos 80 y 2799 de ese año, que pretendían remediar el problema de la desconexión entre la educación superior y la realidad del país.

Más adelante, con la Constitución de i99i que, como hemos visto, establece la función social de la educación, las universidades empezaron a avanzar hacia una proyección social a favor del desarrollo, la construcción de nación y la promoción de la paz. Después, la Ley 30 de 1992 definió la extensión universitaria como la serie de actividades mediante las cuales la institución interactúa directamente con el medio en procura del bienestar general y de la satisfacción de las necesidades sociales. Finalmente, con la implementación de los parámetros para acreditación y registro calificado, la proyección social quedó instituida como uno de los parámetros de calidad ${ }^{197}$.

En la Santo Tomás la proyección social se contempló en el Plan Prospectivo 2020 que sirvió de referencia para los años siguientes. Por ello la Unidad de Proyección Social y Extensión Universitaria fue una de las unidades creadas en medio de la reestructuración institucional de la rectoría de fray Eduardo González, con su primer director, el doctor Luis Ernesto Solano Gutiérrez, lo cual sirvió para unificar las políticas sociales tomasinas en torno a la planeación. También en esta época surgieron los primeros Centros Multimodales de Servicios, organismos de la Universidad destinados a llegar a sectores marginales de la población del país y en los cuales participan todos los estamentos de la Universidad para la solución de necesidades básicas de esas comunidades.

Una manera de entender los Centros Multimodales es mediante su contraste con la Pastoral; el objetivo de la Universidad con estos centros no era hacer presencia pastoral, sino colocar la Universidad al servicio de la comunidad como plantel educativo e investigativo ${ }^{\text {198 }}$. El primer centro creado fue en el sector de Altos de Cazucá, en Soacha, entre los años 1999 y $2000^{199}$, y en 200 r nació el de Monte de Galilea en el sector Bolonia de la localidad de Usme, en donde el Convento San Alberto Magno hacía presencia desde 1996, con el objeto de prestar servicios de pedagogía, cerámica, cursos de inglés, entre otros. En Bucaramanga, a través de su Institución Prestadora de Salud (IPS), se dio luz verde para la prestación de los servicios en optometría y odontología. En Tunja se creó el Genor (Ecosistemas Estratégicos del Nororiente Colombiano) para el estudio del ecosistema y páramos de la región. En Medellín se inició el servicio comunitario en asocio con los centros regionales de la VUAD. En Chiquinquirá se realiza a través de prácticas profesionales de psicología y asesoría de empresas. Y en la VUAD son los mismos Centros Regionales los que le prestan servicios a la comunidad.

\section{Estatuto Orgánico de 2002}

La promulgación de Ex Corde Ecclesiae, las transformaciones del sistema colombiano de educación superior en la década de 1990 y otros procesos históricos como la globalización habían restado actualidad a la estructura estatutaria de la USTA ${ }^{200}$. La Ley 30 de I992, por ejemplo, preveía participación para profesores y estudiantes en los organismos directivos de la Universidad $^{201}$, mientras que el Decreto I478 de 1994 


\section{4}

Madurez institucional I995-20I8

establecía concretamente los contenidos estatutarios de las universidades privadas ${ }^{202}$. De manera que las autoridades de la Provincia y universitarias veían la necesidad de reformar el Estatuto Orgánico ${ }^{203}$.

En un documento de rectoría de junio de 1996 titulado "Criterios para la reforma al Estatuto Orgánico" se mencionaban algunos de los cambios que debían ser incluidos en la reforma. Aunque buena parte de sus propuestas no fueron llevadas a efecto, este documento permite apreciar el ánimo que impulsaba dicha reforma; se esperaba, por ejemplo, conceder mayor autonomía al rector general en su relación con los consejos Superior y de Fundadores, abolir algunas figuras administrativas, reacomodar las funciones de otras, incluir representación estudiantil en el Consejo Superior y concederle a este organismo mayor capacidad de maniobra en sus relaciones con el Consejo de Fundadores:

Las principales funciones del Consejo de Fundadores son las de establecer las grandes políticas y prioridades de la Universidad, establecer los elementos básicos de su plan de desarrollo, aprobar los estatutos, crear seccionales, nombrar al rector general y hacer un seguimiento de la gestión rectoral. Con el objeto de otorgar mayor autonomía a la dirección de la universidad, todo lo que se refiera a actividades de administración y gestión, y que actualmente figuran como funciones del Consejo de Fundadores, se trasladarán al Consejo Superior ${ }^{204}$.

En últimas, en el año I996 se aprecia una necesidad sentida entre las directivas de generar mayor democracia, agilidad, eficiencia, transparencia y mejores respuestas a las necesidades del país ${ }^{205}$. Desde ese mismo año se empezó a construir el nuevo Estatuto a partir de propuestas de diversos sectores de la comunidad tomasina ${ }^{206}$. El Estatuto Orgánico fue aprobado por el Icfes en diciembre de 2001 y promulgado por el Consejo de Fundadores en julio del año siguiente. La reforma fue profunda, dada la magnitud de las transformaciones sucedidas en el fin del milenio.

Los rectores seccionales y los vicerrectores adquirieron gran autonomía respecto del rector general, puesto que su nombramiento pasó a ser responsabilidad del Consejo de Fundadores ${ }^{207}$. En cuanto a los rectores seccionales, se les adjudicaron responsabilidades análogas a las del rector en sus respectivas regiones y se aumentó su periodo rectoral de dos a tres años. Además, en comunión con el giro hacia la planeación tomado por la Universidad, se estableció como primera función del rector la presentación de un Plan General de Desarrollo,

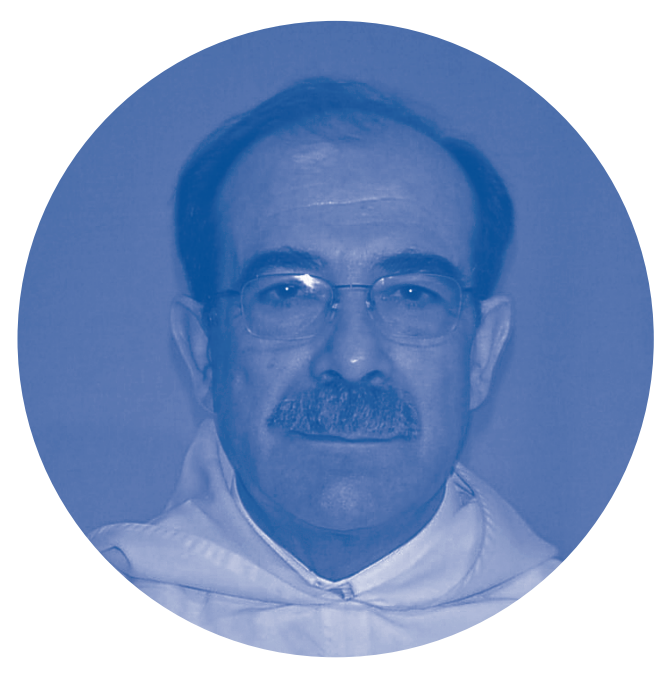

Fray Vicente Becerra Reyes, O.P., uno de los vicerrectores administrativos durante la rectoría de fray Eduardo González Gil, O.P.

en los cuatro primeros meses de la gestión, a los consejos Superior y de Fundadores para su aprobación ${ }^{208}$.

La estructura administrativa de la VUAD y las seccionales fue concretizada. Las seccionales quedaron bajo la dirección máxima de un Consejo Directivo, análogo al Consejo Superior de la Universidad, mientras que el vicerrector general de la Universidad Abierta y a Distancia quedó con funciones análogas a las de un rector seccional ${ }^{209}$. La investigación tuvo por primera vez un lugar relevante en la normatividad estatutaria al disponerse la creación de un "Centro responsable del fomento, promoción y administración de la investigación científica y tecnológica, dependiente de la Vicerrectoría Académica”; se dispuso así mismo que las seccionales y la VUAD crearan "su propio Centro de Investigaciones"

Por otro lado, en este estatuto se establecen claramente varias incompatibilidades e inhabilidades para los directivos. La primera de ellas, quizá la más importante, por lo sucedido en años anteriores, fue la prohibición de presidir el Consejo de Fundadores y ejercer la Rectoría General simultáneamente, pero también se establecen otras para evitar conflictos entre los intereses de la comunidad y los de la Universidad, así como algunas inhabilidades por lazos laborales y familiares para empleados ${ }^{2 I}$. Aparte del Estatuto Orgánico, durante la rectoría de fray Eduardo González 


\section{5}

Madurez institucional 1995-2018

se actualizaron otras estructuras normativas como el Estatuto Docente y el Reglamento Interno de Trabajo.

Como se ha afirmado más arriba, podemos concluir que son tres los logros más importantes de este periodo rectoral; siguiendo los derroteros marcados por el PEI y expresados en el Plan de Desarrollo, estos fueron: la reforma curricular nacional, la planificación de la investigación con el sentido de servirle a la comunidad y el sistema de información institucional.

En cuanto a la reforma curricular, se realizó un trabajo nacional tanto con los programas y asignaturas presenciales como a distancia, para unificar, conservando las especificidades regionales, los planes de estudios. La Unidad de Planeación Académica, bajo la dirección del vicerrector académico general fray Faustino Corchuelo Alfaro, O.P., jugó un papel importante, reuniendo a docentes, estudiantes, directivos y administrativos para estructurar y aportar en esa reforma curricular que incluía los planes de estudio. Se buscaba flexibilizarlos y adecuarlos a las exigencias normativas del Ministerio introduciendo las competencias como indicadores evaluativos y de aprendizaje. "Participación, flexibilidad, interdisciplinariedad y evaluación” ${ }^{212}$ fueron las premisas fundamentales de este proceso, con el objeto de consolidar la comunidad académica no solo en torno al conocimiento del saber disciplinar, sino también a la formación integral de la persona en la sociedad.

La investigación en el contexto de la proyección social también se fortaleció con la creación de la Unidad, con el reconocimiento y estímulos a la labor investigativa, con la vinculación de docentes de tiempo completo y con la consolidación de los diferentes centros de investigación en las sedes, seccionales y vUAD. Esto llevó a un fortalecimiento de los posgrados, en especial de las maestrías, como lugares propios de la investigación. Pero, sin duda, se destaca el establecimiento del modelo investigativo en la Universidad a partir de los siguientes aspectos: la cultura de la investigación, el sistema organizacional y el proyecto investigativo PROIN, con ocho líneas de investigación y sus respectivos programas. Se favoreció la creación de semilleros para acercar a docentes con estudiantes en busca de la excelencia académica, el desarrollo social, el progreso científico de la comunidad tomasina y la participación activa en redes de investigación como RedCOLSI.

En cuanto al sistema de información institucional se logró reestructurar el área administrativa y hacer más eficientes sus procesos, dentro de las exigencias modernas para la gestión. Abarcó tres subsistemas: el académico (SAC), el administrativo y financiero (SAF) y el universitario de gestión (sug). Destacamos el

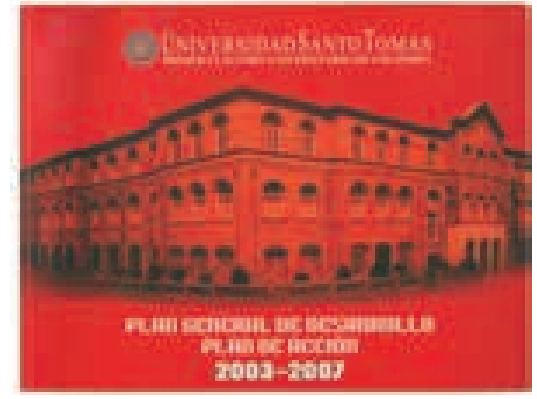

Las rectorías de las sedes y seccionales empezaron, a finales de los 9o, a construir planes de desarrollo como derrotero de su administración

primero por su trascendental relación con los planes de estudio y asignaturas. "El proyecto SAC se inició en 2002, como una herramienta de mayor capacidad, más ágil y moderna que el existente Sisacad. Por ser flexible, permite administrar los procesos académicos, integrándolos para que interactúen con los sitemas de información institucional" ${ }^{213}$.

El sAC centralizó los datos de docentes, estudiantes, asignaturas y notas para agilizar la atención y tomar mejores decisiones administrativas y académicas. Esto llevó a la adquisición de equipos de cómputo, y ampliar y mejorar internet, así como iniciar la cultura del uso del correo institucional.

Para finalizar, también es importante destacar la implementación del sistema de la calidad a través de la unidad creada. Bogotá inició con la capacitación a todo su personal en la norma IsO 9000:2000, que complenta los procesos de autoevaluación y mejoramiento ${ }^{214}$. Se creó una especialización en este campo para docentes de la USTA con la participación de dieciséis de ellos. La consecuencia fue mejorar el ambiente institucional, que unido a las actividades para el bienestar integral que lideran recursos humanos, bienestar universitario, servicios generales, entre otros, benefició los indicadores de salud ocupacional, creó espacios de descanso, dotó el gimnasio, señalizó las áreas, asignó sillas ergonómicas, identificó los riesgos, mejoró los servicios médicos, cafeterías, entre otros. 


\section{6}

Madurez institucional 1995-2018

\section{FRAY JOSÉ ANTONIO BALAGUERA CEPEDA, O.P., RECTOR GENERAL 2003-2OII}

En junio de 2003 el Consejo de Fundadores eligió a fray José Antonio Balaguera Cepeda, O.P., como rector general para el periodo 2003-2007. Al terminar su cuatrienio, fray José Antonio Balaguera fue confirmado en el cargo por cuatro años más para el periodo 2007-20II ${ }^{215}$.

Fray José Antonio nació el to de septiembre de 1948 en Belén, Boyacá. Ingresó a la Orden de Predicadores el r. ${ }^{\circ}$ de febrero de 1967 , hizo profesión simple en febrero de 1968 y profesión solemne en 1971. En el Convento de Santo Domingo de Bogotá estudió Filosofía y Teología y se ordenó sacerdote en diciembre de 1972 . Es licenciado en Educación, Filosofía y Letras y especialista en Gerencia de Instituciones de Educación Superior por la Universidad Santo Tomás y doctor en Ciencias Sociales por la Pontificia Universidad Santo Tomás de Roma.

Fray José Antonio Balaguera se ha desempeñado como vicerrector del Colegio Lacordaire de Cali en 19741975, vicerrector del Colegio Santo Tomás de Bogotá, rector del Colegio Jordán de Sajonia de Bogotá en 1979-1982 y catedrático en las facultades de Psicología y Derecho de la usTa Bogotá entre 1982-1984. Entre 1983 y 1987 fue rector del Colegio Santo Tomás en Bogotá. Durante los primeros años de la década de 1990, fray José Antonio Balaguera fue vicerrector académico y administrativo de la Seccional Bucaramanga y entre I994 y 1995 rector de la misma Seccional. Más tarde, en 1996, se convirtió en el primer decano de la división de los programas presenciales y a distancia de la USTA Tunja. Entre sus publicaciones se destaca El tema de la cultura en la doctrina social del posconcilio, publicado en 1990 en Roma por la Editorial Lebrit ${ }^{216}$.

El Plan General de Desarrollo y el Plan de Acción 2003-2007 de fray Balaguera fue construido teniendo en cuenta como marco de referencia los documentos institucionales de fines de la década de 1990 (PEI, Plan Prospectivo), así como el Plan General de Desarrollo 2000-2003 con su respectivo Plan de Acción. Proseguir con el reordenamiento organizacional que se venía dando desde mediados de la década anterior fue la prioridad de este nuevo Plan, más tarde complementado por los planes de acción de las distintas seccionales y de la VUAD ${ }^{217}$.

El Plan 2003-2007 significó, por tanto, la continuidad del proceso de ajuste de la Universidad a los

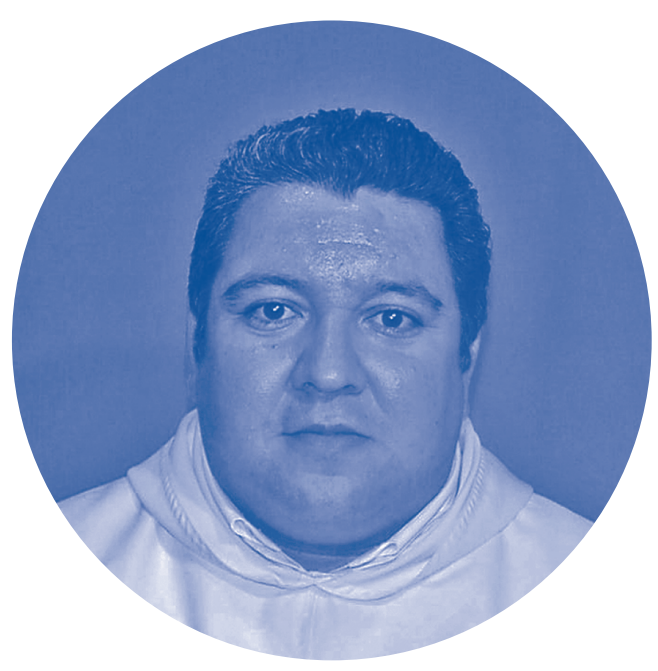

Fray José Gabriel Mesa Angulo, O. P., prior

provincial durante el periodo 2002-2006

retos del siglo XXI en términos de reestructuración y revisión de la gestión académica y administrativa para adaptar los procesos a las "nuevas exigencias de eficiencia, efectividad y agilidad procedimental" ${ }^{218}$. En este orden de ideas, la gestión del nuevo rector se definió como orientada por principios de formación sustantiva, equidad, pertinencia, comunidad, calidad, interdisciplinariedad, flexibilidad, compromiso, dimensionamiento y evaluación, cooperación internacional, administración y financiamiento.

Fundamentalmente, el Plan se proponía consolidar vínculos con el medio externo, continuar el fortalecimiento académico, revisar, contextualizar y actualizar los programas, promover y desarrollar la investigación y ampliar la participación en el orden regional a través de los Centros Regionales y la vuAd. En este marco general, había dos grandes estrategias: I) avance investigativo y científico y 2) mejoramiento de los procesos administrativos.

Estas dos estrategias se desarrollaron mediante siete programas concretos que cubrieron toda la vida académica de la Universidad. Ellos fueron: I) Desarrollo científico y académico, 2) Acreditación y registro; 


\section{7}

Madurez institucional 1995-20I8

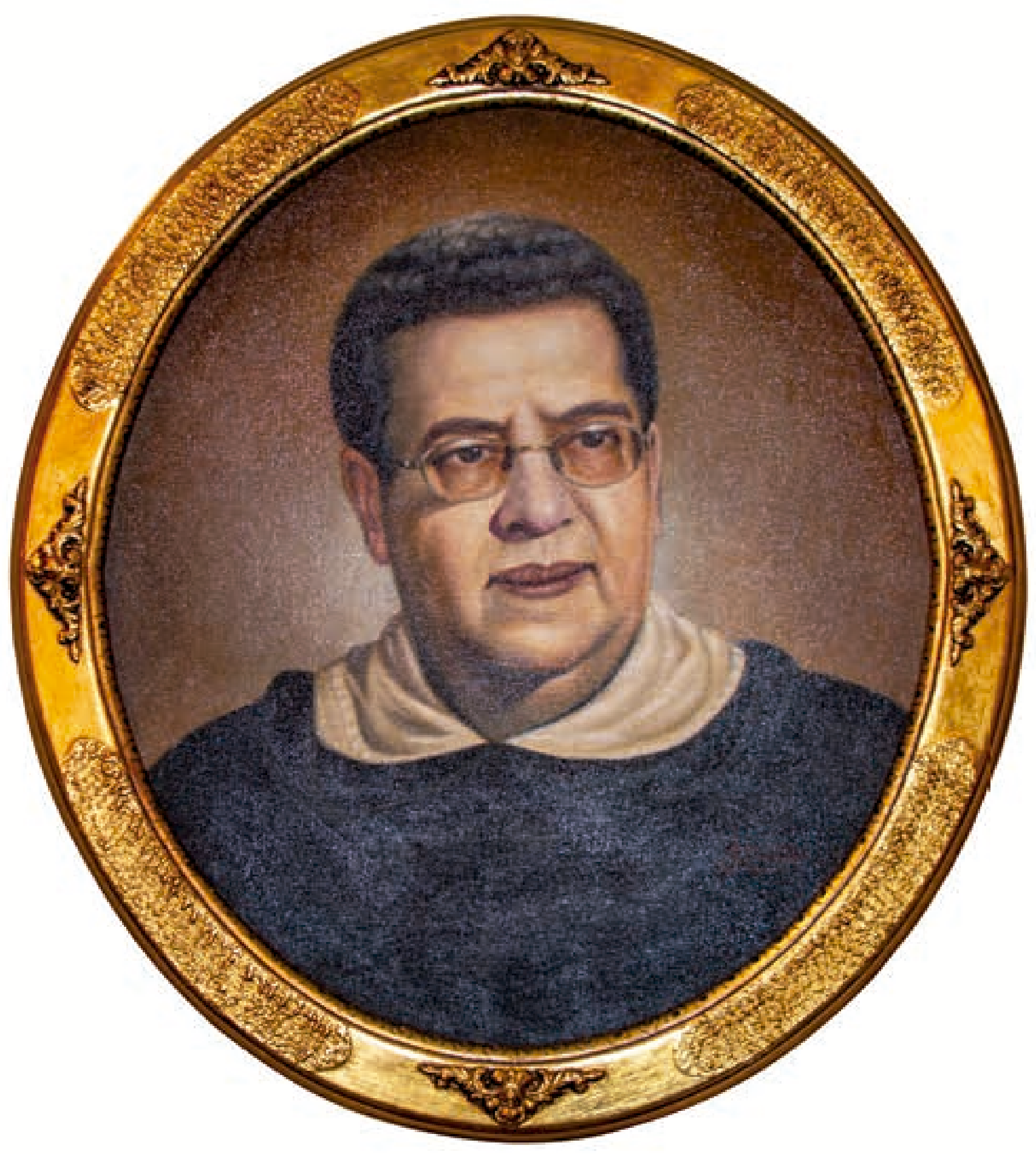

Fray José Antonio Balaguera Cepeda,

O. P., rector general 2003-20II 
La Orden de

Predicadores vio

la oportunidad

de construir un

nuevo edificio en

la Sede Norte de

Bogotá, atendiendo

al crecimiento

estudiantil
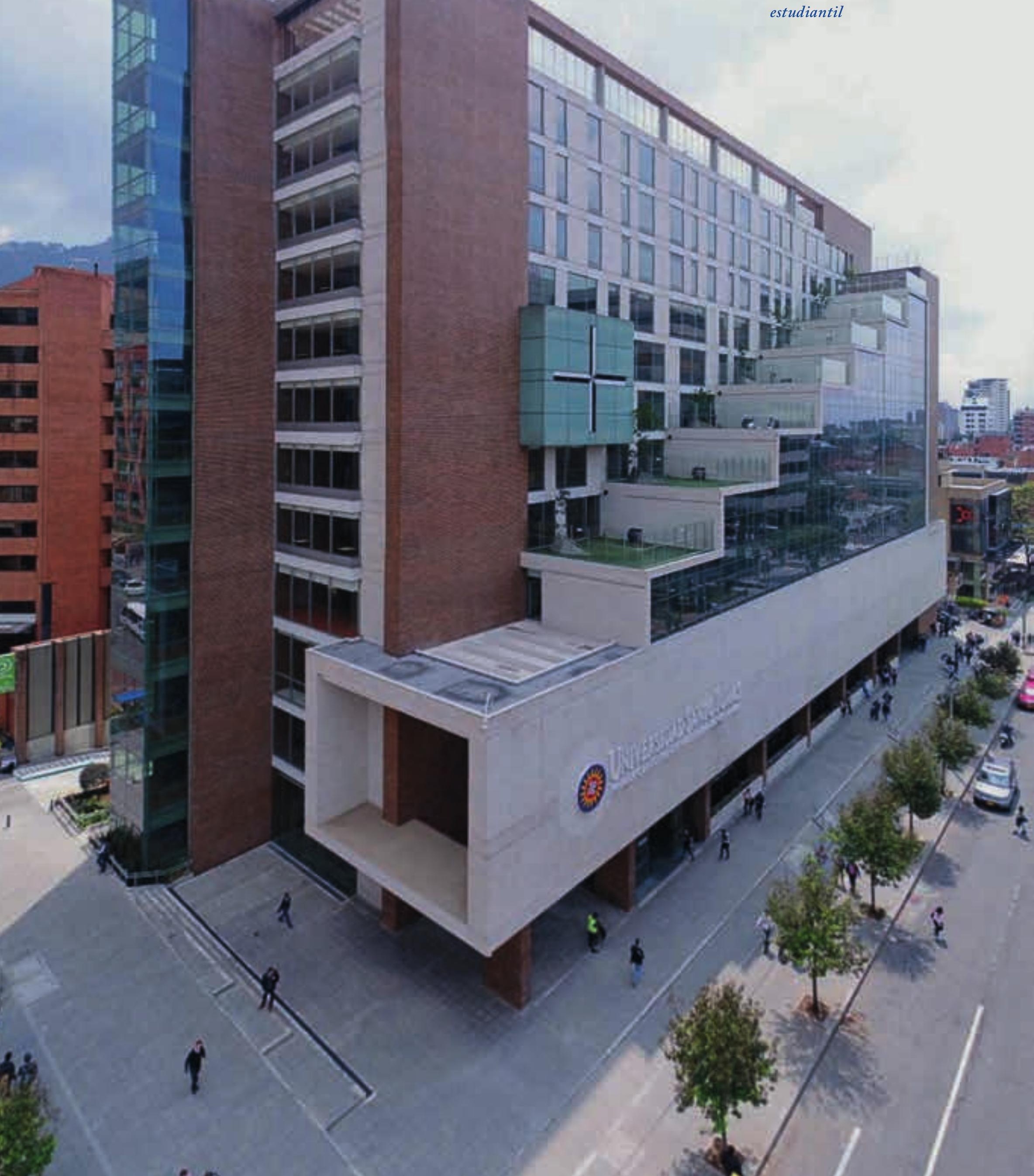


\section{9}

Madurez institucional 1995-2018

3) Desarrollo humano integral, 4) Proyección social e interacción con el medio externo, 5) Mejoramiento de la infraestructura tecnológica para la información y la comunicación, 6) Mejoramiento del sistema administrativo y 7) Ampliación, mejoramiento y adecuación de la planta física ${ }^{219}$.

Para el avance en el campo investigativo y científico se propusieron una serie de acciones como actualización y flexibilización curricular a partir de la Ley 30 de 1992 y los decretos 808 de 2002 y 2566 de 2003 , evaluación de la pertinencia de programas con menor demanda, creación de programas académicos "distintos a los tradicionales para responder a los retos de la educación superior mundial con una oferta académica diversificada ${ }^{220}$, fortalecimiento de las maestrías, innovación pedagógica y curricular, apoyo a la proyección social en términos de prácticas, pasantías, consultorios, laboratorios, convenios, etc., fortalecimiento de Bienestar Universitario, del área de Humanidades y de la Pastoral, ampliación del portafolio académico, continuación de la autoevaluación y la autorregulación de los programas, consolidación de la cultura de autoevaluación y de los estándares de calidad, mayor articulación de sedes, seccionales y programas en el proceso de acreditación institucional, aplicación de una política institucional de mercadeo, aumento de la presencia institucional a través de redes de educación, intercambios, programas de cooperación interinstitucional e integración en redes de posgrado e investigación.

Con respecto al desarrollo académico, llevó a cabo una política de estímulo para el perfeccionamiento docente, consciente de su trascendental papel en el quehacer universitario, a través del documento "Políticas y procesos de selección, aceptación y seguimiento docente para realizar estudios de maestrías y doctorados". No solo la USTA aumentó sus docentes con títulos de posgrado, sino también favoreció la realización de cursos intersemestrales sobre temas de currículo, evaluación y didáctica, entre otros, para mejorar la formación pedagógica general de estos.

Otro aspecto que se vió favorecido fue la continuación de la virtualización de los procesos de enseñanza-aprendizaje con la incorporación de nuevas tecnologías, el uso de herramientas virtuales de información y comunicación, la implementación de aulas virtuales, el montaje e implementación de los sistemas para la administración del aprendizaje en línea y el diseño gráfico de los objetos de aprendizaje para uso óptimo de las aulas virtuales ${ }^{221}$.
En cuanto al mejoramiento de los procesos administrativos se propuso continuidad en el equipamiento tecnológico, sistematización generalizada, integración de los procesos académicos y administrativos, ampliación de redes de información y comunicación, promoción de pedagogías informáticas, agilización de procesos operativos de presupuesto, contabilidad, etc., búsqueda de nuevas fuentes de financiación, promoción del uso racional de los recursos, aplicación de políticas de reordenamiento jurídico institucional, mejoramiento de edificios e infraestructura deportiva, adquisición de nuevos inmuebles en la manzana entre las carreras séptima y novena y calles $5 \mathrm{I}$ y 52, culminación del campus de San Alberto Magno y mejoramiento de instalaciones en varios centros regionales, entre otros.

En cuanto a la expansión de la Universidad, el Consejo de Fundadores autorizó efectuar los estudios de factibilidad necesarios para determinar la conveniencia de crear las sedes en los Llanos Orientales y en el Eje Cafetero. Solo la primera tuvo éxito, lo que permitió la adquisición de terrenos en Villavicencio con los aportes del Fondo de Inversiones Institucionales -FIUSTA-, de las sedes, de las seccionales y de la VUAD. Al mismo tiempo que fue aprobado el diseño arquitectónico para la construcción de la Sede, el Ministerio de Educación Nacional autorizó la extensión de los programas de Derecho, Ingeniería Mecánica, Contaduría Pública, Administración de Empresas Agropecuarias y Comercio Exterior, para iniciar en el primer periodo académico del 2007.

Con la campaña publicitaria "Un nuevo sol alumbra nuestro Llano", la sede pronto obtuvo buenos frutos iniciando con 167 estudiantes en tres programas (Derecho, Comercio Exterior y Administración de Empresas Agropecuarias) ${ }^{222}$.

\section{Acreditación}

E1 rector estableció para este fin un proceso continuo de mejoramiento a través de la cultura de la autoevaluación y la autorregulación, con el fin de ofrecer en todo el territorio nacional programas con altos estándares de calidad, para responder a las directrices establecidas por el Ministerio de Educación y el Consejo Nacional de Acreditación (CNA). Entre el 2005 y el 2007 se fueron obteniendo los registros calificados de varios de los programas, así como la acreditación de alta calidad en otros. Bogotá recibió el registro de ocho pregrados y cinco de posgrado, y de cinco pregrados con acreditación; Bucaramanga, el 
registro de 5 programas de pregrado y tres de postgrado; y la acreditación de siete pregrados; en Tunja, recibieron el registro ocho pregrados y cuatro posgrados; en Medellín, fueron cuatro los pregrados que recibieron el registro calificado; en Villavicencio, cinco recibieron el registro en pregrado y un posgrado; y en la VUAD lo recibieron dieciocho programas entre las dos facultades existentes y siete de posgrado ${ }^{223}$.

Con estos resultados, se conformó el Comité Institucional de Acreditación ${ }^{224}$, para solicitar la Acreditación Institucional ante los organismos correspondientes del Estado, continuar con los procesos de autoevaluación y autorregulación, y presentar la documentación exigida para las condiciones iniciales ante el CNA.

\section{Formación integral}

Uno de los puntos del Plan de Desarrollo del rector, lo enfocó en la promoción de tres aspectos: pastoral, humanidades y bienestar universitario.

En pastoral, para continuar con el crecimiento cristiano de la comunidad universitaria, fortaleció espacios para la oración, realizó convivencias, misiones, campamentos, encuentros espirituales, encuentros de jóvenes, consejería espiritual, cursos de formación humana y cristiana y creó el Plan Padrinos para abuelos y niños; así mismo, fortaleció el Movimiento Juvenil Dominicano con el fin de obtener nuevas vocaciones para la Provincia.

En humanidades, para favorecer la formación integral de los estudiantes, se establecieron seis cátedras obligatorias para todos los programas académicos: Filosofía Institucional, Antropología, Cultura Teológica, Epistemología, Filosofía Política y Ética; a las que se sumaron las de idiomas y la cátedra de Cultura Física. Mientras que el componente flexible lo integraron tres cátedras institucionales opcionales, como lo contemplaba el PEI. A este plan curricular se sumaron las conferencias, salidas pedagógicas, cine foros, entre otros, para reflexionar sobre las condiciones sociales externas y su lectura desde el humanismo cristiano tomista. Igualmente, se realizaron talleres de ética en convenio con la ONG Transparencia por Colombia, tanto para estudiantes como para docentes.

En cuanto a bienestar universitario, la gestión del rector estuvo encaminada a mejorar el servicio médico, realizar jornadas de prevención contra las drogas alucinógenas, el consumo de alcohol, el tabaquismo y el autocuidado; prácticas de exámenes de salud ocupacional; talleres de primeros auxilios y de orientación psicológica. Así mismo, impulsó la creación de grupos estudiantiles de música, artes plásticas y de equipos en diferentes deportes que dieron como resultado tres medallas de oro en el Torneo Suramericano Universitario en Brasil, en 2006, y cuatro de oro, una de plata y dos marcas nacionales en los Juegos Nacionales de 2005 en atletismo.

\section{PEI 2004}

Desde el año 2003, por cuenta de la evolución del sistema de educación superior y en atención a lineamientos sugeridos por el CNA en cuanto a: I) naturaleza y misión de la Universidad, 2) sujeto colectivo responsable y 3)

\section{En el 2012, por primera vez en la historia de la Universidad, se llevó adelante un proceso de autoevaluación} de manera coordinada entre sus diferentes sedes $y$ seccionales. 


\section{I I}

Madurez institucional 1995-2018

gestión, la Universidad dio inicio a la renovación de su Proyecto Educativo Institucional. El nuevo PEI, que fue presentado a la comunidad en agosto del 2004, mantuvo inalterada gran parte de su estructura. Buena parte de las modificaciones introducidas estaban en el orden de la redacción y la organización temática; además se hicieron ampliaciones relacionadas con el currículo, la pertinencia de los programas y el sistema de créditos, y se cuidó de mantener la organicidad con el Estatuto Orgánico del $2002^{225}$. Según este PEI,

La misión de la Universidad Santo Tomás, inspirada en el pensamiento humanista cristiano de Santo
Tomás de Aquino, consiste en promover la formación integral de las personas, en el campo de la educación superior, mediante acciones y procesos de enseñanza-aprendizaje, investigación y proyección social, para que respondan de manera ética, creativa y crítica a las exigencias de la vida humana y estén en condiciones de aportar soluciones a la problemática y necesidades de la sociedad y del país ${ }^{226}$.

Esta misión se desarrolla más adelante como una "misión universitaria integral” con facultades de "autonomía y competencia legales" para desempeñar un "cometido" particular que es el de la educación superior. Este

La escultura en homenaje a fray Henri Didon, O. P., pionero de los Juegos Olimpicos, saluda a los visitantes del Campus San Alberto Magno

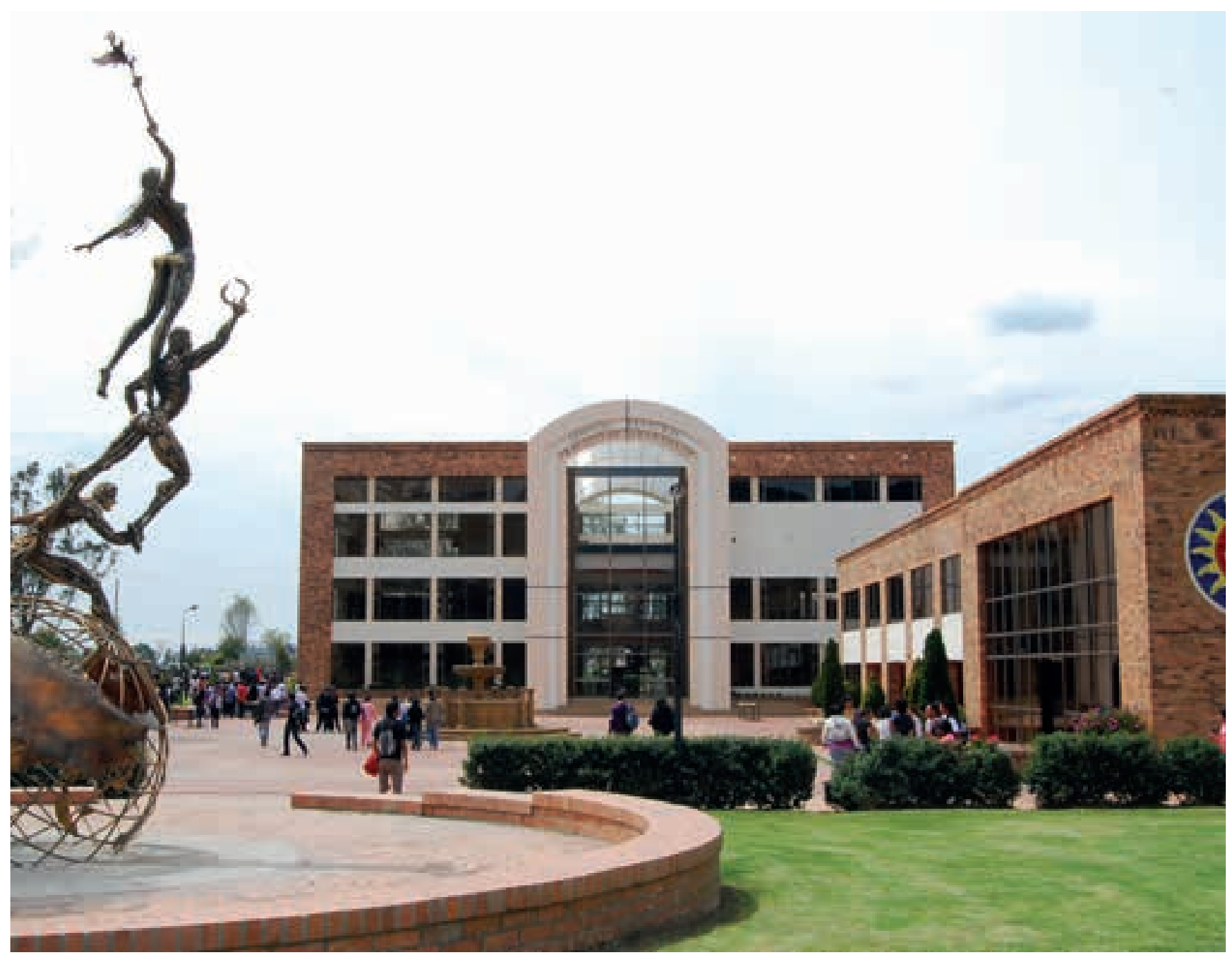




\section{I 2}

Madurez institucional $1995^{-2018}$

cometido se define además como parte de la "función evangelizadora" de la Orden de Predicadores. Por otro lado, las sedes se definen como "misiones locales" y la comunidad universitaria como "misión corporativa" con una "tarea" educativa como misión-función. Finalmente, se establecen una "misión teleológica" que es la formación integral y unas determinadas competencias para alcanzar la "misión-meta"227.

Por supuesto que el carácter de "Estudio General" de la UsTA, el humanismo, la integralidad en su accionar, la confianza en el progreso humano y la preeminencia del Doctor Angélico como la figura guía en el ejercicio académico permanecen como pilares fundamentales de la identidad de la Universidad. Al mismo tiempo, cobran protagonismo los valores que se habían estado estableciendo en los últimos años, como la pertinencia y la flexibilidad curricular, la acción en el medio externo y la concepción del quehacer académico como orientado a la solución de problemas ${ }^{228}$.

Por otro lado, el PEI 2004 institucionaliza más claramente las funciones sustantivas del plantel: docencia, investigación y proyección social. Quizá la mejor manera de graficar la centralidad de la pertinencia y la proyección social de la Universidad, tal como quedó establecido en el PEI 2004, es la metáfora que el documento recoge para indicar justamente aquello a lo que se aspira superar:

Tenía hambre, y ustedes formaron un comité para investigar mi hambre; no tenía hogar, e hicieron un informe sobre mi problema; estaba enfermo, y organizaron un seminario sobre la situación de los desprotegidos; investigaron todos los aspectos de mi condición, pero todavía tengo hambre, carezco de hogar y sigo enfermo ${ }^{229}$.

Este y otros elementos que en los años anteriores a 2004 habían surgido como centrales para la vida universitaria en los ámbitos de la organización administrativa, la presencia institucional en el medio externo, la gestión de los recursos y el bienestar universitario, entre otros, que hemos tenido oportunidad de observar, fueron institucionalizados en el PEI 2004. En cuanto a bienestar, vale la pena resaltar que sus programas quedaron organizados alrededor de las dimensiones espiritual-religiosa, psicoafectiva, cultural, física y recreativa de los miembros de la comunidad tomasina ${ }^{23}$.

\section{Investigación}

En el marco de un Proyecto Educativo Institucional actualizado en 2004, la Universidad consolidó entre los años 2004 y 2005 su política investigativa institucional. Los lineamientos generales de esta política; es decir, la estructura de líneas de investigación y el Proyecto Investigativo Institucional, se presentaron en el primer número de Hallazgos, revista del Centro de Investigaciones USTA, en abril de $2004^{231}$. Al año siguiente fue presentado oficialmente el nuevo Proyecto Investigativo Institucional (Proin) ${ }^{232}$ como una reelaboración del que había sido aprobado en el año 2000 y como una herramienta en constante transformación destinada a dar cumplimiento a los planes de desarrollo y a la proyección investigativa de la USTA:

\begin{abstract}
Sin pretender constituirse en un paradigma, el Modelo Investigativo Institucional de la Santo Tomás recoge las diversas experiencias que se gestaron históricamente a través de investigación profesoral, institucional, asistida, formativa y científica que derivaron en el Centro de Investigaciones y de diversas acepciones que dieron como fruto los intentos por fijar un modelo en 1983 , otros esfuerzos en 1985 con el Centro de Investigaciones del Centro de Enseñanza Desescolarizada - Ciced-, más tarde con el Centro Interdisciplinario de Investigaciones - CIDI- y el planteamiento de un Modelo Investigativo en 1995 que brindó algunos elementos de reflexión sobre el proceso investigativo ${ }^{233}$.
\end{abstract}

Las tareas primordiales del Proyecto son la revitalización de la estructura investigativa, la articulación de los esfuerzos, la identificación y consolidación de las líneas, la estandarización de procesos, la generación de una formación investigativa en pregrado y posgrado, el fomento de acuerdos y convenios, la integración de la USTA al Sistema Nacional de Ciencia y Tecnología de Colciencias, el apoyo financiero y de infraestructura, el establecimiento de un sistema de posgrados interrelacionado con la investigación y la apertura de espacios para la socialización de los resultados ${ }^{234}$.

Además, se establecen la política de calidad, los principios que rigen la práctica de la investigación tomasina (curiosidad, contradicción, comparación, causalidad, abstracción, deducción, ensoñación, diversidad, globalidad, complejidad, crítica, cooperación e intercambio, entre otros), sus criterios (calidad, 
universalidad, pertinencia, responsabilidad, eficiencia, entre otros), su misión, visión y objetivos.

Uno de sus más importantes avances con respecto al Proin de los años 2000-200I fue la caracterización específica de líneas medulares de investigación que constituye el elemento central que organiza la investigación tomasina. Sobre las "líneas institucionales de investigación” se venía debatiendo desde el Proin 2000 hasta que en septiembre del 2004 se definió institucionalmente el tema con unas "líneas medulares" y unas "líneas activas" de investigación:

Dentro del presente modelo, las líneas de investigación se conceptualizan como los principios básicos articulados alrededor de un eje temático precisado por la Institución o por una serie de elementos contextuales que responden a determinados problemas y apuntan o posibilitan la realización de proyectos investigativos $^{235}$.

Las líneas medulares son expresadas desde la filosofía institucional y su relación con las disciplinas del conocimiento que se manejan en los programas académicos y contienen su objeto de estudio y su núcleo problémico ${ }^{236}$. En el Proin 2005 las líneas medulares establecidas eran las siguientes:

- Tomás de Aquino (en torno al humanismo, la política y el derecho)

- Francisco de Vitoria (derechos humanos y relaciones internacionales)

- Alberto Magno (ciencia, tecnología y medio ambiente)

- Bartolomé de las Casas (identidades culturales y justicia social)

- Catalina de Siena (liderazgo femenino y problemática de género)

- Fray Angélico (en torno al arte y cátedra Fray Luis de Granada sobre literatura)

- Enrique Lacordaire (sobre las libertades y la educación)

- Louis Joseph Lebret (sobre economía y humanismo) ${ }^{237}$

Además de estas, se encontraban en desarrollo las líneas:

- Fray Luis de Granada (literatura y retórica)

- Giordano Bruno (visiones del universo)

- Tomás de Campanella (sociedad, política y utopía)

- Fray Cristóbal de Torres (prospectiva de la educación superior)

- Raimundo de Peñafort (legislación y racionalidad jurídica)

- Henri Didon (cultura física y desarrollo personal)
Para 20io la investigación tomasina se organizaba alrededor de quince líneas medulares ${ }^{23^{8}}$ y para su justificación los docentes del Departamento de Humanidades, Francisco Javier Yate Rodríguez y Ómar Asdrúbal León Carreño ${ }^{239}$, presentaron un documento donde soportaban epistemológicamente cada una de ellas y mostraban su relación con las cátedras opcionales del Departamento. Por otro lado, en el Proin 2005 ya aparecen consolidados los programas que para la consecución de los logros del proyecto habían sido propuestos en el $2000^{240}$, a los que se les suman el Programa de grupos de investigación y el Programa de convocatorias, ambos ausentes en el Proin $2000^{241}$.

Durante la rectoría de fray José Antonio Balaguera la estructura investigativa en la Sede Bogotá y la VUAD tuvo una ampliación importante. Entre el año 2005 y el 2008 los centros de investigación aumentaron de 9 a 13 y en el mismo periodo los grupos pasaron de 53 a 7I. De estos 7I, 3I estaban categorizados por Colciencias, así: i2 en Categoría A, I3 en categoría B y 6 en categoría C. Además, de los 14 semilleros con participación de 137 estudiantes en 2005 se aumentó a 66 semilleros con participación de 700 estudiantes en $2008^{242}$.

El Departamento de Humanidades y Formación Integral creó cuatro grupos de investigación que se registraron en Colciencias: los grupos Catalina de Siena, Investigación Social y Humanística y Docimófilos y la calificación, en categoría $A$, del grupo Ciencia y Espiritualidad.

Más adelante, en 2010, había I3 centros y 69 grupos de investigación en la Sede Principal mientras que la VUAD tenía 2 y 28 respectivamente. De la totalidad de estos 97 grupos registrados en Colciencias, 47 estaban categorizados mientras que los restantes 50 estaba aún en formación. Entre la Sede Principal y la VUAD contaban 59I investigadores y 74 semilleros con participación de 572 estudiantes ${ }^{243}$. Ese mismo año, se contaba en Bogotá con 6 revistas indexadas: Diversitas, CIFE, Hallazgos, Análisis, Iusta y Vía Inviniendi et Iudicandi ${ }^{244}$.

En los últimos años de la rectoría de fray Balaguera se ejecutaron políticas hacia la tecnificación de la administración investigativa. En ese marco se implementó la red de investigación institucional USTA Net, se diseñó el software para la gestión de la investigación (SIGI) y se implementó el Fondo de Investigación (Fodein); este último, en particular, constituyó un avance fundamental en la dirección de criterios institucionales de investigación, que hasta entonces se venían manejando desde las diferentes facultades ${ }^{245}$. 


\section{I 4}

Madurez institucional 1995-2018

\section{Proyección social e interacción con el medio externo}

La máxima realización en este campo lo constituyó el sistema de educación abierta y a distancia, a través del cual la USTA sigue haciendo presencia en los lugares más apartados de la geografía nacional con sus programas de tecnología, licenciaturas y profesiones, posicionándose no solo como el primer claustro en ofrecer estos programas bajo la metodología a distancia, sino como la institución más sólida en este ámbito, capaz de ofrecer su formación en todo el país.

La proyección social durante esta rectoría se ejecutó a través de cuatro proyectos: I) Promoción de la Proyección Social y de la Extensión, 2) Promoción de los Egresados, 3) Imagen y Posicionamiento Institucional, y 4) Proyección Internacional e Interinstitucional.

Con respecto al primer punto, este se desarrolló a través de dos aspectos: prácticas sociales y actividades con la comunidad, y establecimiento de convenios. Entre lo realizado se destacaron los consultorios de psicología, derecho, odontología, optometría, comercio exterior y contaduría pública; igualmente, bridagas de salud en asocio a las Entidades Prestadoras de Salud en varias de las regiones en donde la universidad a distancia hace presencia. En el segundo aspecto, se realizaron los convenios con la Federación Internacional de Universidades Católicas (FIUC) para realizar investigaciones sobre el desplazamiento de grupos humanos al interior del país, con la Agencia para el Desarrollo Internacional de los Estados Unidos (USAID) para la creación del Centro de Documentación de Medios Alternativos de Solución de Conflictos; con la ONG Cooperative Housing Foundation (CHF) para el diseño, asesoría y supervisión técnica de la construcción de tramos de alcantarillado de nueve barrios en Altos de Cazucá y con la Corporación Autónoma de Boyacá (Corpoboyacá) para formular el Plan de Manejo y Protección del acuífero de Tunja.

En promoción a egresados, se dotó a Prousta de su sede, de la planta administrativa, de su página web y la disponibilidad financiera para realizar sus congresos, ferias y encuentros. E1 Consejo Superior creó la condecoración Cuarto Centenario, Categoría Oro para distinguir a Egresados Ilustres en los campos social, cultural, económico y político del país. Además se realizaron convenios con el portal elempleo.com, el SENA para oferta de empleos y se les otorgaron beneficios institucionales como carné de egresado, uso de la biblioteca, servicios de salud y acceso a los gimnasios, asesorías jurídicas y psicológicas cuando lo requirieran, entre otras.
Vista aérea del Campus

Bucaramanga de la USTA

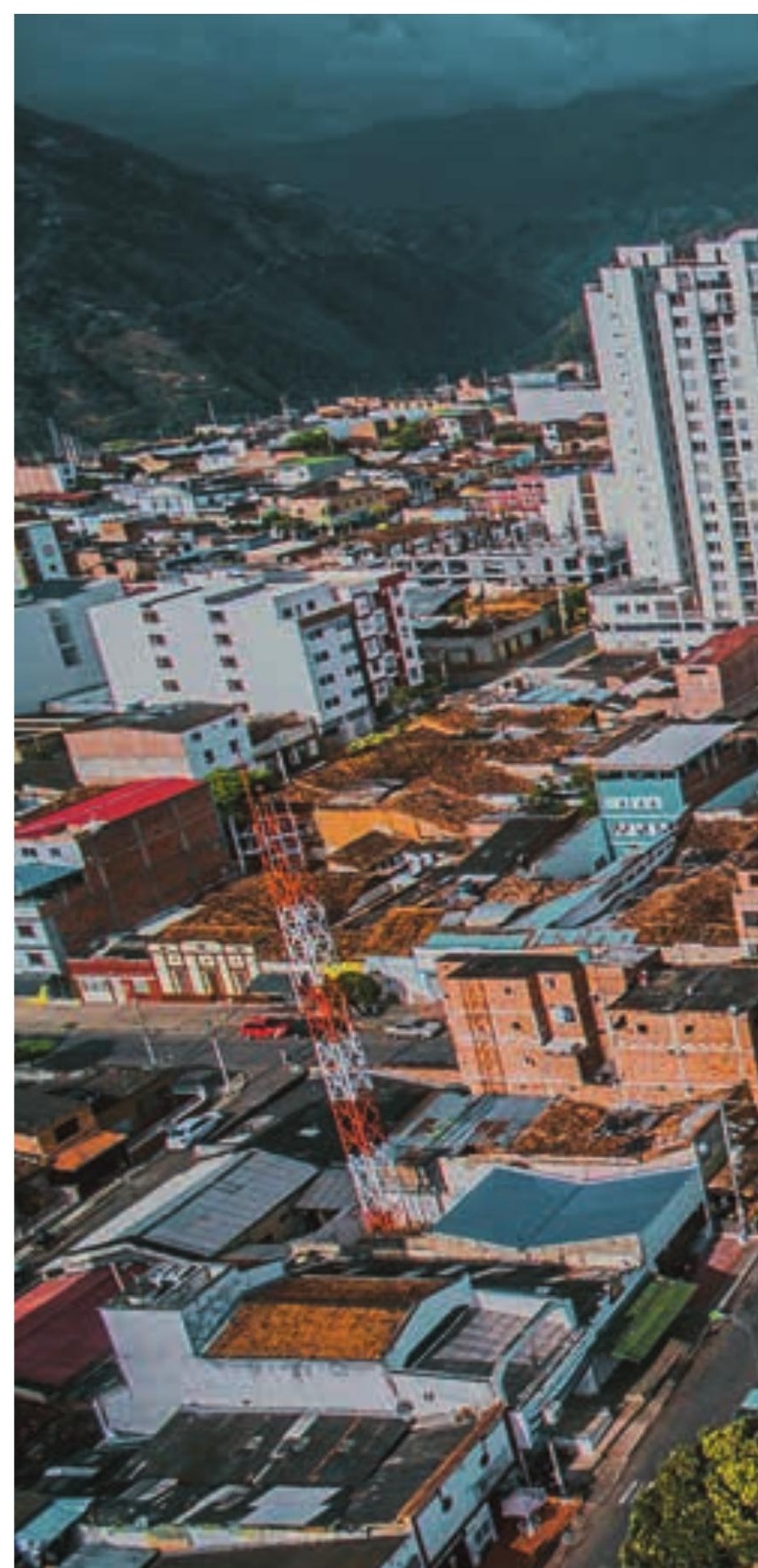




\section{I 5}

Madurez institucional 1995-2018

En cuanto al proyecto de imagen y posicionamiento de la USTA, el rector, entre las varias condecoraciones que recibió, se destacan: la Orden a la Educación Superior y a la Fe Pública Luis López de Mesa, mediante Decreto 4I34 de 2005, como exaltación y reconocimiento de la Presidencia de la República al interés de la Universidad por ofrecer programas de alta calidad; la Orden Civil al mérito José Acevedo y Gómez en el grado de Cruz de Oro, mediante Resolución n. 488 del 2 de junio de 2004, por ser el Primer Claustro
Universitario fundado en Colombia y por promover la formación integral de las personas en el campo de la educación superior; la Medalla al Mérito Francisco de Paula Santander, por Decreto I7o del 2 de agosto de 2006, a la Facultad de Tecnología en Laboratorio Dental, conferida por la Gobernación de Santander. Entre los premios y menciones, se destacan: Premio Cátedra Unesco de Salud Visual y Desarrollo, en octubre de 2006; Premio al Mejor Documental en Defensa de los Derechos Humanos, otorgado el r6 de

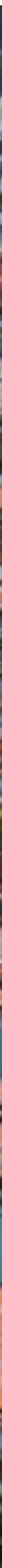




\section{6}

\section{Madurez institucional 1995-20I8}

septiembre de 2004 por la Asociación Pro Derechos Humanos de Andalucía - Cádiz (España), al trabajo Utopias visuales; primer puesto en el Cuarto Concurso Latinoamericano de Robótica, realizado en el 2005 en Sao Luis (Brasil), con el robot Luke IV.

En la proyección internacional, la USTA pasó a ser miembro, entre otras, de la Federación Internacional de Universidades Católicas (FIUC), la Organización Universitaria Interamericana (OUI), la Confederación Mundial de Instituciones Universitarias Católicas de Filosofía (Comiucap), la Red de Facultades de Filosofía de Instituciones Universitarias Católicas - que asumieron el nombre de Instituciones Católicas Universitarias Santo Tomás (Icusta)-, la Asociación Iberoamericana de Educación Superior a Distancia (Aiesad) y la Organización de Universidades Católicas de América Latina (Oducal). Así mismo, favoreció la movilidad y participación docente y estudiantil en congresos académicos en Alemania, Chile, Argentina, Canadá, Costa Rica, Cuba, España, Francia, México y EE.uU.

\section{Otros logros}

Para finalizar con este periodo rectoral, además de la apertura de nuevos programas académicos - Ingeniería Ambiental y Negocios Internacionales, entre otros-, es importante destacar el mejoramiento continuo que tuvo la infraestructura tecnológica para la información y la comunicación. En la Sede Bogotá, se mejoró el Servicio Académico ( $\mathrm{AAC}$ ), se implementó el software para la evaluación docente por internet y la base de datos del Sistema Unicornio para la biblioteca. En la Seccional Bucaramanga, se mejoró el Sistema Académico de Información (Sisacac) y el sistema de información de las clínicas de Odontología y Optometría (Sipco y Sicop, respectivamente). En la Seccional Tunja y en las sedes Medellín y Villavicencio, se implementaron el sAc, el Sistema Unicornio y el Sistema de Información Administrativo-Financiero Informa. En la Universidad a Distancia, el código de barras en los recibos de pago de matrícula, las aulas virtuales y el Sistema Académico, Administrativo y Financiero (Safead). A esto se suma el rediseño de la página web, el aumento del ancho de banda, el servicio de red inalámbrica y el uso de SKYPE para los centros regionales. Con esto se daba un paso más en la unificación de una sola Universidad.

De la misma manera, para mejorar los procesos administrativos y académicos, se creó la Unidad de Gestión de la Calidad Universitaria como eje central para implementar el sistema de la calidad en la USTA.
Su resultado inmediato fue la obtención del certificado NTC ISO 900r:2000 que posicionó a la Universidad en el contexto de la educación superior y que en la actualidad sigue obteniéndolo por su transparencia en los procesos administrativos y académicos. De igual forma, se creó la Oficina de Archivo General en Bogotá según lo había establecido la Ley 594 de 2000 (Ley General de Archivos) para la organización de los archivos de la Universidad, su manejo, consulta y preservación del patrimonio cultural.

En cuanto a las obras de infraestructura física realizadas, se destacan: modernización tecnológica del Aula Central que pasó a llamarse Aula de Fundadores, se remodeló el edificio de laboratorios Ángel Calatayud, se adquirió y remodeló la casa para la Escuela de Bellas Artes Fra Angélico, se adecuaron los espacios en el edificio Santo Domingo de Guzmán y en las casas del Consultorio Jurídico en la zona de Chapinero, se contruyeron en el Campus San Alberto Magno los edificios Fray Luis de Granada, Central, Coliseo Sol de Aquino, áreas administrativas, la capilla, campos deportivos y zonas comunales.

En Medellín se construyeron dos pisos en el ala norte del edificio San Alberto Magno y se adecuó la sede social y deportiva (antiguo club de Telecom). En Villavicencio se adquirieron lotes en Loma Linda y se planeó una construcción moderna para la Sede. En Tunja se adecuaron la cafetería, salones y oficinas. En Bucaramanga se construyó la capilla, se arreglaron la cafetería, las zonas deportivas, las oficinas administrativas, las aulas de clase y se realizó el puente que comunica los edificios Santander con las clínicas odontológicas, en Floridablanca. Para el Centro Regional de Cúcuta de la VUAD se compró la casa en el barrio Blanco donde actualmente funciona y en Quibdó, el lote en la vía Yuto km 3.5, para su futuro desarrollo; se intervinieron varios Centros Regionales como Yopal, Ibagué, Pasto y Villavicencio.

\section{Segundo periodo rectoral}

Para el cuatrienio 2007-20II, el Consejo de Fundadores decidió reelegir a fray José Antonio Balaguera, O.P. Esta nueva administración la estructuró desde su Plan de Desarrollo, que dividió en seis ejes temáticos que articulaban objetivos y acciones estratégicas: I) académico, 2) de bienestar universitario e interacción con el medio, 3) de internacionalización e interinstitucionalización, 4) de aseguramiento de la calidad, 5) administrativo y 6) de infraestructura física y desarrollo tecnológico. 


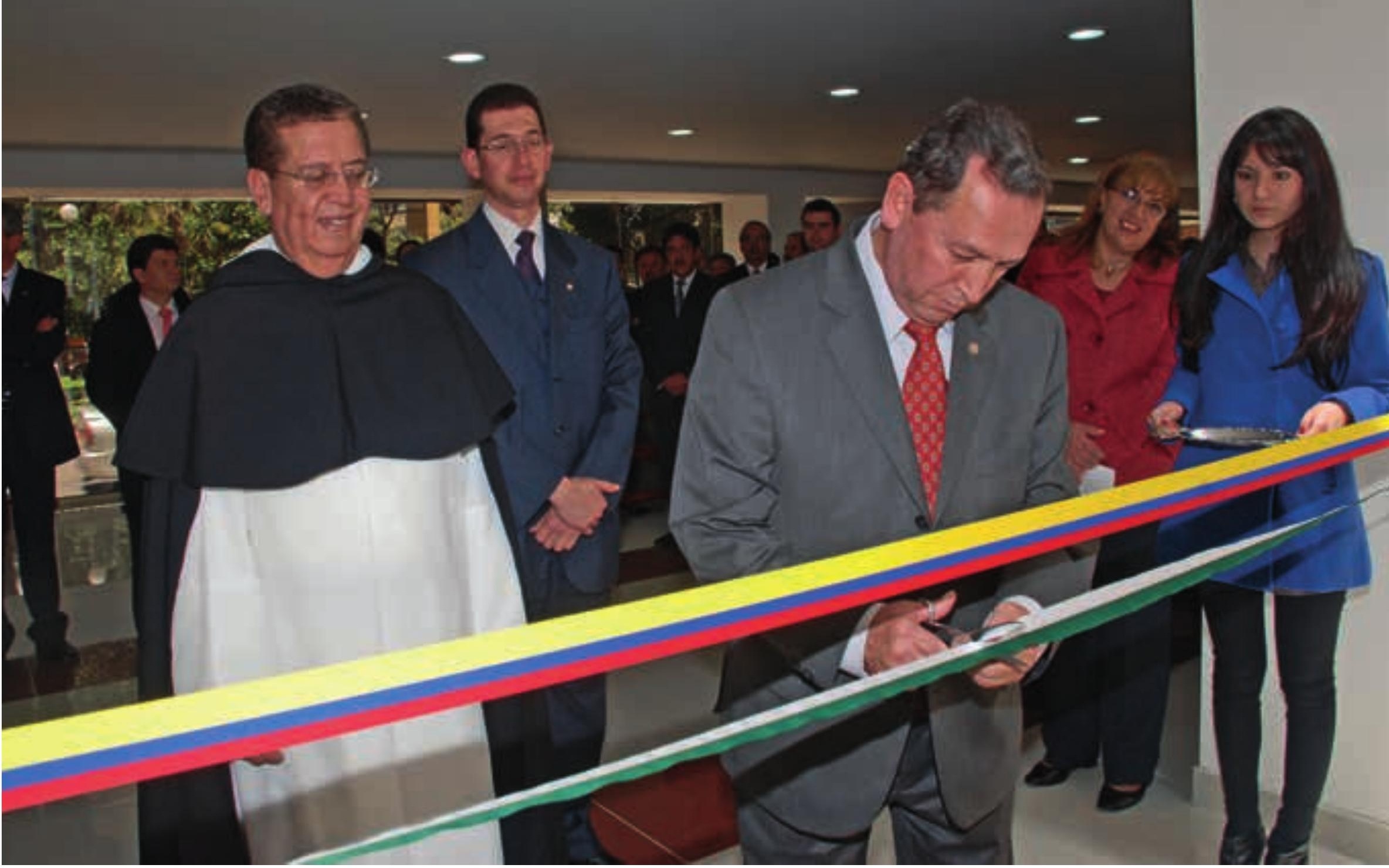

Inauguración del edificio Aquinate, el

7 de octubre de 2ого. Corta la cinta fray

Luis Francisco Sastoque Poveda, O. P., en

compañía del rector y vicerrector académico

En el eje académico, con el objetivo de mejorar la competitividad de los programas, consolidar el perfeccionamiento docente $\mathrm{y}$ fortalecer los procesos investigativos, su divulgación y socialización, se propuso continuar la renovación y adaptación de currículos, dar a conocer y desarrollar el modelo pedagógico institucional, propiciar la vinculación de docentes a redes y comunidades, implementar el plan de perfeccionamiento docente, incrementar la oferta académica en maestrías, doctorados, educación continuada o permanente y generar y difundir conocimiento de primer nivel.

En el eje de bienestar universitario e interacción con el medio, con el objetivo de generar condiciones para el desarrollo de los proyectos personales y colectivos de la comunidad, fortalecer la capacidad de respuesta hacia el medio externo, fomentar el desarrollo del medio social y los vínculos entre la Universidad y sus egresados, el Plan 2008-20Ir contempló una mayor vinculación de pastoral y bienestar universitario al modelo de formación integral, un fortalecimiento de las relaciones con los egresados y el sector productivo, una mayor efectividad de las prácticas profesionales, una dinamización de procesos de investigación, asesoría y consultoría y un mayor acceso de la comunidad a la educación continuada.

En el eje de la internacionalización e interinstitucionalización, cuyos objetivos eran lograr mayor reconocimiento internacional y fortalecer procesos de intercambio, se propuso continuar la adecuación de los currículos a las tendencias internacionales, promover mayor movilidad de los miembros de la comunidad tomasina con centros nacionales e internacionales de excelencia y fortalecer el dominio de la segunda lengua.

En el eje de aseguramiento de la calidad, para mantener la excelencia académica y desarrollar cultura de calidad en los procesos, servicios y desempeño institucional, la administración del rector Balaguera propuso cualificar la acción pedagógica y didáctica con miras a la realización del modelo formativo institucional, generar procesos de apoyo a la actividad académica y al perfeccionamiento del talento humano, fortalecer la autoevaluación y promover la formación docente doctoral. 


\section{I 8}

Madurez institucional $1995^{-20 I 8}$

Fachada del edificio Aquinate, en el sector de Lourdes, en Bogotá, donde funciona la División de Filosofía y Teología

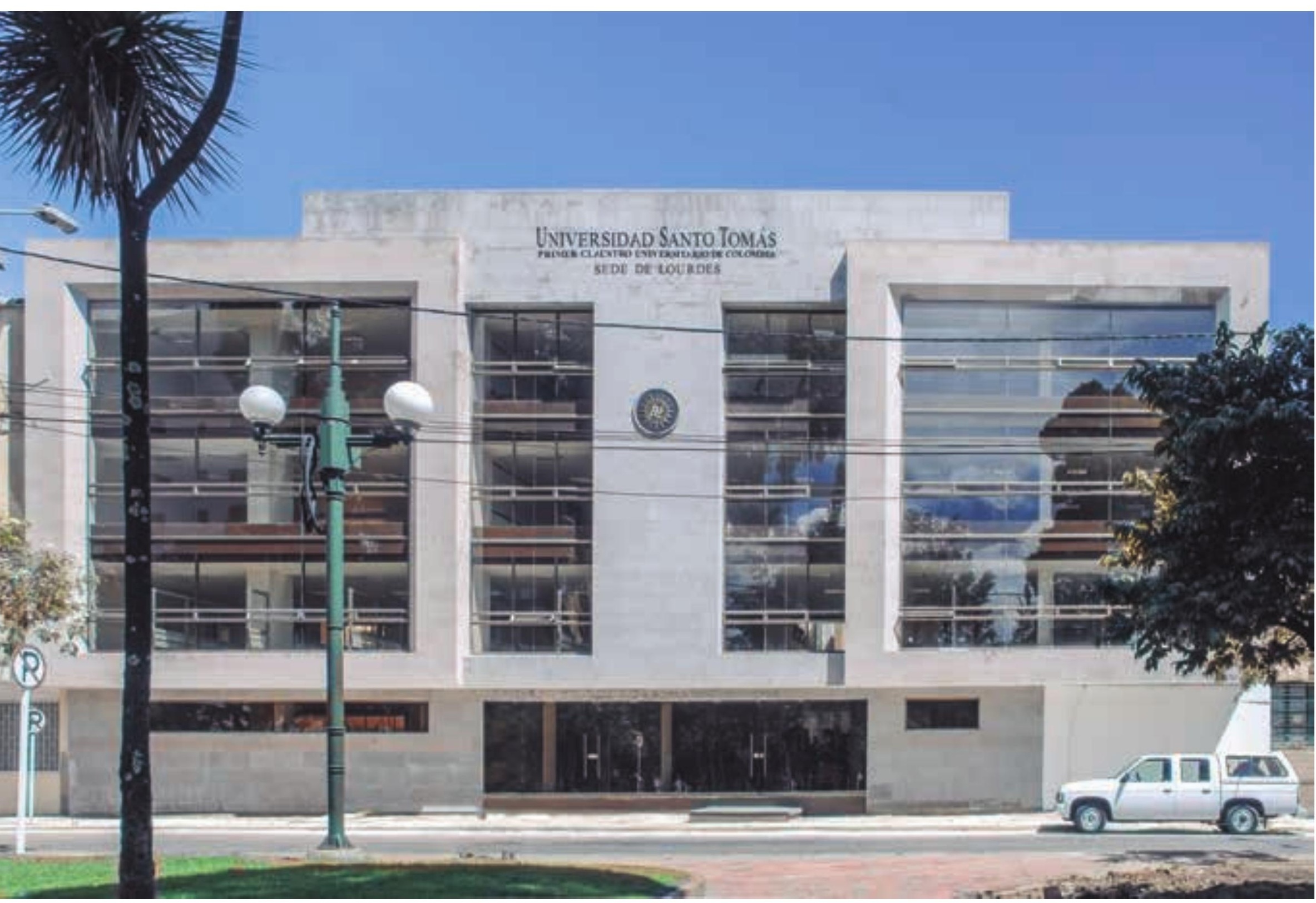




\section{I 9}

Madurez institucional 1995-2018

Por otro lado, adecuar el modelo de gestión administrativa a las funciones misionales y mejorar los procesos de gestión y desempeño eran los objetivos estratégicos del eje administrativo. Para lograrlo se propuso promover la cultura organizacional, modernizar y flexibilizar la estructura administrativo-financiera, fortalecer y generar convenios y alianzas para el desarrollo científico y la proyección social, mejorar el sistema de comunicación, generar estrategias efectivas de mercadeo de los servicios educativos, desarrollar el talento humano y diversificar las fuentes de financiación.

Finalmente, con el fin de consolidar la estructura tecnológica y comunicacional, así como ampliar, mejorar y readecuar los espacios físicos existentes y la construcción de otros nuevos, en el eje de infraestructura física y desarrollo tecnológico se propusieron acciones estratégicas como modernización tecnológica para el mejoramiento de los servicios al estudiantado, aprobación del plan de regularización y manejo de inmuebles, adecuación y construcción de planta física, adquisición de inmuebles y readecuación y mantenimiento de los espacios físicos y de los recursos tecnológicos.

Vale la pena observar que los planes de desarrollo fueron pensados fundamentalmente para la Sede Bogotá, dejando amplio margen a las sedes y seccionales para la planeación de sus propias rutas. Esto contrasta con las rectorías de los frailes Eduardo González Gil (I9992003) y Carlos Mario Alzate Montes (2011-2015), cuyos planes de desarrollo se caracterizaron por un enfoque nacional en que el Plan General de Desarrollo sirvió de referente para la construcción de los planes locales en las sedes, seccionales y VUAD ${ }^{246}$.

La rectoría de fray José Antonio Balaguera se caracterizó por la fuerte inversión en la construcción de edificios y ampliación en infraestructura. Se llevaron a cabo varias reformas, construcciones y ampliaciones en el Campus San Alberto Magno, se adquirieron terrenos y se inició la construcción del edificio El Aquinate en el sector de Lourdes, que fue inaugurado el 7 de octubre de $20{ }^{247}$. Por esta época también se inició la construcción del edificio Doctor Angélico en la carrera novena con calle 73 , que finalmente fue inaugurado el 8 de agosto de 2013 .

Aunque la gestión de fray José Antonio Balaguera constituyó una continuación de las reformas de las administraciones anteriores en términos de adecuación de la Universidad al cambiante sistema de educación superior colombiano (ajuste al sistema de créditos, flexibilización curricular, obtención de registro calificado para los programas académicos, etc. $)^{248}$, frente al espíritu de consolidación que caracterizó la rectoría de fray Eduardo González Gil, durante la administración Balaguera se aprecia un mayor esfuerzo hacia el crecimiento y la expansión. Expresión de esto fue la creación de programas académicos tanto de pregrado como de posgrado en las diferentes sedes, seccionales y en la modalidad a distancia ${ }^{249}$.

Entre las unidades académicas surgidas durante la época de fray José Antonio Balaguera, vale la pena señalar la Escuela de Bellas Artes, inaugurada en marzo de 2007 después de la adquisición y remodelación de una casa en la calle 52 de Bogotá y que vino a suplir un gran vacío de las artes que había marcado la Universidad a lo largo de los años ${ }^{25}$. Otro vacío académico, curioso en sí mismo, que tenía la Universidad era en el estudio profesional de la teología. Desde 2004 se empezó a discutir el proyecto de crear un programa en esta área ${ }^{25}$, lo que terminó con la creación de la División de Ciencias Teológicas ${ }^{252}$ y su Facultad de Teología ${ }^{253}$. La Facultad fue restaurada el i3 de junio de 2011 a 43 I años de la expedición de la bula Romanus Pontifex de Gregorio XIII, un acto de profundo significado simbólico que cerró ocho años de la rectoría de Balaguera. Así hablaba el prior provincial fray Orlando Rueda O.P., en el acto de restauración:

Con la apertura de la Facultad de Teología queda hoy restaurada en su plenitud la Universidad Santo Tomás. La historia de nuestra Provincia Dominicana de Colombia, de nuestra universidad y de la sociedad colombiana estampan hoy su nombre - fray José Antonio- sobre el imborrable pergamino de la gratitud inmortal; y en letra de molde bruñida sobre las imperecederas páginas de la historia de la Orden Dominicana en Colombia quedará grabado para las generaciones futuras su noble gesto e insigne labor como digno e inolvidable restaurador de la Facultad de Teología del primer claustro universitario de Colombia ${ }^{254}$.

En el primer semestre de 2oro, la Sede Principal llegó a 18 pregrados y 35 posgrados de los cuales un $40 \%$ eran de maestría o doctorado ${ }^{255}$. Más tarde, en marzo del 201 y y partir de un viejo anhelo institucional, fue inaugurado el programa de Doctorado en Filosofía, adscrito a la Facultad de Filosofía y Letras ${ }^{256}$. En total, en el periodo $2003^{-20 I I}$, el número de programas académicos se amplió en un $32 \%$ y entre la Sede Principal y la VUAD se llegó a 90 programas, 4I de pregrado, 3I de especialización, I4 de maestría, 3 de doctorado y uno de posdoctorado ${ }^{257}$. 


\section{0}

Madurez institucional 1995-2018

Durante la rectoría de fray José Antonio Balaguera se culminó la reorganización de los departamentos interfacultativos. En el año 2004 se contaba con el Departamento de Ciencias Básicas con la dirección de la ingeniera Adriana Páez, integrado por las áreas de matemáticas, estadística, física, biología, química y sistemas, y el Departamento de Humanidades y Formación Integral, bajo la dirección del doctor Carlos Julio Flórez Márquez, integrado por las áreas de humanidades, idiomas y cultura física ${ }^{258}$. Más adelante, en 20ro el área de idiomas se separó de Humanidades y se convirtió en el Instituto de Lenguas Fray Bernardo de Lugo, O. P. ${ }^{259}$, siendo su primer director el licenciado en idiomas Eduardo Martínez. También hubo reestructuraciones como la aparición en el año 2004 de las divisiones de Ciencias Sociales, por un lado, y de Ciencias de la Salud, por otro, a partir de una única División que hasta ese momento agrupaba ambas áreas ${ }^{260}$. Además, en el año 2006 empezó a funcionar la Oficina de Archivo General de la Sede Principal ${ }^{26 r}$.

Por otro lado, durante la administraciónes de fray José Antonio se continuó con el proceso de autoevaluación y acreditación ante el Ministerio de Educación Nacional (MEN) de los programas académicos, obteniéndose finalmente el registro calificado por siete años en Bogotá (Ingeniería Civil, Psicología, Ingeniería de Telecomunicaciones, Comunicación Social, Ingeniería Ambiental, Estadística, Negocios Internacionales y Administración de Empresas, junto a dos especializaciones y dos maestrías), Bucaramanga (Derecho, Economía, Ingeniería Mecatrónica, Ingeniería de Telecomunicaciones, Administración de Empresas Agropecuarias, Ingeniería Industrial, Química Ambiental, junto a una especialización y una maestría), Tunja (Administración de Empresas, Contaduría Pública, Ingeniería Electrónica, Ingeniería Informática, Ingeniería Mecánica, Arquitectura, Ingeniería Civil, Derecho, junto a tres especializaciones), Medellín (Derecho, Ingeniería de Telecomunicaciones y Arquitectura), Villavicencio (Derecho, Ingeniería Mecánica, Contaduría Pública, Administración de Empresas Agropecuarias y Comercio Exterior) y VUAD (en la Facultad de Ciencias y Tecnología: las tecnologías en Administración de Empresas de Economía Solidaria y en Recursos Naturales Renovables; las administraciones en Ambiental de los Recusos Naturales, de Empresas Agropecuarias, de Sistemas e Informática, de Empresas y la Ingeniería en Informática, junto a la Licenciatura en Lengua Extranjera Inglés y una maestría; en la Facultad de Educación: las licenciaturas en Biología con énfasis en Educación Ambiental, en Educación Básica con énfasis en Humanidades y Lengua Castellana, en Educación Básica con énfasis en Matemáticas, en Educación Preescolar, en Filosofía y Cultura para la Paz, en Filosofía y Cultura Religiosa, en Filosofía y Lengua Castellana, en Filosofía y Pensamiento Político y Económico, en Filosofía, Ética y Valores Humanos, en Literatura y Lengua Castellana, junto a cinco especializaciones). Esto permitió la obtención de la primera Acreditación Institucional de Alta Calidad para la sede de Bogotá y la vuAD, concedida por cuatro años el 18 de octubre de $20 \mathrm{II}^{262}$.

En cuanto a la proyección social, durante la rectoría de fray José Antonio Balaguera se destaca principalmente la expansión de los Centros Multimodales, que bajo su rectoría pasaron a denominarse Centros de Proyección Social (CPS). A los CPS de Cazucá y Monte de Galilea se les sumó el cPs Santo Domingo, ubicado en los cerros orientales de Chapinero que fue creado en 2005 e inició labores al año siguiente. Más tarde, desde 2008 se comenzó a perfilar el CPS del barrio La Gaitana en la localidad de Suba que se viene consolidando desde el $2009^{263}$. En estos CPS la Universidad empezó a trabajar por medio de la coparticipación de las comunidades en su propio desarrollo y también a través de alianzas con ONG y organismos del Estado ${ }^{264}$.

E1 desarrollo de los CPS hizo necesario crear la Coordinación de Centros de Proyección Social en enero del 2oro, al frente de la cual ha estado desde entonces fray Adalmiro Arias Agudelo, O. P. ${ }^{265}$. Después se fueron creando los CPS de las sedes y seccionales. El cPs Comuneros de la Seccional Bucaramanga fue creado en marzo del $2010^{266}$ y actualmente se encuentran en desarrollo los CPS de Villavicencio (Aguas Claras y Comuna 3), de Tunja (Altamira) y Medellín (Bello Horizonte).

Hacia el final de la administración de fray José Antonio Balaguera, la Proyección Social tenía cinco ejes transversales: I) empoderamiento de las comunidades, 2) trabajo de promoción humana y comunitaria, 3) participación de la comunidad beneficiaria como metodología y como finalidad, 4) desde la misión, posibilidades y potencialidad de la Universidad y 5) alianzas con la sociedad civil, el Estado y el sector privado.

En estos cinco ejes se enfatizaba la coparticipación y gestión de las comunidades en su propio desarrollo, una concepción a largo plazo de prevención, rehabilitación y promoción sin abandonar la asistencia en casos de emergencia, la potencialización del aprendizaje a través del trabajo social y las alianzas con sectores estratégicos para el cumplimiento de los 


\section{I}

Madurez institucional 1995-2018

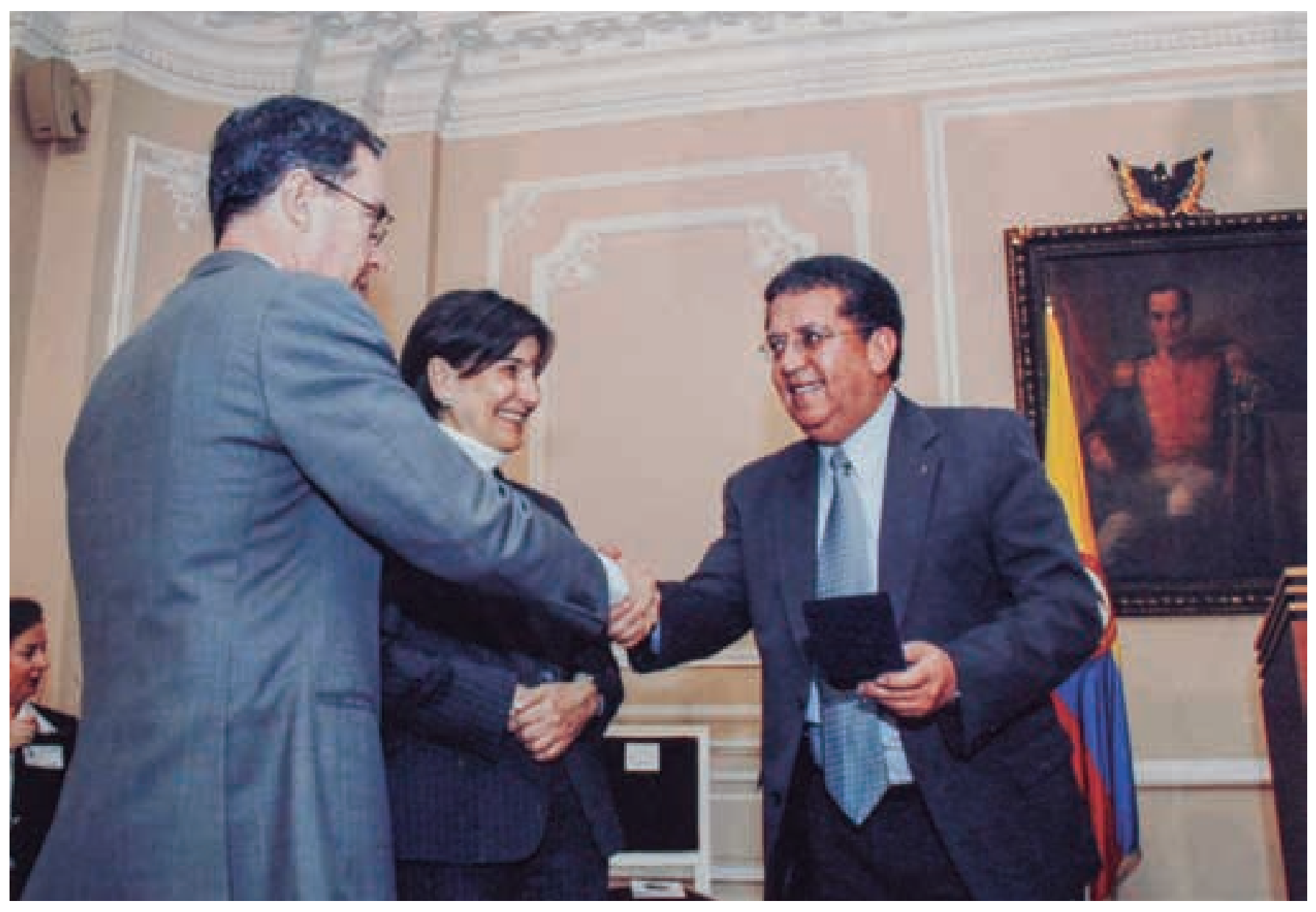

El presidente de la República, Dr. Álvaro Uribe Vélez, y la ministra de Educación, Cecilia María Vélez, con el rector fray José Antonio Balaguera, O. P.

propósitos sociales ${ }^{267}$. En cuanto a las líneas estratégicas, en aquel momento específico se trabajaban: I) productividad, empleo e ingresos, 2) educación, 3) salud y nutrición, 4) cultura y 5) servicios (consultorios jurídicos, psicológicos y contables) ${ }^{268}$.

Por otro lado, el esfuerzo de internacionalización que la Universidad había hecho en los últimos años pronto empezó a rendir frutos. Uno de los casos más emblemáticos de presencia tomasina en redes internacionales ha sido su participación en el proyecto "Comprender los desplazamientos de población. Miradas plurales desde la universidad" desde 2006, liderado por la FIUC y con participación de varias universidades de América Latina y Asia. En este marco, la Usta fue sede entre el 2I y 24 de junio de 2010 del "Coloquio Internacional América Latina-Asia. Comprender los desplazamientos de población. Miradas plurales desde la universidad", que sirvió para reunir la totalidad de los equipos investigativos de los dos continentes involucrados ${ }^{269}$.

\section{IESHFAZ}

En el año 20Io, en el marco del bicentenario del grito de Independencia, se crea el Instituto de Estudios Históricos Fray Alonso de Zamora, O. P., a cuyo cargo estuvo la producción de la presente obra ${ }^{270}$. La creación del Instituto fue propuesta por el entonces vicerrector de la VUAD, fray Carlos Mario Alzate O.P., quien fue su director por varios años. Adscrito a la Vicerrectoría Académica General desde su creación, el Instituto tomó el nombre de Instituto Estudios SocioHistóricos Fray Alonso de Zamora, O. P., (IEshfaz) en el 20I2, con el propósito de ampliar su campo de 


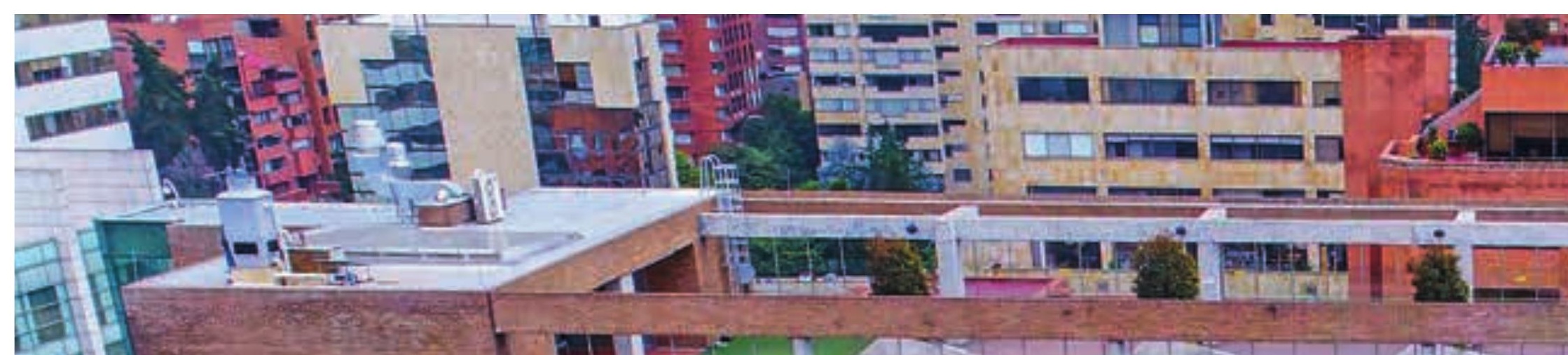

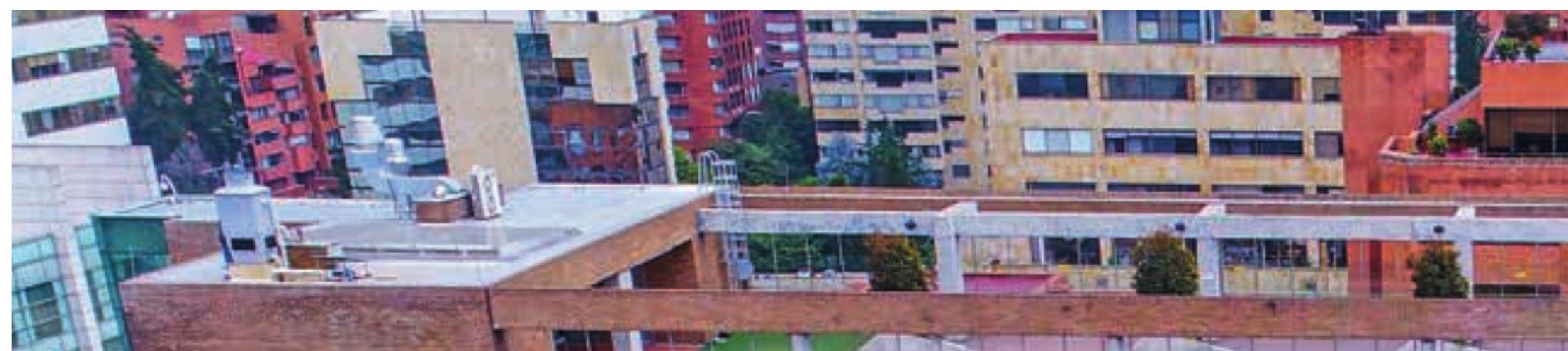

If

Et

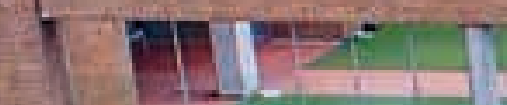
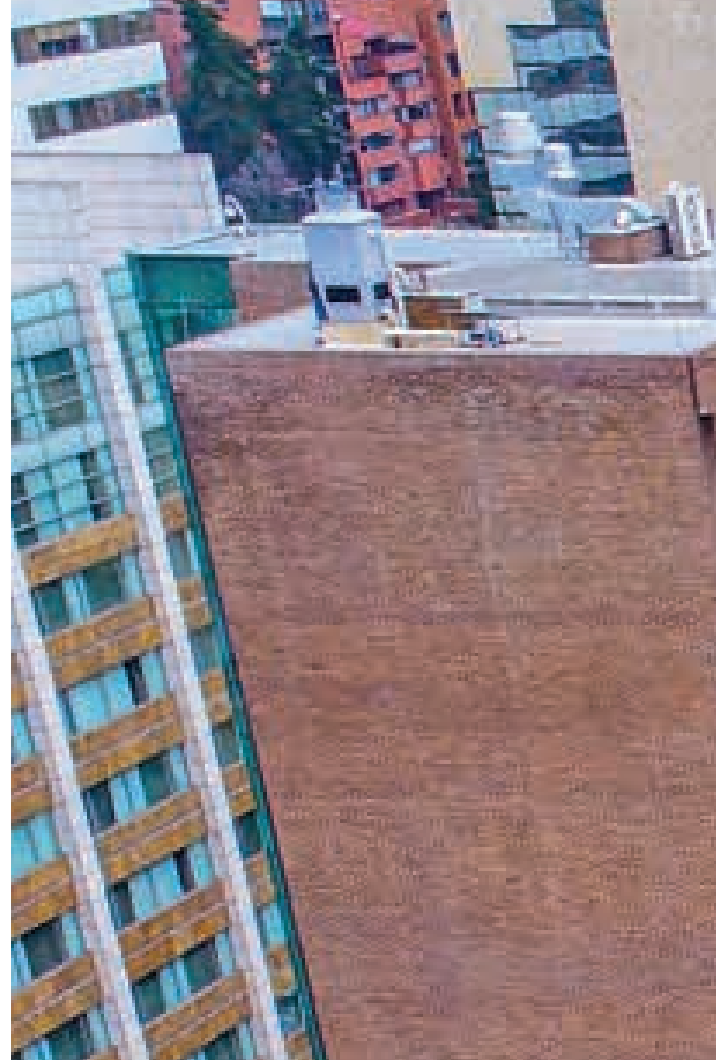

(1)
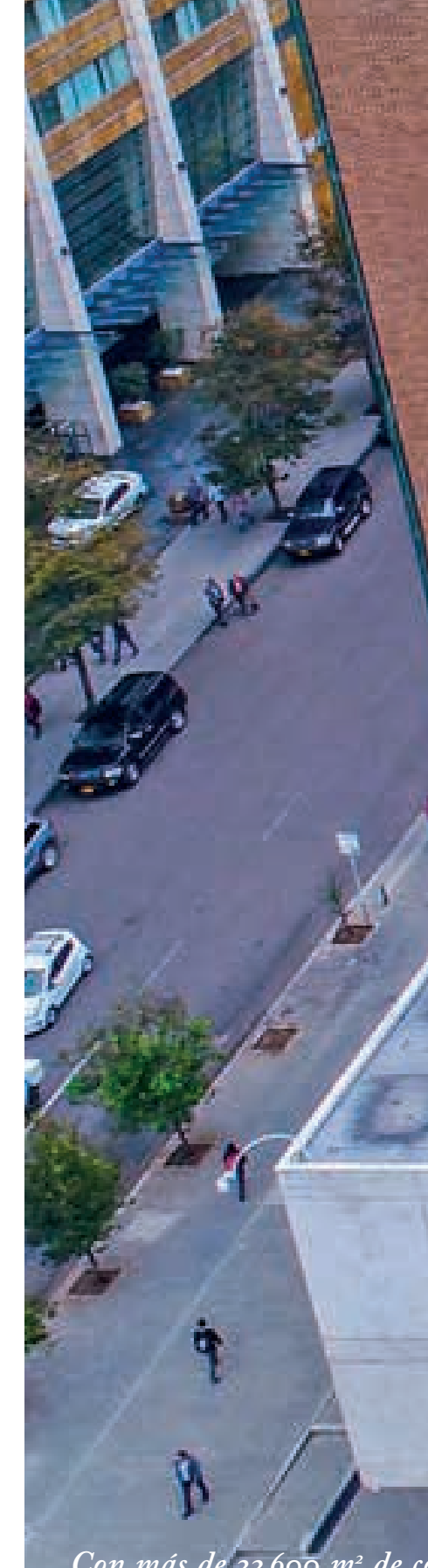

Con más de $22600 \mathrm{~m}^{2}$ de construcción, el arquitecto Gabriel

Arango proyectó el moderno edificio Doctor Angélico en pleno corazón financiero de la capital $\mathbf{A}$

A capital la cay
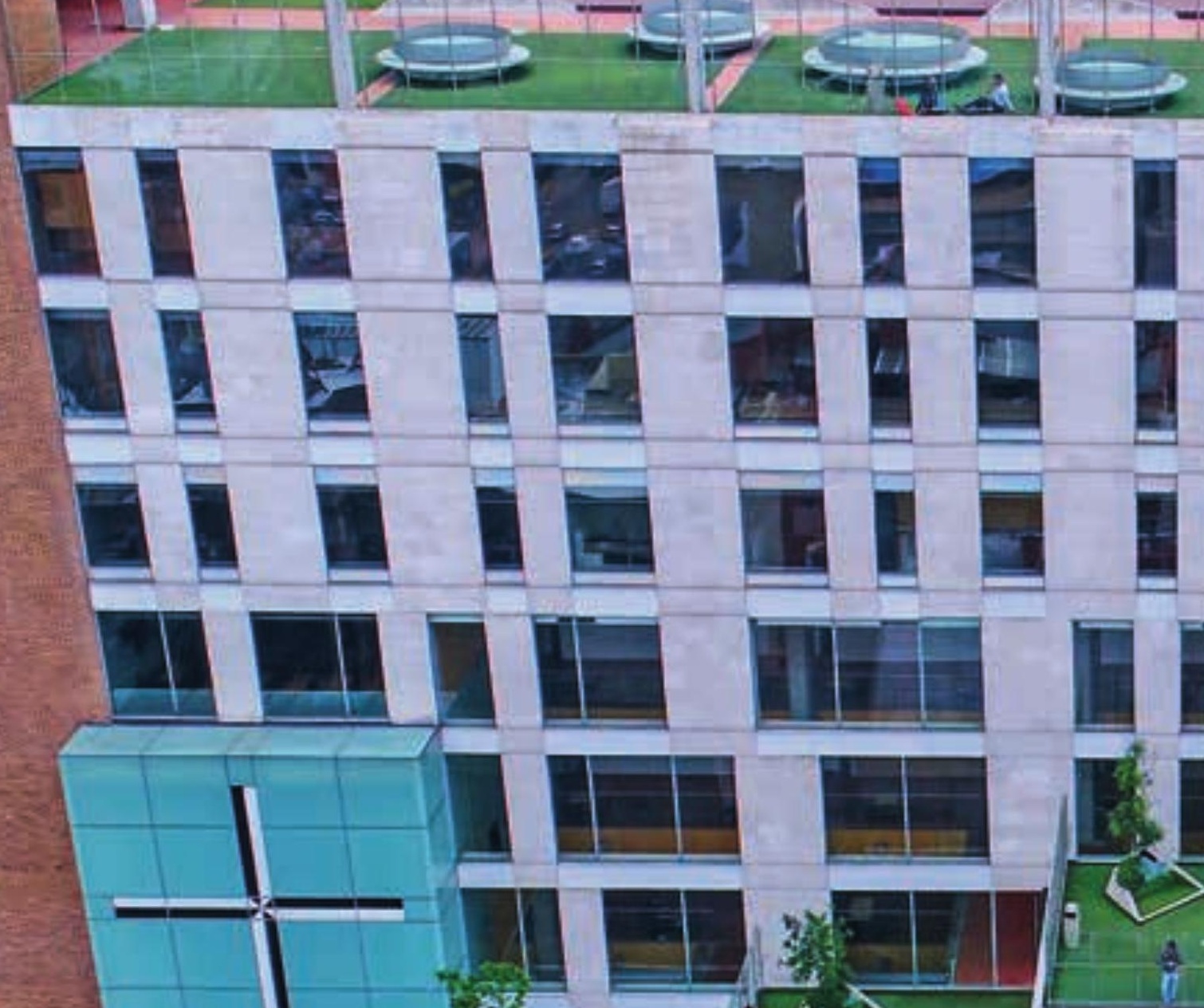

1.
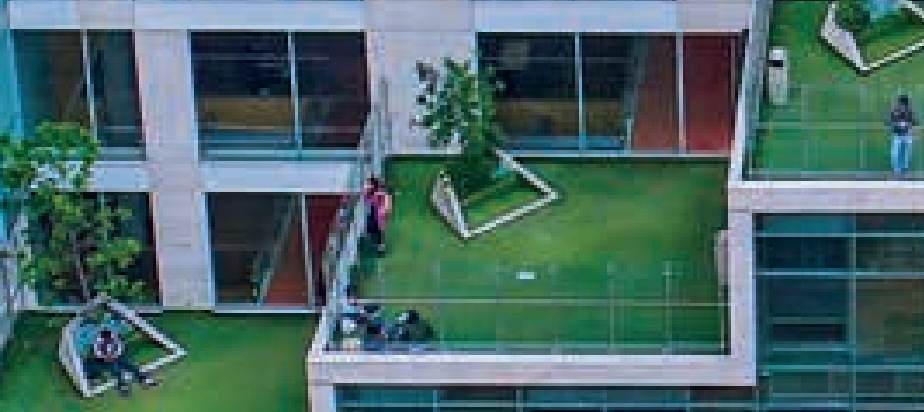


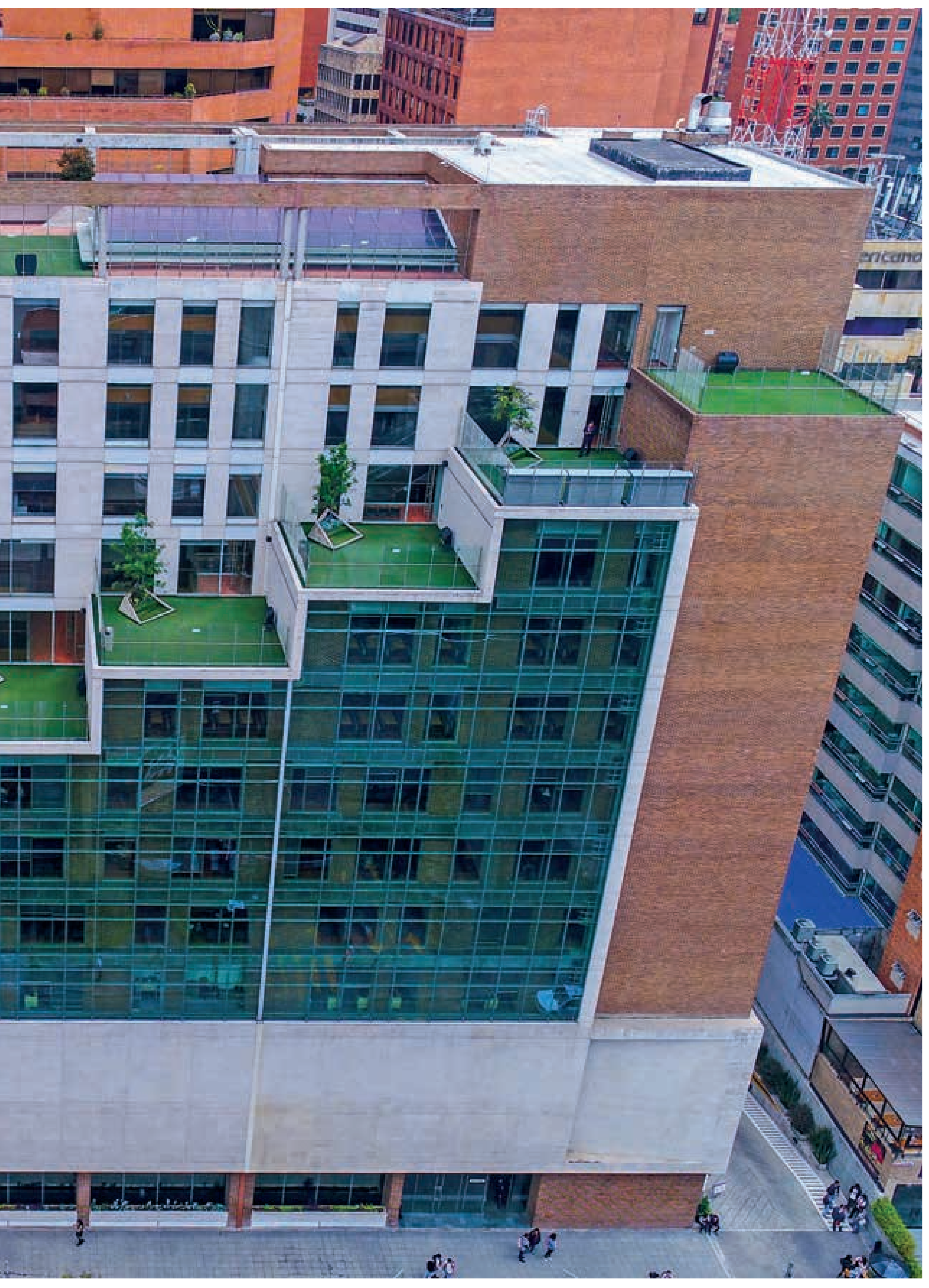




\section{4}

Madurez institucional 1995-2018

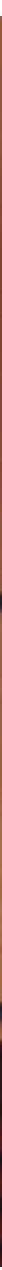

Para hacer honor a su tradición histórica, de universidad de Estudios

Generales, en junio de 201 se restauró la Facultad de Teología

acción y, de este modo, desarrollar proyectos multidisciplinares en los campos de las ciencias humanas y sociales ${ }^{271}$, así como promover inicitivas o eventos relacionados con la gestión cultural.

Desde su creación, el IEshFAz ha contribuido al conocimiento y debate de fenómenos sociales a través de libros, artículos, seminarios, concursos y encuentros académicos con participación de investigadores colombianos y extranjeros ${ }^{272}$. Vale la pena resaltar el Segundo Congreso Internacional de Historia de la Orden de Predicadores en América, transcurrido en abril de 2016 con motivo de las efemérides de los ochocientos años de la aprobación pontificia de la Orden de Predicadores. Desde el año 20I7, el IEshfaz pasó a funcionar dentro de la estrucutra académico-administrativa del Departamento de Humanidades y Formación Integral.
Situación de las sedes y seccionales

El desarrollo de la Vicerrectoría de la Universidad Abierta y a Distancia continuó siendo una preocupación institucional durante la rectoría de fray José Antonio Balaguera. En su Informe de Gestión Rectoral 2003-2007, explicaba:

La Universidad considera como máxima expresión de su proyección social y de su interacción con el medio externo su sistema de educación abierta y a distancia, a través del cual hace presencia en los lugares más apartados de la geografía nacional y brinda sus programas de tecnologías, licenciaturas y profesiones con lo más altos índices de calidad, posicionándose, no solo como el primer claustro en ofrecer estos programas bajo las metodologías a distancia, sino como la institución más sólida en 
este ámbito, capaz de ofrecer su formación en todo el país y fuera de él ${ }^{273}$.

En el primer semestre de 2005 la VUAD tenía nueve licenciaturas, cinco pregrados, cuatro tecnologías, diez especializaciones y una maestría ${ }^{274}$. En los años siguientes los pregrados aumentaron llegando en 2008 a once licenciaturas, siete pregrados y cuatro tecnologías; los posgrados, por otro lado, se reorganizaron en ocho especializaciones y dos maestrías ${ }^{275}$. En la tabla 25, “Población estudiantil VUAD 2005-2008”, se aprecia la evolución de la población estudiantil en dicho periodo.

En el año 2009, a partir de procesos iniciados en los primeros años de la década, la VUAD estableció los Lineamientos para la Gestión de la Investigación. Dos años más tarde, el centro de investigaciones de la Facultad de Ciencias y Tecnología y el sistema de investigación de la Facultad de Educación, que habían sido creados en el 2000 y 200 r respectivamente, se fusionaron en un solo Centro de Investigaciones de la VUAD, que sigue gestionando la investigación de la modalidad a distancia en la actualidad.

Más adelante, en el primer semestre del 20Io había 3696 estudiantes en pregrados y tecnologías, 2240 de ellos en la Facultad de Ciencias y Tecnologías y I456 en la Facultad de Educación ${ }^{276}$. En ese mismo momento había $2 \mathrm{I} 4$ inscritos en 5 especializaciones y una maestría ${ }^{277}$. La oferta de los programas permaneció prácticamente sin variaciones durante los dos últimos años de la década del $2000^{278}$. Vale la pena destacar que desde octubre del 2007 los centros regionales de la VUAD se conocen como Centros de Atención Universitaria (CAU) ${ }^{279}$

En Bucaramanga, por otro lado, la primera adminis tración rectoral de fray José Antonio Balaguera coincidió con la rectoría seccional de fray Carlos Arturo Díaz Rodríguez, O.P. Durante ese tiempo se trabajó con el Plan de Desarrollo de la Seccional 2003-2007, en el cual se propuso el avance investigativo y científico y el mejoramiento de la administración, su gestión y financiamiento ${ }^{280}$. Para el periodo 2007-20Io el Plan de Desarrollo se desenvolvió sobre el aseguramiento de la calidad, el desarrollo integral humano, el fortalecimiento académico, la interacción e impacto en el medio externo y la administración educativa ${ }^{281}$.

En el primer cuatrienio se obtuvieron las primeras acreditaciones de calidad para los programas de Odontología, Contaduría Pública, Arquitectura, Optometría, Derecho, Administración de Empresas Agropecuarias y Comercio Exterior; durante ese tiempo también se dinamizó la internacionalización de la
Seccional a través de convenios de cooperación institucional con universidades del exterior ${ }^{282}$.

En 2005 Bucaramanga tenía trece programas de pregrado, cuatro licenciaturas en modalidad a distancia y una tecnología ${ }^{283}$. El año siguiente se creó el programa de Ingeniería Industrial y en 2007 el programa en Química Ambiental, pionero en el país ${ }^{284}$. En cuanto a posgrados, todavía en 2005 Bucaramanga contaba con treinta y tres programas (aunque cuatro de estos eran inactivos), de los cuales trece eran semipresenciales, uno a distancia, dos maestrías y el resto especializaciones ${ }^{285}$. Cinco años después, en 2010 se llegó a los catorce pregrados y se redujeron los posgrados a veintidós especializaciones y una maestría, todos con registro calificado ${ }^{286}$.

En cuanto a la investigación, entre 2008 y 2010 Bucaramanga tenía veinticuatro grupos de investigación, veinte de ellos inscritos y quince categorizados por Colciencias ${ }^{287}$. Durante este tiempo Bucaramanga, la Seccional más consolidada de la USTA, obtuvo acreditación de alta calidad para Cultura Física, Deporte y Recreación, Ingeniería de Telecomunicaciones, renovó la acreditación para Odontología ${ }^{288}$ y creó el Centro de Proyección Social y Extensión; también concluyó mejoras en la infraestructura física como la plazoleta de los estudiantes y la modernización de unidades odontológicas y laboratorios.

La Seccional Tunja, por otra parte, vivió un importante periodo de crecimiento entre 2002 y 2005 . En su infraestructura, Tunja pasó de 7 I96.I5 $\mathrm{m}^{2}$ en 2003 a $52485.84 \mathrm{~m}^{2}$ en 2004 . El crecimiento de la oferta académica no es menos notable. De los cuatro programas de pregrado que tenía en $2002^{289}$ se pasó a ocho en 2005: I) Administración de Empresas, 2) Arquitectura, 3) Contaduría Pública (diurna y nocturna), 4) Derecho, 5) Ingeniería Civil, 6) Ingeniería Electrónica, 7) Ingeniería Informática e 8) Ingeniería Mecánica. De estos solo Ingeniería Mecánica y Contaduría eran extensiones, el resto eran programas propios de la Seccional $^{290}$. En ese momento, Tunja contaba ya con cinco especializaciones, cuatro de ellas en metodología semipresencial y una presencial; a su vez, tres eran programas propios de la Seccional y dos eran extensiones ${ }^{291}$. Además, en el año 2004 se crearon los departamentos de Humanidades y Ciencias Básicas e Idiomas, con lo que quedó plenamente constituida la educación interfacultativa en la USTA Tunja ${ }^{292}$.

Durante estos años también se avanzó en el proceso de obtención del registro calificado y para el año 2006 se había obtenido el registro para seis pregrados y dos especializaciones $^{293}$. El segundo lustro de la década fue de estabilidad en el crecimiento de pregrados y 


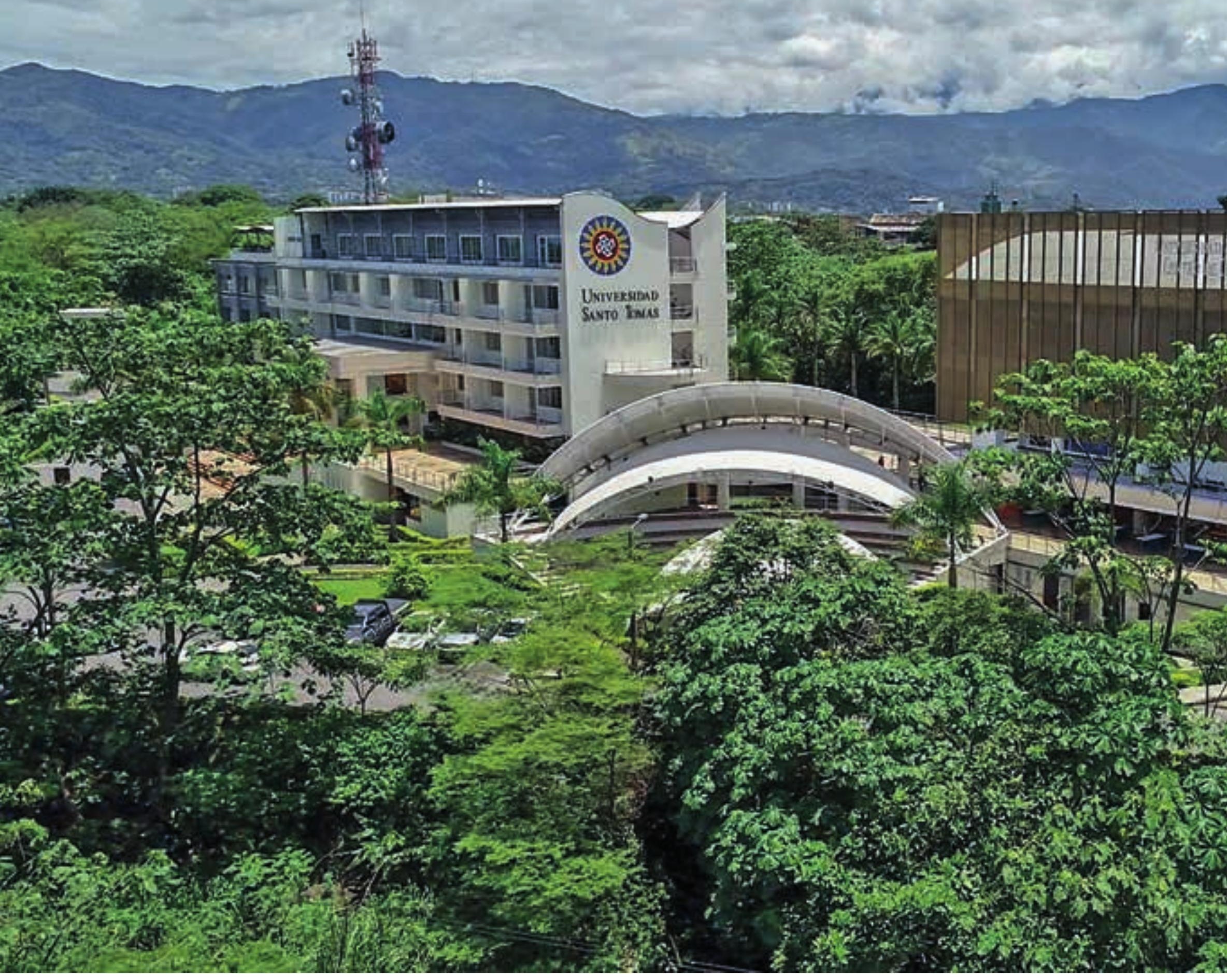

Vista aérea del de la USTA Villavicencio

notable actividad en el de los posgrados. En 20II, al tiempo que se mantuvo el número de pregrados, las especializaciones sumaban catorce ${ }^{294}$.

En lo que a investigación concierne, inicialmente el Centro de Investigación Institucional (Ciusta) cumplía las funciones propias de las unidades de Investigación, de Posgrados y de Formación Permanente. Sin embargo, en el primer semestre del año 2004 la Seccional reestructuró la administración ${ }^{295}$; se creó la Unidad de Posgrados y Educación Continuada, con lo que Ciusta adquirió autonomía para definir y coordinar la investigación en la Seccional trabajando en conjunto con el Centro de Investigación Socio Jurídica (CIS), de la Facultad de Derecho ${ }^{296}$. En 2006 Tunja tenía veintitrés grupos de investigación, una suma impresionante teniendo en cuenta que era una Seccional con apenas una década de existencia ${ }^{297}$. Empero, en los años siguientes la Seccional reorganizó los grupos reduciéndolos a diez, mientras que desarrolló sus semilleros de investigación ${ }^{298}$.

Durante el periodo 2006-2009, Tunja tecnificó la comunicación, amplió la infraestructura, fortaleció sus espacios académicos, culturales, deportivos y de investigación, entre otros. También se generaron importantes procesos sociales; uno de ellos fue el desarrollo de proyectos de promoción de pequeñas y medianas empresas en comunión con la ONG Opción Vida, Justicia y $\mathrm{Paz}^{299}$.

Mientras tanto, la Sede Medellín continuó su proceso de consolidación. En el año 2003 Ingeniería de 


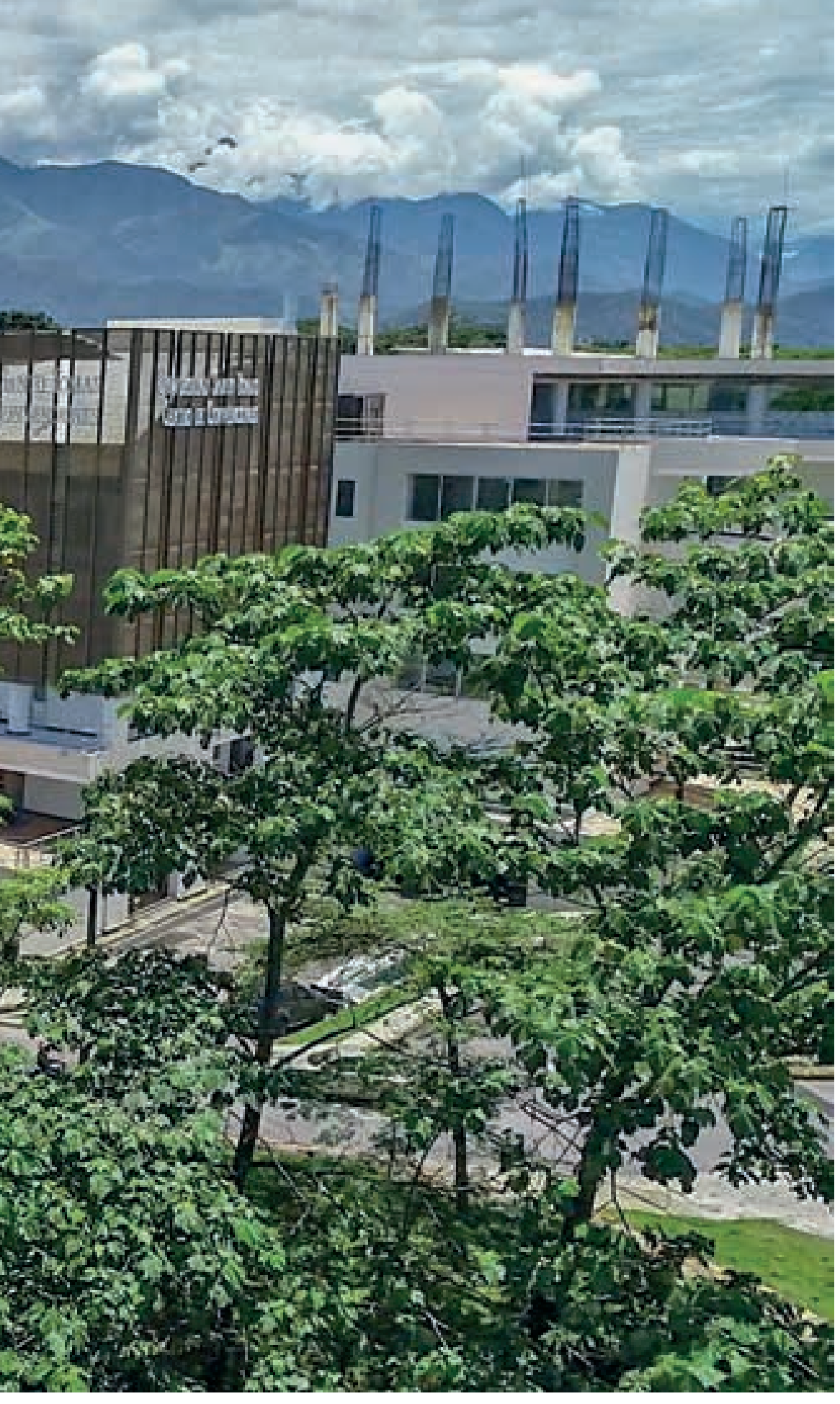

programas extendidos mientras que los programas de Arquitectura e Ingeniería de Telecomunicaciones, que venían funcionando como extensiones, pasaron a ser programas propios de la Sede. Entre 2009 y 20I2, con la decanatura de fray Arturo Restrepo Restrepo, O. P., se reestructuró la coordinación de investigaciones, se consolidaron los grupos de investigación, se abrieron nuevas especializaciones, se aprobó la creación del consultorio jurídico y se estructuró el sistema de gestión documental y archivo de la Sede ${ }^{304}$. Durante todos estos años se propiciaron debates entre las directivas sobre las direccionalidades para un mejor desarrollo de la Sede, principalmente en términos de un mejor posicionamiento geográfico de esta y con la idea de convertirla en Seccional ${ }^{05}$.

\section{Creación de la Sede Villavicencio}

El actual horizonte de la presencia nacional de la USTA en la modalidad presencial se terminó de concretar durante la rectoría de fray José Antonio Balaguera con la creación de la Sede Villavicencio. La Santo Tomás hacía presencia en la capital del Meta desde 1985 cuando se había creado el Centro Regional de Educación a Distancia, que con el tiempo llegó a cobijar el trabajo de la Universidad Abierta y a Distancia en Meta, Guaviare, Vichada, Guainía, Vaupés y algunos pueblos de Cundinamarca y Casanare. Diez años después de su creación, la Regional tenía ya una oferta de diez programas académicos ${ }^{306}$.

La idea de hacer presencia en Villavicencio a través de programas presenciales data al menos de fines de la década de 1990. Desde el segundo semestre de 1996 las directivas aprobaron constituir el Centro Regional de la ciudad en "zonal de posgrados" y se inició la oferta de ocho especializaciones; dos años

Telecomunicaciones tenía I8I estudiantes y 33 profesores, mientras que Arquitectura atendía a Iio estudiantes con 26 docentes $^{300}$. Entre los años 2003 y 2007, bajo la Decanatura de División de fray Diego Orlando Serna, O.P., se construyó el edificio San Alberto Magno ${ }^{30}$, se continuaron las gestiones para extender los pregrados de Derecho, Contaduría Pública, Comercio Exterior (llamado desde 2004 Negocios Internacionales) ${ }^{302}$ y la Especialización en Derecho Administrativo. En el año 2005 Medellín contaba con los pregrados extendidos de Arquitectura, Comercio Exterior e Ingeniería de Telecomunicaciones (diurna y nocturna $)^{303}$.

Luego, entre 2007 y 2009 con la decanatura de fray Luis Alberto Orozco Arcila, O. P., se iniciaron nuevos después, con voluntad de expansión, se compró el predio Loma Linda ${ }^{307}$. La gestión quedó pausada por algunos años, dado que, recordemos, la rectoría de fray Eduardo González se caracterizó por una orientación hacia la consolidación más que hacia la creación de nuevas sedes y seccionales.

En los primeros años de la rectoría de fray José Antonio Balaguera se realizaron estudios de factibilidad para la extensión de programas presenciales y en 2006 se acordó extender Contaduría Pública, Derecho e Ingeniería Mecánica de Bogotá y Administración de Empresas Agropecuarias y Comercio Exterior de Bucaramanga ${ }^{308}$. Para la concreción del proyecto se adquirieron nuevos terrenos ${ }^{309} \mathrm{y}$ se conformó, ese mismo año, el Comité USTA Villavicencio, conformado por 


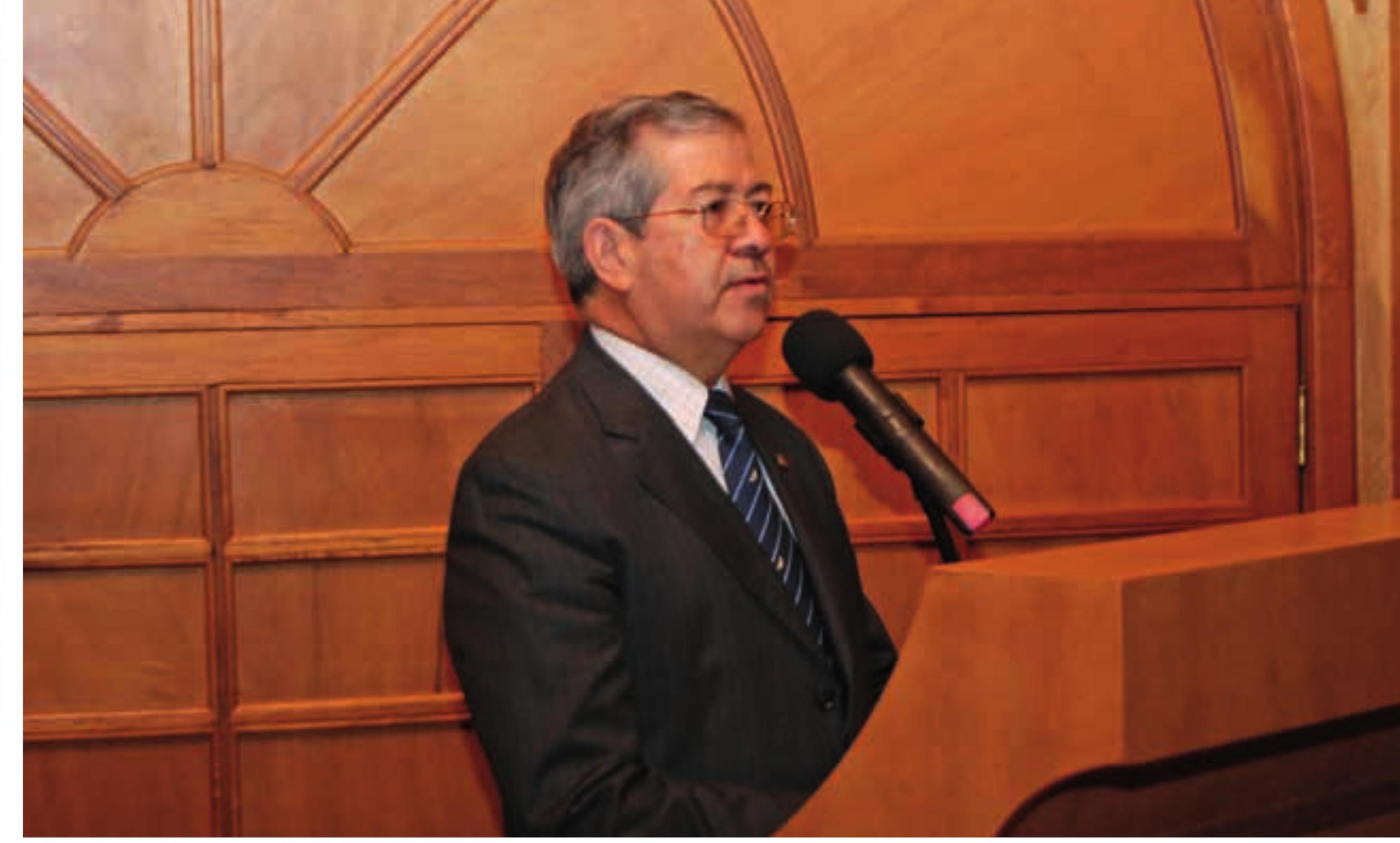

otra región en donde se pensó dar este paso fue en Pereira, pero diversos factores llevaron a la escogencia de Villavicencio). En muy poco tiempo, la USTA Villavicencio se ha convertido en un referente central de la educación superior en una zona que, como es el caso de los Llanos Orientales, ha estado tradicionalmente fuera del circuito de la educación superior.

\section{Estatuto Orgánico de 2010}

Entre fines de 2009 y comienzos de 2010 el Consejo de Fundadores llevó a cabo una actualización del Estatuto Orgánico de la Universidad, que fue aprobada por el Ministerio de Educación en julio del 2010 ${ }^{316}$. El Estatuto, que empezó a regir el mes siguiente, es el que ha presentado menos variaciones en relación con el anterior en comparación con los de I972, I985 y 2002. Un cambio que vale la pena notar es la ampliación del poder del Consejo de Fundadores sobre el Estatuto al adjudicársele como función "ejercer la potestad reglamentaria del Estatuto Orgánico mediante la expedición de Decretos, para la cumplida ejecución de sus disposiciones, en aquellos asuntos que no sean de competencia del Consejo Superior"317; esto se sumó a la competencia que ya tenía para interpretar el estatuto, resolver sus ambigüedades y colisiones de competencias. Por otro lado, el Estatuto de 2010 confirió mayor identidad estatutaria a las sedes, hasta entonces un poco desdibujada:
Las sedes de la Universidad Santo Tomás diferentes a la Sede Principal, donde se desarrollan programas presenciales, directamente o por extensión de programas acreditados de alta calidad, se estructuran como Decanaturas de División de Sede, y sus órganos serán semejantes a los de la Sede Principal y Seccionales, cumpliendo, mutantis mutandis, funciones similares a sus homólogos, en consonancia con las capacidades, necesidades y desarrollo, propios de cada Sede ${ }^{318}$.

Así, el decano de División de Sede quedó institucionalizado como la autoridad ejecutiva en lo académico, administrativo y financiero, así como representante del rector general en su sede. A su vez, se establecieron comités administrativo-financieros particulares para la gestión, el control y la supervisión del presupuesto en la Sede Principal, las seccionales y las mencionadas decanaturas de división de las sedes ${ }^{319}$.

Este estatuto incluyó además un artículo en donde se establece el conducto regular para casos académicos y disciplinarios estableciéndose como primera instancia el Consejo de Facultad con apelación ante el Consejo Académico Particular y el Consejo Académico General, quedando el Consejo Superior Universitario como la última instancia. Otras variaciones incluyen pequeños cambios en los requisitos para ocupar cargos directivos y en los periodos de los directivos y de los miembros de los consejos de la Universidad ${ }^{320}$. 


\section{0}

Madurez institucional 1995-2018

FRAY CARLOS MARIO ALZATE MONTES, O.P., RECTOR GENERAL 2OII-2OI5

A la gestión de fray José Antonio Balaguera le siguió la de fray Carlos Mario Alzate Montes, O.P., en el periodo 20II-20I5. Fray Carlos Mario nació el I9 de mayo de 1959 en Sonsón, Antioquia. Ingresó al noviciado en 1978 e hizo profesión solemne en 1982. Dos años después fue designado para la misión en el Catatumbo donde trabajó bajo el liderazgo de fray Leonardo Gómez, O.P. En 1986 fue asignado al convento de Chiquinquirá para apoyar la misión preparatoria de la visita de Juan Pablo II y trabajó allí como docente y capellán del Instituto Técnico Industrial y en el Liceo Nacional. En 1987, fray Alzate Montes fue ordenado sacerdote en Chiquinquirá y poco después fue encargado de la coordinación del Cread.

A finales de 1993 fue asignado al Convento de San José como catedrático del Studium Generale. A comienzos del año siguiente fue nombrado capellán general de la Universidad San Martín y poco después fue nombrado director del Departamento de Doctrina y Ecumenismo de la Conferencia Episcopal de Colombia. Entre 1998 y 2002 fue prior provincial y como tal fue uno de los más importantes impulsores de la Corporación Dominicana Opción Vida ${ }^{322}$.

Fray Carlos Mario es licenciado en Filosofía por la USTA y bachiller en Teología por la Universidad Javeriana. También tiene un diplomado en Archivística y Paleografía por la Escuela Vaticana, una especialización en Gerencia de Instituciones de Educación Superior por la USTA y un magíster en Historia por la Universidad Pedagógica y Tecnológica de Colombia; ha cursado estudios de Doctorado en Historia de la Iglesia en la Universidad Gregoriana de Roma.

Antes de ser rector, fray Carlos Mario fue decano de la División de Ciencias Económicas y Contables (Economía y Contaduría), de la División de Ingenierías y de la Facultad de Filosofía, rector de la Seccional Tunja, vicerrector de la VUAD, entre otros ${ }^{322}$. Es miembro de la Academia Boyacense de Historia y ha sido docente del Estudio General de la Provincia y del Seminario Mayor de Bogotá.

El documento guía durante el cuatrienio de fray Carlos Mario fue el Plan General de Desarrollo 20122015. USTA: excelencia que transforma el país, cuya visión era como sigue: "En el 2015 la Universidad Santo Tomás de Colombia, institución acreditada de alta calidad, contribuye a la construcción de una sociedad equitativa y solidaria, mediante una cultura investigativa que dinamiza sus procesos formativos y sus relaciones con el entorno". Para lograr esto se propone la articulación de la "Universidad Santo Tomás Colombia" ${ }^{23}$, concepto más conocido como "Usta Colombia" y que expresa una visión de la USTA como un proyecto común a nivel nacional construido a partir de procesos sincrónicos en sus diferentes sedes, seccionales, etc. ${ }^{324}$. E1 Plan se estructura en tres ejes: I) USTA y sociedad, 2) comunidad universitaria y 3) gestión institucional ${ }^{325}$.

E1 primer eje articula las políticas que buscan impactar el entorno global a través de la cultura investigativa y la docencia cualificada e incluye estrategias tales como renovación curricular, fortalecimiento de asesorías y consultorías, de las alianzas estratégicas, de la relación investigación-sector externo (Estado, comunidad, empresa, etc.), consolidación de programas académicos, de la educación continuada, inserción en comunidades académicas internacionales, fortalecimiento de la relación investigación-currículo, nuevas modalidades de formación, desarrollo comunitario, emprendimiento, internacionalización de currículo, consolidación de comunidad académica bilingüe y ampliación de la cooperación técnica internaciona ${ }^{326}$.

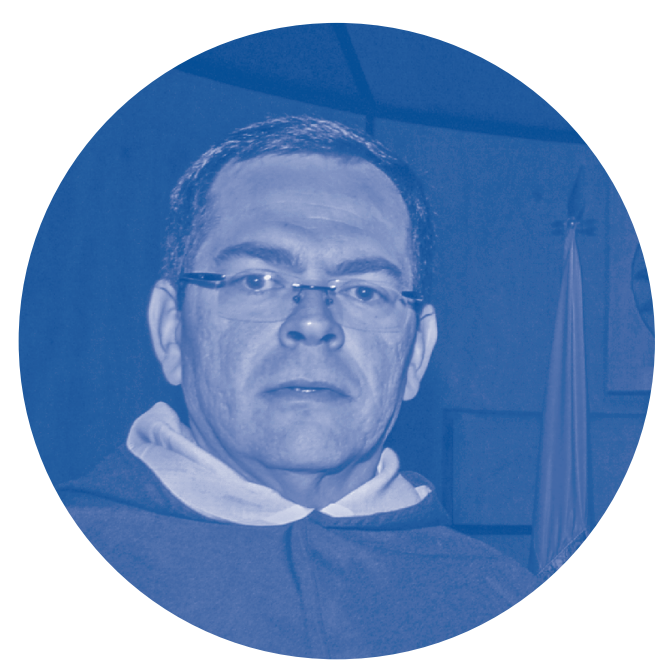

Fray Orlando Rueda, O.P., prior provincial durante el periodo 20I0-20I4 


\section{I}

Madurez institucional I995-2018

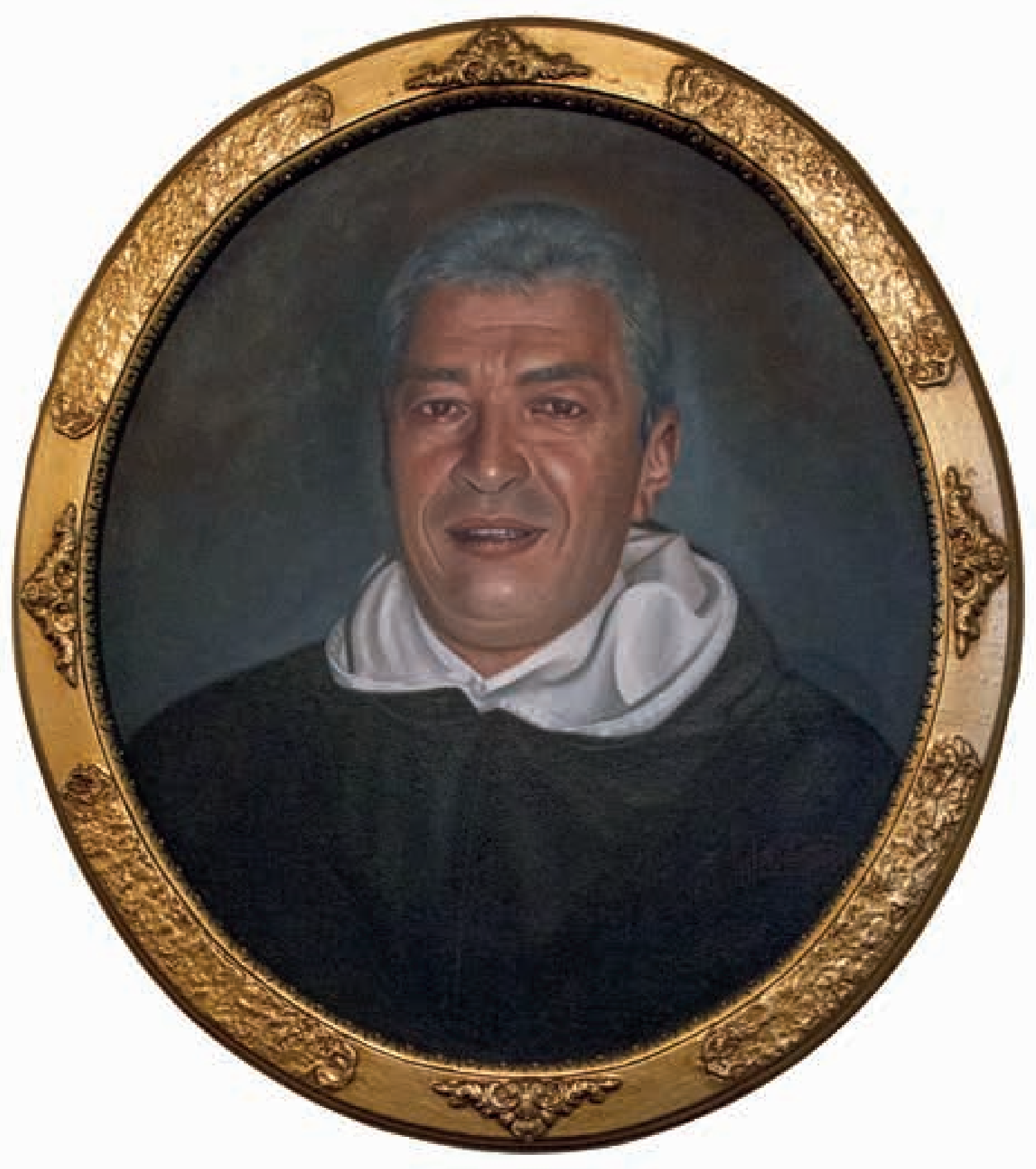

Fray Carlos Mario Alzate Montes, O. P., rector general $201 \mathrm{II}^{-2015}$ 


\section{2}

\section{Madurez institucional 1995-2018}

El segundo eje está conformado por estrategias hacia la promoción de la integración, la participación y la formación de la comunidad universitaria con sentido humanista cristiano. Por ello se propone el fortalecimiento de la cultura y del clima institucional, desarrollo de la comunidad universitaria, formación y desarrollo docente, capacitación y actualización del personal directivo y administrativo, articulación de las políticas UsTA Colombia, articulación y fortalecimiento de los procesos misionales, pastoral, diálogo fe-cultura-ciencia, portafolio de servicios para egresados, proyección del egresado, participación de los estudiantes en la vida universitaria y formación integral ${ }^{32}$.

Finalmente, el tercer eje articularía respuestas a los desafíos del entorno, consolidación de procesos y racionalización de recursos para el cumplimiento de la misión. Aquí, las propuestas incluyen renovación de la acreditación institucional, acreditación de programas académicos, consolidación de sistema de información, mejora institucional, diseño e implementación de un sistema de gestión presupuestal, fortalecimiento de los procesos académico-administrativos, automatización de procesos de gestión documental, robustecimiento tecnológico y planeación coordinada de la infraestructura acorde al desarrollo académico $^{328}$.

Desde cierto punto de vista, este tercer eje equivaldría a la continuación del proceso que la USTA había iniciado quince años atrás para ajustarse al nuevo panorama de la educación superior en Colombia. Por lo mismo, se puede interpretar que hacia este periodo, fundamentalmente gracias a la acreditación institucional de alta calidad obtenida en 20ro, ese largo proceso estaba plenamente consolidado.

Uno de los elementos centrales de este plan de desarrollo es su énfasis en la relación de la Universidad con el medio externo. Es por ello que enfatiza en la pertinencia y los problemas del entorno como criterio para la creación de programas académicos, así como para su revisión y actualización curricular, el desarrollo de la investigación y de la proyección social, la extensión, la política de egresados, la educación a distancia, la acogida de nuevas modalidades de formación y el fortalecimiento del programa de emprendimiento, etc. ${ }^{329}$.

Es apreciable la consciencia global del Plan en la medida en que se pretende una apertura a la comunidad internacional y un mayor posicionamiento de la usta allí. Para lograrlo se plantea aumentar la movilidad con universidades extranjeras, vincular docentes e investigadores a redes académicas y científicas, promover la cooperación con organismos internacionales, ampliar la oferta de doctorados en convenio con universidades extranjeras, aumentar la formación en lenguas, entre otras ${ }^{33^{\circ}}$. Es decir, durante el cuatrienio de fray Carlos Mario, la USTA, fortalecida por los procesos institucionales de los previos diecisiete años, se orientaba ya consistentemente hacia el mundo globalizado del siglo XXI.

El Plan fue socializado en el 2012 en Bogotá, Villavicencio, Medellín y la VUAD. Al año siguiente el trabajo se amplió a Tunja y Bucaramanga, se activaron mesas nacionales y se articularon los planes de desarrollo de Medellín, Villavicencio y Tunja. En el 2014 se consolidó la gestión nacional y regional - se construyeron 39 proyectos nacionales - articulando objetivos comunes, desarrollos propios de las sedes y seccionales, y sinergias entre academia y administración ${ }^{33^{1}}$.

En el marco de la construcción de ese proyecto común denominado Usta Colombia, en 2013 se inició un proceso de sincronización para que las sedes y seccionales construyeran sus planes bajo la directriz del Plan General de Desarrollo, puesto que hasta entonces la gestión y formulación de planes de sedes y seccionales obedecía a sus distintos periodos rectorales, que no eran simultáneos entre sí32

Después del Plan General de Desarrollo vinieron el Plan de Desarrollo de la VUAD 20I2-2015, el Plan de Desarrollo de Villavicencio 2013-20r6, el Plan de Desarrollo 20I3-20r6 de Medellín, el Plan de Desarrollo de la Seccional Tunja 2013-2015 y el Plan de Desarrollo de la Seccional Bucaramanga 2013-2016333. Los planes de desarrollo y la gestión administrativa de las sedes y seccionales atienden a elementos característicos de sus realidades regionales. Así, en el Plan de Desarrollo de la Seccional Tunja, a los tres ejes del Plan General se les sumó un cuarto eje de "regionalización" en el que el medio ambiente, la identidad departamental, el tema de la paz y el conflicto y finalmente la familia se proponen como campos por desarrollar, específicamente por la UsTA Tunja ${ }^{334}$.

\section{Acreditación institucional, reforma en Vicerrectoría}

Desde el principio de la gestión del rector Carlos Mario se empezó a avanzar en la renovación de la acreditación institucional de alta calidad. En septiembre de 2012 se creó el Comité Nacional de Aseguramiento de la Calidad para liderar el proceso de autoevaluación y autorregulación institucional ${ }^{335}$ y en noviembre de ese año se aprobó el cronograma de autoevaluación con fines de acreditación ${ }^{336}$. 


\section{3}

\section{Madurez institucional 1995-2018}

Lo que siguió fue un proceso de integración de sedes y seccionales bajo un propósito común: "Ofrecer al país una institución de educación superior con fuerte impacto regional, procesos concertados de calidad y mejora continua, y una probada vocación de acompañamiento a las comunidades bajo el sello humanista cristiano de Santo Tomás de Aquino"337. De manera que por primera vez en la historia de la Universidad se llevó adelante un proceso de autoevaluación de manera coordinada entre sus diferentes sedes y seccionales. Así define el Informe de Autoevaluación 2014-2015 el modelo de gestión UsTa Colombia:

El aseguramiento de la calidad se expresa en un esfuerzo conjunto de sedes y seccionales con el propósito de identificar y articular intencionalidades, políticas, planes, programas, proyectos, estrategias y demás componentes del Modelo de Gestión Institucional, con el fin de promover el desarrollo de las funciones universitarias, atendiendo problemáticas nacionales y fortaleciendo el desarrollo de cada una de las sedes y seccionales en atención a las condiciones y requerimientos regionales ${ }^{33^{8}}$.

Tal como ha sido característico de la USTA a lo largo de los años, también la construcción de la USTA Colombia se adelantó teniendo en cuenta el contexto histórico. En este sentido, las posibilidades abiertas por las negociaciones de La Habana entre el Gobierno colombiano y las Fuerzas Armadas Revolucionarias de Colombia (FARC) influyeron en la direccionalidad institucional del periodo 2012-2015 en que se quiso contribuir, desde las capacidades y funciones substantivas propias del plantel, a la construcción de un país en paz ${ }^{339}$.

Más adelante, en 2015, el Consejo Nacional de Acreditación introdujo nuevos lineamientos para el proceso de acreditación como parte de un proceso progresivo a más largo plazo para ir elevando los requerimientos básicos. Entre los cambios más significativos de los lineamientos introducidos por el CNA se destacan un aumento al 25\% del mínimo de programas acreditables acreditados y la introducción de la evaluación multicampus, y no por sede: "En el caso de las instituciones de educación superior que tienen en su estructura sedes o seccionales, estas deben solicitar una acreditación institucional multicampus" ${ }^{34^{\circ}}$. Con esto, sedes, seccionales y centros regionales de educación superior - como los que tiene la USTA - en cualquiera de sus modalidades entran a ser evaluados. Además:
En las instituciones multicampus, el proceso de evaluación incluirá la forma como la institución funciona como sistema académico integrado, interacción sistemática que permita una visión holística y global de la IEs. La acreditación se otorgará con una temporalidad única que se aplica a toda la institución. El concepto del CNA será integral para toda actividad amparada con el nombre de la institución ${ }^{341}$.

Sorprende la gran coincidencia entre la filosofía multicampus del CNA introducida en $2015 \mathrm{y}$ el proyecto USTA Colombia que se venía trabajando desde el inicio de la rectoría de fray Carlos Mario Alzate Montes; ambas son visiones globales en las cuales las universidades son sistemas académicos integrados en un proyecto común ${ }^{342}$. Por ello, 2012-2015 fue un periodo de estandarización y unificación de políticas, indicadores y servicios, etc. ${ }^{343}$.

Para poder realizar el proyecto USTA Colombia y responder al desafío de la Acreditación Multicampus, se adelantaron procesos de autoevaluación con criterios comunes que abrieron la puerta a un mayor diálogo entre las unidades académico-administrativas a lo largo y ancho del país y entre sus diferentes modalidades. Además, en la Vicerrectoría Académica General se hicieron importantes ajustes a las unidades que habían sido creadas durante la rectoría de fray Eduardo González Gil y que coordinan la gestión curricular, la investigación, la proyección social, los posgrados y el aseguramiento de la calidad.

Así, la Unidad de Planeación Académica y Perfeccionamiento Docente se convirtió en Unidad de Desarrollo Curricular y Formación Docente ${ }^{344}$. La Unidad de Proyección Social y Extensión quedó convertida en Unidad de Proyección Social para enfocar los esfuerzos institucionales en la fortaleza histórica de la USTA que ha sido la proyección social ${ }^{345}$. La Unidad de Investigación y Posgrados que se había enfocado fundamentalmente en la investigación se escindió en Unidad de Investigación y Unidad de Posgrados en diciembre del $2012^{346}$. A partir de la antigua Oficina de Gestión Integral de la Calidad y la Unidad de Evaluación y Regulación Académica, se creó la Unidad de Gestión Integral de la Calidad Universitaria (Ugicu) ${ }^{347}$. Mediante la Ugicu se aglutinó en un solo organismo la coordinación de procesos de obtención de certificados Iso, del registro calificado y de la acreditación.

Finalmente, entre octubre del 2012 y junio del 2013 se creó la Unidad de Desarrollo Integral Estudiantil 


\section{5}

Madurez institucional 1995-20I8

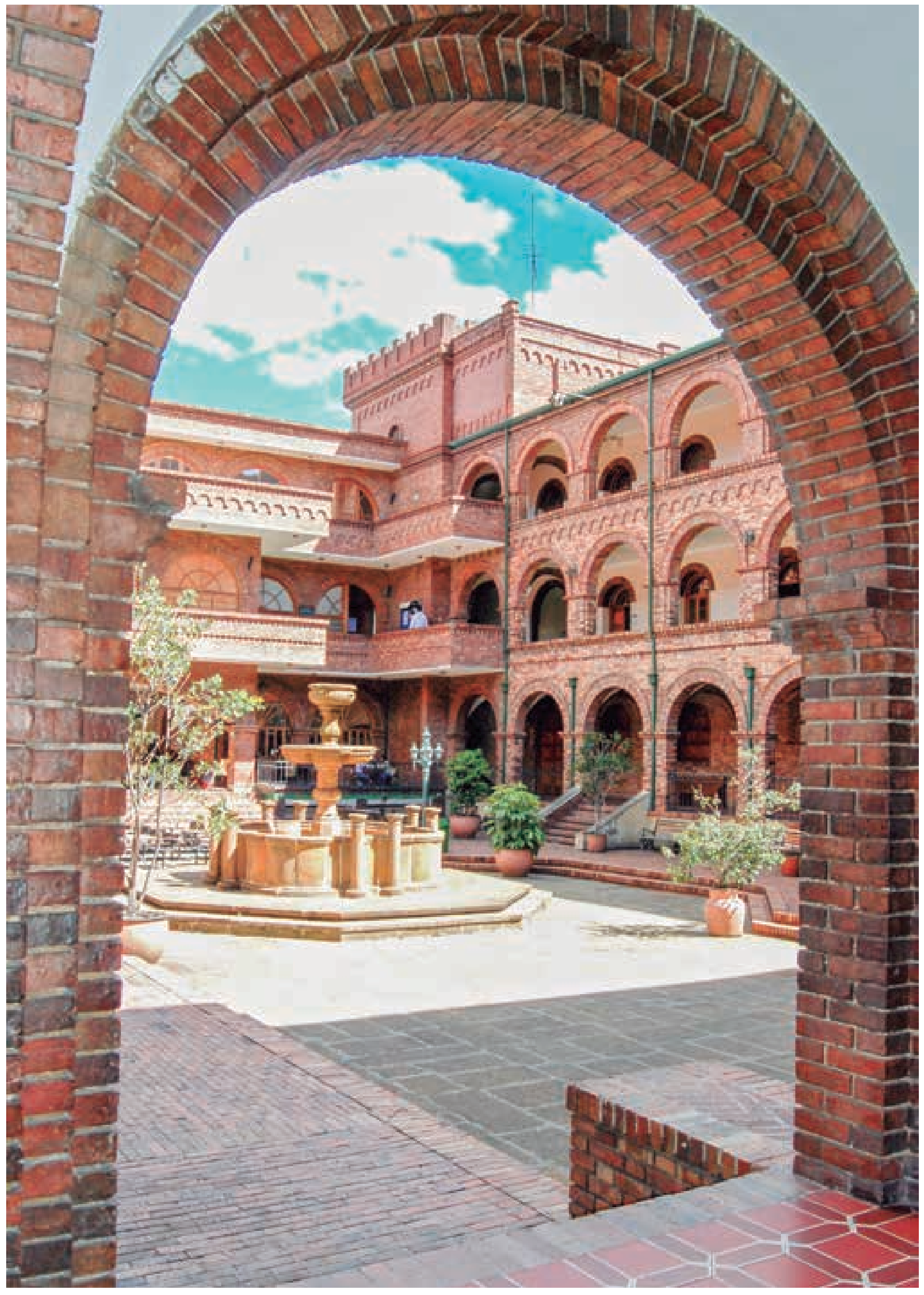

Claustro de la USTA con la réplica de la fuente del

Convento de Nuestra Señora del Rosario 


\section{6}

Madurez institucional 1995-2018

En el documento marco de proyección social del año 2015 se contemplan cinco líneas de acción ${ }^{353}$. La línea de desarrollo comunitario cobija consultorios jurídicos, contables, psicológicos, atención de optometría y odontología, prácticas sociales y empresariales, pasantías y extensión de cátedra. Los consultorios son espacios de interrelación de las tres funciones sustantivas de la Universidad, pues en ellos, al atender a las poblaciones vulnerables, los estudiantes aplican lo aprendido en clase y tienen oportunidad de conocer de primera mano la práctica de sus respectivas áreas.

En segundo lugar, mediante la línea de educación continua se pretende profundizar en temas especializados, actualizar en innovaciones de todo tipo, $\mathrm{ca}^{-}$ lificar en habilidades específicas, formar en torno a problemas concretos y capacitar en temas académicos; todo esto a través de talleres, seminarios, diplomados y cursos ofrecidos a la comunidad universitaria y a la comunidad en general.

La línea de emprendimiento, por otro lado, actúa mediante investigación, asesorías, cátedras, concursos y convocatorias. Los estudiantes también tienen la posibilidad de generar emprendimiento como parte orgánica de su programa de estudios a través de la opción de grado en programas como Cultura Física, Deporte y Recreación, Negocios Internacionales, Administración de Empresas, Comunicación Social e Ingeniería Mecánica ${ }^{354}$.

La cuarta línea es la política de egresados, que está conformada por cinco componentes: I) seguimiento y acompañamiento, 2) intermediación y promoción laboral, 3) desarrollo humano, profesional y

Posesión de fray Carlos Mario Alzate, O. P., como rector general, en julio 13 de 20II. Lo acompañan el prior provincial, fray Orlando Rueda Acevedo, O. P., y el saliente rector, fray José Antonio Balaguera, O. P.

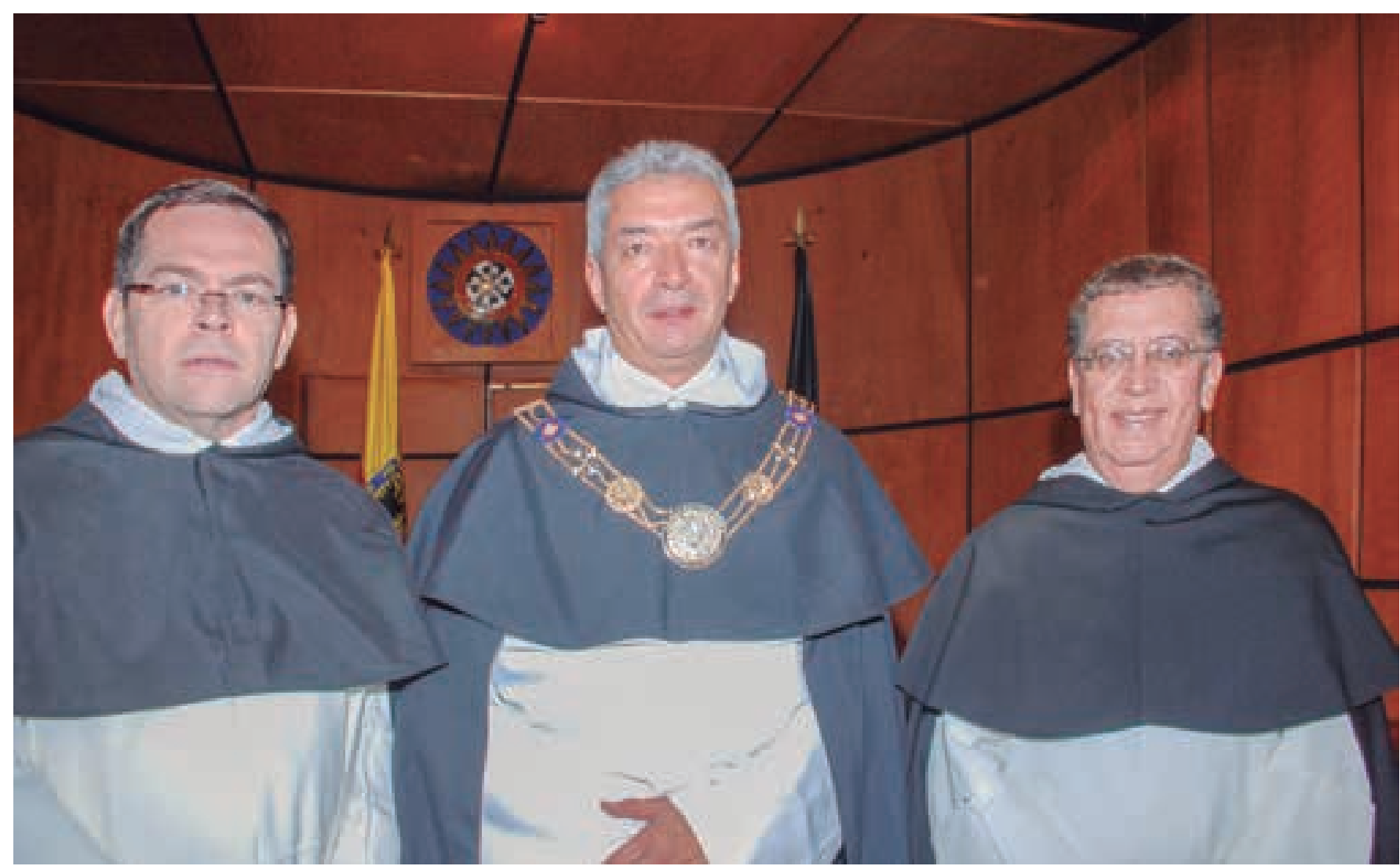




\section{7}

Madurez institucional 1995-2018

empresarial, 4) pertenencia y vinculación del egresado a la Universidad y 5) pertinencia e impacto del egresado tomasino. Como parte del proceso hacia la acreditación, durante la administración Alzate Montes se hicieron avances hacia una relación más estrecha con los egresados tomasinos. Así, desde 2012 se empezó a dar un descuento para los hijos de los egresados que se convirtió en el servicio de la Universidad con mayor demanda ${ }^{355}$. También desde 2012 se empezó a fortalecer el trabajo a nivel nacional de la Oficina de Egresados y se empezaron a unificar tanto las políticas como el portafolio de servicios para los egresados en el marco de USTA Colombia.

Finalmente, la línea de relaciones interinstitucionales se enfoca en alianzas y convenios con los sectores público y privado, mientras que la línea de asesorías y consultas se refiere a participación de la Universidad en licitaciones y oferta de servicios ${ }^{356}$. La concepción nacional de la USTA trajo nuevos vientos para las relaciones con el medio externo. Cada sede y seccional comenzó a contar con su propia Oficina de Relaciones Internacionales e Interinstitucionales ${ }^{357}$ y se trabajó para el establecimiento de convenios internacionales que llegaron a II7 en $2014^{35^{8}}$. Se abrieron 5 programas de doble titulación con planteles educativos de Francia, México y Medellín 359 . Además, el número de estudiantes salientes por intercambió subió de 94 en el año 2010 a 2 I4 en 2014 y en el mismo periodo se pasó de 4 a 98 docentes extranjeros en la USTA ${ }^{360}$. En este sentido, la Universidad aumentó sensiblemente la movilidad académica de estudiantes y profesores, así como la internacionalización de currículos ${ }^{36}$.

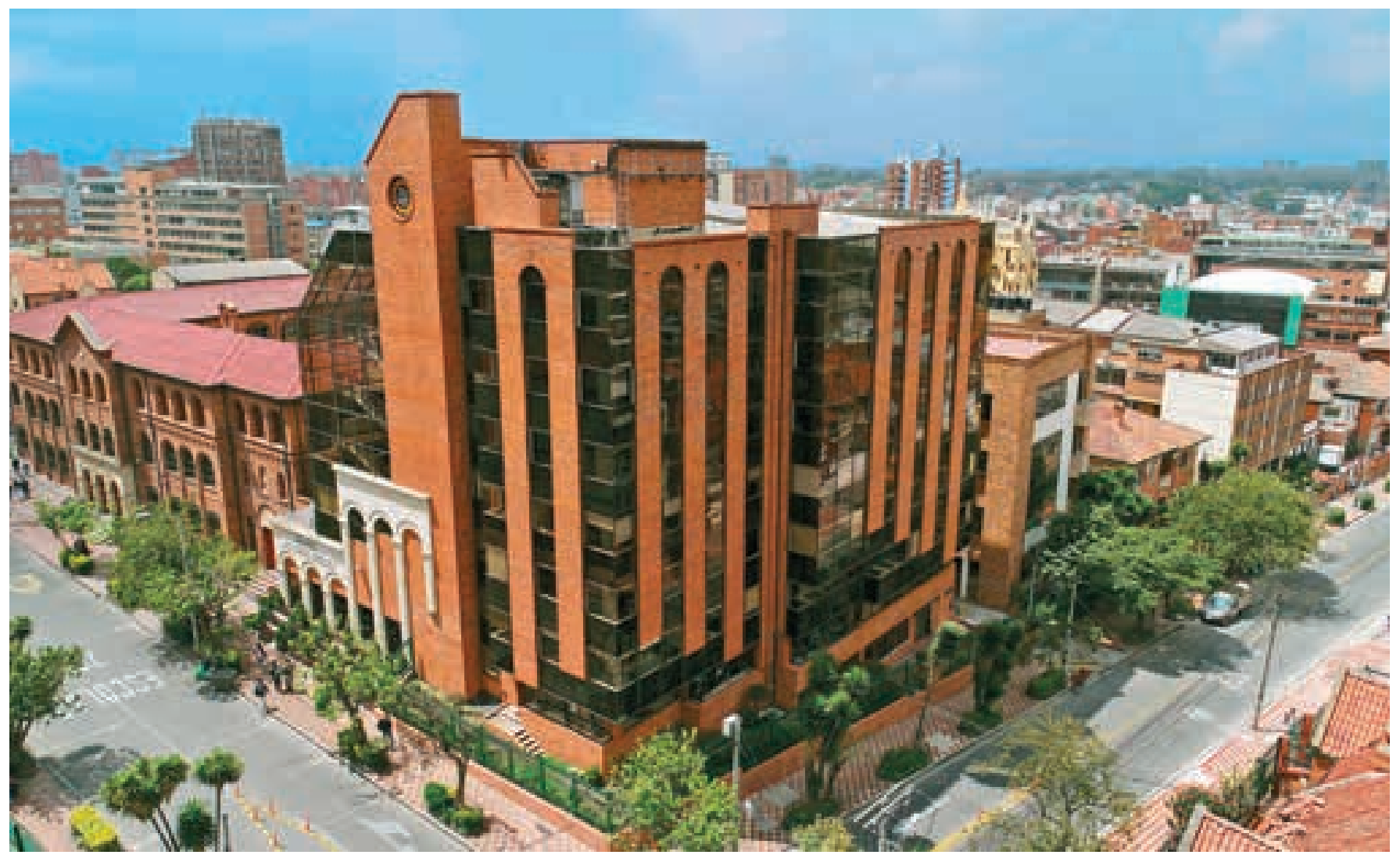




\section{8}

Madurez institucional 1995-20I8

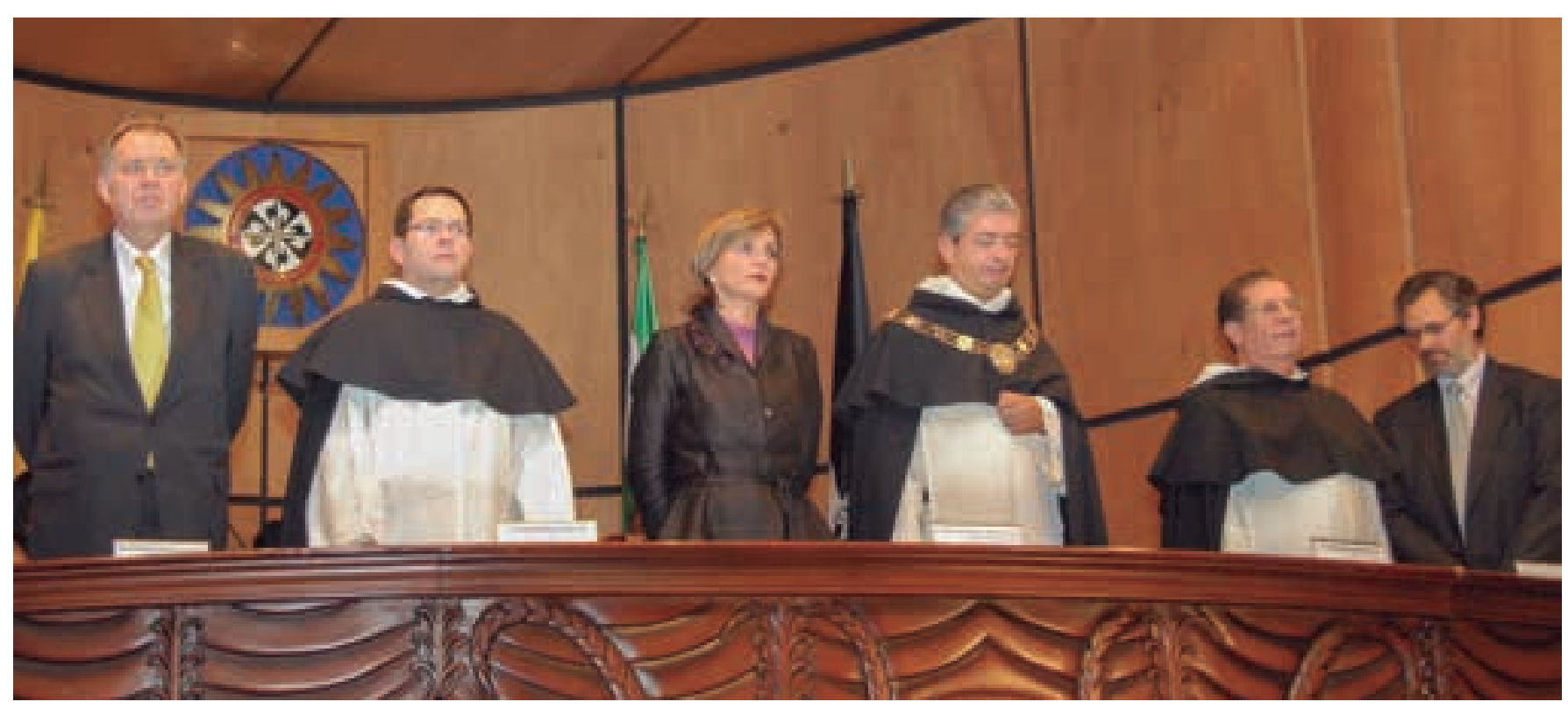

Entrega de Acreditación Institucional de Alta Calidad a cargo de la ministra de Educación María Fernanda Campo al rector fray Carlos Mario Alzate. Lo acompañan, de izquierda a derecha, el Dr. Alejandro Ordoñez, procurador general de la Nación, el prior provincial, el rector saliente y el secretario general de la USTA, el I7 de noviembre de $20 I I$

Ciertamente, en los últimos años se conformó progresivamente una proyección social tomasina multicampus. Un protagonista central de esta transformación ha sido la Mesa Nacional de Proyección Social, en que participan las unidades y oficinas de proyección social de todo el país y que ha servido para articular un proyecto común que se caracteriza por su pretensión de pertinencia en atención a las particularidades históricas y humanas del país y sus regiones.

Históricamente, la USTA ha hecho una apuesta muy clara por la paz, la reconciliación y la rehabilitación de las víctimas del conflicto colombiano. Ese compromiso se fortaleció desde la década de i99o con iniciativas como la creación de Comunicación Social para la Paz. En particular las áreas de Psicología, Derecho y Comunicación mantienen una importante tradición de trabajo en estos temas. Recientemente se han venido creando en las sedes y seccionales espacios transdisciplinarios en los que se realizan las tres funciones substantivas de la Universidad alrededor de un tema particularmente característico de la realidad colombiana como es el de las víctimas, la victimización, el conflicto y la violencia.

E1 Instituto de Victimología de Bucaramanga fue el pionero de este tipo de experiencias en la Universidad. E1 Instituto, que fue presentado oficialmente en marzo de 201 en el marco del II Congreso Internacional de Derecho Penal, Victimología y Ciencias Forenses organizado por la Facultad de Derecho de la Seccional ${ }^{362}$, desarrolla su acción en cuatro áreas: investigación, capacitación, difusión y gestión de observatorios.

Los dos observatorios que se han venido desarrollando, uno de la víctima y otro del delito, realizan 


\section{9}

Madurez institucional 1995-20I8

análisis cuantitativos y cualitativos del fenómeno de la criminalidad y de la victimización con miras a formular alternativas de política criminal ${ }^{363}$. El Instituto ha sido un activo ejecutor de las cátedras de paz en varias instituciones santandereanas de educación básica y media y ofrece gran variedad de servicios como asesorías, consultorías, cátedras virtuales, programas de extensión y educación continuada, además de la organización de foros, congresos y campañas cívicas ${ }^{364}$

La preocupación por las temáticas propias del contexto social colombiano se desarrolla así mismo en la Maestría en Reconciliación y Convivencia de la misma seccional, creada y aprobada a finales del año 2015. Este programa transdisciplinario se ocupa del tema de derechos humanos y victimología y, asî como el Instituto, tiene unos objetivos sociopolíticos muy concretos que giran en torno a la formulación, implementación y gestión de políticas para el desarrollo de alternativas al conflicto; todo esto ha sido pensado en el marco del proceso de paz de La Habana ${ }^{365}$. Por tanto el programa, que ya cuenta con registro calificado, está llamado a desempeñar un papel importante en el escenario del posconflicto colombiano, en el que se requerirá de la participación de la academia para el manejo de justicia restaurativa, entre otros temas ${ }^{366}$.

En Tunja, el Instituto de Victimología Fray Bartolomé de las Casas, O. P., adscrito a la Facultad de Derecho, empezó a funcionar en septiembre del 2014 y fue oficializado por Acuerdo del Consejo Superior el 15 de diciembre de ese año ${ }^{367}$. Para el lanzamiento se desarrollaron varias actividades culturales, artísticas y académicas y se contó con la presencia y participación de las Madres de Soacha. El Instituto, creado en el marco del Plan de Desarrollo de la Seccional del rector seccional Aldemar Valencia, O.P., investiga, promueve y desarrolla conocimiento sobre el fenómeno de la violencia y hace acompañamiento a las víctimas.

Las dos grandes líneas de acción social del Instituto son la atención psicológica y sociojurídica a víctimas (de conflictos sociales, violencia intrafamiliar, etc.). Por otro lado, el Instituto, fiel a su carácter universitario, desarrolla actividades académicas de investigación proyectadas hacia el diseño de estrategias para la protección de la dignidad humana y la resolución pacífica de conflictos; en esta línea de acción académica el Instituto articula su labor a la Maestría en Derechos Fundamentales y Derechos Humanos de la misma secciona ${ }^{368}$. A lo largo de sus dos años de vida, el Instituto ha llevado adelante una importante cantidad de acciones y actividades de todo tipo, consolidándose como un organismo de importante vitalidad en su seccional.

En Medellín, por otra parte y también en el marco de la proyección social multicampus, se cuenta con el Observatorio de Victimología, cuya creación fue aprobada el 23 de mayo de 2014 por el Consejo Directivo particular de la usta Medellín y que está adscrito al Consultorio Jurídico Fray Bartolomé de las Casas. El Observatorio asumió como misión una transformación integral en el campo de la victimología, así como la atención a víctimas a través de la academia, la investigación y la proyección social tanto para su dignificación como para la prevención.

El Observatorio cuenta con cuatro líneas de acción, a saber: I) estudio e investigación, 2) capacitación y promoción, 3) interacción y 4) atención a víctimas. Vale la pena mencionar que una de las particularidades del Observatorio de Medellín ha sido su atención a los problemas de la población penitenciaria de su región. A través de estos organismos y de la participación en redes de universidades, entidades privadas, públicas y $\mathrm{ONG}^{369}$, la USTA ha sido acompañante activa y generadora de debate a lo largo del proceso de paz de La Habana participando tempranamente en procesos sociales tendientes al establecimiento del posconflicto en Colombia y echando mano de una de sus fortalezas fundamentales, como es la presencia regional.

\section{Investigación, publicaciones, reorganización académica, tecnología, infraestructura y creci- miento académico}

Durante la rectoría de fray Carlos Mario la investigación tomasina siguió siendo problematizadora y dirigida hacia una relación cada vez más estrecha con la sociedad colombiana ${ }^{370}$. Así mismo, se incentivó una mayor articulación entre la investigación y la formación curricular; por ello, desde 2012 hubo un gran impulso a los semilleros y a la participación de estudiantes en la investigación bajo la modalidad "auxiliares de investigación" ${ }^{371}$. E1 número de semilleros así como de docentes y estudiantes vinculados a ellos aumentó en alrededor de un roo\% entre los años 2010 y $2014^{372}$.

Por otro lado, frente a la desaforada creación de líneas temáticas y la falta de conocimiento y coordinación entre diferentes unidades académicas que trabajaban temas comunes, desde 2012 en la Unidad de Investigación se hizo una labor de reconfiguración, 


\section{0}

Madurez institucional 1995-2018

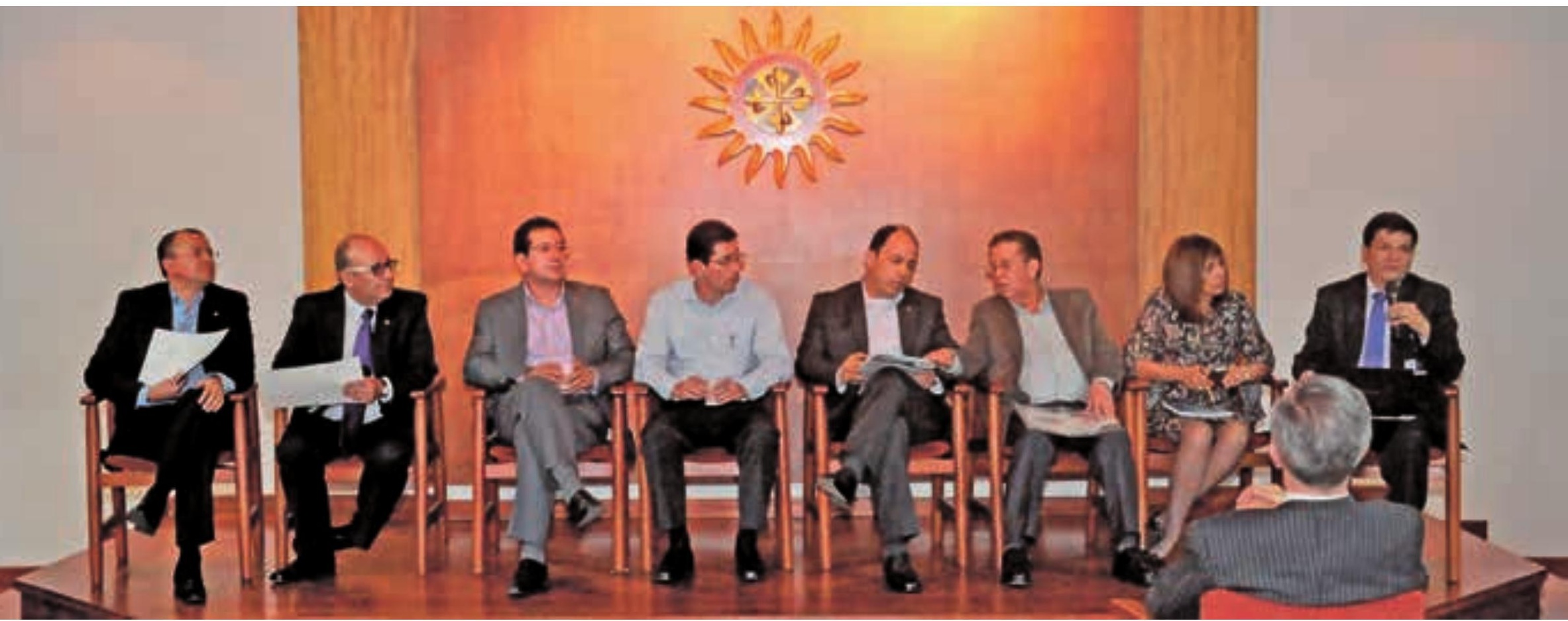

Directivas de la Universidad

diseñan los Planes de Desarrollo

2016-20I9

fusión y articulación de las líneas, centros y grupos de investigación. Es por ello que en la Sede Principal los grupos se redujeron de 73 en 201 a 6 I en 20I $4^{373}$. Las líneas activas también fueron reducidas y empezaron a cobijar a un mayor número relativo de grupos en un mayor rango de campos disciplinarios.

Las líneas medulares, sin embargo, aumentaron a dieciséis en el año $2014^{374}$, pues se crearon en los últimos años las líneas Domingo de Guzmán (estudios sociohistóricos), Bernardo de Lugo (idiomas) y Martín de Porres (salud y calidad de vida), que se sumaron a las previamente existentes. Por otro lado, el proyecto USTA Colombia y más adelante la visión multicampus permitieron el manejo de proyectos de mayor envergadura de tipo "intersedes" e "interseccionales" ${ }^{375}$. No obstante, no sobra aclarar que persisten en las diferentes sedes y seccionales concepciones y enfoques regionales de investigación, lo cual aplica también para las otras funciones sustantivas de la USTA.

En cuanto a la producción editorial, esta vivió una importante transformación en los últimos años. En el año 2012 el Departamento de Publicaciones se transformó en Departamento Editorial eliminándose la imprenta y enfocándose el trabajo en el establecimiento del sello editorial Ediciones Usta. E1 Acuerdo I4 del 29 de julio de 2013 estableció funciones y condiciones institucionales del Departamento que también responde al Reglamento Editorial publicado ese mismo año. 
Es por ello que desde ese año Ediciones usta viene atravesando una profunda transformación tendiente a profesionalizar el proceso de edición y publicación de materiales científicos y académicos. También vale la pena destacar que desde el año 2014 la USTA empezó a hacer presencia en la Feria Internacional del Libro de Guadalajara, la más importante de su tipo en habla hispana.

Otras políticas de la rectoría de fray Carlos Mario incluyen el fomento de la virtualización y el fortalecimiento tecnológico mediante la creación, en el segundo semestre de 2012, de la Oficina de Educación Virtual como estrategia para fortalecer procesos de enseñanza y aprendizaje por medio de las tecnologías de la información y la comunicación (TIC). En lo que se refiere a la organización académica, las divisiones de Teología y Filosofía se fusionaron en la División de Filosofía y Teología; también, a partir de la antigua División de Ciencias Humanas, se creó la División de Ciencias Jurídicas y Políticas ${ }^{376}$. En el plano de la infraestructura física, la Biblioteca Luis J. Torres fue modernizada y se hicieron remodelaciones en varias locaciones. Además, en agosto de 2013 se inauguró el nuevo edificio Doctor Angélico, en la carrera novena con calle 73 , cuyas obras habían sido iniciadas durante la rectoría de fray José Antonio Balaguera.

Al final de la rectoría Alzate Montes, la UsTA Colombia contaba con 185 programas, 85 de pregrado y roo de posgrado 377 . La Sede Bogotá contaba con 2I programas de pregrado y 39 de posgrado de los cuales 18 eran especializaciones (una de ellas en modalidad a distancia), i9 de maestría y 2 de doctorado ${ }^{37^{8}}$. Muchos de estos programas habían sido acreditados entre el $201 \mathrm{I}$ y el 20I3, y aun otros estaban en proceso de acreditación. Los más nuevos, como Teología e Ingeniería Industrial, estaban aún en proceso de verificación de condiciones iniciales para el proceso de acreditación ${ }^{379}$. En cuanto a la distribución de los programas de acuerdo con el área de conocimiento, había uno en Bellas Artes, uno en Ciencias de la Educación, uno en Matemática y Ciencias Naturales, dos en Ciencias de la Salud, i en Ingeniería, Arquitectura, Urbanismo y afines, 20 en Economía, Administración, Contaduría y afines, y 24 en Ciencias Sociales, Derecho y Ciencias Políticas ${ }^{380}$

\section{Sedes y seccionales}

Durante la rectoría de fray Carlos Mario Alzate Montes, sedes, seccionales y VUAD llegaron a un nivel de unificación de criterios y de coordinación de sus lineamientos básicos que permite hablar de una USTA Colombia. A esto se llegó principalmente mediante el proceso de autoevaluación coordinada con fines de acreditación multicampus. No obstante, la presencia regional de la USTA está así mismo marcada por la pertinencia local y la consciencia de la diversidad sociocultural de nuestro país.

En el periodo 20I2-20I5 en la VUAD se trabajó, entre otras cosas, en el fortalecimiento de los grupos de investigación, su articulación con docencia y proyección social, así como en la extensión y fortalecimiento de los servicios de bienestar y de los convenios interinstitucionales, internacionales, redes y

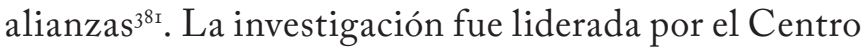
de Investigación, apoyado a su vez en comités de las dos facultades. Durante el cuatrienio se trabajaron en la VUAD 3 campos interdisciplinares y 6 líneas de investigación en grupos de investigación de cantidad variable, que para el año 2013 eran $29^{382}$. Por otro lado, en el año 2014 se creó la oficina de Proyección Social, que permitió la convergencia de las iniciativas sociales institucionales a través de seis estrategias: I) educación continua, 2) internacionalización, 3) desarollo comunitario, 4) apoyo a egresados, 5) emprendimiento y 6) convenios y consultorías ${ }^{383}$.

En 2014 la VUAD contaba con centros de Atención Universitaria en 24 ciudades y ofrecía 3I programas académicos, 23 de pregrado y 8 de posgrado. De los 23 de pregrado, 4 eran programas de tecnología y i9 profesionales. De los 8 de posgrado, 6 eran especializaciones, uno de maestría y uno de doctorado, este último en modalidad presencial. La mayor densidad estudiantil se presentaba en los CAU de Bogotá, Bucaramanga, Medellín, Villavicencio, Tunja y Valledupar ${ }^{384}$.

La gran fortaleza de la VUAD, un rasgo característico de su identidad pedagógica desde hace muchos años, sigue siendo el área de la educación, en donde se ubican I6 de los 3I programas académicos; el resto de los programas se ubican en el área de economía, administración, contaduría y afines (6), ingeniería, arquitectura, urbanismo y afines (5), agronomía veterinaria y afines (2) y ciencias sociales, derecho y ciencias

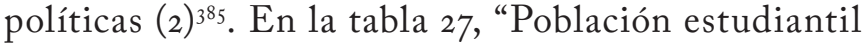
VUAD 2009-II a 20I4-II”, se aprecia la estabilidad a que se ha llegado en la población estudiantil de la VUAD.

En los últimos seis años, Bucaramanga tuvo dos planes de desarrollo seccionales. En el Plan 20Io-20I3, que ya inaugura cierta articulación al Plan General de Desarrollo, se continuó con la política de aseguramiento 


\section{Históricamente, la USTA ha hecho}

una apuesta muy clara por la paz, la reconciliación y la rehabilitación de las víctimas del conflicto colombiano. Ese compromiso se fortaleció desde la década de 1990 con iniciativas como la creación de la Facultad de Comunicación Social para la Paz. de la calidad, la cualificación humana, el fortalecimiento académico, el posicionamiento nacional e internacional y la optimización de la gestión administrativa; además de estos factores, se trabajó específicamente en el fortalecimiento de la investigación y el desarrollo físico y tecnológico ${ }^{386}$. En el año 2012, se inauguró el Coliseo Sol de Aquino en el Campus de Piedecuesta y se lanzaron cinco programas de maestría. E1 año siguiente, la Seccional celebró sus cuarenta años de actividad, por lo cual fue reconocida y condecorada por la nación, el departamento de Santander y la ciudad de Bucaramanga.

E1 Plan 2013-2016 consolida su articulación al Plan General de la UsTA Colombia y por ello trabaja a partir de los mismos ejes estratégicos. Durante este periodo se llevaron adelante modificaciones de reglamentos particulares de sus facultades ${ }^{387}$, se creó el Departamento de Ciencias Básicas que ofrece educación interfacultativa, se extendieron desde Bogotá los programas de Ingeniería Ambiental e Ingeniería Civil y se creó la Maestría en Odontología. Así mismo, la Seccional se redefinió en cinco campus: Bucaramanga, Floridablanca, Piedecuesta, E1 Limonal y el Campus Virtual.

En 2015 se llegó a una oferta académica de I7 pregrados, 23 especializaciones y 9 maestrías $^{388}$. Ese año la Seccional contaba con 22 grupos de investigación avalados institucionalmente divididos entre sus varias facultades, además de 32 semilleros en los cuales participaron unos 300 estudiantes entre 2012 y $2014^{389}$. En la tabla 26, "Población pregrado UsTA Bucaramanga 2009-I a 20I4-I", se puede apreciar el comportamiento estable de la población estudiantil.

Durante estos últimos años, bajo la rectoría de fray Samuel Elías Forero Buitrago, O. P. (2014-2016), ha sido preocupación constante la proyección social como el desarrollo de acciones interdisciplinarias encaminadas a la solución de los problemas sociales ${ }^{390}$. En este sentido, se han adelantado diversos proyectos como atención a sectores marginados del área metropolitana de Bucaramanga y un trabajo junto con la Unidad para la Atención y Reparación Integral a las Víctimas para el apoyo a la Asociación de Trabajadores Campesinos del Carare (ATCC), entre otros ${ }^{39}$.

En los años 2010-2012 Tunja fortaleció su interacción con el medio, Bienestar Universitario, infraestructura física y tecnológica, además se crearon los primeros programas de especialización $\operatorname{propios}^{392}$. En 


\section{3}

Madurez institucional 1995-20I8

los últimos años, la Seccional ha hecho una apuesta curricular e investigativa por temas medioambientales, de identidad departamental, paz, conflicto y familia ${ }^{393}$. La proyección social ha tenido un desarrollo importante; en los años 2013-2015 se consolidó el Centro de Proyección Social del barrio Altamira, se desarrolló el programa Construyendo Tejido Social en varios sectores y municipios de Boyacá y surgió el Instituto de Victimología, ya mencionado 394 . La inclinación por los temas de la paz y la reconciliación siguen vigentes hoy en día. Así, en el segundo semestre del 2016 se llevó a cabo el Diplomado en Reconciliación y Paz en la Seccional ${ }^{395}$

Para el año 2015 Tunja ofrecía y desarrollaba dos tecnologías, dos programas técnicos, diez pregrados, ocho especializaciones, siete maestrías y dos doctorados (uno de ellos en convenio con quince universidades iberoamericanas y la Universidad de la Coruña, España) ${ }^{396}$. Además, contaba con seis grupos de investigación registrados en Colciencias y cinco revistas científicas reconocidas ${ }^{397}$. En la tabla 28, "Población estudiantil pregrado USTA Tunja 2009-2 a 20I4-I”, se puede apreciar el comportamiento de la población estudiantil en los últimos años.

Mientras tanto, en Medellín, con la decanatura de fray Alberto Orozco Arcila, O.P., se crearon las direcciones académica y administrativa-financiera de la Sede, la Unidad de Investigación, la ORII y otras dependencias encargadas de la coordinación de aspectos como egresados, currículo, autoevaluación, admisiones, talento humano y registro y control. A su vez, se amplió la oferta de servicios de proyección social con la creación del mencionado Observatorio de Victimología, del consultorio contable y de la unidad de proyectos estudiantiles ${ }^{398}$.

En 2015, la Usta Medellín mantuvo sus cinco programas de pregrado: Arquitectura, Derecho, Ingeniería de Telecomunicaciones, Negocios Internacionales y Contaduría Pública, además de cinco especializaciones $^{399}$. Así mismo contaba con tres grupos de investigación consolidados, reconocidos por Colciencias, y uno más en formación. Para la evolución de la población estudiantil en la UsTA Medellín durante estos años, véase la tabla 23, "Población estudiantil de pregrado, Sede Medellín 2009-2 a 2014-I”.

Finalmente, en los últimos años la Sede Villavicencio ha continuado su crecimiento académico, lo que evidencia el entusiasmo propio de una sede joven. En $201 \mathrm{I}$ se aprobaron nuevas extensiones: Ingeniería Ambiental, Psicología e Ingeniería Civil; las dos primeras comenzaron en el segundo semestre de 2012, coincidiendo con las primeras graduaciones de la Sede. En el primer semestre de 2013 entraron en actividades Ingeniería Civily la Especialización en Derecho Administrativo ${ }^{400}$. También ese año fue aprobado el Centro de Conciliación del Consultorio Jurídico. En su infraestructura física, Villavicencio ha vivido un proceso importante de expansión. En 2012 se había empezado a construir el Campus Aguas Claras y en 20I3 se hizo el traslado a la nueva sede. La inauguración del nuevo campus fue el 7 de marzo de ese año.

Por otro lado, en febrero de 201 s se creó en Villavicencio la Unidad de Investigación "como unidad gestora y administrativa de la investigación formativa a partir de la cual confluyen los esfuerzos académicos y administrativos que contribuyen al fortalecimiento de la cultura investigativa"4or. La creación de la Unidad sirvió para apoyar los incipientes esfuerzos investigativos de la Sede que comenzaron en 2010 con el nacimiento del primer grupo de investigación; en $201 \mathrm{I}$ se crearon otros tres y entre $2012 \mathrm{y}$ 20I4 Villavicencio creció en grupos de investigación a razón de dos por año. Así, al finalizar 20I4 había diez grupos de investigación activos que trabajaban dieciocho líneas activas vinculadas a cuatro líneas medulares ${ }^{402}$.

Para 20I5 la Sede tenía siete programas de pregrado (Derecho, Administración de Empresas Agropecuarias, Negocios Internacionales, Contaduría Pública, Psicología, Ingeniería Ambiental e Ingeniería Civil), cinco extendidos por Bogotá y dos por Bucaramanga, además de dos programas de posgrado, la Especialización en Derecho Administrativo y la Especialización en Gerencia Empresarial403. En la tabla 29, "Población estudiantil Villavicencio programas de pregrado 2009I a 20I4-I", y en la gráfica 6, "Población estudiantil Villavicencio programas de pregrado 2009-I 20I4-I", se aprecia cómo, en contraste con la estabilidad en el resto de sedes y seccionales, en Villavicencio el crecimiento de la población sigue siendo exponencial. En 2015 la Sede tenía 2823 estudiantes de pregrado, Io6 de posgrado y 234 profesores ${ }^{404}$.

En el segundo semestre de 20I5, USTA Colombia contaba con 8I programas de pregrado, Io4 de posgrado, 32535 estudiantes, 266I docentes, 54 grupos de investigación y 276 convenios nacionales e internacionales. 


\section{4}

Madurez institucional 1995-2018

\section{FRAY JUAN UBALDO LÓPEZ SALAMANCA, O. P., RECTOR GENERAL 2015-2019}

En julio del año 2015 el Consejo de Fundadores nombró a fray Juan Ubaldo López Salamanca, O. P., séptimo rector general de la USTA para el periodo 2015-2019. Fray Juan Ubaldo ingresó a la Orden en el año 2000 y tomó el hábito un año después. Hizo profesión religiosa el 2 de febrero del 2002 , que fue confirmada solemnemente en el 2006. El año siguiente fue ordenado sacerdote.

El fray Juan Ubaldo López Salamanca es contador público por la Universidad Jorge Tadeo Lozano, bachiller en Teología por la Pontificia Universidad Bolivariana de Medellín y licenciado en Filosofía con énfasis en Pensamiento Político y Económico por la Universidad Santo Tomás, además es magíster en Pedagogía por la UsTA Tunja ${ }^{405}$.

En la Provincia de San Luis Bertrán, fray Juan Ubaldo ha sido prior del Convento Santo Domingo de Tunja, maestro de prenovicios y misionero en Aruba, entre otros; al momento de su nombramiento como rector, se desempeñaba como síndico de la Provincia ${ }^{406}$. En la Universidad Santo Tomás ha sido docente de Humanidades y miembro del Centro de Investigaciones Louis Joseph Lebret en la línea de Desarrollo Humano, Humanismo y Educación; allí contribuyó al diseño de la Cátedra Lebret en 2004 y en 2010 publicó como coautor el libro Economía y humanismo, actualidad de una propuesta dominicana ${ }^{407}$. Entre 2007 y 2008 se desempeñó como director administrativo-financiero de la Sede Villavicencio y en octubre del 2012 fue nombrado decano de la División de Ciencias Administrativas y Contables en la Seccional Tunja ${ }^{408}$. El i7 de julio de 2015 , en su discurso de posesión, fray Juan Ubaldo López, evocando las tareas específicas e ineludibles de la Universidad, según Santo Tomás, afirmó:

La primera tarea consiste en situarse en la cima del proceso cultural, lo que se ha llamado "altura de los tiempos”. La universidad tiene que ser el lugar de la tradición cultural y de la memoria del pasado, por ello se impone el diálogo con todos los que nos han precedido. La tarea primordial de la universidad consiste en la memoria viviente de la tradición cultural.

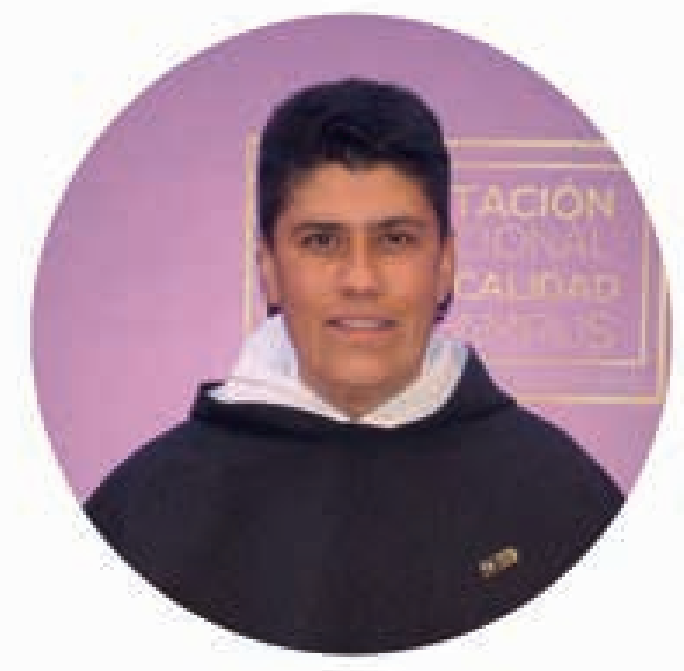

Fray Said León Amaya, O. P., prior provincial durante el periodo 20I4-20I8

La segunda tarea está en la transmisión de la verdad en el presente. Si la vida universitaria desde la anterior perspectiva podría parecer mera arqueología, desde esta nueva dimensión, que es su complemento, requiere la novedad. Para nuestro hermano Chenu, dominico de mediados del siglo pasado, Tomás era un constructor de una nueva cultura; Tomás nunca fue un mero repetidor, fue siempre un creador, innovador. Por ello, la tarea universitaria es la aproximación a la verdad. La universidad tiene que ser el lugar del diálogo y de la investigación.

La tercera tarea está orientada hacia el futuro. La universidad está llamada a ser un lugar de la forja integral del hombre en todas sus dimensiones, donde se debe hacer posible el futuro más racional de la humanidad. La universidad no puede dejar de lado esta dimensión del futuro del hombre que ya ha comenzado y todavía no se ha consumado. Tomás ha querido ser en los primeros años de vida universitaria un arquitecto de la Universidad, abierta a las tres dimensiones esenciales del servicio al hombre: conserva, vivifica y proyecta la capacidad racional del ser humano ${ }^{409}$.

En el mismo discurso, fray Juan Ubaldo señala siete desafíos para la modernización deseada en docencia, investigación, movilidad y transferencia: 


\section{5}

Madurez institucional 1995-20I8

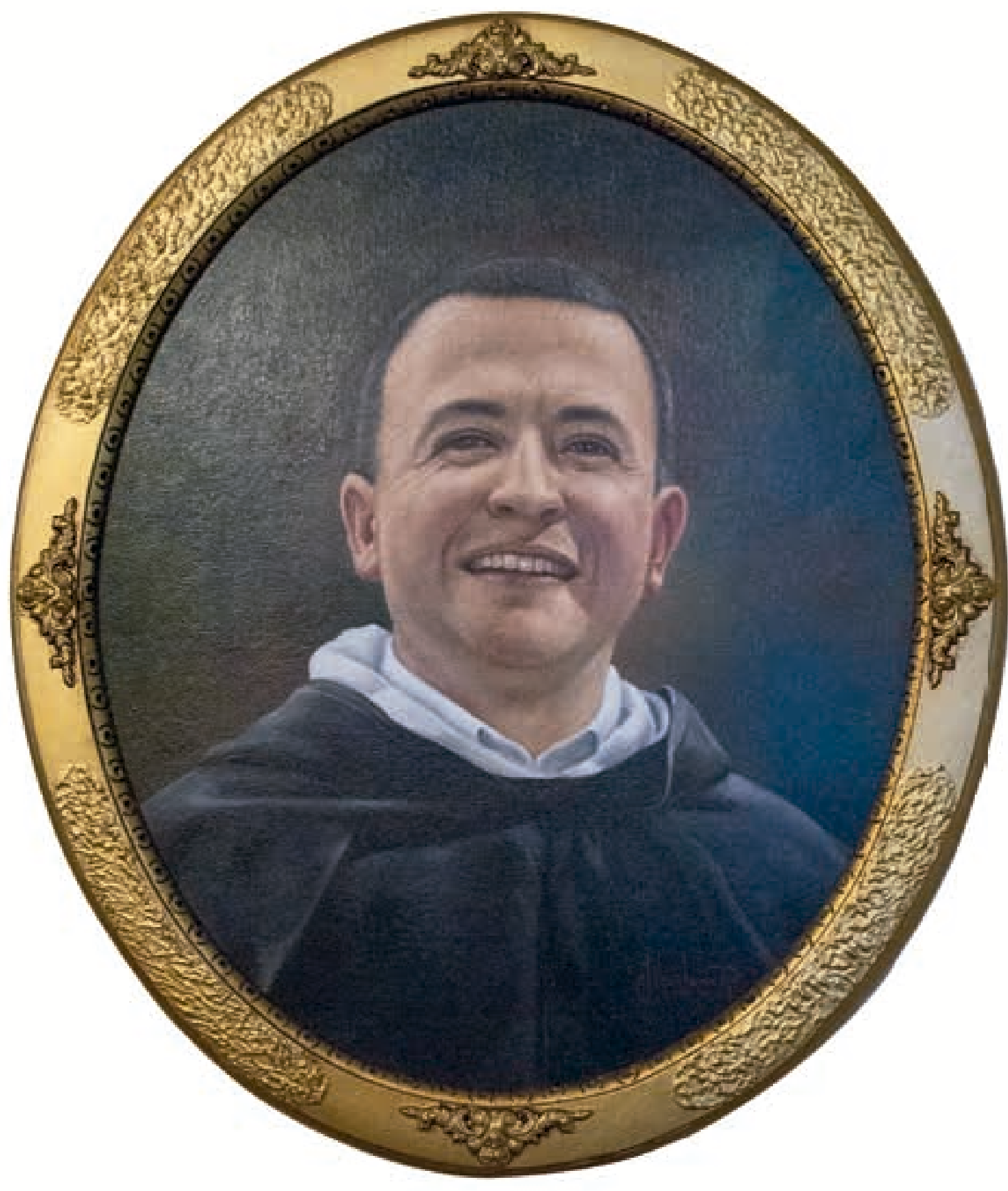

Fray Juan Ubaldo López Salamanca, O.P.,

rector general 2015-2019 


\section{6}

Madurez institucional 1995-20I8

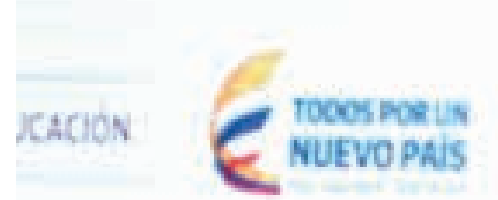

Entrega de la Orden a la Acreditación Institucional de Alta Calidad de la Educación Superior Francisco José de Caldas a fray Juan Ubaldo López, O.P., por parte de la Dra. Yaneth Giha Tovar, ministra de Educación

El primer desafío: asumir con responsabilidad las políticas públicas que nos permitan gestionar los procesos de calidad y la implementación de sistemas de certificación que cada vez más exigen.

El segundo desafío: nuestros docentes, el personal directivo, administrativo y de servicios generales. [Es decir] el apoyo para la formación avanzada en programas nacionales e internacionales, que posibiliten en ascenso del ser humano.

El tercer desafío: nuestros egresados y el impacto en el entorno nacional e internacional.

El cuarto desafío: nuestro fortalecimiento en la investigación a través de la participación en redes de cooperación y la movilidad, además de los sistemas abiertos de gestión de conocimiento.

El quinto desafío: la internacionalización a través de la estructuración de una política que permita consolidar el bilingüismo y el multilingüismo, la cooperación, la cultura de la internacionalización universitaria y la promoción de Colombia como destino de educación superior.

E1 sexto desafío: nuestra gestión académica y administrativa. La búsqueda de un sano equilibrio, de armonía y cohesión en cada uno de los procesos en los que medie la responsabilidad y sistematicidad que facilite el intercambio de información con docentes, estudiantes, administrativos y directivos.

Y el último: la armonización, la cohesión y la sinergia de los documentos legislativos que rigen las políticas de la Universidad. Los lineamientos que el Capítulo Provincial de los dominicos en Colombia, celebrado en el mes de noviembre, nos dan las pautas y los criterios para animar la acreditación institucional y prepararnos para el próximo cuatrienio en la construcción de un Plan General de Desarrollo que lance a la Universidad, que la arriesgue y que permita ser líder en la formación de cada uno de los seres que se nos han confiado ${ }^{4 \mathrm{I}}$.

A la llegada de fray Ubaldo a la rectoría la Universidad contaba con 32535 estudiantes; entre ellos, 254 eran beneficiados del programa del Gobierno Nacional Ser 


\section{Iglesia del Convento Santo Domingo, faro}

espiritual de la Provincia de San Luis

Bertrán

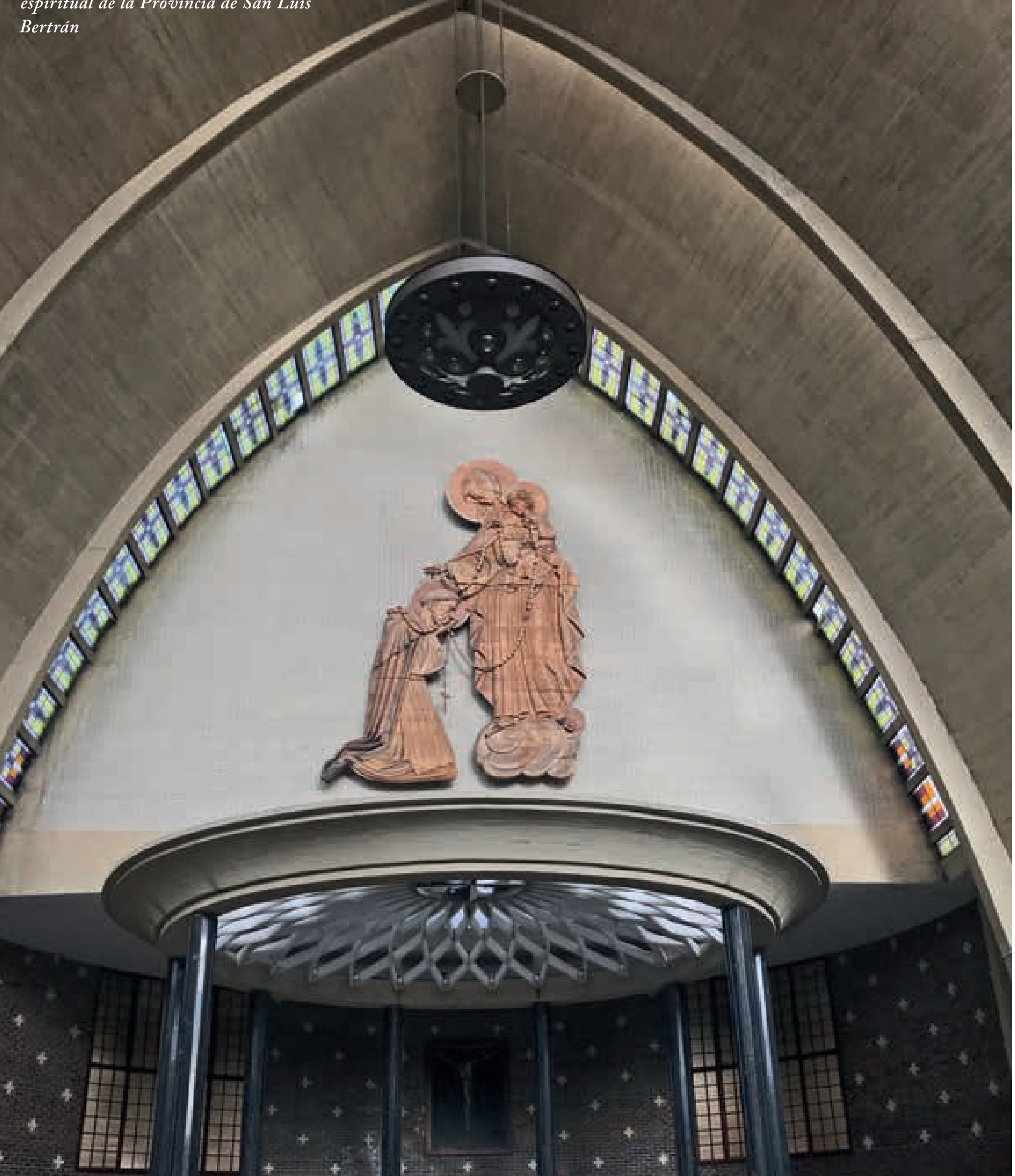

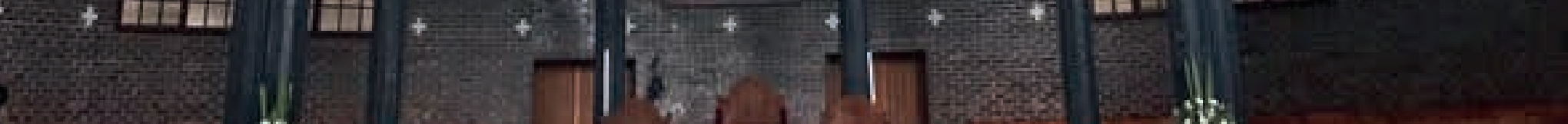

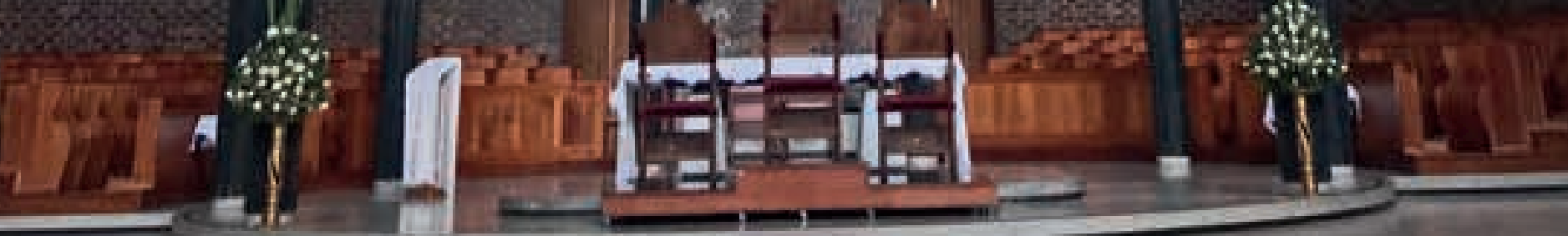




\section{9}

Madurez institucional 1995-2018

\section{USTA Multicampus}

En términos globales, durante el último cambio de rectoría la Universidad pasaba por un proceso de transformación denominado USTA Colombia que apuntaba hacia una mayor articulación orgánica entre sedes y seccionales. Desde entonces el proceso se ha intensificado y ha pasado a denominarse USTA Multicampus. El 29 de enero de 20I6, y como culminación de un proceso de cuatro años, el plantel se convirtió en la primera universidad privada con presencia nacional en obtener del Ministerio de Educación Nacional la Acreditación Institucional de Alta Calidad Multicampus, que le fue otorgada por seis años. La acreditación cubre las sedes de Bogotá, Medellín y Villavicencio, las seccionales de Tunja y Bucaramanga y los más de veinte CAU de la Universidad Abierta y a Distancia.

En la resolución de Acreditación, el Ministerio de Educación Nacional destacó la creciente articulación interinstitucional, las notables mejoras en infraestructura, internacionalización y modelo gerencial, así como el compromiso con la calidad y la autoevaluación, el carácter humanista de la USTA, el impacto de la proyección social, entre otros factores, que llevaron a conceder la acreditación ${ }^{42}$.

E1 Modelo de Universidad que hace de la docencia y la investigación medios al servicio de la sociedad y se orienta como una institución ante todo humanista. La Institución demuestra coherencia entre su naturaleza, tradición, principios y objetivos y sus desarrollos misionales [...].

La proyección social, como intención final de la docencia y la investigación, a través de diversos proyectos en las líneas de: el desarrollo comunitario, educación continua, emprendimiento, asesorías, consultorías y relaciones interinstitucionales. La Universidad participa en diferentes redes y organizaciones del sector público y privado e instituciones encargadas de la construcción de políticas públicas. Se resaltan las diversas acciones, programas e investigaciones en los temas de violencia, conflicto y posconflicto, desplazamiento forzado, paz y convivencia, diversidad e inclusión social, derechos humanos y deterioro ambiental con el concurso interdisciplinario de los programas académicos. ${ }^{43}$

Las instituciones de educación superior multicampus, según el Consejo Nacional de Acreditación, son aquellas que tienen estructura de sedes y seccionales; para ellas, el proceso de acreditación incluye necesariamente la evaluación sobre su funcionamiento como sistema integrado y sus interacciones sistémicas que permitan una visión global. Una vez concedida la acreditación, esta aplica para todas las sedes y seccionales cobijadas por la institución ${ }^{414}$.

La Acreditación Multicampus es el corolario de veinte años de un esfuerzo institucional sostenido hacia la sincronización de los procesos administrativos, la institucionalización de la planificación y la organicidad académica. Así mismo, fue resultado de procesos de alta calidad que involucraron la participación de amplios segmentos de la Universidad a lo largo y ancho del país a través de comités nacionales de calidad ${ }^{45}$. Por supuesto que los pares académicos hicieron algunas recomendaciones importantes que vienen siendo abordadas desde entonces ${ }^{416}$.

Vale la pena destacar que hasta el año 2015 la política institucional en la USTA se daba principalmente a través de los planes generales de desarrollo de los rectores generales y de planes específicos para las sedes, seccionales y la VUAD. Si bien ya en el Plan General de Desarrollo 2012-2015 de fray Carlos Mario Alzate Montes había una clara orientación hacia la unificación, con el tiempo se introdujeron variantes para sedes y seccionales ${ }^{47}$. Empero, por cuenta de la Acreditación Multicampus, la Universidad ha redireccionado sus procesos para culminar cabalmente la realidad multicampus generando un nuevo tipo de planeación estratégica sincronizada que se estructura en tres niveles.

En un primer nivel está el Plan Integral Multicampus 2016-2027 (PIM). En el segundo, el Plan General de Desarrollo (PGD) 20I6-20I9 que corresponde al actual periodo rectoral y por tanto a las acciones proyectadas para el primer tercio del PIM. Como es obvio, habrá sendos planes generales de desarrollo para las siguientes rectorías. En el tercer nivel, los Planes de Desarrollo (PD) de las sedes y seccionales y la VUAD, 20I6-20I9 para todos, apuntan a la aplicación específica de los objetivos del PGD.

Los planes fueron construidos a partir de un diagnóstico situacional en el que se incluyeron elementos de la autoevaluación con fines de acreditación y de la evaluación de pares, entre otros; dicho diagnóstico se construyó en los meses de enero y febrero de 2016. Después, entre febrero y marzo se avanzó a un consenso estratégico con la participación de directivos y expertos. Finalmente, se procedió a la elaboración de los planes comenzando por el PIM en abril y siguiendo con el PGD y los PD entre mayo y septiembre ${ }^{418}$. 


\section{0}

Madurez institucional 1995-2018

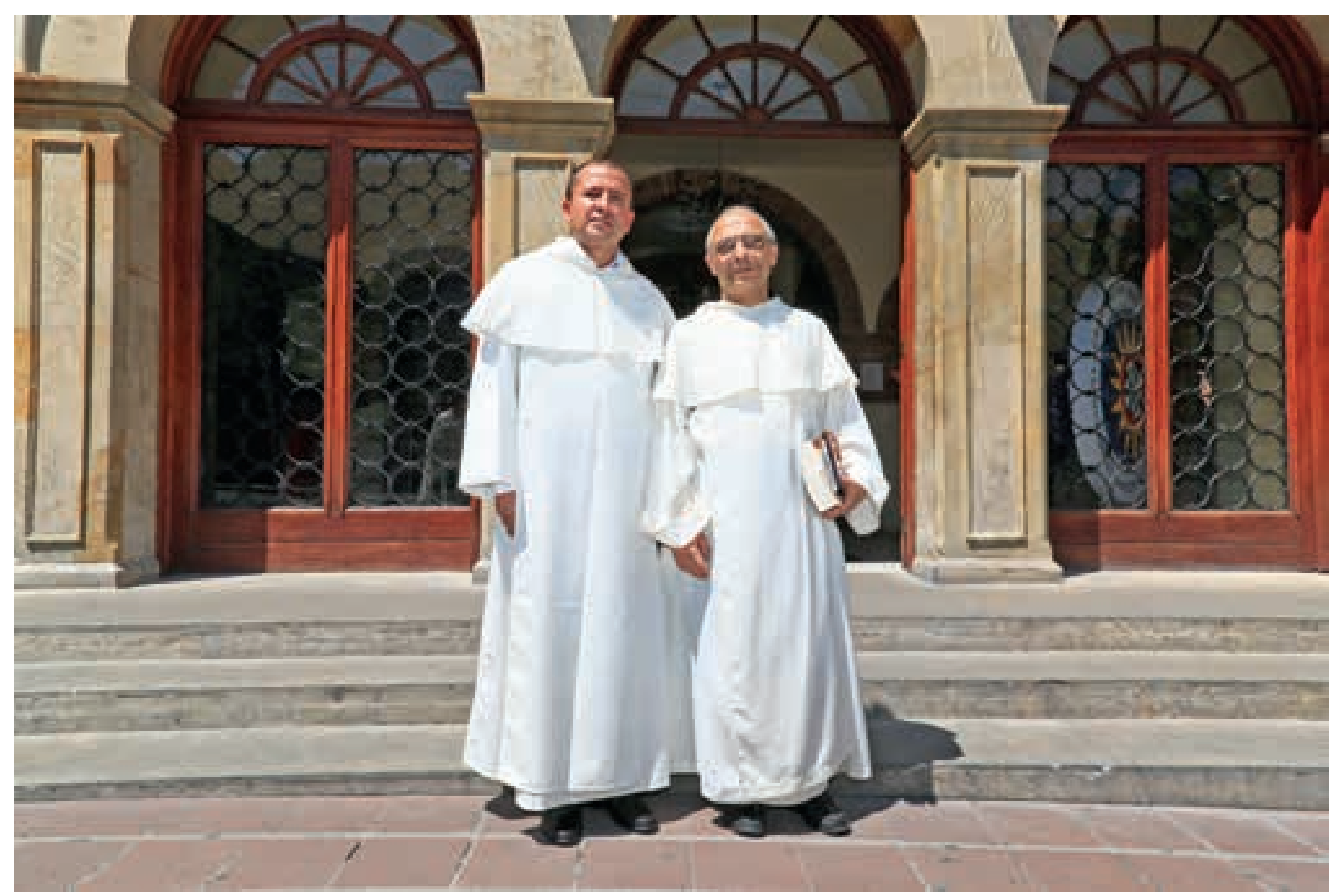

Eucaristía en Bogotá con motivo de la visita del maestro de la Orden, fray

Bruno Cadoré, O. P., en el Convento Santo Domingo en enero de 20I6, y

visita oficial a la Universidad,

El PIM fue aprobado por el Consejo de Fundadores el 5 de mayo de 2or6, mientras que el PGD como los PD fueron aprobados por la misma instancia el 9 de diciembre de $2016^{419}$.

El PIM, que acoge el lema "Comprometidos con la excelencia”, proyecta el desarrollo institucional para el periodo 2016-2027, subdividido en tres periodos que culminan respectivamente en 2019, 2023 y 2027. La Visión Institucional reza:

En 2027 la Universidad Santo Tomás de Colombia es referente internacional de excelente calidad educativa multicampus, por la articulación eficaz y sistémica de sus funciones sustantivas, y es dinamizadora de la promoción humana y la transformación social responsable, en un ambiente sustentable, de justicia y paz, en procura del bien común ${ }^{420}$.
Esta visión está conformada por 4 componentes. Es en primer lugar, un componente sistémico, puesto que pretende la conformación de una comunidad académica orientada por la filosofía dominicana, integrada por sus diferentes sedes y seccionales a escala nacional y en obediencia a las demandas de la comunidad tomasina y del entorno, así como a las exigencias del devenir socioeconómico y político del pueblo colombiano. Por otro lado, el PIM ofrece una visión de universidad en constante construcción en un proceso cíclico ininterrumpido; para el logro de esta constante construcción se propone una estructura organizacional abierta. En tercer lugar, encontramos el componente de transformación social al que la Universidad ha apuntado desde sus inicios por medio de la capacitación para el liderazgo y el cambio social por medio de la ciencia y el humanismo tomista. En estrecha relación con esta, 


\section{$25 \mathrm{I}$}

Madurez institucional 1995-2018

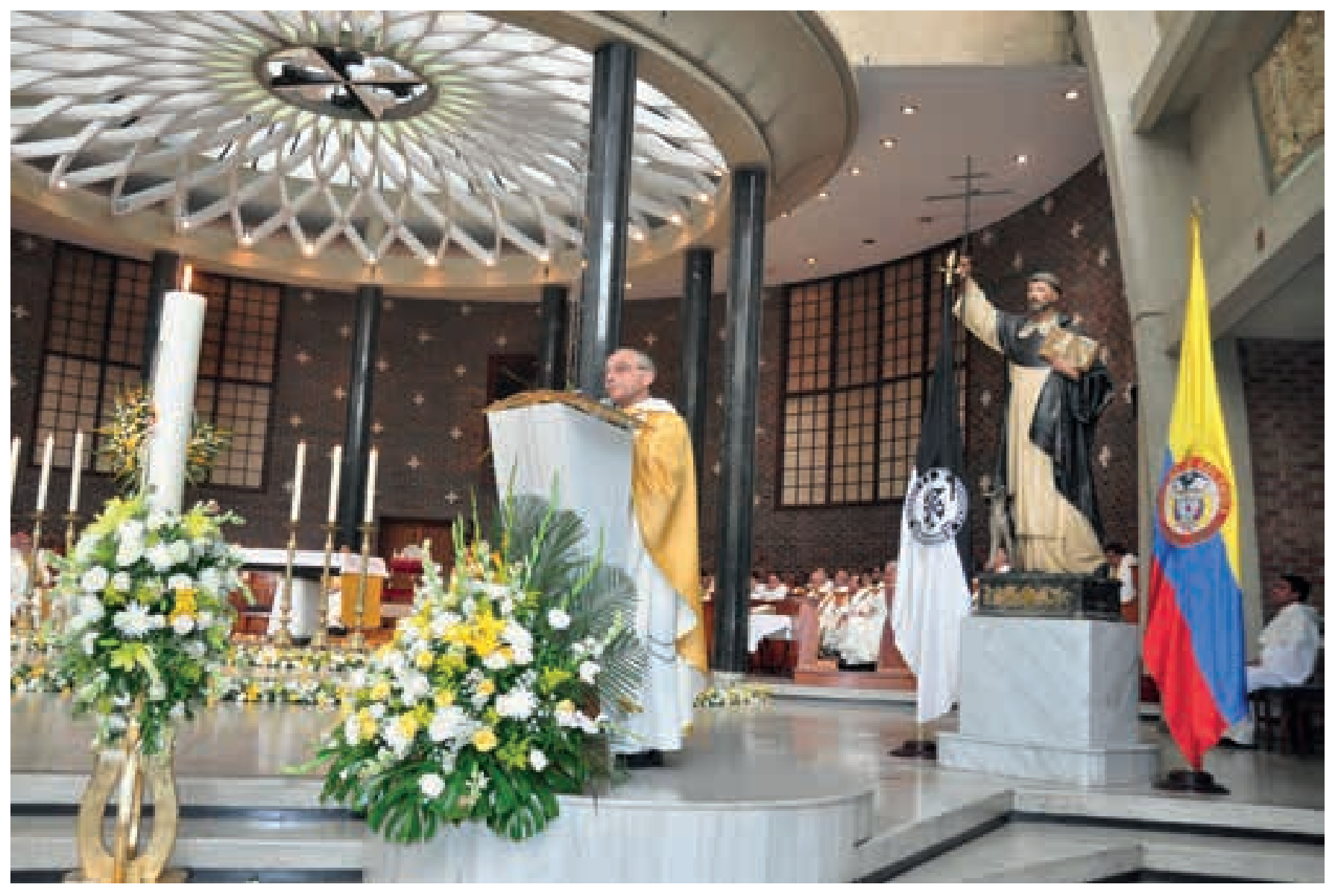

finalmente el PIM propone una visión de construcción del bien común; para lograr esto se promoverá la consciencia entre los estudiantes de su condición actuante en la sociedad $^{421}$.

El PIM, concebido según los parámetros de la planeación estratégica, modelo de planeación que permite análisis sistemáticos de desempeño, se estructura alrededor de seis líneas de acción: I) Gobierno consolidado y fortalecido, 2) Compromiso con el Proyecto Educativo Institucional, 3) Proyección social e investigación pertinentes, 4) Enriquecimiento regional de los programas con estándares comunes, 5) Personas que transforman la sociedad, y 6) Capacidad y gestión institucional que logran la efectividad multicampus ${ }^{422}$. Estas líneas de acción recogen las quince apuestas de mejoramiento establecidas en el proceso de autoevaluación con fines de acreditación ${ }^{423}$.
Pero es en el Plan General de Desarrollo 20I6-20I9 que estas líneas de acción adquieren una materialidad más palpable. Así, en la línea de gobierno consolidado y fortalecido se plantea específicamente una reforma al Estatuto Orgánico, una revisión de la naturaleza del vínculo de la VUAD con la modalidad presencial y un plan de evangelización con fines de fortalecimiento de la identidad tomasina ${ }^{224}$.

En la línea de compromiso con el proyecto educativo institucional se pretende una puesta en práctica del Modelo Educativo Pedagógico de la usta en el ejercicio docente, un fortalecimiento de las estrategias pedagógicas, didácticas y evaluativas de acuerdo con las modalidades presencial, virtual y a distancia, un aumento de la vinculación de los docentes a las funciones sustantivas de la Universidad (docencia, investigación y proyección social), una actualización del 


\section{2}

Madurez institucional $1995^{-2018}$

Estatuto Docente, el desarrollo de mejores condiciones para la permanencia y el bienestar docente y una potenciación de la identidad tomasina ${ }^{425}$.

En la línea de proyección social e investigación pertinentes se propone una definición de los campos de acción desde locales hasta internacionales en los que la USTA enfocará sus esfuerzos investigativos y de proyección social, una mayor articulación de las acciones de proyección social a las otras funciones sustantivas, implementación de un Sistema Nacional de Investigación Multicampus y el incremento tanto de la producción investigativa como de la cooperación $\mathrm{y}$ los convenios interinstitucionales ${ }^{426}$.

En la línea de enriquecimiento regional de los programas con estándares comunes se plantea la unificación curricular en un sistema académico integrado, la adecuación de los programas académicos a las particularidades regionales y a los estándares de calidad, un mayor uso de las Tecnologías de la Información y las Comunicaciones (TIC), de las Tecnologías del Aprendizaje y el Conocimiento (TAC), de las Tecnologías para el Empoderamiento y la Participación (TEP) y diversificación de las modalidades a nivel nacional, y finalmente una consolidación de la modalidad virtual ${ }^{127}$.

La línea de personas que transforman la sociedad incluye propuestas para consolidar el Sistema Nacional de Desarrollo Integral Estudiantil, fortalecer la permanencia estudiantil, el éxito académico y la graduación oportuna en todos los niveles y modalidades, un aumento del impacto a través de la inserción laboral y un mayor liderazgo y responsabilidad social de los egresados ${ }^{428}$.

Antiguo Monasterio de la Visitación de Santa María, hoy nueva sede de la USTA Medellín en la zona de el Poblado

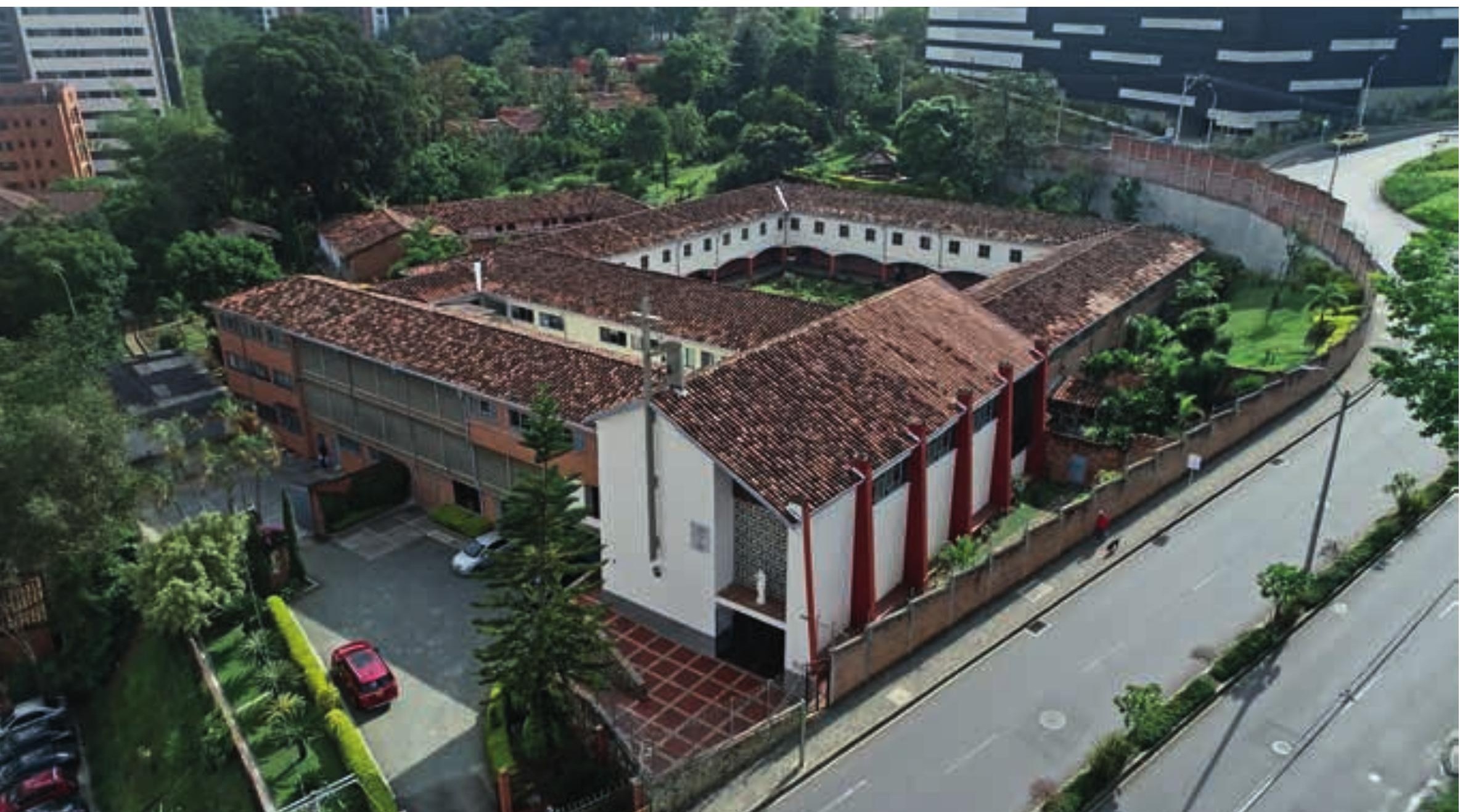




\section{3}

Madurez institucional 1995-20I8

Finalmente, en la línea de capacidad y gestión institucional que logran la efectividad multicampus se propone la implementación del Sistema Integrado de Información Multicampus (sıiM), la consolidación del Sistema de Aseguramiento de la Calidad (siAC), el fortalecimiento y desarrollo de la infraestructura física, tecnológica y de servicios, la consolidación de la arquitectura institucional de la USTA, la generación de una proyección financiera del plantel a corto, mediano y largo plazo, y finalmente el fomento de una cultura institucional de información y comunicación ${ }^{429}$.

Para el logro efectivo de lo planteado en estas líneas de acción, el PGD 20I6-20I9 cuenta con un presupuesto de \$ 408244 millones con rubros diferenciados por cada uno de los tres años (20I7 a 2019), por cada una de las sedes y seccionales y por cada una de las líneas de acción. En la tabla 30 "Presupuesto consolidado USTA 20I7" se presenta dicho presupuesto. Llama la atención la absorción del 79,2 \% de los recursos por parte de la línea de acción de capacidad y gestión institucional que logra la efectividad multicampus. Esto se podría deber a que es en esta línea que se encuentran las acciones de fortalecimiento y desarrollo de la infraestructura material tomasina, por mucho las más costosas.

Si dirigimos nuestra mirada al presupuesto para Tunja, es posible apreciar que justamente en la línea sexta su presupuesto supera con creces el de la siguiente sede con mayor apropiación presupuestal (Bogotá). Así las cosas, para los próximos años podemos esperar un gran desarrollo de la infraestructura material en la Seccional Tunja.

Ya a través de los PD se van concretizando las diversas metas, como por ejemplo la participación de las sedes, seccionales y VUAD en la reforma al Estatuto Orgánico. También en ellos se asume la introducción del Modelo Educativo Pedagógico en la enseñanza, la unificación curricular, la acreditación de programas y el fortalecimiento de las relaciones interinstitucionales.

Es palpable entonces una profunda transformación de las macroestrategias de planeación en la Universidad. La articulación entre el PIM, el PGD y los PD se está dando de manera orgánica teniendo en cuenta el largo plazo y los periodos rectorales. Se trata del espíritu multicampus que ha permitido sincronizar la planeación tomasina, que antes se daba de manera asincrónica entre las diferentes sedes y seccionales y con temporalidades muy diferentes entre ellas; sin embargo, es importante señalar que, gracias a la metodología de la planeación estratégica, la ejecución de lo planeado no queda atado a camisas de fuerza, sino que hay márgenes de adaptabilidad para que la operatividad vaya dialogando con una realidad por fuerza cambiante ${ }^{43}$.

A lo largo de los siguientes acápites, navegaremos por lo que ha sido la vida tomasina en los últimos tres años guiados por las seis líneas de acción planteadas en el PIM. Por razones de espacio, nos hemos enfocado en unas líneas por encima de otras. Los criterios para esta selección son la relevancia, el nivel de avance y el protagonismo institucional que estas acciones han tenido sobre las demás.

La reforma al Estatuto Orgánico, primera tarea formulada por el PGD, culminó y se encuentra en ejecución ${ }^{4{ }^{1}}$. La reforma permitirá estrechar la relación entre el gobierno institucional y la identidad multicampus, alinear la temporalidad de algunos cargos para mejorar la planeación, agilizar la toma de decisiones, revisar las relaciones entre gobierno central y sedes y seccionales, precisar la naturaleza de las decanaturas de División de Sede, establecer reglas claras para la creación de seccionales, propiciar una reestructuración de la investigación e impulsar una transformación de la VUAD de acuerdo con las tendencias globales y la realidad multicampus ${ }^{432}$. Otras innovaciones son la Dirección Nacional de Evangelización, la Dirección Nacional de Investigación e Innovación, la Dirección Nacional de Responsabilidad Social Universitaria y la Decanatura de División de la Universidad Abierta y a Distancia, que depende directamente de la Rectoría General.

Como se puede observar, la VUAD ha sido reformulada de nuevo bajo un régimen especial y similar a como funcionó durante un corto tiempo en la década de r99o bajo el nombre de DUAD. Con esto se pretende solventar la crisis generalizada que vienen enfrentando las facultades de educación de todo el país en los últimos años ${ }^{43}$. Es importante recordar en ese sentido que en la VUAD se presentaban los desafíos tanto de las facultades de educación como de las metodologías abiertas y a distancia.

Finalmente, los consejos generales serán propuestos como espacios para pensar la Universidad académica y administrativamente. En diciembre del 2017 se presentó el primer avance de reforma del estatuto Orgánico al Consejo de Fundadores y en enero de 2018 se hizo el cierre del documento. La reforma fue presentada el 7 de marzo de 2018 al Ministerio de Educación Nacional y aprobada en julio del mismo año ${ }^{434}$.

Un protagonista muy importante dentro de esta línea de acción es el Centro de Pastoral Universitaria, que desde febrero de 2018 se denomina Centro de Evangelización y Cultura ${ }^{435}$. Desde allí se viene 


\section{4}

Madurez institucional $1995^{-2018}$

PLAN INTEGRAL MULTICAMPUS

PIM 2016-2027

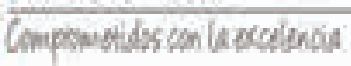

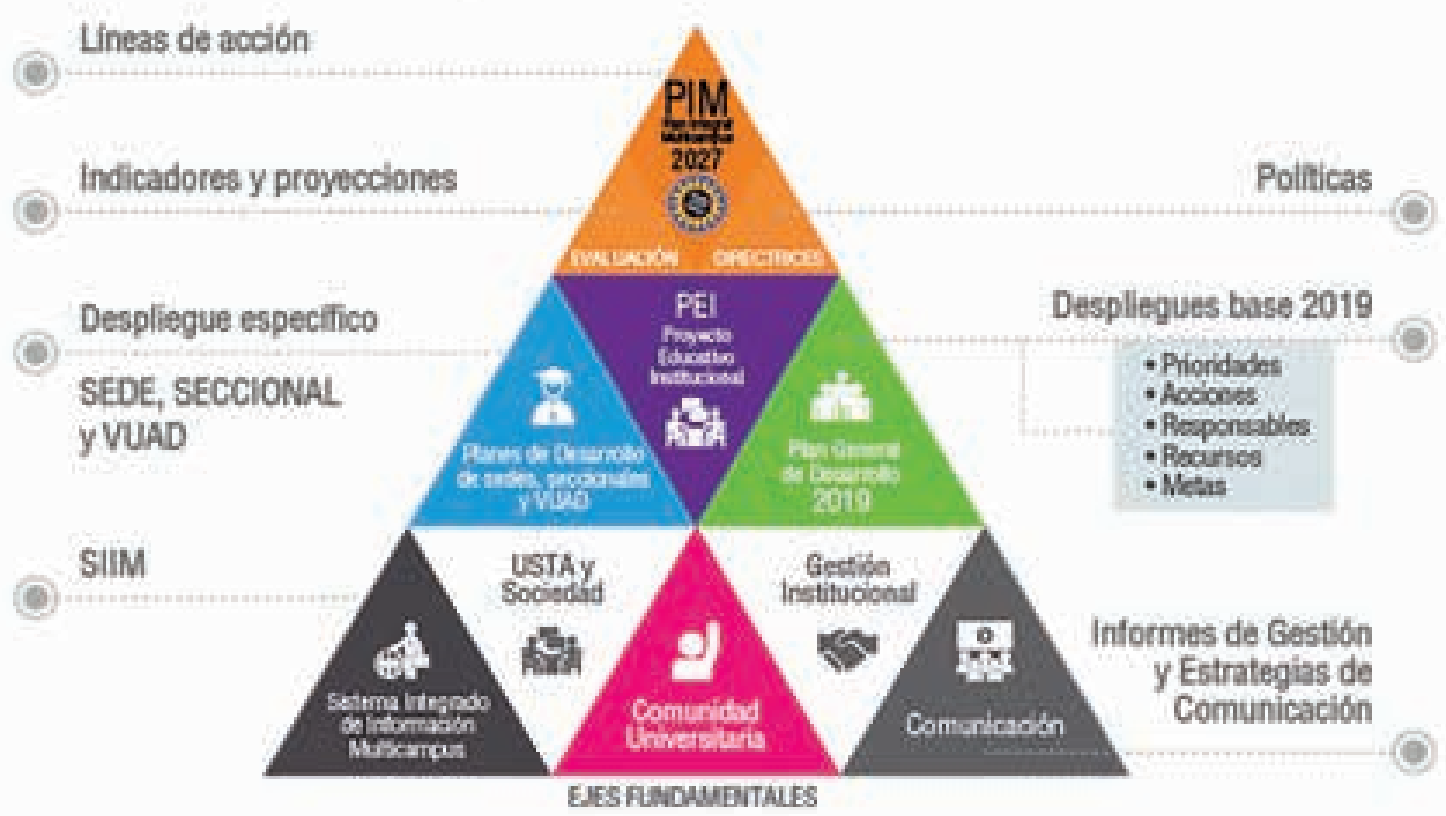

LÍNEA DE ACcIÓN 1. Gobierno consolidado y fortalecido

Actualización del Estatuto Orgánico • Centro de Pastoral Universitaria

LÍNEA DE ACCIÓN 2. Compromiso con el proyecto educativo

Población docente

LÍNEA DE ACCIÓN 3. Proyección social e investigación pertinentes

Investigación • Proyección social • Convenios • Movilidad estudiantil

LÍNEA DE ACCIÓN 4. Enriquecimiento regional de los programas con estándares comunes

Oferta académica - Acreditación de programas

LÍNEA DE ACCIÓN 5. Personas que transforman sociedad

Población estudiantil • Egresados • Promoción y bienestar universitario

LÍNEA DE ACCIÓN 6. Capacidad y gestión institucional que logran la efectividad multicampus

Población administrativa •Infraestructura física • Recursos tecnológicos • Recursos bibliográficos • Apoyos financieros • Evolución comparativa

Modelo de planeación y líneas de acción del PIM, con las cuales se proyecta el quehacer de la Universidad a 2027 a través de los ejes presentes en cada una de ellas 


\section{5}

\section{Madurez institucional 1995-2018}

construyendo el "Plan de Evangelización Permanente Multicampus - USTA Colombia 2027”, que será la propuesta estratégica desde la Pastoral Universitaria en el marco de la universidad multicampus.

El Plan está conformado a partir de unos presupuestos bíblico-teológicos y pedagógicos dominicanos que, desde la pedagogía de la respuesta desarrollada por fray José de Jesús Sedano, O.P., desarrollan unas líneas de acción evangelizadora de la USTA, de su misión e identidad: I) formar hombres y mujeres libres que hagan libres a los demás (perfil humano), 2) formar hombres y mujeres críticos en la fe a la luz de la razón (perfil evangélico) y 3 ) formar hombres y mujeres defensores y promotores de la vida (perfil apostólico).

En el Plan hay un compromiso serio con el proyecto de construcción de paz en que se encuentra nuestro país y por ello se propone formar "agentes de cambio por la paz”. Así mismo, el Plan se desarrolla por medio de cuatro mesas de trabajo que recogen los cuatro pilares fundamentales que identifican la formación permanente de un dominico según sus constituciones: I) la unidad en torno a la vida común: Mesa de la Comunidad (familia), 2) fomento de la espiritualidad: Mesa de la Palabra (la Palabra), 3) amor por el estudio: Mesa de la Formación (verdad) y 4) servicio incondicional: Mesa de la Misión (compromiso misional).

Para cada mesa se plantean unas problemáticas específicas, así como unos perfiles particulares para sus respectivos líderes, todo esto con el objetivo central de lograr "despertar y promover la persona que todos llevamos dentro, tener el coraje de llegar a ser lo que somos”, como sostenía fray José de Jesús Sedano, O.P.

En cuanto a la investigación, vale la pena destacar que la Universidad se encuentra entre las primeras 20 universidades colombianas en el Ranking Mundial de Investigación en Universidades de Scimago Institutions Rankings. Así mismo, en el ranking ASC-Sapiens, que se establece a partir de la apropiación social del conocimiento que se genera en las universidades, la Universidad ocupó el lugar I4 entre todas las universidades colombianas, mejorando I2 puestos con respecto a la medición anterior, realizada en $2016^{436}$.

Recientemente, se han modificado los términos en el Fondo de Desarrollo de la Investigación (Fodein) para incentivar la cooperación y el trabajo en redes, la interdisciplinariedad, la gestión de recursos externos, la orientación multicampus y la articulación de las funciones sustantivas. En 2017 la Universidad invertía \$ 5004937502 en 368 proyectos de investigación activos durante el primer semestre de ese año ${ }^{437}$.
Por su parte, Ediciones usta, en comunión con los cambios mencionados previamente que viene 1levando adelante desde el año 2013 se ha concentrado desde 2015 de manera exclusiva en la edición académica de materiales científicos, dejando de lado el proceso de edición, publicación e impresión de material institucional - informes de gestión, documentos de presentación de todo tipo, piezas promocionales, procedimientos, modelos institucionales, etc. - , que pasó al área de Comunicaciones.

Con ese fundamento, se han consolidado dos grandes procesos que han propiciado una cultura editorial académica que cumple con las exigencias de producción, gestión y visibilidad de la producción científica en el mundo universitario. El primero de ellos es la producción de libros que cumplen con criterios de evaluación y cuidado editorial universalmente reconocidos: evaluación por pares académicos, validación por comités editoriales disciplinares, normalización bibliográfica, inclusión en colecciones temáticas, y divulgación y visibilidad a través de distribuidores comerciales en formatos físicos y digitales. Así, según los registros de la Cámara Colombiana del Libro - IsBN solicitados-, en 2015 la Universidad, contado sus sedes y seccionales, publicó 54 títulos; en 20I6, 47; y en 20I7, 73. En el trienio se suman entonces 174 novedades editoriales, que además de hacer parte del circuito regular de distribución editorial a través de librerías y ferias del libro nacionales e internacionales, se presentan en versiones electrónicas para distribución mundial y quedan debidamente presentadas en el repositorio institucional de la Universidad.

El segundo gran proceso es la gestión de revistas científicas a partir de los criterios propios de la contemporánea circulación de conocimiento. Esto es, con el objetivo de cumplir los estándares establecidos por sistemas de indexación y referencia que aseguran la visibilidad y la calidad de la producción académica en el mundo. E1 fortalecimiento de los comités editoriales de las revistas, la profesionalización de la labor de los editores de estas y el trabajo mancomunado de la coordinación de revistas de Ediciones USTA, con el apoyo tecnológico de la oficina de tecnologías, han permitido, en el trienio 2015-2017, consolidar la publicación de los números de las revistas de la Universidad en el Sistema ojs de la Universidad, que es el estándar de publicación universal, cumpliendo con requisitos de evaluación por pares, superación de altos índices de endogamia, estricta periodicidad en la publicación y número de artículos resultado de investigación, entre otros criterios. 


\section{6}

Madurez institucional $1995^{-2018}$

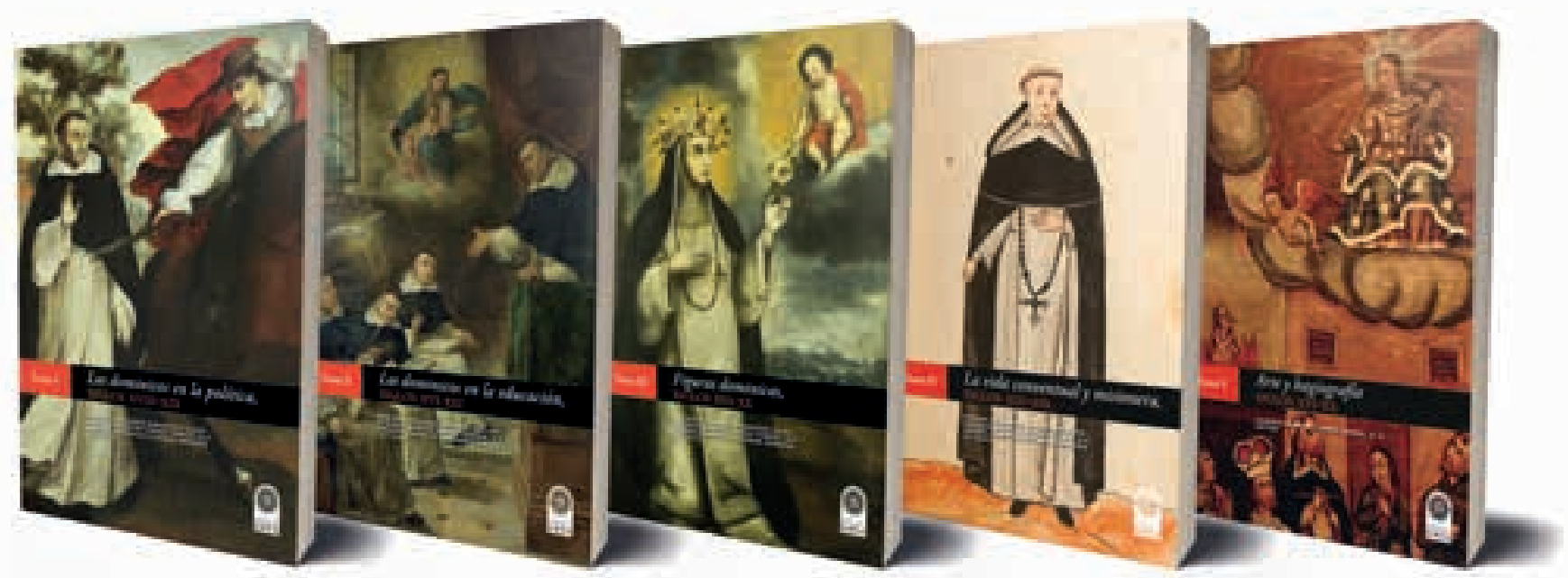

Con motivo del VIII centenario de la fundación de la Orden de Predicadores, el Instituto de Estudios Socio-Históricos Fray Alonso de Zamora, O.P., y Ediciones USTA publicaron la colección Orden de los Dominicos 800 años

Producto de este esfuerzo, en el año 2016 la Editorial logró la indexación de ir revistas de la Santo Tomás en sistemas de indexación como EBSco, Redalyc, Scielo, DOAJ, ProQuest, Dialnet, Latindex, entre otras ${ }^{43^{8}}$. Además, en la última clasificación Publindex de Colciencias de 20I7, fueron aceptadas 5 de las 24 revistas científicas de la Universidad -Diversitas, Hallazgos, Cuadernos de Filosofía Latinoamericana, Principia Iuris y Iteckne-. Los números de revistas publicados por Ediciones USTA en todas las sedes y seccionales entre 2015 y 2017 fueron 154. Gracias a la sincronización con el espíritu multicampus se aprecia una mayor visibilidad de los productos, algo ya notoria en el catálogo de Ediciones USTA, que ahora se presentan como obra de una sola universidad independiente de la sede o seccional. ${ }^{439}$

Por otra parte, en octubre de 2015 el Convento de Santo Domingo de la Orden de Predicadores en Bogotá recibió el Cxxxvi Consejo Nacional de Rectores de la Ascún; en dicho evento las universidades hicieron un reconocimiento honorífico a la USTA por sus cincuenta años de restauración ${ }^{40}$.

En febrero de 20I6, a partir de la iniciativa de monseñor Luis Augusto Castro, se conformó la Red de Universidades Católicas de Colombia (RUCC) conformada por I8 planteles. El objetivo de la Red es aunar esfuerzos, intercambiar experiencias y fortalecer la orientación espiritual de las universidades católicas en el país. Después del encuentro fundacional, los rectores de universidades católicas se han vuelto a reunir en otras cuatro oportunidades en las que se ha impulsado el trabajo conjunto sobre educación, investigación y pastoral universitaria. Desde su creación, la Red ha sido coordinada por la Universidad Santo Tomás a través de fray Juan Ubaldo como su presidente ${ }^{44}$.

Además, es este periodo, la Universidad fundó junto a otras universidades, ONG y entidades privadas del programa Reconciliación Colombia que impulsa iniciativas conducentes a una sociedad en paz. E1 programa gestiona recursos, promueve la articulación de proyectos, impulsa acciones y las visibiliza.

Asimismo, la Universidad participa activamente en Colombia Líder, una alianza entre la sociedad civil y el sector privado que promueve y premia el liderazgo local y regional desde la eficiencia, la innovación y la inclusión. Es por ello que en el edificio Doctor Angélico se celebraron, en noviembre de 2017 , los primeros diez años de existencia y funcionamiento de dicha iniciativa.

En marzo de 2018 se realizó la Primera Cumbre "Manos por Colombia", sobre innovación empresarial para la construcción de país, organizada por la USTA y la Revista Semana. El espacio, que contó con participación de empresarios, docentes, emprendedores y otros líderes, sirvió para visibilizar diversas iniciativas de responsabilidad social. Todas estas iniciativas son la base que en el periodo permitió consolidar la puesta en marcha del concepto responsabilidad social universitaria. 


\section{7}

Madurez institucional 1995-2018

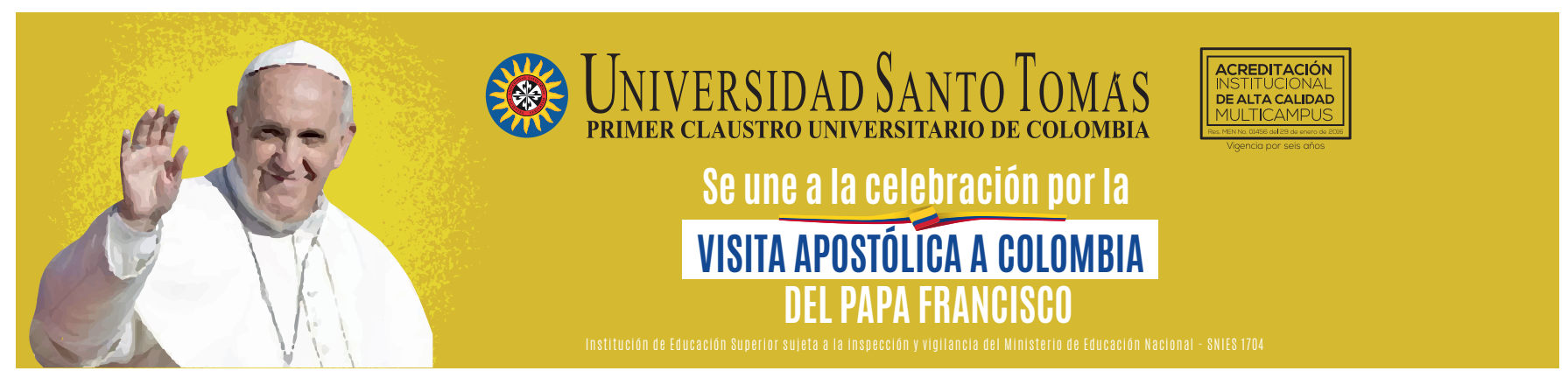

La USTA participó de diversas maneras en la organización y la ejecución de la visita del papa Francisco a Colombia en septiembre de 2017

Si el año 2016 comenzó bajo buenos auspicios por cuenta de la Acreditación Multicampus, su culminación no fue menos importante. El 30 de noviembre, la ministra de Educación Yaneth Giha Tovar entregó a la Universidad la Orden a la Acreditación Institucional de Alta Calidad de la Educación Superior Francisco José de Caldas, en que se honra justamente la Acreditación y que constituye un importante reconocimiento para cualquier universidad colombiana ${ }^{44^{2}}$.

En el horizonte cercano se avizoran también acontecimientos importantes a nivel nacional. En julio de 2019 se celebrarán cien años de la coronación de la Virgen del Rosario de Chiquinquirá como reina y patrona de Colombia. El año jubilar dará inicio en julio de 2018 y a lo largo de los meses siguientes se llevarán a cabo diversas actividades con participación de la Provincia, de la Universidad y de la Iglesia católica. La participación de la USTA será notoria principalmente en el Congreso Mariano Nacional que se llevará a cabo en Bogotá en mayo de 2019, pero también por medio de publicaciones y de la promoción apostólica del acontecimiento ${ }^{43}$.

Otras efemérides, ya de carácter internacional han marcado la vida universitaria en los últimos años. A lo largo del año 2016 se llevaron a cabo diferentes actividades para celebrar los ochocientos años de existencia de la Orden de Predicadores. En abril de ese año, en el edificio Doctor Angélico se llevó a cabo el Segundo Congreso Internacional de Historia de la Orden de Predicadores en América Latina. El Congreso contó con la participación de investigadores procedentes de diversas regiones del país y varios países del mundo. A partir de las ponencias presentadas se viene lanzando entre 20I7 y 2018 una colección editorial de la cual se han publicado hasta el momento cuatro tomos que abordan diversos aspectos de la vida dominica: la política, la educación, estudios específicos de frailes y monjas dominicanas y la vida conventual y misionera.

También en el contexto del Jubileo, en agosto de 2016 la Usta participó en el II Encuentro de la Red de Comunicaciones y Radios Dominicas de América Latina y El Caribe, que se realizó en la ciudad de Lima. Al evento asistieron el maestro de la Orden fray Bruno Cadoré, O. P., y el entonces presidente de la República del Perú, Pedro Pablo Kuczynski ${ }^{44}$. El mes siguiente, la Universidad participó en el Congreso Internacional los Dominicos en la Promoción y Defensa de los Derechos Humanos. Pasado, Presente y Futuro, realizado en la Universidad de Salamanca. Este encuentro, que convocó 200 dominicos de 50 países del mundo, culminó con una declaración final en la que la Orden de Predicadores se comprometió a adelantar diez acciones para la promoción y la defensa de los derechos humanos, la justicia y la paz en el mundo ${ }^{445}$.

A lo largo de todo ese año, la Provincia también participó, a través de fray Orlando Rueda Acevedo, O.P., en 


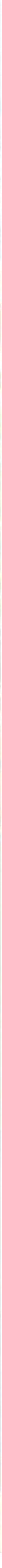

Visita de las directivas a Cazucá como parte del esfuerzo de proyección social de la Universidad

el diseño, traducción y publicación del libro Dominicus: 800 destellos de la luz de la Iglesia. Finalmente, en enero de 20I7, la Universidad asistió al Congreso Internacional para la Misión de la Orden, realizado en Roma. Allí se abordan y reevalúan diversos aspectos de la acción pastoral de la Orden y se sincroniza dicho accionar con el cambiante contexto global, así como con las nuevas necesidades de la Iglesia ${ }^{44^{6}}$.

De manera que durante estos años la Universidad se viene destacando en importantes acontecimientos para la Iglesia católica: entre el Jubileo de la Orden en 2016 y el centenario de la Coronación de la Virgen en 20I9, es digno de mención que la UsTA participó de diversas maneras en la organización y la ejecución de la visita del papa Francisco a Colombia en septiembre de 20I7.

Destaquemos otros procesos que contribuyen al posicionamiento internacional de la Universidad Santo Tomás. El 28 de en enero de 2016 el maestro de la Orden fray Bruno Cadoré, O.P., con motivo de su visita canónica a la Provincia de San Luis Bertrán de Colombia visitó la Universidad Santo Tomás. En aquella visita, el maestro afirmó:
El contexto actual del país exige a la Orden que cumpla su papel: ser frailes predicadores hoy en Colombia y ser predicadores de paz y de reconciliación. En esta misión de evangelización, las instituciones de educación (Universidad y colegios) tienen una función importante. [...] En la Universidad, a la vez que felicitamos a sus autoridades por la acreditación conseguida, sería necesario tomar una decisión significativa: en nuestra Universidad queremos que la Orden (hermanos, hermanas y laicos) se comprometan principalmente en la enseñanza de las humanidades, la teología y la investigación en diálogo con la pastoral ${ }^{447}$.

Además, en diciembre de 2016 la USTA hizo presencia en la revista Time en un especial de dicha publicación sobre las perspectivas para Colombia en los próximos años; en cuanto al proceso de paz, la revista resaltó las palabras del rector, quien destacó los objetivos de la USTA de humanizar, evangelizar y servir en el marco del proceso. Así mismo, la revista destacó la antigüedad de la Universidad, su orientación hacia estudiantes de clases no acomodadas y, por supuesto, la educación abierta y a distancia. En temas de paz, 


\section{9}

Madurez institucional 1995-20I8

también se destacaron el Instituto de Victimología y el programa de Comunicación Social para la $\mathrm{Paz}^{448}$.

En junio de 2017 la USTA ingresó al ranking mundial de investigación Scimago, en el que aparecen 2I universidades colombianas ${ }^{449}$. El mes siguiente, en el marco del año Colombia-Francia, el rector participó en el IV Encuentro de Rectores de Universidades Colombo-Francesas que se llevó a cabo en el Instituto Nacional de Ciencias Aplicadas (INSA) de Lyon. E1 encuentro, al que asistieron unos 80 rectores de universidades colombianas y francesas, tuvo por tema central "desarrollo rural y ciudad sostenible" ${ }^{50}$. También en julio, fray Juan Ubaldo participó en un encuentro en la Universidad de Guadalajara en el que directivos universitarios de América Latina fueron capacitados sobre indicadores y metodología de los rankings de la revista Times Higher Education ${ }^{45}$.

Un hito realmente significativo ocurrió en en agosto del 2017. La Provincia de San Agustín, que agrupa países del África Occidental, solicitó a la USTA acompañamiento y asesoría para la iniciativa de fundación de una universidad dominicana en Burkina Faso. Un elemento que atrajo a los dominicos africanos a pedir la asesoría de la USTA fue su cualidad multicampus, que permite la proyección regional del plante1 ${ }^{452}$.

En el contexto de un Convenio Marco de Cooperación, una delegación compuesta por fray Benjamin Sombel Sarr, O.P., prior provincial, la directora de enseñanza de educación superior del Ministerio de Educación de Burkina Faso y laicos y frailes de dicho país, realizó una visita oficial a la USTA en marzo de 2018. La Santo Tomás continúa haciendo acompañamiento al proyecto en los programas de Derecho, Economía, Arquitectura, Administración de Empresas Agropecuarias e Ingeniería Civil. La apertura de la universidad está programada para octubre de $20188^{453}$.

En 2017 la revista The Business Year entrevistó al rector en su sección sobre la educación en Colombia. Allí, fray Juan Ubaldo resaltó las estrategias para los próximos años tanto en el corto como en el largo plazo y expuso las contribuciones de la Universidad al proceso de paz $^{454}$. Allí se hizo énfasis en el espíritu de la investigación y la proyección social en la Universidad:

Our goal has been to develop people to be aware of events within Colombia. We developed the undergraduate program in Social Communications for Peace, which teaches our students throughout all stages of their education about peace. We wanted to be close to the communities who had to leave their lands because of the narcotics traffic. We work in prisons as well to educate criminals to re-integrate them into society. This is our contribution and commitment to communities and to society. Another important aspect is that we work with territories affected by the war to restore the land to the people from whom it was expropriated. We also have a mission called University Pastoral that is bringing the Dominican humanist though to very distant areas of Colombia and bringing students to places like Los Llanos Orientales (Eastern Colombian Plains) for them to be more sensitive and to know more about the people in their country from poor and rural areas. This shows our commitment to the entire country.

Vale la pena resaltar, también, el especial de la revista Semana de noviembre de 20I7, "Esta Bogotá Promete", en que se hizo reseña de la historia de la USTA, así como de su situación actual y las perspectivas para los próximos años, poniendo particular atención al estado de la investigación ${ }^{45}$.

Más recientemente, en abril de 20I8, el rector participó en la 8th Global Private Education Conference que llevó por nombre Learning for the jobs of tomorrow. Este encuentro, organizado por la Corporación Financiera Internacional (IFC, por sus siglas en inglés), órgano del Banco Mundial, agrupó 370 líderes de 50 países en Ciudad del Cabo. Más tarde, en mayo, la Universidad participó en el IV Encuentro Internacional de Rectores Universia 20I8, llevado a cabo en Salamanca. Como resultado, los participantes acordaron la "Declaración de Salamanca", en que los directivos universitarios apuntaron a importantes acciones tales como flexibilización y aplicación de métodos educativos innovadores, mayor interacción con la industria, entre otras.

También en mayo, la misma IFC firmó un convenio de inversión con la Universidad Santo Tomás con un cupo de 25 millones de dólares para los próximos ocho años, plazo propuesto para el desarrollo del PIM. El objetivo del proyecto es modernizar y estandarizar los campus de la USTA en todo el país, con lo que se estará contribuyendo a la regionalización de la educación universitaria y la consolidación del posconflicto en las regiones gracias al fortalecimiento tecnológico de la Universidad en perspectiva multicampus, la unidad de sistemas debida al proyecto Sinergia, y al fortalecimiento denodado de las sedes Medellín y Villavicencio. El contacto con la IFC le permitirá a la Universidad acceder a tecnologías verdes y eficientes ${ }^{456}$. 


\section{0}

Madurez institucional 1995-2018

En junio de 20I8, la Universidad participó en la II Conferencia Regional de Educación Superior (CREs) llevada a cabo en Córdoba (Argentina) ${ }^{457}$. Se generó una declaración final en la que, evocando la Reforma de Córdoba de 19ı8, las universidades latinoamericanas y del Caribe se comprometieron con la ciencia, el humanismo y la responsabilidad social. Se sumaron también nuevos compromisos, propios del presente contexto global como el desarrollo sostenible, la articulación de la educación superior con los otros niveles del sistema educativo, la internacionalización e integración universitaria, la interculturalidad, entre otros.

Probablemente el paso más importante hacia el posicionamiento nacional es obtener la Acreditación Internacional. En este camino, el primer paso lo constituyó la Acreditación Multicampus; ahora, la internacional permitirá elevar su presencia en el concierto mundial de universidades y facilitar más la movilidad académica con otros países. La agencia encargada de este proceso será el Instituto Internacional de Aseguramiento de la Calidad (IAC), división del Centro Interuniversitario de Desarrollo (CINDA) con sede en Bogotá y Chile.

E1 Plan General de Desarrollo 2or6-2org de la USTA y la Visión 2027 le han brindado a la internacionalización un papel preponderante en el marco de sus tres ejes fundamentales e interdependientes. Para ello, la Universidad busca consolidar las relaciones internacionales, logrando incrementar y fortalecer el currículo académico, su investigación y las acciones de proyección social, permitiendo con ello difundir la imagen tomasina en Colombia y en el mundo, mediante programas, convenios y proyectos que representen los valores tomasinos y su excelencia académica.

Como parte de esta transformación, desde la Rectoría General se han dado lineamientos de gestión internacional para que la ORII sea el catalizador de los procesos de internacionalización con miras a cumplir las metas y objetivos que el Plan establece en su numeral

El Consejo Superior es la máxima autoridad colegiada en el orden académico, administrativo y financiero de la Universidad

Presentación del Plan Integral Multicampus 2016-2027 y el Plan General de Desarrollo a las directivas de la Universidad
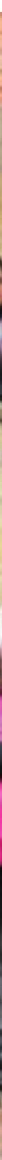


\section{$26 I$}

Madurez institucional $1995^{-2018}$

3.5: "Aumentar de manera progresiva y sostenible la cooperación académica con otras instituciones nacionales e internacionales" ${ }^{\prime 5}$.

Dentro de las estrategias y acciones que se han desarrollado en los últimos tres años, se encuentra la cooperación con más de 50 Instituciones de Educación Superior - IES-, hecho que facilita la participación académica para el desarrollo de las funciones universitarias. Estos convenios han permitido el aumento de manera progresiva en todas las áreas de la Universidad, que se ha enfocado primordialmente en países europeos. La USTA Colombia cuenta hoy con más de 272 convenios internacionales que se actualizan de manera constante para responder a las necesidades de la comunidad tomasina. Se tienen convenios principalmente con España, Alemania, Francia, Italia, Rusia Portugal, México, Chile, Brasil, Perú, Argentina, Panamá, Costa Rica, Ecuador, Cuba, El Salvador, Puerto Rico, Uruguay y Corea del sur, todos estos con alcance multicampus.
El desarrollo de eventos de impacto internacional, coordinados y ejecutados por la USTA en 2016, como la Conferencia Latinoamericana y del Caribe para la Internacionalización de la Educación Superior (LACHEC, por sus siglas en inglés) y el Congreso Internacional de Ciencia, Innovación y Conocimiento (CIKI), así como las misiones académicas de estudiantes tomasinos al extranjero y la participación anual desde 2016 en dos de las principales ferias educativas mundiales sobre internacionalización -NAFSA y EAIE- han permitido visibilizar a la USTA a nivel mundial, demostrando la alta calidad de su educación y el desarrollo de sus proyectos.

De la misma forma en que se ha generado el aumento progresivo de convenios, este proceso se acompaña con el incremento exponencial de intercambios de estudiantes en movilidad entrante como saliente (local, nacional y mayoritariamente internacional). Desde septiembre de 2016 , por ejemplo, se viene realizando

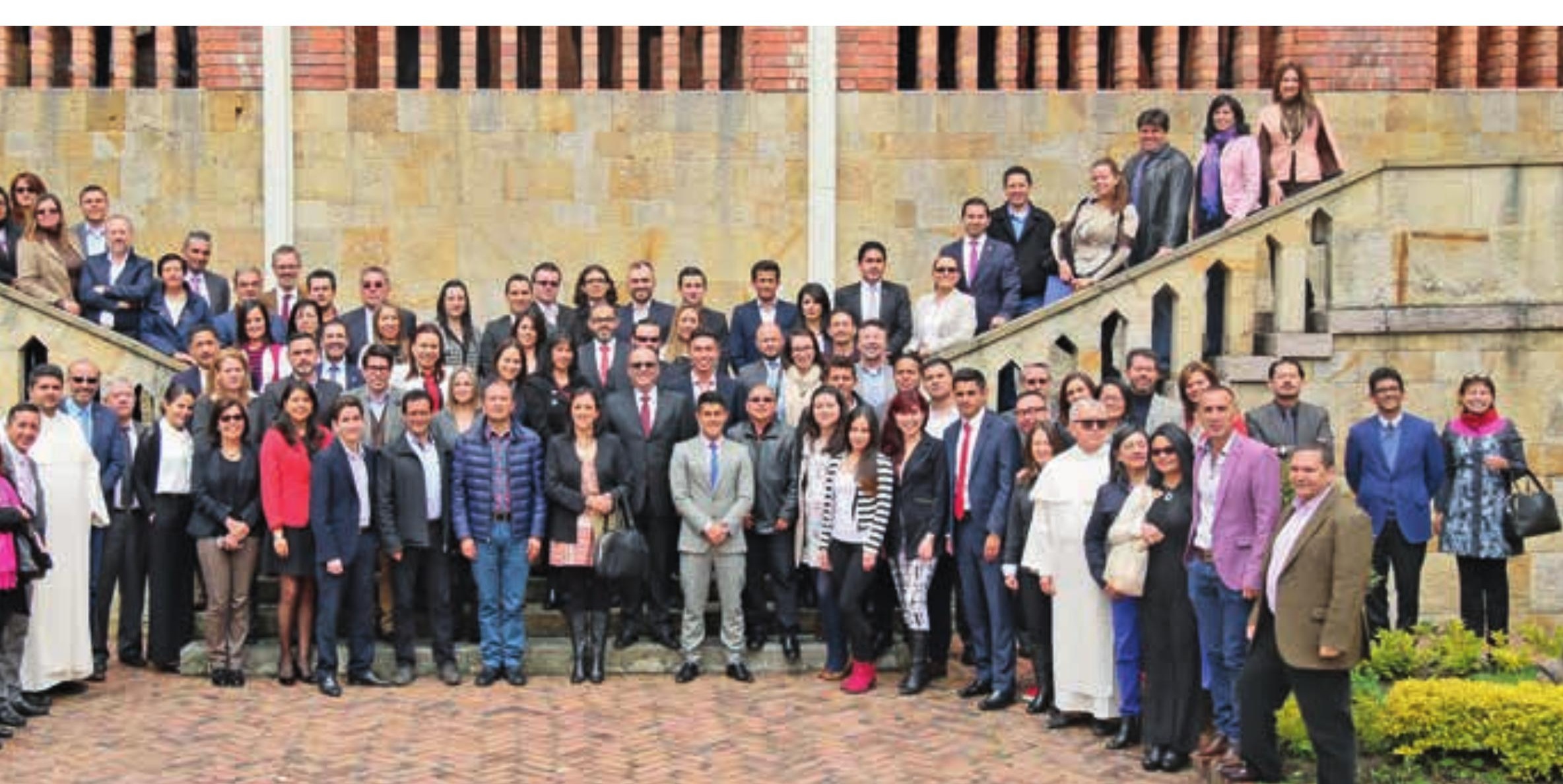




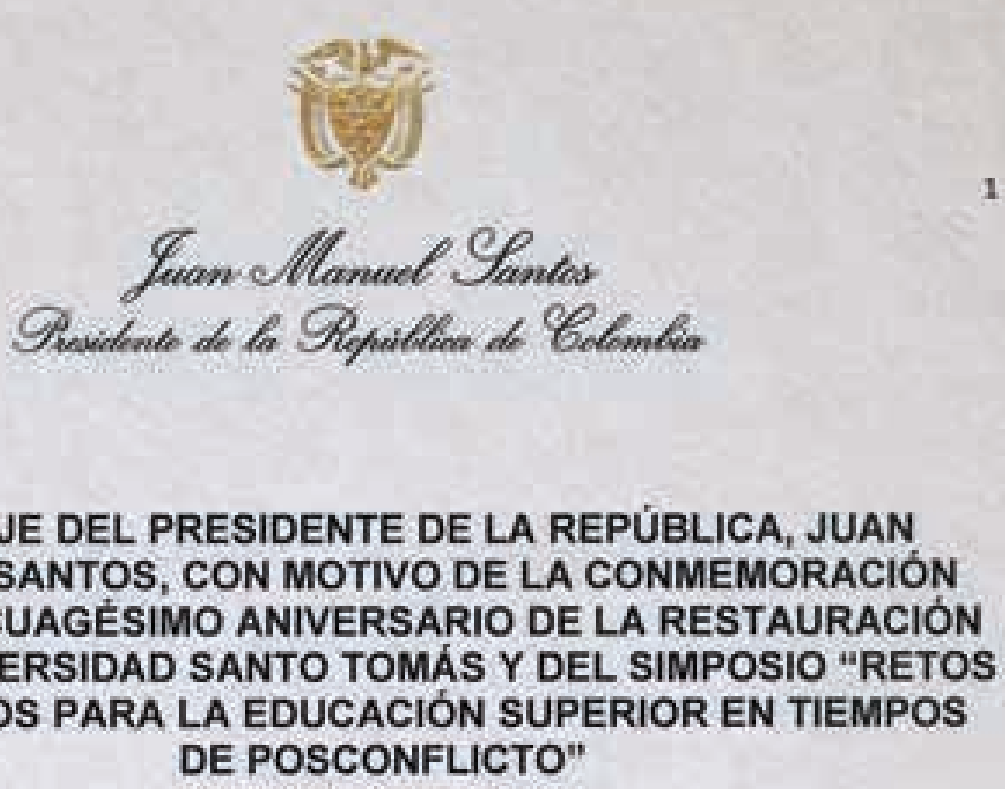

MENSAJE DEL PRESIDENTE DE LA REPÚBLICA, JUAN MANUEL SANTOS, CON MOTIVO DE LA CONMEMORACIÓN DEL QUINCUAGÉSIMO ANIVERSARIO DE LA RESTAURACIÓN DE LA UNIVERSIDAD SANTO TOMÁS Y DEL SIMPOSIO "RETOS $Y$ DESAFIOS PARA LA EDUCACIÓN SUPERIOR EN TIEMPOS DE POSCONFLICTO"

Bogotả, 24 de septiembre de 2015

Me alegra poder saludar hoy la celebración de dos eventos que son muy importantes para su institución y para el pais: por un lado, la conmemoración del quincuagésimo aniversario de la restauración de la Universidad Santo Tomás que en 1965 -después de más de un sigio- volvió a abrir sus puertas, para beneficio de nuestros estudiantes y de nuestra educación superior. Por el otro, la realización del simposio "Retos y desafios para la educación superior en tiempos de posconflicto", que representa un aporte muy significativo a la comprensión de los esfuerzos que-desde el gobierno y la sociedad-estamos haciendo para alcanzar la paz.

Les agradezco mucho su invitación a acompañarios -que me honra- $y$ aunque no me ha sido posible asistir, no puedo dejar pasar esta ocasión $\sin$ expresarles mis sinceras felicitaciones y mi reconocimiento por su trabajo. 


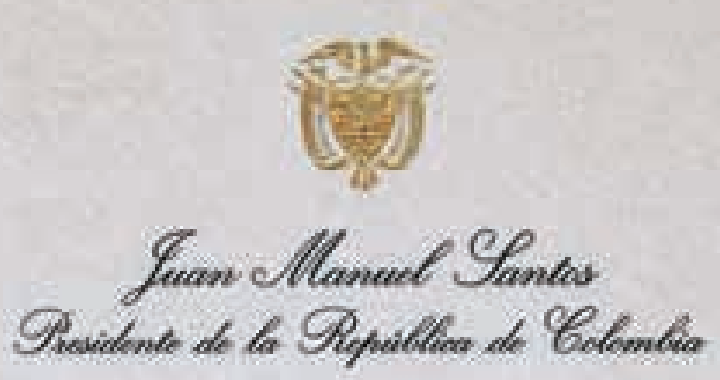

Como ustedes saben, la historia de esta universidad está estrechamente vinculada a la historia de nuestra nación, más aủn porque no se remonta únicamente al último medio siglo sino a 435 años, desde su original fundación en 1580 , lo que la convierte en el primer claustro universitario del pais. Gracias a la notable labor de sus directivas y profesores, el excelente nivel educativo con que cuentan hoy - y que confirma la acreditación de alta calidad- está a la altura de su legado.

Durante los últimos cincuenta años, la Universidad Santo Tomás se ha convertido en uno de los principales centros educativos de Colombia, y ha sido responsable de la formación académica y profesional de miles de estudiantes.

Igualmente, a través del trabajo de sus facultades y de sus sedes en varias ciudades del pais, ha contribuido decisivamente a la innovación, al cierre de las brechas sociales y al mejoramiento de la calidad de vida de muchisimas personas. Por esa razón, la celebración de este aniversario es una buena noticia para todos los colombianos.

En el Gobierno nacional entendemos que la educación es uno de los pilares fundamentales sobre los cuales se construye una sociedad 


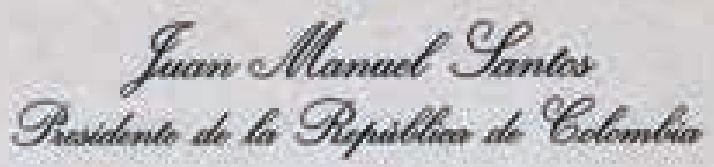

pacifica, próspera y moderna. Es por eso que queremos que la Santo Tomás siga creciendo y consolidándose como referencia para la investigación y la actividad académica; porque sabemos que una formación superior de calidad es indispensable para alcanzar las transformaciones que nuestro pais requiere, y ustedes son aliados muy valiosos que tenemos para avanzar en ese objetivo.

Quiero señalar, asimismo, su gran contribución a la causa de la paz. El simposio que acompaña esta celebración es, precisamente, una muestra de esa sintonia con el propósito del gobierno de dejar atrás la guerra que, lamentablemente, ha marcado el último medio siglo de nuestra historia. Por fortuna, los desarrollos de los últimos dias nos muestran que vamos por el camino correcto y que esa paz, que nos ha sido tan esquiva, por fin se vislumbra cercana.

Una vez más, mis sinceras felicitaciones al señor rector, fray Juan Ubaldo López, al Padre Carlos Mario Alzate, a las directivas de la universidad, al cuerpo administrativo, a los docentes y a los estudiantes de esta gran institución. Estoy seguro de que en los años venideros nos seguirán llenando de motivos de orgullo. 


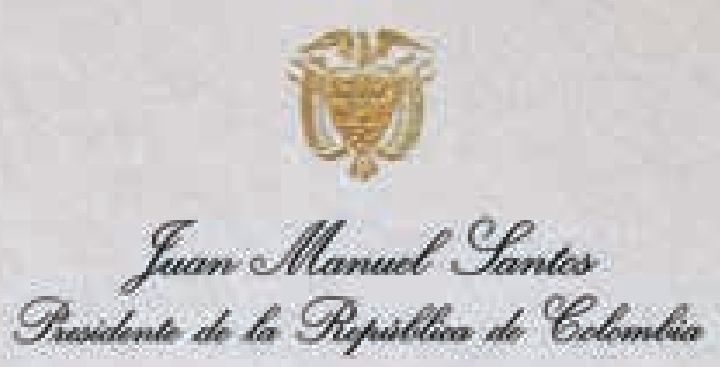

Con el aporte de todos ustedes, seguiremos avanzando en la construcción de la Colombia que queremos: con mayor equidad, mejor educada y en paz.

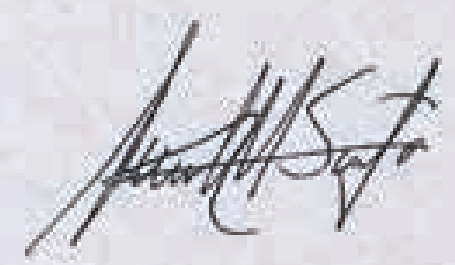




\section{Universidad Santo Tomás}

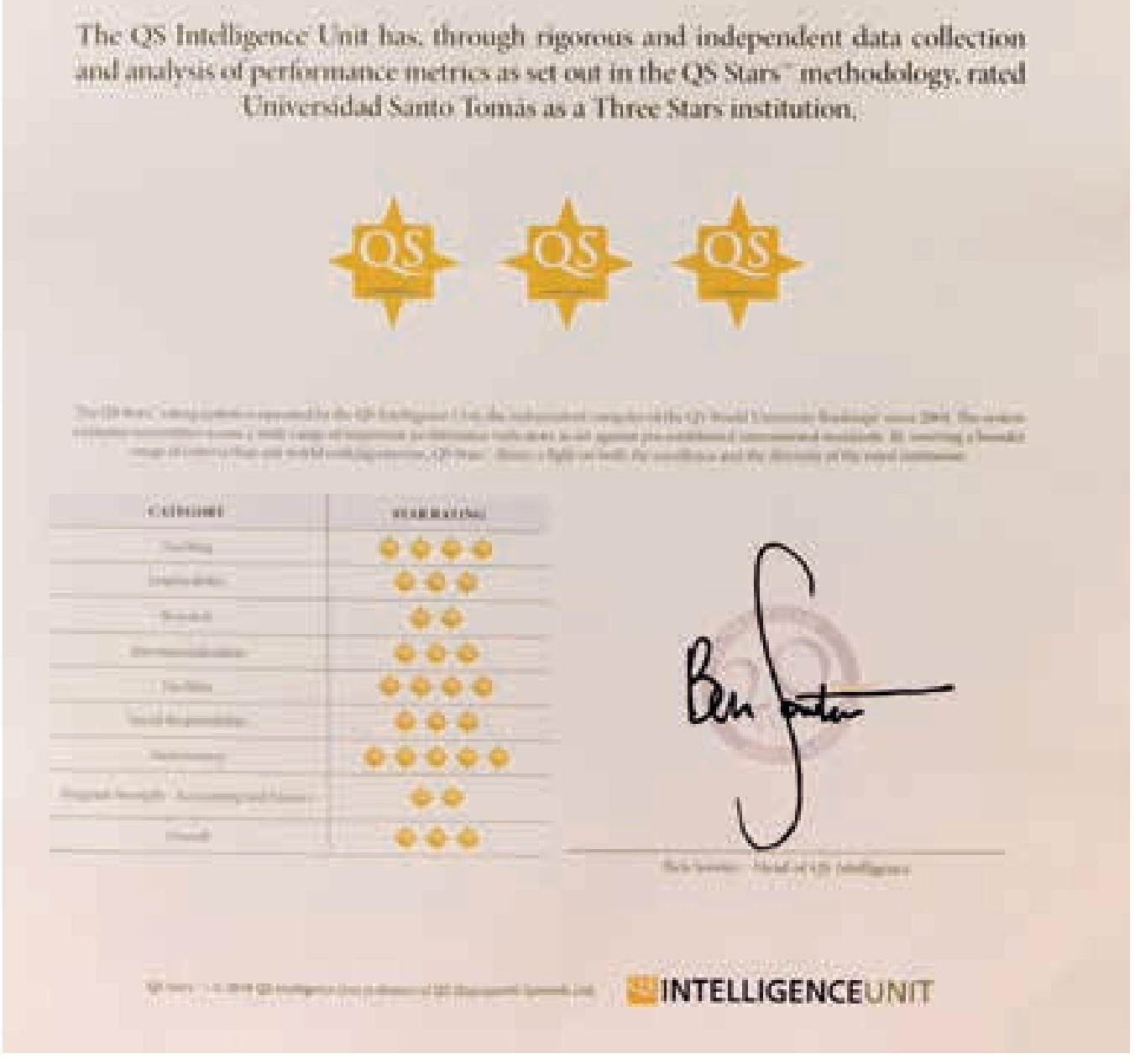

En 2018, la Universidad fue merecedora de la calificación de tres estrellas por parte de la auditora internacional de calidad Qs Stars

una labor de trabajo conjunto hacia la movilidad con la Universidad Nacional de Lanús (Argentina) y la Corporación para la Educación y el Desarrollo de América Latina y el Caribe (CEDALC, Colombia). ${ }^{459} \mathrm{Se}$ han ofertado becas de movilidad internacional, ampliando la cobertura a jóvenes del programa "Ser Pilo Paga”, estudiantes de las VUAD, estudiantes con movilidad reducida internacional y para estudiantes de posgrados. Se ha venido trabajando continuamente en la articulación y actualización del programa Promousta a nivel nacional, en el que a través de políticas e incentivos se ha permitido la movilidad de la comunidad académica, administrativa y directiva a diferentes eventos de impacto internacional, logrando dejar en alto el nombre de la USTA.

Una de las acciones estratégicas que se trabaja constantemente es el fortalecimiento de convenios con programas e instituciones que destaquen el nombre de la UsTA a nivel global, muestra de ello es la beca Erasmus + de la Unión Europea o la selección por parte del Servicio de Intercambio Alemán (DAAD) para hacer parte nuevamente del programa Jóvenes Ingenieros del DAAD Colombia 2018-202I, que permite a jóvenes de las facultades de ingenierías hacer semestres académicos y prácticas profesionales en las mejores universidades y empresas de Alemania. Así mismo, la USTA ofrece becas de reciprocidad para movilidad de estudiantes, en todas sus sedes y seccionales, y beneficia anualmente a más de 50 estudiantes con apoyos económicos en alojamiento y manutención. Se ha incrementado la participación en los programas que ofrece el Icetex y se han obtenido beneficios de financiación para la movilidad de profesores invitados - expertos internacionalesa la Usta.

En el marco del fortalecimiento de los programas de lenguas se han implementado estrategias de internacionalización en casa (actividades de internacionalización dentro del campus), que permiten reforzar el bilingüismo en las aulas. Se han implementado dos 


\section{7}

Madurez institucional 1995-20I8

estrategias como el Santoto Summer School, que articula una oferta de cursos intersemestrales en idioma inglés con docentes extranjeros y la Semana Internacional, con conferencias en inglés con docentes de la USTA sobre temas de actualidad internacional y actividades de multiculturalismo con estudiantes extranjeros. Todo lo anterior, con el apoyo y la sinergia del Instituto de Lenguas, las facultades y el Departamento de Humanidades.

La Rectoría ha apoyado el proceso de implementación de un software de gestión de la internacionalización que permitirá a los estudiantes — tanto tomasinos como externos - realizar todos sus procesos de movilidad en línea, contribuyendo así a la innovación en los procesos administrativos y de servicios a la comunidad en la USTA Colombia. De igual forma, esta plataforma digital contará con un módulo que apoyará el proceso de gestión de convenios que se trabaja en conjunto con departamentos académicos y administrativos.

Con el fin de fortalecer la gestión en la ORII, se ha creado la Coordinación de Internacionalización, que ha permitido articular y coordinar los procesos de fomento a la internacionalización al interior de cada facultad con la asignación de horas nómina para docentes. En 2016 se contaba con tres horas mensuales por cada docente, en 2017 se triplicaron las horas a diez horas mensuales y en 2018 cada facultad tiene un docente con horas nómina para internacionalización entre treinta y cincuenta horas mensuales. Por lo anterior, se reactivó el Comité Particular de Internacionalización con los docentes líderes de internacionalización y sus decanos para trabajar de manera eficaz y oportuna en las acciones de internacionalización de cada facultad y de la USTA en general. Adicionalmente, se ha propuesto fortalecer los procesos de la VUAD a través de un profesional especializado de la ORII para procesos en la modalidad abierta y a distancia.

La estrategia de visibilidad internacional de la USTA también trabaja de la mano con el Departamento de Admisiones y Mercadeo, y ha logrado impactar a nivel internacional a nacionales de Ecuador y Perú para que estudien sus programas profesionales de pregrado y posgrado en la Universidad Santo Tomás.

El diseño y la difusión de piezas de comunicación y promoción en español e inglés -videos, folletos y pagina web- permiten que el público internacional interesado en la Universidad tenga acceso a la información adecuada y oportuna. Adicionalmente, desde el 2016 se viene fomentando una estrategia de articulación de todas las sedes y seccionales a través del Campus
Internacional Usta Colombia. En este evento, todos los estudiantes de intercambio - movilidad entrantecuentan con la oportunidad de tener una dimensión multicultural, en la cual, a lo largo de cuatro días, cada semestre en una determinada sede o seccional se realizan actividades académicas, con el fin de impactar a los estudiantes internacionales y crear vivencias que evidencian la alta calidad de la Universidad. Este evento tiene como fin visibilizar a la USTA en las ciudades donde las sedes y seccionales están ubicadas.

La ORII, en conjunto con el departamento de Planeación, la UGICU y la Unidad de Investigación, realizaron el análisis para la implementación de la auditoria internacional Qs Stars (Qs Rankings) con el fin de hacer una evaluación integral de carácter internacional, y así trabajar por el cumplimiento de la Visión del 2027: ser referente internacional. Esta auditoría le otorgó a la Universidad tres estrellas en el ranking, convirtiéndola en la sexta institución de educación superior del país en obtener esta calificación.

Así mismo, se han llevado a cabo talleres en la Sede Bogotá que han tenido alcance nacional (presencia de sedes y seccionales) para trabajar en la acreditación internacional de ingenierías ABET; la Ugicu, la División de Ingenierías (Bogotá) y la ORII, llevaron a cabo la contratación de una asesoría con la Universidad del Norte para hacer un análisis sobre las capacidades y la implementación de los procesos ABET a los currículos de ingeniería usta Colombia, con el fin de obtener esta acreditación internacional.

En este orden de ideas, el proceso de internacionalización de la USTA se ajusta constantemente a los procesos de un mundo cada vez más globalizado, partiendo del conocimiento real de sus fortalezas y oportunidades de mejora continua, y centrando su discusión en el alcance y los resultados de la Institución.

\section{Enriquecimiento regional de programas con estándares comunes}

A partir de lo establecido en el PIM y el PGD, se está llevando a cabo un proceso de unificación curricular por medio de una política de 80/20: un $80 \%$ de los contenidos curriculares corresponde a la unificación curricular que consolida a la Universidad como multicampus y un $20 \%$ corresponde a las realidades locales y regionales. Esta política, que en ningún caso puede ser asimilada como una homogeneización, permite fortalecer frente a los estudiantes la Universidad Santo Tomás como una sola institución: "Entonces, un estudiante que ingresa a la Universidad, debe garantizársele 


\section{8}

Madurez institucional 1995-2018

Vista aérea del nuevo campus de la USTA

Tunja en el sector de Avenida Universitaria

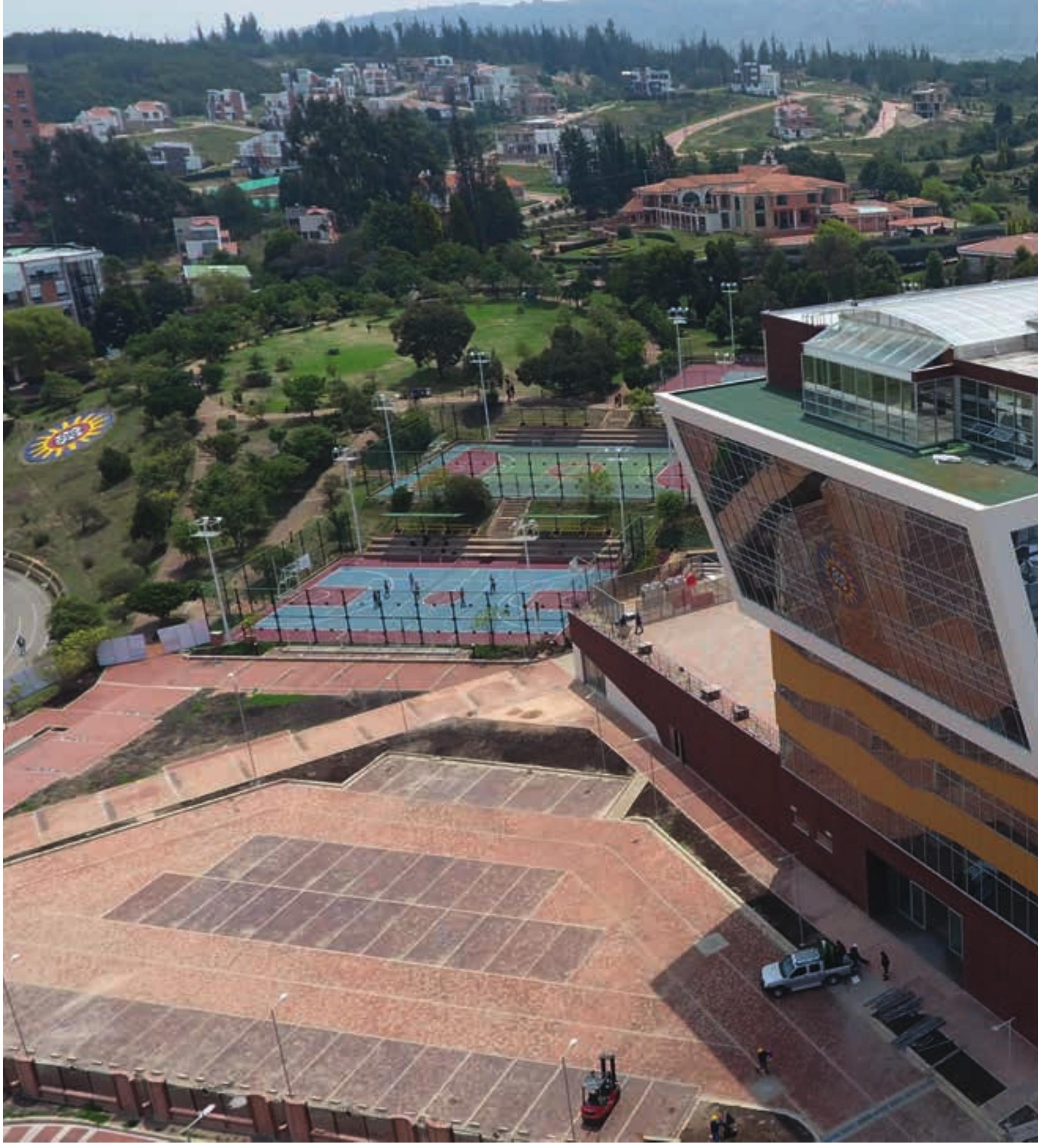




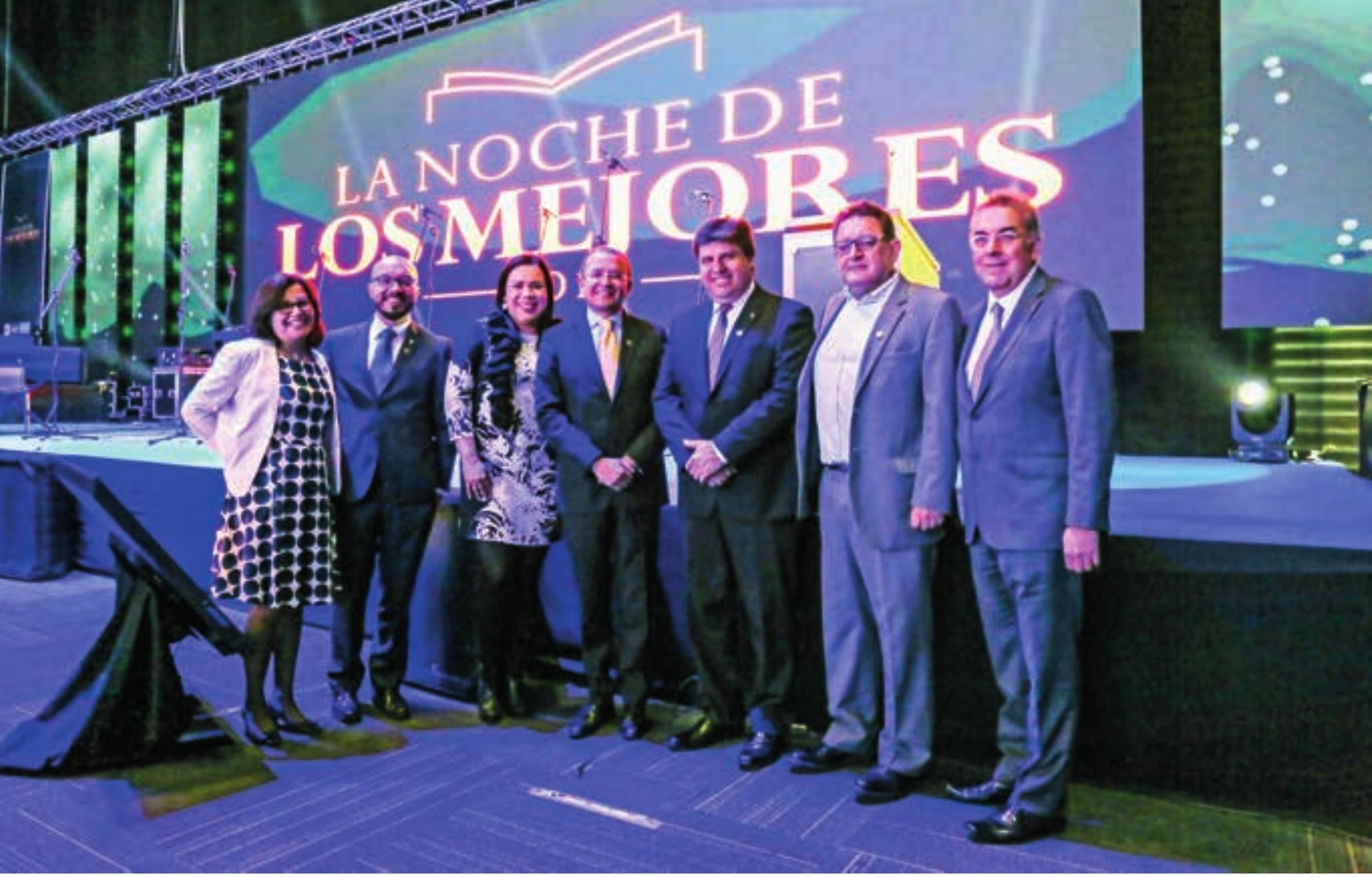

Como todos los años, la Universidad Santo Tomás hizo parte de la gala La Noche de los Mejores, en la que el Ministerio de Educación hace un reconocimiento a las instituciones educativas de alta calidad

que es miembro de la comunidad con todas las condiciones con las cuales se puede acceder a desarrollar su disciplina y su programa académico"460.

Para finales de 2018, de los 28 programas académicos que se ofertan con la misma denominación en todo el país, 24 están unificados. Todo esto además tiene la ventaja de que facilita enormemente la movilidad académica entre las diferentes sedes y seccionales. El proceso ha sido liderado por la Vicerrectoría Académica en cabeza de fray Mauricio Cortés Gallego, O. P., y a través de los comités curriculares ampliados. $\mathrm{El}$ avance ha sido significativo principalmente en las cuestiones académicas, mientras que aspectos administrativos como la diferenciación local y regional en términos de matrículas, salarios, capacidades instaladas, etc., será abordada subsecuentemente.

Precisamente en cuanto a cobertura regional, además de los once registros calificados que se sumaron a la oferta académica en 2018 -incluyendo pregrados, posgrados y doctorados en Bogotá, Villavicencio y Medellín-, Villavicencio se destaca por su crecimiento en los últimos años y próximamente alcanzará los 5000 estudiantes; su oferta académica es un ejemplo de proyección hacia las necesidades de la región y hoy por hoy la USTA es un actor preponderante de la cultura en los Llanos. Finalmente, aunado a la ya aludida transformación en la VUAD, allí también se ejecuta una gran renovación curricular que conllevará un mayor uso de herramientas tecnológicas, virtualidad y cualificación docente.

\section{Personas que transforman sociedad}

En su discurso de posesión, fray Juan Ubaldo López Salamanca, O.P., propuso como tercer desafío los egresados y el impacto en el entorno nacional e internacional:

Cada vez se requieren personas con capacidades de creación y abstracción, con una formación que les permita identificar y resolver problemas, planear alternativas, ser gerentes estratégicos, de pensamiento sistémico, de experimentación, de colaboración y de una alta autoestima y menos de aquellos que están capacitados únicamente para llevar a cabo labores rutinarias de acuerdo a normas preestablecidas.

Es por ello que en la línea cinco del PIM denominado "Personas que trasforman sociedad" y en concordancia 


\section{I}

Madurez institucional $1995^{-2018}$

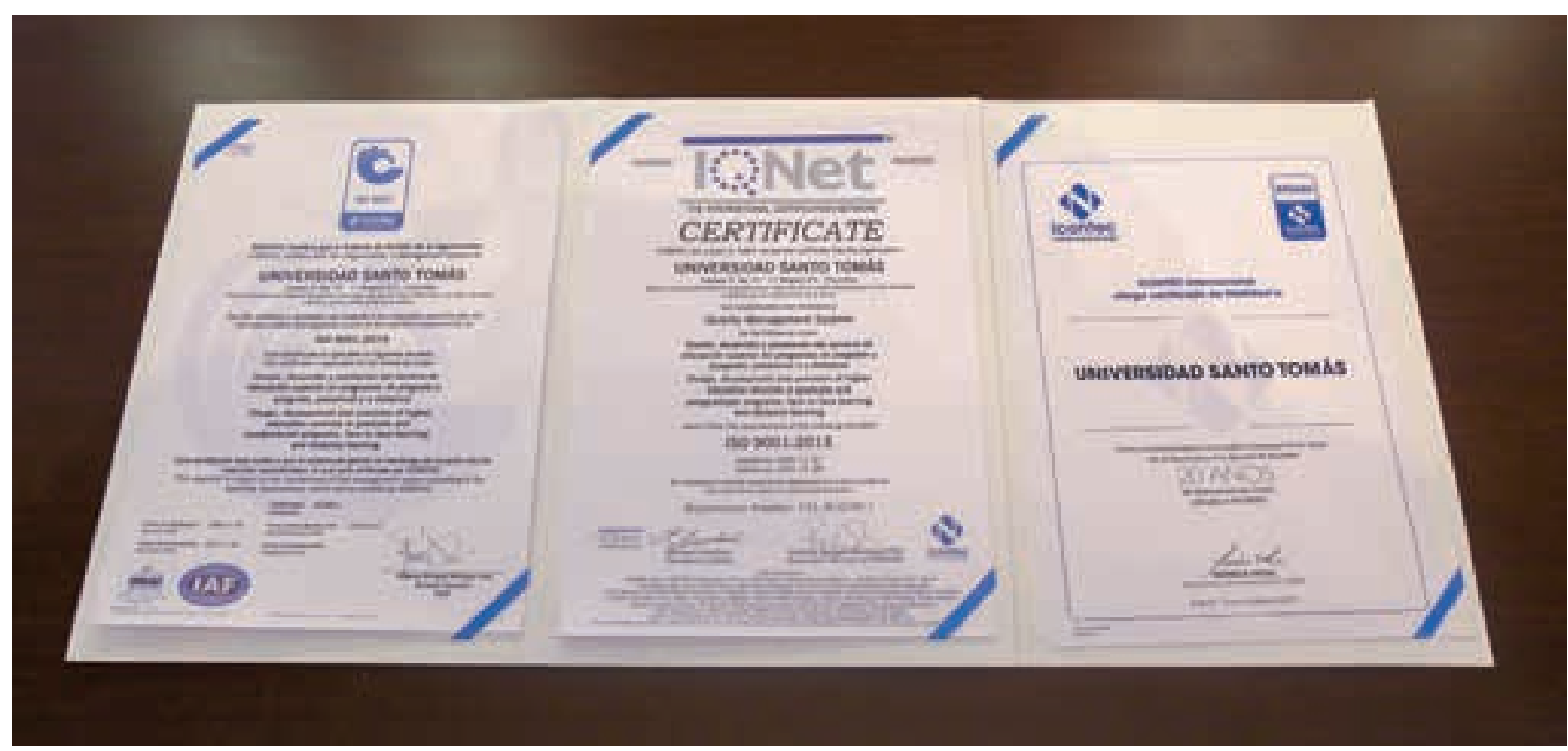

En 2018 la Universidad recibió la certificación del Sistema de Gestión de la Calidad bajo la NTC ISO 90oI:2015, con el alcance: diseño, desarrollo y prestación del servicio de educación superior en programas de pregrado y posgrado, presencial y a distancia

a ese tercer desafío un objetivo es el de mantener y fortalecer vínculos entre los egresados y su alma mater, creando condiciones favorables para su participación activa en los procesos que lleven al engrandecimiento de la Institución, a su desarrollo integral y al beneficio de la comunidad.

A continuación, se resumen algunos de los logros en la Oficina de Egresados:

I. Uno de los proyectos más relevantes planteado en la línea 5 del PIM es la caracterización de los egresados de la UsTa basada en la movilidad social y la percepción de los empleadores, estudio que estará finalizado a finales del año 2018.

2. Fortalecimiento de la Red de Empresarios Tomasinos creada en el año 2014 y que actualmente cuenta con más de 500 empresas de tomasinos a nivel nacional. Ya la Red cuenta con con sedes en Bogotá, Villavicencio y Bucaramanga, y se espera abrir más en las regiones en donde la universidad está presente. A los empresarios la USTA les organiza diversas actividades como capacitaciones en diversos temas de interés, ruedas de negocios generando espacios para que los tomasinos se conozcan y puedan realizar alianzas. El lema de la
Red es “Tomasino, negocia con Tomasinos”. Para fines de este año se espera contar en la página web de la USTA con el directorio de los empresarios ya registrados.

3. Consolidación de la diáspora tomasina, conformada por los egresados que viven el en exterior, de manera que se pueda tener identificados los tomasinos dispersos en el mundo, tener comunicación con ellos y generar redes de apoyo.

4. Con el fin de fortalecer el programa de Acompañamiento e Inserción Laboral, se realizaron cambios en el portal de trabajo tomasino y se implementaron conferencias, talleres para estudiantes de últimos semestres y egresados para el fortalecimientos de habilidades laborales y en temas relacionados, para que sean más competitivos en los procesos de selección.

5. Con el fin de fortalecer vínculos de los egresados con su Alma Mater y el sentido de pertenencia se han incrementado los eventos y encuentros anualmente a nivel general como por facultades para los egresados y también se motiva a los tomasinos para que regresen a la USTA a celebrar con sus compañeros años de graduación. 


\section{2}

Madurez institucional 1995-2018

6. Desde el primer semestre del 2016 la Oficina de Egresados es la dependencia que organiza el reconocimiento a los estudiantes de último semestre de pregrado. Debido a la culminación de sus estudios, dicha celebración se conocía anteriormente como "La despedida", pero se quiso dar un cambio, ya que los egresados nunca deberían irse de su universidad. El objetivo es que los estudiantes, una vez se gradúen, sigan en contacto con su casa de estudios, razón por la cual dicho evento se denomina actualmente "Somos tomasinos" y se realiza una vez por semestre. En el marco del evento, se realiza un reconocimiento especial al estudiante con el mejor promedio acumulado por cada uno de los programas.

Durante el periodo rectoral de fray Juan Ubaldo se han realizado tres encuentros generales de Egresados (en julio de 2015, julio 2016 y octubre 2017), a cada uno de los cuales asistieron en promedio 500 egresados.
Estos encuentros son espacios para que los egresados vuelvan a su alma mater y se reencuentren con amigos, docentes y se enteren de los avances de la USTA, y además se hace un reconocimiento a los egresados que se hayan destacado por su labor profesional.

En el año 20I5, teniendo en cuenta que la USTA conmemoraba cincuenta años de la restauración, se aprovechó para hacer un reconocimiento a los "egresados restauradores", los cuales fueron los pioneros en I965, y agradecerles por haber creído en la Universidad y abrir el camino para tantas generaciones de egresados.

En los últimos años se han incrementado los encuentros de egresados por facultades y por generaciones, quienes retornan a su universidad para celebrar años de graduación.

En el mes de octubre del 2018 se llevó a cabo el V Congreso Nacional de Egresados Tomasinos, evento que se realiza cada cuatro años en la USTA. La sede de este importante evento es Bogotá y el tema
$V$ Congreso Nacional de Egresados realizado del I2 al I4 de octubre de 2018 en Bogotá, donde se reunieron los "tomasinos que transforman la sociedad"

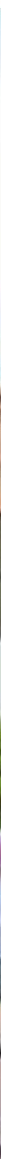




\section{3}

Madurez institucional 1995-2018

central tuvo por título "Tomasinos que transforman sociedad".

Desde el año I996 cuando se creó Prousta, la Universidad Santo Tomás ha venido apoyando esta asociación, y en aras de fortalecerla aún más aprobó en el segundo semestre del 2015 un descuento del I5\% para los egresados afiliados a esta. Se encuentra liderada por un Consejo Directivo Nacional y un director ejecutivo. Sus últimos presidentes han sido el ingeniero Ricardo Galindo Lozano, 2015-2016; el economista Esneider Pesca Polanco, 2016-20I7; y la abogada Myriam López Rojas, 2017-2018. Por su parte, la Dirección Ejecutiva Nacional ha estado a cargo de la economista Eva Flye Quintero, desde 2013 hasta el 2018.

En esta línea y para honrar a los frailes que le han aportado su vida, conocimiento y han transformado la comunidad universitaria, fray Juan Ubaldo les otorgó la máxima condecoración que tiene la Universidad: la Orden Facientes Veritatem, Categoría Oro.
Esta misma condecoración les fue otorgada a los cuatro frailes rectores que fueron consolidando y fortaleciendo la USTA hasta verla convertida hoy en la primera universidad privada en recibir la Acreditación Multicampus por parte del Gobierno Nacional, ellos fueron: Jaime de Jesús Valencia García, O. P., Eduardo González Gil, O. P., José Antonio Balaguera Cepeda, O. P., y Carlos Mario Alzate Montes, O.P.

Capacidad y gestión institucional que logran la efectividad multicampus

El Plan Integral Multicampus ha permitido sumar y visibilizar esfuerzos, actividades, experiencias y logros que antes se encontraban dispersos debido a la amplitud de la presencia de la USTA en Colombia. Mientras que anteriormente la valoración que se hacía de la Universidad se fragmentaba, como si se tratara de varias universidades que eran valoradas por separado, ahora dicha valoración se ha empezado a

Ceremonia de condecoración a los frailes de la Provincia San Luis Bertrán por su contribución a la USTA. De izquierda a derecha, abajo: Marco Antonio Peña, Tito Belisario Murcia, Jaime Valencia, José María Prada Dietes, Carlos Arturo Ortiz, José Antonio Balaguera Cepeda, Faustino Corchuelo Alfaro, Eduardo González Gil y Carlos Mario Alzate Montes; arriba: Juan Ubaldo López Salamanca, Said León Amaya y Jorge Hernando Murcia Florián

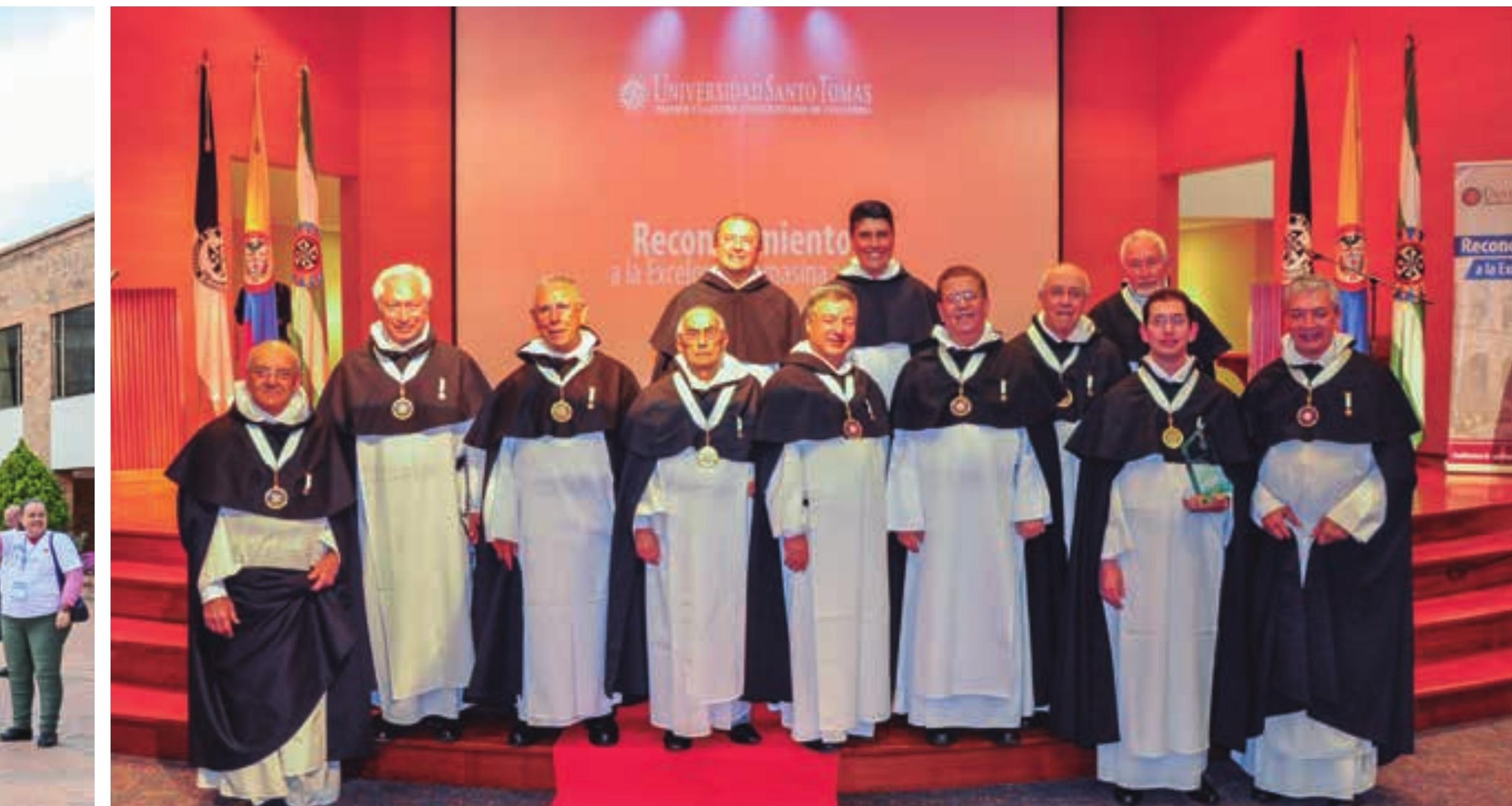




\section{4}

Madurez institucional 1995-20I8

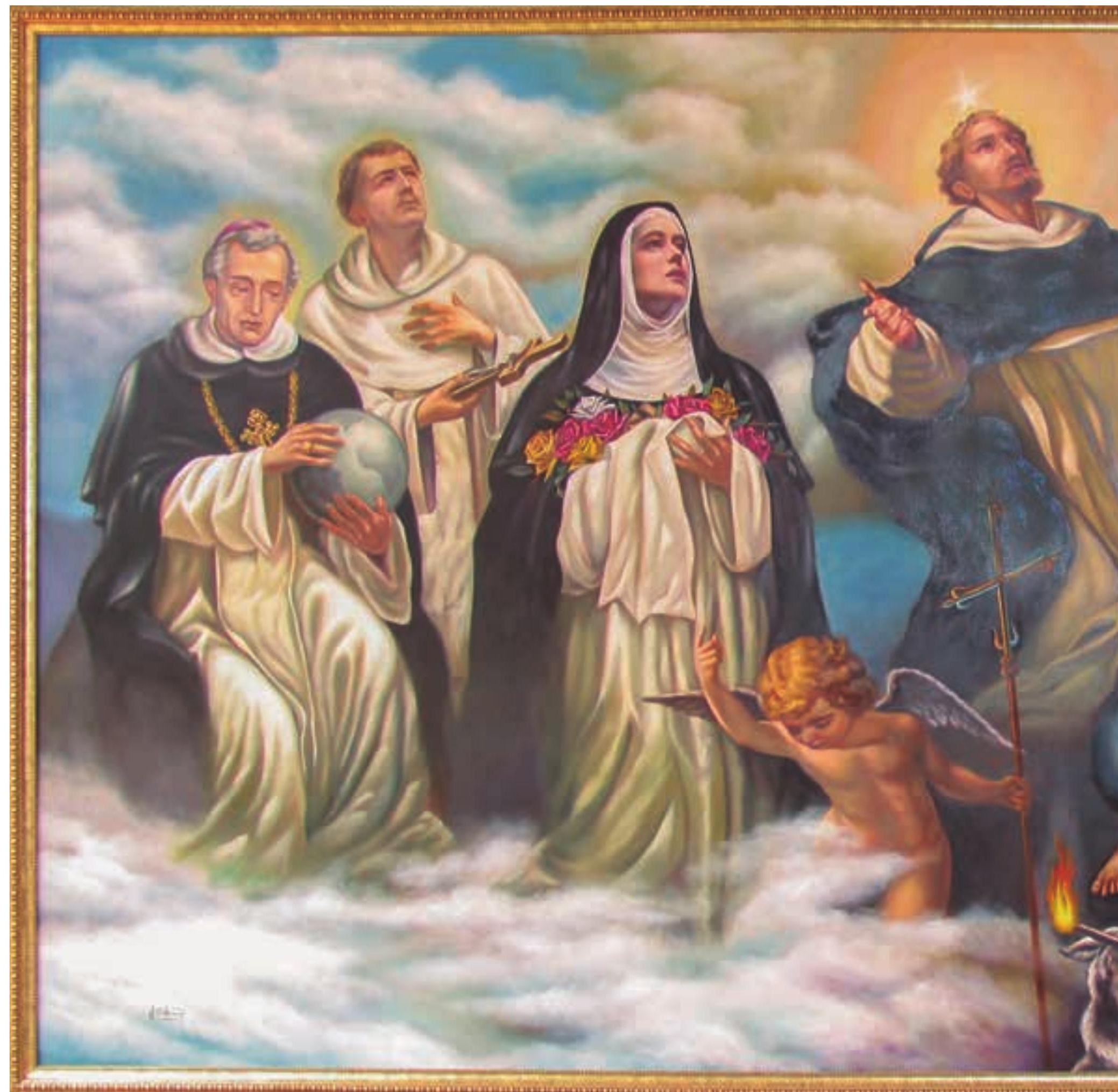

La glorificación de la Orden de Santo Domingo, pintura mural, Campus San Alberto Magno, Bogotá 


\section{5}

Madurez institucional 1995-20I8

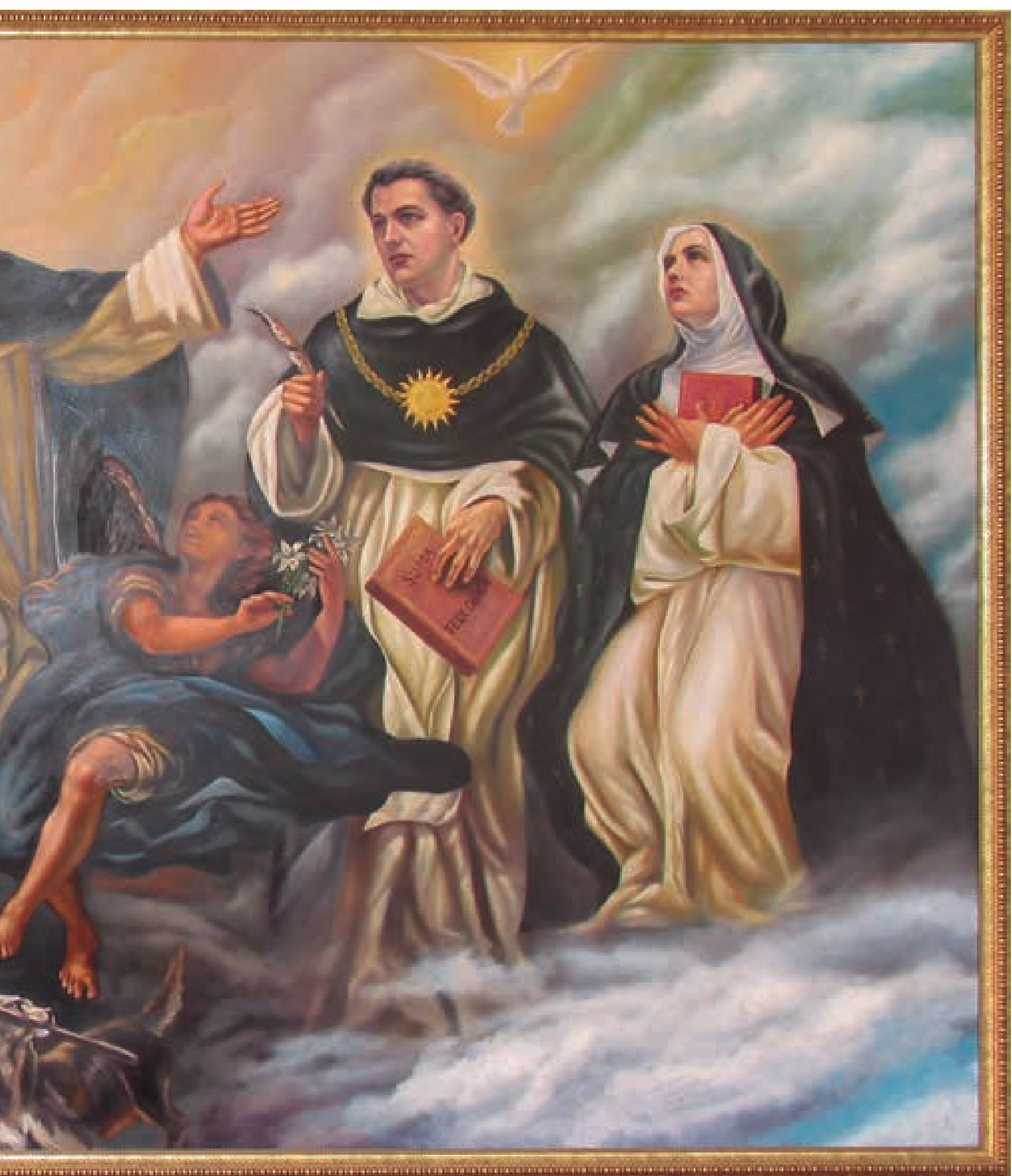




\section{6}

Madurez institucional $1995^{-2018}$
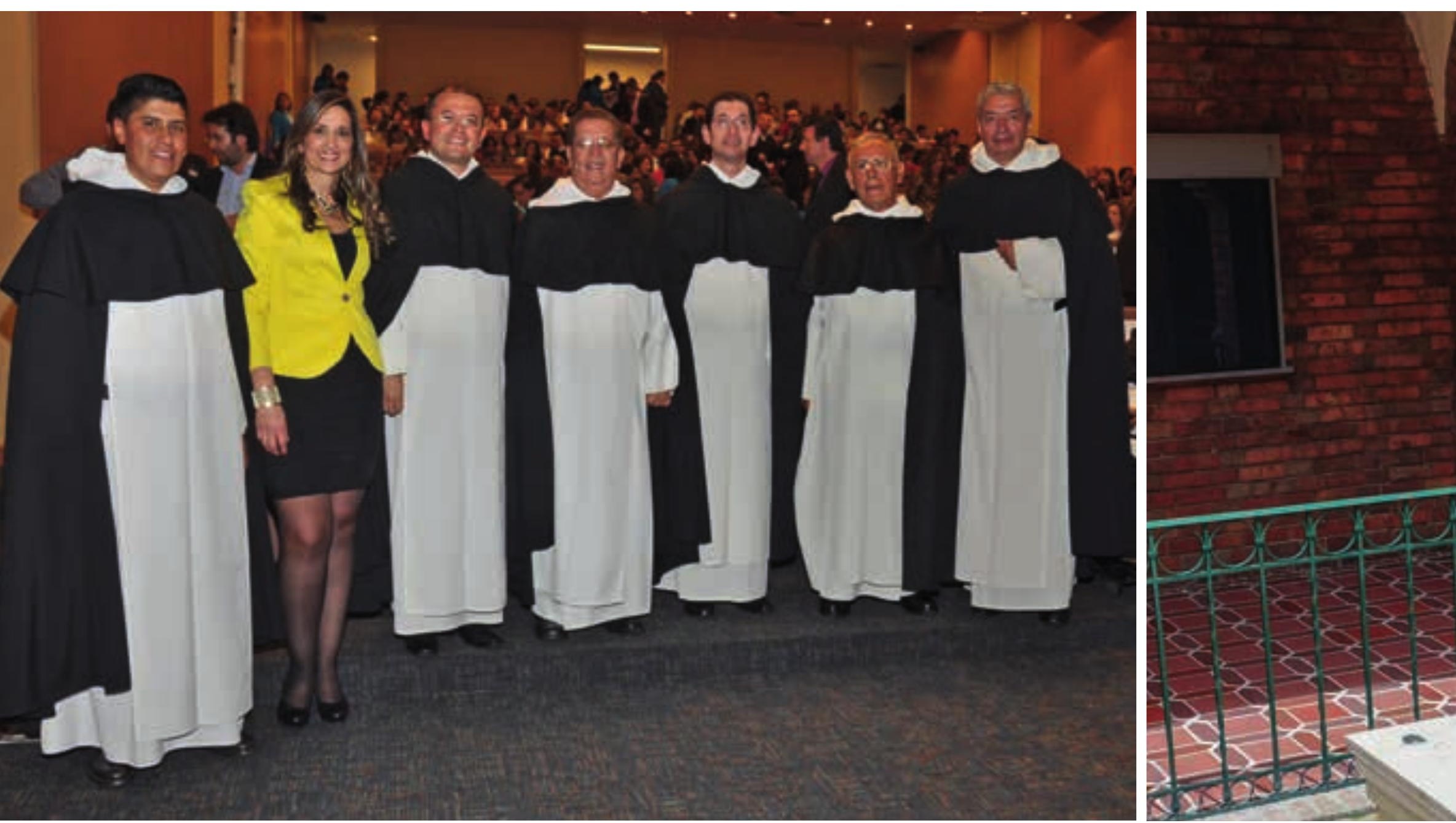

El reconocimiento a la excelencia docente fue la excusa perfecta para reunir a los rectores de la USTA. De izquierda a derecha, acompañados por Eva Flye, directora de la Oficina de Egresados, los frailes: Said León Amaya, Juan Ubaldo López, José Antonio Balaguera, Eduardo González, Jaime Valencia y Carlos Mario Alzate

realizar considerándola como una sola institución. Es importante recalcar que esto no significa de ninguna manera un proceso de centralización en Bogotá.

Como parte de la línea de acción capacidad y gestión institucional que logran la efectividad multicampus, se estableció el objetivo de diseñar e implementar el Sistema Integrado de Información Multicampus (SIIM) que soporta la gestión académico-administrativa de la Universidad. Se espera que en el año 2019 el silm ya provea a la Insitución del conocimiento necesario para la toma de decisiones, así como para adelantar los procesos de acreditación de programas, acreditación institucional, gestión de registros calificados, reportes a entidades y plataformas del Estado y del Ministerio de Educación. Así mismo, se espera que el siım facilite a los diferentes líderes académicos y administrativos herramientas para poder realizar análisis e inteligencia de información que genere mayor conocimiento de la Institución para el mejoramiento continuo en la gestión académica y administrativa.

En cuanto a la infraestructura, en octubre de 2016 dio inicio la construcción del edificio Santo Domingo en Tunja. El edificio tendrá un área de $22000 \mathrm{~m}^{2} \mathrm{y}$ contará con laboratorios, cubículos de investigación, aulas, gimnasio, cafeterías, centro de convenciones, auditorios, capilla, áreas administrativas, entre otras ${ }^{46 \mathrm{r}}$.

Vale la pena recordar que desde la creación de la Sede Medellín, esta ha afrontado innumerables crisis. Al respecto, se han tomado determinaciones importantes y se ha establecido la necesidad de cambiar la ubicación de dicha sede, un tema recurrente desde hace varios 


\section{7}

Madurez institucional 1995-2018

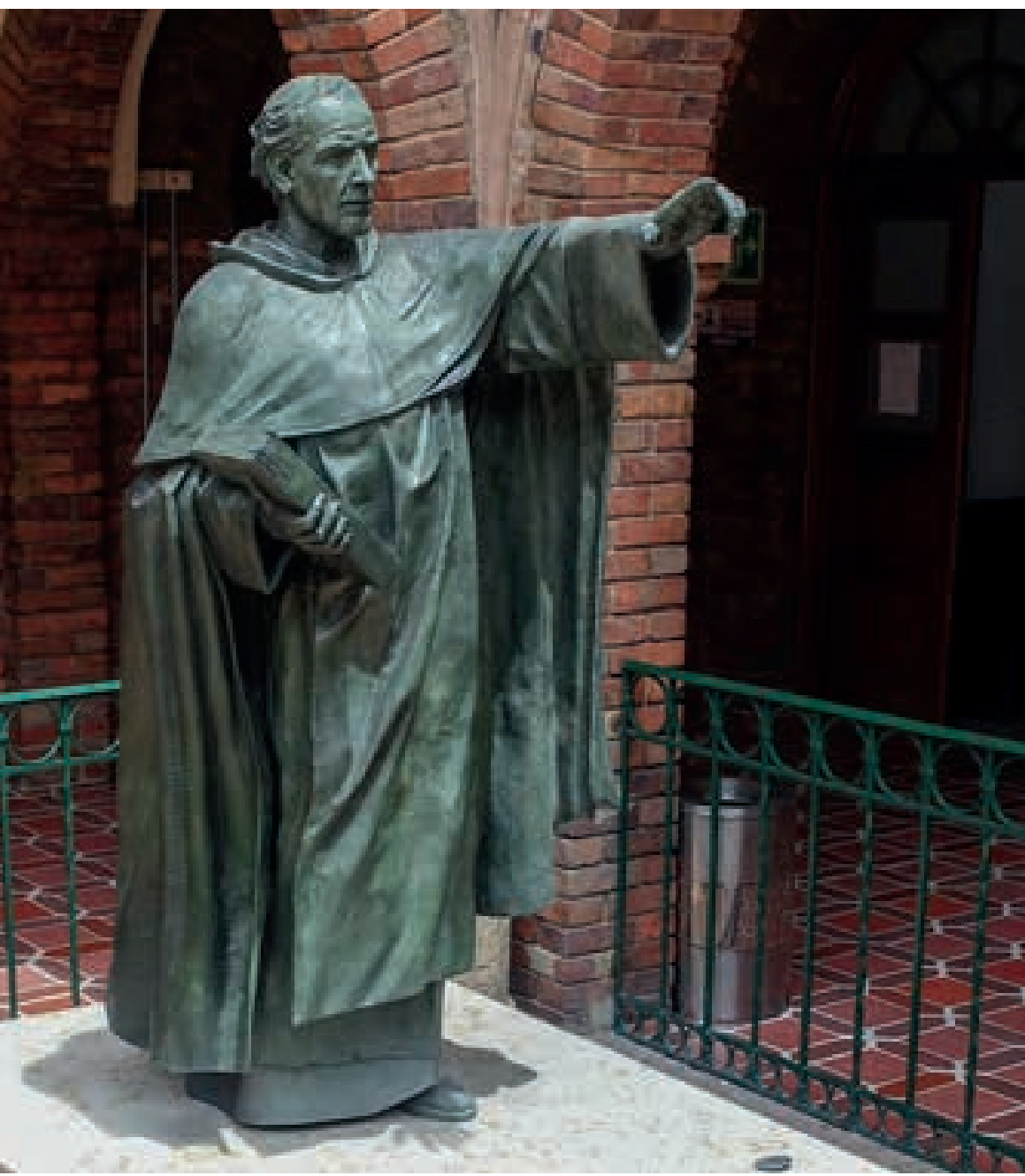

Las nuevas esculturas de San Alberto Magno y Santo

Tomás, en el claustro de la Sede Central, obra del artista Juan José Cobos Roa

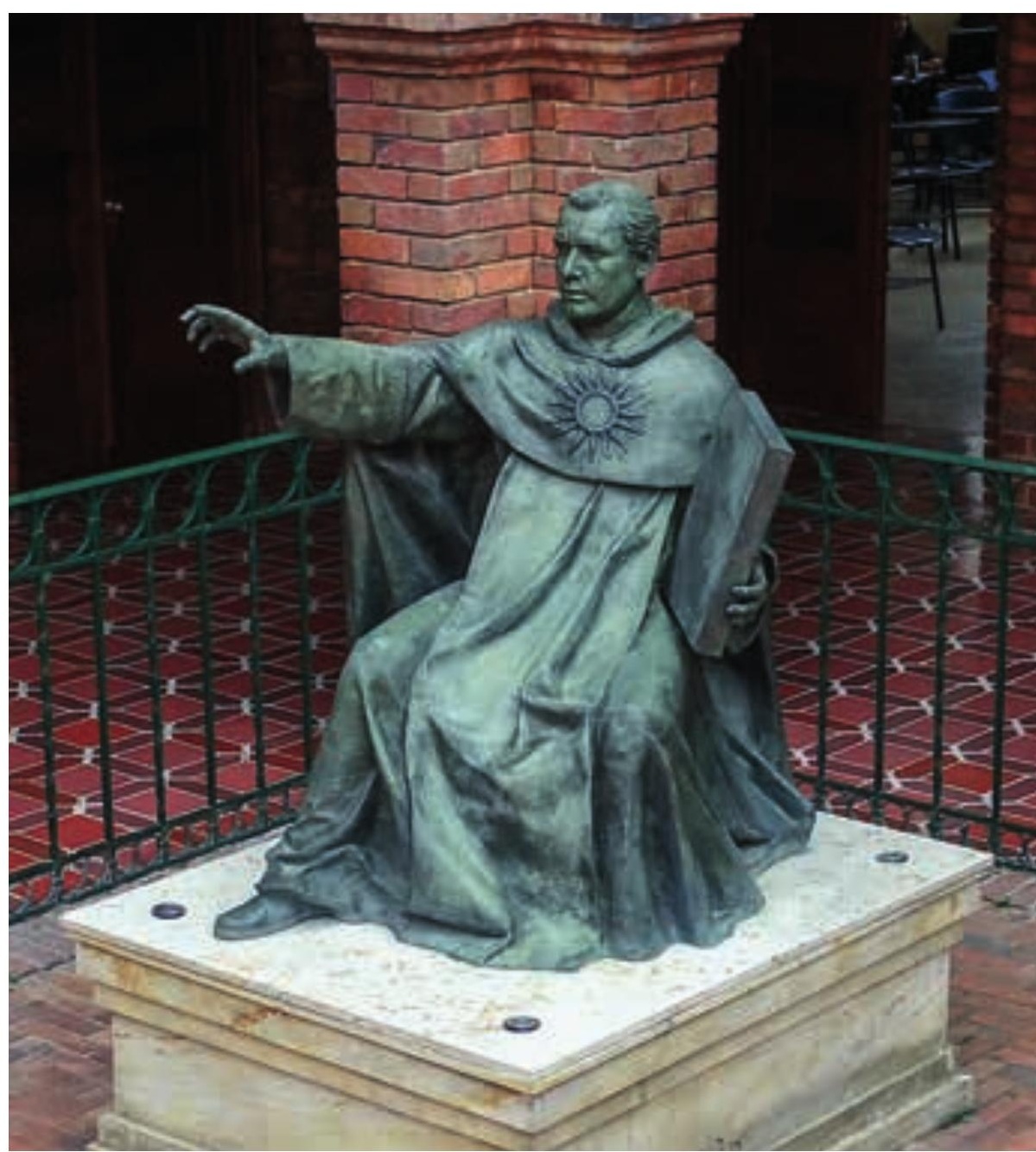

están orientadas a proporcionar una mejor base para la toma de decisiones enfocada en la transparencia de la información. Y es que, en el marco de la globalización, es fundamental la estandarización del lenguaje contable para la elaboración y presentación de estados financieros que favorezcan la transparencia de las entidades. En consecuencia, un compromiso estratégico de las organizaciones es hablar el mismo idioma financiero, de ahí el acogimiento de las NIIF o IFRS.

En Colombia se inició el proceso de adopción de las Normas Internacionales de Información Financiera (NIIF) con el Decreto 2784 que reglamenta la Ley I3I4 del 2009, estableciendo el régimen normativo para los preparadores de información financiera. A partir de este año, Colombia inició el proceso de adopción bajo NiIf. Este proceso implica importantes cambios, nidades para mejorar la función financiera, puesto que
Por otro lado, en este momento, la Universidad está adoptando las normas NIIF/IFRS ${ }^{464}$, que ofrecen oportu-

años, pero también ha quedado claro que es imperativo generar una mayor oferta de programas de posgrado. yecto de infraestructura que permitirá relanzar la Sede Medellín, a la que se le suma el monasterio de las la Visitación de Santa María en terio será adecuado para la vida universitaria, con la le permitirá observar su desempeño fuera de Rob en los próximos años. En cuanto a los posgrados, la ede viene creciendo en ese sentido. 


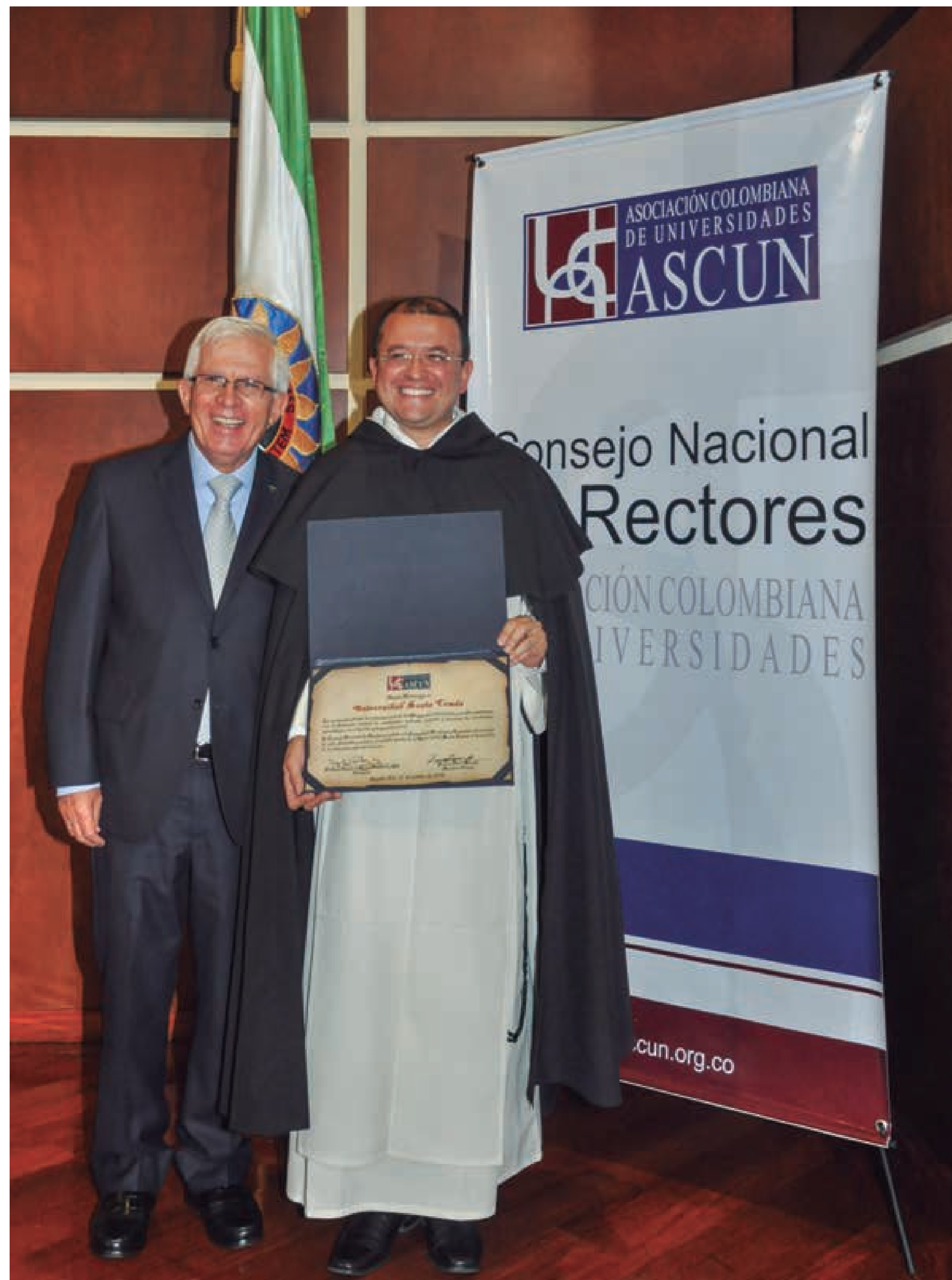

Fray Juan Ubaldo López, O.P., y el padre Jorge Humberto Peláez Piedrabita, S. J., rector de la Pontificia Universidad Javeriana. Reunión de rectores, Ascún, 20I5, en el Convento Santo Domingo 


\section{9}

Madurez institucional 1995-20I8

pues lleva hacia un sistema de información gerencial y cultural, por lo que directivos y personas involucradas en la toma de decisiones deben tener un mayor acercamiento y conocimiento de las novedades que traerá esta transición de normas nacionales a estándares internacionales de contabilidad.

La Universidad Santo Tomás, consciente de la necesidad de dar cumplimento a los procesos de convergencia y a su proyección en el Plan general de Desarrollo, se acoge a los parámetros establecidos por IASB, por el Consejo Técnico de la Contaduría Pública el 5 de diciembre del 2012 y basándose en los decretos 3022 del 27 de diciembre del 2013 y 2267 del ir de noviembre de 20I4. Con dicha adopción la Universidad obtiene el mismo nivel que los competidores extranjeros, toda vez que se hablará con los mismos términos financieros.

Los beneficios obtenidos por la implantación de las NiIf son: mayor transparencia en las cifras de los estados financieros, el acceso a mercados de capital, obtener información que permita ser comparada tanto entre las sedes como con el mercado financiero, unificar el lenguaje contable y financiero dentro de la universidad, agilizar los negocios con empresas extranjeras, brindar credibilidad y facilitar el acceso al sistema financiero, así como visualizar oportunidades de inversión, disponer de información para la toma de decisiones y simplificar la elaboración de los estados financieros de la Universidad.

Por último, es importante insistir en que las iniciativas anteriormente destacadas responden a las directrices emanadas del Consejo Nacional de Educación Superior, a la intención explícita de fortalecer la Institución desde y hacia las regiones, y son posibles, además, gracias a los denodados adelantos en el mejoramiento de los sistemas de gestión universitarios, del Plan Maestro 2035 y de la gestión de comunicaciones interna y externa que adelanta la Universidad.

\section{Situación para finales de 2018}

En la tabla 3I, "Población estudiantil 20I8-I" se puede observar la totalidad de la población estudiantil al primer semestre del año 2or8. Actualmente, la USTA cuenta con 197 programas académicos a nivel nacional, I699 administrativos, I95 aprendices, 292 convenios nacionales e internacionales, I4 304 estudiantes beneficiados con apoyo financiero y 982 estudiantes beneficiados con el programa gubernamental Ser Pilo Paga ${ }^{465}$.
En cuanto a la investigación, la USTA cuenta actualmente con 102 grupos, de los cuales 65 se encuentran reconocidos y categorizados por Colciencias, así como con 23I semilleros ${ }^{466}$. Además, la Santo Tomás hace presencia nacional a través de 23 Centros de Atención Universitaria (CAU) en I8 departamentos del país ${ }^{467}$. En la actualidad, la Proyección Social tomasina impacta a más de 60000 personas a través de sus 472 programas y sus 9 Centros de Proyección Social ${ }^{468}$. La acción de la Proyección Social se efectúa a través de los mismos servicios que hemos mencionado al comienzo del presente capítulo, a los que se ha sumado el de consultorías empresariales.

En infraestructura física, la USTA tiene $159088 \mathrm{~m}^{2}$ construidos repartidos nacionalmente para un promedio de $5.5 \mathrm{~m}^{2}$ por estudiante ${ }^{469}$. Actualmente, la Universidad Abierta y a Distancia, que cuenta con 23 CAU, tiene una oferta de pregrados compuesta por II licenciaturas, 7 tecnologías, más programas presenciales en Teología y Licenciatura en Filosofía y Lengua Castellana. En posgrados, ofrece 2 especializaciones y 2 maestrías en la Facultad de Educación, así como 4 especializaciones y una maestría en la Facultad de Ciencias y Tecnologías.

Bucaramanga, por su parte, ofrece 17 programas de pregrado en sus 4 divisiones, además de io maestrías, 2I especializaciones presenciales y una en modalidad virtual. A su vez, Tunja cuenta con ro programas de pregrado, uno por cada facultad, además de in especializaciones, 8 maestrías y 2 doctorados. Medellín cuenta actualmente con 4 pregrados, desde que se dejara de ofertar Contaduría Pública, además de 3 especializaciones. Finalmente, Villavicencio ofrece 7 programas de pregrado y 2 especializaciones.

Como símbolo de este nuevo rumbo Multicampus, que es un desarrollo consecuente con la tradición universitaria, el 7 de marzo de 2018 en el marco de la celebración del día de Santo Tomás de Aquino, la Universidad hizo renovación de las tan familiares esculturas de San Alberto Magno y Santo Tomás de Aquino que custodian la entrada principal del edificio Fray Alberto E. Ariza, O. P. Las nuevas esculturas son obra de Juan José Cobos Roa, egresado de la Facultad de Arquitectura de la Seccional Bucaramanga y graduado como Escultor de la Academia de Arte de Florencia (Italia) ${ }^{470}$. Las antiguas esculturas, elaboradas por el antioqueño José Augusto Rivera Castro, fueron instaladas en el Campus San Alberto Magno. 


\section{0}

\section{Madurez institucional I995-20I8}

\section{Notas de este capítulo}

I "Constitución Apostólica del Sumo Pontífice Juan Pablo II sobre las Universidades Católicas", La Santa Sede. Consultado el 6 de diciembre, 20I6. http://w2.vatican.va/content/john-paul-ii/es/ apost_constitutions/documents/hf_jp-ii_apc_I5081990_ex-corde-ecclesiae.html.

2 Claudio Rama, "La tercera reforma de la educación superior en América Latina y el Caribe: masificación, regulación e internacionalización", en Informe sobre la educación superior en América Latina y el Caribe. 2000-2005. La metamorfosis de la educación superior (Caracas: Iesalc, 2006), II-I3.

3 Véase: Jorge Charum, Misión de ciencias y tecnología. I. Estructura cientifica y entorno social. A. Estructura y transformaciones en la enseñanza superior. Informe final. Documento n. ${ }^{\circ}$ I (Bogotá: Ministerio de Educación Nacional - Departamento Nacional de Planeación - Fondo Nacional de Proyectos de Desarrollo, 1990).

4 Axel Didriksson, "Contexto global y regional de la educación superior en América Latina y el Caribe", en Tendencias de la educación en América Latina y el Caribe, editado por Ana Gazzola y Axel Didriksson (Caracas: Iesalc, 2008), 23.

5 Naomi Klein, La doctrina del shock: el auge del capitalismo del desastre (Barcelona: Paidós, 2007), 109-I23.

6 Jorge Landinelli, "Escenarios de diversificación, diferenciación y segmentación de la educación superior en América Latina y el Caribe", en Tendencias de la educación en América Latina y el Caribe, editado por Ana Gazzola y Axel Didriksson (Caracas: Iesalc, 2008), I62.

7 André Roth, Los procesos de cambios en las politicas públicas de educación superior en América latina desde una perspectiva comparada (Bogotá: Universidad Nacional, 20II), I8. Consultado el 25 de noviembre, 20I6. https://mesaampliaun.wordpress.com/ documentos/

8 Véase: Carlos Hernández y Juliana López, "Reformas en educación superior. Aspectos y perspectivas", Pensamiento Jurídico 3I (20II): IO9-IIO.

9 Alberto Martínez, "Formación y experiencia en la universidad", Revista Colombiana de Educación 70 (2016): 307-309.

Io Landinelli, "Escenarios de diversificación", I62-I63.

II Rama, "La tercera reforma de la educación superior", I2.

I2 José Dias Sobrinho, "Calidad, pertinencia y responsabilidad social de la Universidad Latinoamericana y Caribeña”, en Tendencias de la educación en América Latina y el Caribe, editado por Ana Gazzola y Axel Didriksson (Caracas: Iesalc, 2008), Io2-103.

I3 Ernesto Villanueva, "Reformas de la educación superior: 25 propuestas para la educación superior en América Latina y el Caribe", en Tendencias de la educación en América Latina y el Caribe, editado por Ana Gazzola y Axel Didriksson (Caracas: Iesalc, 2008), 259.

I4 Ángel, "El difícil tránsito a la virtualidad", 51.

I5 Rama, "La tercera reforma de la educación superior", I2.

I6 Hebe Vessuri, "El futuro nos alcanza: mutaciones previsibles de la ciencia y la tecnología", en Tendencias de la educación en América Latina y el Caribe, editado por Ana Gazzola y Axel Didriksson (Caracas: Iesalc, 2008), 83.

I7 Duque y Lucio, "Estado del arte de las comunidades académicas", II.

I8 Soto, "Aproximación histórica a la Universidad colombiana", I29.

I9 Un documento del Icfes y de la Asociación Colombiana de Facultades de Ingeniería del año 2000 resaltaba la notable proliferación de programas de esa área que claramente había empezado en 1992: Nomenclatura de títulos en la formación técnica profesional, tecnológica y de ingeniería en Colombia, diciembre del 2002, Mod. I, Est. 2, Caj. 44, Carp. I2, Fol. 54, Agust.

20 Valencia, Informe de Rectoría General I995-I999, 68.

2I Se reglamentó por ejemplo el Proyecto Educativo Institucional (PEI) como el documento oficial de una institución educativa en que se presenta su identidad a través de su misión, propósitos, objetivos, etc. El PEI es una herramienta pensada por las reformas educativas de la primera mitad de la década de 1990 para tecnificar la administración, unificar criterios y consolidar la madurez institucional en las instituciones educativas colombianas.

22 Oficio circular dirigido a los rectores y comunidad académica de la directora general del Icfes, 3 de mayo de 2002, Mod. I, Est. 3, Caj. 53, Carp. 2, Fol. 330, Agust.

23 En Colombia, la financiación de estudios en el exterior era el único esfuerzo sistemático por acceder a la sociedad de conocimiento global según un informe del Banco Mundial del año 2003 sobre educación terciaria en el país: World Bank, Tertiary education in Colombia. Paving the way for reform (Washington, D. C.: World Bank, 2003), 32. Informe a su vez marcado por los valores propios de la época, educación para la productividad la competencia, y visión de la educación como un valor económico.

24 Duque y Lucio, "Estado del arte de las comunidades académicas", 9-ז0.

25 Invitación del Ministerio de Educación Nacional al Seminario Internacional "Pertinencia de la educación: la educación para la competitividad", 24 y 25 de octubre de 2007, Mod. I, Est. 4, Caj. 94, Carp. 7, Fol. 36, Agust.

26 En el documento original de Visión 20I9, se define la política educativa 2002-2010, conocida como la Revolución Educativa, como basada en la expansión de la cobertura y el mejoramiento de la calidad "basada en el estímulo a los mejores". Departamento Nacional de Planeación, Visión Colombia II Centenario: 2019 (Colombia: Departamento Nacional de Planeación, 2006), 5-6.

27 Invitación para Taller Regional Bogotá del Observatorio Laboral para la Educación del MEN, del viceministro Gabriel Burgos Mantilla dirigida al rector José Antonio Balaguera, 6 de noviembre de 2007 , Mod. I, Est. 4, Caj. 94, Carp. 7, Fol. 46, Agust. Véase: Adolfo Atehortúa, "La 'revolución educativa': transcurso, resultados y perspectiva", Análisis Político I9 (2006): 106-125.

28 Informe rectoral 1999-200I, sin fecha, Mod.I, Est. 3, Caj. 70, Carp. io, Pág. 3, Agust.

29 "Actas del Capítulo Provincial Electivo de la Provincia de San Luis Bertrán de Colombia de la Orden de Predicadores celebrado en el Convento de Santo Domingo de Tunja del r.o al Io de mayo de I969", en Acta Capituli Provincialis Provinciae S. Ludovici Bertrandi de Columbia (Bogotá: Provincia de San Luis Bertrán de Colombia), I8.

30 Ortiz, Rostros del centenario de la restauración, 374 .

3I Valencia, Informe de Rectoría General 1995-1999, II9-I2I.

32 Invitación del rector Valencia para una reunión de los dominicos que trabajan en la Universidad, 27 de julio de I998, Mod. I, Est. 3, Caj. 69, Carp. 15, Fol. I-7, Agust.

33 Valencia, Informe de Rectoría General 1995-1999, 7.

34 Ellos fueron los frailes: Jaime Valencia, Jorge Murcia, Bernardo Vallejo, Carlos A. Díaz, José Ma. Prada, Carlos M. Alzate, Rodrigo Arias, Enrique Aranda, Generoso Gutiérrez, Adalmiro Arias, Antonio Balaguera, Faustino Corchuelo, Domingo Guerrero, Carlos Ortiz, Alberto Orozco, Orlando Sánchez, José Medrano y, fue invitado y ofició como secretario de esta, Alberto Cárdenas Patiño. La reunión se dio desde el i2 al i4 de noviembre. 


\section{I}

Madurez institucional $1995-2018$

35 Valencia García, Jaime. Acta n. ${ }^{\circ}$ oor. Encuentro Universitario Tomasino, Comunidad Dominicana - Paipa, Boyacá, I3 de noviembre de 1996, Archivo Grupo de Investigación Raimundo de Peñafort, O.P.

36 Valencia, Acta $n .{ }^{\circ}$ oor, 4.

37 Informe de Rectoría 1995-1997, marzo de 1998, Mod. I, Est. I, Caj. I, Carp. 6, Fol. 62-63, Agust.

38 Valencia, Informe de Rectoría General 1995-I999, 80 y I5I.

39 Valencia, Informe de Rectoría General 1995-1999, I5I.

40 Informe DofA 1997, I997, Mod. I, Est. 2, Caj. 45, Carp. I, Agust.

4I Informe de Rectoría General 1995-1997, marzo de I998, Mod. I, Est. 2, Caj. 45, Carp. I, Fol. 5 y II, Agust.

42 Blanca Pita, "La Universidad Santo Tomás y su contribución en el campo de la educación a distancia en Colombia", RIED 9 (2006): 96-97.

43 Más tarde la denominación quedó reducida a Vicerrectoría General de Universidad Abierta y a Distancia. Por su modalidad distintiva, la VUAD es una unidad académica y administrativa especial de la Universidad no asimilable ni a una sede ni a una seccional: Universidad Santo Tomás, Informe de autoevaluación con fines de acreditación institucional 2014-2015. Vicerrectoría de Educación Abierta y a Distancia (Bogotá: Universidad Santo Tomás, 2014-2015), 33

44 Valencia, Informe de Rectoría General 1995-I999, 272.

45 Informe de gestión vicerrectoría general I999-200I presentado por fray Tito B. Murcia F., O.P. - Vicerrector general UAD, $29 \mathrm{de} \mathrm{ju-}$ nio de 200I, Mod. I, Est. 3, Caj. 72, Carp. II, sin folio, Agust.

46 Universidad Santo Tomás, Plan Prospectivo USTA 2020 (Santa Fe de Bogotá: Universidad Santo Tomás, 1999), 39.

47 Desde 2009 Comercio Exterior pasó a llamarse Negocios Internacionales: Universidad Santo Tomás, Informe de Autoevaluación con fines de acreditación institucional 20I4-20I5. Seccional Bucaramanga (Bogotá: Universidad Santo Tomás, 2014-2015), 37.

48 Informe del periodo rectoral de P. José Antonio Balaguera Cepeda, O. P., en la Universidad Santo Tomás Seccional Bucaramanga I995 I996, sin fecha, Mod. I, Est. 4, Caj. 95, Carp. II, Fol. 3, Agust.

49 I) Metodología de la Enseñanza del Español y la Literatura, 2) Auditoría de Sistemas, 3 ) Revisoría Fiscal, 4) Gerencia Tributaria 5) Derecho Administrativo, 6) Derecho Procesal, 7) Interventoría de la Construcción, 8) Finanzas Públicas.

50 Informe del periodo rectoral de P. José Antonio Balaguera Cepeda, O. P., en la Universidad Santo Tomás Seccional Bucaramanga 1995 1996, sin fecha, Mod. I, Est. 4, Caj. 95, Carp. II, Fol. I5, Agust.

5I Informe del periodo rectoral de P. José Antonio Balaguera Cepeda, O.P., en la Universidad Santo Tomás Seccional Bucaramanga 1995I996, sin fecha, Mod. I, Est. 4, Caj. 95, Carp. II, Fol. I4, Agust.

52 Informe del periodo rectoral de P. José Antonio Balaguera Cepeda, O.P., en la Universidad Santo Tomás Seccional Bucaramanga 1995I996, sin fecha, Mod. I, Est. 4, Caj. 95, Carp. II, Fol. II, Agust.

53 Universidad Santo Tomás, Informe de autoevaluación Bucaramanga 20I4-20I5, 37.

54 Informe sobre acreditación de la Vicerrectoría Académica Seccional Bucaramanga, sin fecha, Mod. I, Est. 4, Caj. 95, Carp. 8, Fol. 5-I5, Agust.

55 Informe rectoral 1996-1998 seccional Bucaramanga por Jorge Murcia Florián, I996-I998, Mod. I, Est. 4, Caj. 77, Carp. Ir, Fol. 19, Agust.

56 Informe rectoral 1996-1998 seccional Bucaramanga por Jorge Murcia Florián, I996-I998, Mod. I, Est. 4, Caj. 77, Carp. Ir, Fol. I9, Agust.

57 Informe de gestión Secretaría General Bucaramanga 1996-2000, I996-2000, Mod. I, Est. 4, Caj. 76, Carp. 6, Fol. 20-23, Agust.
58 Informe de gestión Rectoría Seccional Bucaramanga 1998-2000, I9982000, Mod. I, Est. 3, Caj. 7I, Carp. 7, Fol. 6I-62, Agust.

59 Carta del provincial Tito Murcia al rector Valencia, to de julio de I996, Mod. I, Est. 4, Caj. 96, Carp. 5, Fol. i9, Agust.

60 Carta del director de la DUAD de Cali fray José Domingo Guerrero al rector Valencia: entrega el proyecto "Estudio de mercado en el suroccidente colombiano" para apertura de programas presenciales en Cali, I5 de julio de 1997, Mod. I, Est. 4, Caj. 96, Carp. 5, Fol. 42, Agust. En el Anteproyecto estudio del mercado en el suroccidente de Colombia para apertura de programas presenciales de la USTA en Cali, sin fecha, Mod. I, Est. 4, Caj. 96, Carp. 5, Fol. 47, Agust, se aprecia que al menos en el segundo semestre de 1996 había deseo de la comunidad en Cali (padres de familia del colegio Lacordaire) para que se abriera la USTA en Cali.

6I Carta del provincial Tito Murcia al rector Valencia, ,o de julio de 1996, Mod. I, Est. 4, Caj. 96, Carp. 5, Fol. 19, Agust.

62 Sobre el desarrollo de la comunidad dominicana en Tunja, véase: Antonio Rivadeneira, Los dominicos en Tunja (I55I-200I) (Tunja: Universidad Santo Tomás, Secional Tunja - Editorial Colecciones Creativas, 2003); Ariza, Los dominicos en Colombia, Vol. I, 576; y Germán Vargas, Milton Bautista y Juan Medina, Universidad Santo Tomás. I5 años de presencia en Tunja, I996-20II (Tunja: Búhos editores, 20II), 44 y ss.

63 Creación de la seccional de Tunja, sin fecha, Mod. I, Est. 4, Caj. 76, Carp. 15, Fol. I, Agust.

64 Vargas, Bautista y Medina, Universidad Santo Tomás. I5 años de presencia en Tunja, 65 y 70.

65 Informe al Consejo Académico de la USTA sobre el proceso de puesta en marcha de los programas presenciales y de posgrado extendidos a la ciudad de Tunja. Por Luis Alberto Orozco Arcila y el profesor Pedro Reyes Zambrano (asesor), febrero de I996, Mod. I, Est. 4, Caj. 82, Carp. 8, Fol. I, Agust.

66 Decisión que fue ratificada por el Consejo de Fundadores mediante Decreto n. ${ }^{\circ} 3$ del 2 de julio de i996: Informe de gestión institucional Tunja 1996-2003, sin fecha, Mod. I, Est. 4, Caj. 80, Carp. 4, Pag. I, Agust; Estudio de factibilidad para la creación de la seccional en Tunja, Vol. I (decreto de creación, marco conceptual, estatuto orgánico, reglamento académico, estatuto docente y estructura orgánica), sin fecha, Mod. I, Est. 4, Caj. 76, Carp. I4, Fol. 3, Agust. A pesar de la creación de la Seccional, Tunja funcionó en sus cuatro primeros años como una Decanatura de División y solo en I999, como veremos más adelante, empezó a funcionar efectivamente con un rector seccional.

67 Informe al Consejo Académico de la USTA sobre el proceso de puesta en marcha de los programas presenciales y de posgrado extendidos a la ciudad de Tunja. Por Luis Alberto Orozco Arcila y el profesor Pedro Reyes Zambrano (asesor), febrero de I996, Mod. I, Est. 4, Caj. 82, Carp. 8, Fol. I, Agust.

68 Informe de gestión institucional Tunja 1996-2003, sin fecha, Mod. I, Est. 4, Caj. 8o, Carp. 4, Pág. 4, Agust.

69 Informe de gestión institucional Tunja 1996-2003, sin fecha, Mod. I, Est. 4, Caj. 80, Carp. 4, Pág. 5, Agust.

70 Informe de gestión de la Decanatura de División de la USTA Tunja durante el periodo comprendido entre 1996 y I999. Resumen ejecutivo, 28 de abril del 2000, Mod. I, Est. 3, Caj. 48, Carp. I, Pág. I, Agust.

7I Informe de gestión de la Decanatura de División de la USTA Tunja durante el periodo comprendido entre 1996 y I999. Resumen ejecutivo, 28 de abril del 2000 , Mod. I, Est. 3, Caj. 48, Carp. I, Pág. 6, Agust; Informe de gestión institucional Tunja 1996-2003, sin fecha, Mod. I, Est. 4, Caj. 8o, Carp. 4, Pág. 5, Agust. 


\section{2}

\section{Madurez institucional I995-20I8}

72 Informe de gestión de la Decanatura de División de la USTA Tunja durante el periodo comprendido entre 1996 y I999. Resumen ejecutivo, 28 de abril del 2000, Mod. I, Est. 3, Caj. 48, Carp. I, Pág. 9, Agust.

73 Informe de gestión de la Decanatura de División de la UsTA Tunja durante el periodo comprendido entre 1996 y I999. Resumen ejecutivo, 28 de abril del 2000, Mod. I, Est. 3, Caj. 48, Carp. I, Pág. 2-3, Agust; Informe de gestión institucional Tunja 1996-2003, sin fecha, Mod. I, Est. 4, Caj. 8o, Carp. 4, Pág. 5, Agust.

74 Valencia, Informe de Rectoría General 1995-1999, 266

75 Plan de Desarrollo Sede Medellin 2003-2008, sin fecha, Mod. I, Est. 3, Caj. 69, Carp. I8, Fol. I, Agust.

76 Informe de gestión, periodo comprendido entre octubre de 1998 y junio de 200o. Secretaría de División, facultades de Arquitectura e Ing. de Telecomunicaciones, 2000, Mod. I, Est. 3, Caj. 59, Carp. 4, Fol. 62, Agust.

77 Plan de Desarrollo Sede Medellín 2003-2008, sin fecha, Mod. I, Est. 3, Caj. 69, Carp. I8, Fol. I, Agust.

78 Universidad Santo Tomás, Boletín Estadístico n. ${ }^{\circ} 3$ I997-2002 (Bogotá: Universidad Santo Tomás, 2002), 48.

79 Informe de Rectoría 1995-1997, marzo de I998, Mod. I, Est. I, Caj. I, Carp. 6, Fol. 27-29, Agust.

80 Valencia, Informe de Rectoría General I995-I999, 94.

8I Informe de Rectoría 1995-I997, marzo de 1998, Mod. I, Est. I, Caj. I, Carp. 6, Fol. 20, Agust.

82 Valencia, Informe de Rectoría General 1995-I999, I7I; Rubio y Salazar, "Sociología: 50 años formando agentes de cambio", 209.

83 Valencia, Informe de Rectoría General 1995-1999, 45.

84 Valencia, Informe de Rectoría General 1995-1999, 50.

85 Valencia, Informe de Rectoría General I995-1999, 56.

86 Universidad Santo Tomás, Plan Prospectivo Usta 2020, 36. E1 crecimiento cuantitativo de programas académicos, tal como había pasado en décadas anteriores, no estuvo excento de crítica. En el ya mencionado Informe DoFA, por ejemplo, se pueden observar algunas opiniones en este sentido; "Caeremos, como en el siglo XIX, en la acusación de que la UsTA produce 'doctores al vapor'": Informe DofA 1997, 1997, Mod. I, Est. 2, Caj. 45, Carp. I, Fol. 6, Agust.

87 Informe de Rectoría 1995-1997, marzo de 1998, Mod. I, Est. I, Caj. I, Carp. 6, Fol. 88, Agust; Valencia, Informe de Rectoría General I995-1999, 55 .

88 Valencia, Informe de Rectoría General 1995-1999, I84.

89 Legitimidad del proceso de cambio en la Rectoría General de la Universidad Santo Tomás. Firmado por Tito Murcia Florián, prior provincial y presidente del Consejo de Fundadores, y Nelson Medina Ferrer, secretario del Consejo de Fundadores, 30 de agosto de I996, Mod. I, Est. 3, Caj. 70, Carp. II, Fol. 55, Agust.

90 Declaración de principios sobre los entornos universitarios y educativos. Foro rectoral, 20 de abril de 2009, Mod. I, Est. 4, Caj. 94, Carp. 2, Fol. 130-I33, Agust.

9I El bienestar y los entornos universitarios. Su contribución a la permanencia de los estudiantes en la educación superior de Colombia, sin fecha, Mod. 2, Est. 239, Caj. I, Carp. 8, Fol. I-20, Agust.

92 Informe de gestión secretaría general Bucaramanga I996-2000, I9962000, Mod. I, Est. 4, Caj. 76, Carp. 6, Fol. 24, Agust.

93 Valencia, Informe de Rectoría General 1995-1999, 27; Informe de actividades Vicerrectoría Académica Septiembre I995 a mayo I996, mayo de 1996, Mod. I, Est. 2, Caj. 34, Carp. 8, Pág. I-9, Agust.

94 Informe de Rectoría General 1995-I997, marzo de I998, Mod. I, Est. 2, Caj. 45, Carp. I, Agust.
95 Universidad Santo Tomás, Proyecto Educativo Institucional PEI 2004 (Bogotá: Editorial USTA, 2004), 50.

96 Informe de actividades Vicerrectoría Académica Septiembre 1995 a mayo 1996, mayo de 1996, Mod. I, Est. 2, Caj. 34, Carp. 8, Pág. I, Agust.

97 Universidad Santo Tomás, PEI 2004, 5-6.

98 Universidad Santo Tomás, Proyecto Educativo Institucional PEI I999 (Santa Fe de Bogotá: Editorial Códice,I999), 57-58

99 Universidad Santo Tomás, PEI 1999, 68-69.

Ioo Universidad Santo Tomás, PEI 1999, 78.

IOI Informe de Rectoría General 1995-1997, marzo de 1998, Mod. I, Est. 2, Caj. 45, Carp. I, pág. 36, Agust.

IO2 Informe para el Capítulo Provincial 2010 del rector José Antonio Balaguera, 2008-20II, Mod. 2, Est. 239, Caj. I, Carp. 4, Pág. I3, Agust.

I03 Universidad Santo Tomás, Plan Prospectivo Usta 2020, 25. I04 Universidad Santo Tomás, Plan Prospectivo USTA 2020, I5-I6. I05 Universidad Santo Tomás, Plan Prospectivo Us TA 2020, I7. Io6 Universidad Santo Tomás, Plan Prospectivo Usta 2020, 20. Io7 Universidad Santo Tomás, Plan Prospectivo Usta 2020, 24. I08 Universidad Santo Tomás, Plan Prospectivo Us TA 2020, 31-32. Iog Universidad Santo Tomás, Plan Prospectivo Usta 2020, 33-40. rio Archivo personal de Alberto Cárdenas Patiño

II Acuerdo n. ${ }^{\circ} 6$ del 3 de junio de 1996. Primer acuerdo para organizar el proceso de acreditación en la USTA.

II 2 Carta de renuncia de Vallejo, 3 de marzo de i998, Archivo personal Dr. Alberto Cárdenas.

II3 Carta de respuesta padre Valencia, Io de abril de 1998, Archivo personal Dr. Alberto Cárdenas.

II 4 Decreto no. 3 de junio 15 de Ig99 del Consejo de Fundadores, I5 de junio de I999, Mod. I, Est. 2, Caj. 46, Carp. 2, Fol. 19-20, Agust.

II5 Entrevista con Eduardo González Gil, II de noviembre de 20I6, Archivo Ieshfaz, Universidad Santo Tomás.

II6 Eduardo González, Memorias de gestión rectoral julio I999-julio 2003 (Bogotá: Universidad Santo Tomás, 2003), II-I4; José Antonio Balaguera, Plan General de Desarrollo. Plan de acción 2003-2007 (Bogotá: Universidad Santo Tomás, 2005), 44.

II7 Plan General de Desarrollo 1999-2003 "La Universidad comprometida con el saber, su enseñanza y el servicio", septiembre del 2009 , Mod. I, Est. 3, Caj. 57, Carp. 9, Fol. 50, Agust; Entrevista con Eduardo González Gil, II de noviembre de 20I6, Archivo IESHFAz, Universidad Santo Tomás.

II8 Estado de la gestión de la Universidad Santo Tomás presentado por el rector general Eduardo González Gil al rector general electo José Antonio Balaguera, II de julio de 2003, Mod. I, Est. 2, Caj. 47, Carp. 8, Fol. 44, Agust.

II9 Informe rectoral I999-200I, sin fecha, Mod.I, Est. 3, Caj. 70, Carp. ıo, Pág. II, Agust.

I20 Plan General de Desarrollo I999-2003 "La Universidad comprometida con el saber, su enseñanza y el servicio", septiembre del 2009, Mod. I, Est. 3, Caj. 57, Carp. 9, Fol. 7, Agust.

I2I Plan General de Desarrollo I999-2003 "La Universidad comprometida con el saber, su enseñanza y el servicio", septiembre del 2009, Mod. I, Est. 3, Caj. 57, Carp. 9, Fol. I3, Agust.

122 Plan General de Desarrollo 1999-2003 "La Universidad comprometida con el saber, su enseñanza y el servicio", septiembre del 2009 , Mod. I, Est. 3, Caj. 57, Carp. 9, Fol. 42, Agust. 


\section{3}

\section{Madurez institucional I995-20I8}

I23 Plan General de Desarrollo 1999-2003 "La Universidad comprometida con el saber, su enseñanza y el servicio", septiembre del 2009 , Mod. I, Est. 3, Caj. 57, Carp. 9, Fol. 67-72, Agust.

I24 Entrevista con Eduardo González Gil, II de noviembre de 20I6, Archivo Ieshfaz, Universidad Santo Tomás.

I 25 Universidad Santo Tomás, PEI 2004, 52.

I26 Plan General de Desarrollo I999-2003 "La Universidad comprometida con el saber, su enseñanza y el servicio", septiembre del 2009 , Mod. I, Est. 3, Caj. 57, Carp. 9, Fol. 76-77, Agust.

I27 Plan General de Desarrollo I999-2003 "La Universidad comprometida con el saber, su enseñanza y el servicio", septiembre del 2009 , Mod. I, Est. 3, Caj. 57, Carp. 9, Fol. 52-53, Agust.

I28 Plan General de Desarrollo 1999-2003 "La Universidad comprometida con el saber, su enseñanza y el servicio", septiembre del 2009 , Mod. I, Est. 3, Caj. 57, Carp. 9, Fol. 65, Agust; Universidad Santo Tomás, PEI $2004,52$.

I29 González, Memorias de gestión rectoral, 32-33.

I30 González, Memorias de gestión rectoral, 33 .

I3I Balaguera, Plan General de Desarrollo 2003-2007, 40-4I.

I32 Lamentablemente las cifras de los tres cuadros mencionados no coinciden.

I33 Valencia, Informe de Rectoría General I995-I999, 286.

I34 Evaluación del sistema de educación abierta y a distancia-Informe de comisión, julio del 200I, Mod. I, Est. 4, Caj. 85, Carp. 9, Fol. 24, Agust. E1 Decreto 272 de 1998 obligaba a la acreditación previa de los programas de educación por lo que la VUAD tuvo que llevar adelante el proceso en I999. Rectoría General: Elementos para el plan quinquenal de desarrollo institucional, ca I998-I999, Mod. I, Est. 4, Caj. 8I, Carp. 6, Fol. 245-252, Agust.

I35 Evaluación del sistema de educación abierta y a distancia - Informe de comisión, julio del 20or, Mod. I, Est. 4, Caj. 85, Carp. 9, Fol. 38, Agust.

I36 Evaluación del sistema de educación abierta y a distancia. Informe de comisión, julio del 200I, Mod. I, Est. 4, Caj. 85, Carp. 9, Fol. I7, Agust.

I37 Evaluación del sistema de educación abierta y a distancia. Informe de comisión, julio del 200I, Mod. I, Est. 4, Caj. 85, Carp. 9, Fol. 26, Agust.

I38 Evaluación del sistema de educación abierta y a distancia. Informe de comisión, julio del 200I, Mod. I, Est. 4, Caj. 85, Carp. 9, Fol. 40, Agust.

I39 Evaluación del sistema de educación abierta y a distancia. Informe de comisión, julio del $200 \mathrm{I}$, Mod. I, Est. 4, Caj. 85, Carp. 9, Fol. I8, Agust.

I40 Evaluación del sistema de educación abierta y a distancia. Informe de comisión, julio del 20or, Mod. I, Est. 4, Caj. 85, Carp. 9, Fol. 30, Agust.

I4I Evaluación del sistema de educación abierta y a distancia. Informe de comisión, julio del 20or, Mod. I, Est. 4, Caj. 85, Carp. 9, Fol. 20-22, Agust.

I42 Acta de visita efectuada a la Universidad Santo Tomás, 22 de noviembre de 200I, Mod. I, Est. 2, Caj. 44, Carp. I2, Fol. 237, Agust.

I43 Evaluación del sistema de educación abierta y a distancia. Informe de comisión, julio del 200I, Mod. I, Est. 4, Caj. 85, Carp. 9, Fol. I8, Agust.

I44 Evaluación del sistema de educación abierta y a distancia. Informe de comisión, julio del 200I, Mod. I, Est. 4, Caj. 85, Carp. 9, Fol. 36, Agust.
I45 Carta del presidente del Consejo de Fundadores Alzate Montes para el rector general González Gil, r.o de julio de 200I, Mod. I, Est.

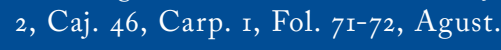

I46 Universidad Santo Tomás, Informe de autoevaluación Bucaramanga $2014-2015,48$.

I47 Informe de gestión secretaría general Bucaramanga I996-2000, I9962000, Mod. I, Est. 4, Caj. 76, Carp. 6, Fol. II, Agust.

I 48 Informe rectoral de Bucaramanga año 2000 , I.O de febrero de $200 \mathrm{I}$, Mod. I, Est. 2, Caj. 46, Carp. 8, Fol. 3, Agust; Informe bienal de gestión. Vicerrectoría académica, diciembre de 1999 - octubre de 200I, fray Carlos Arturo Ortiz, Usta Bucaramanga, sin fecha, Mod. I, Est. 3, Caj. 7I, Carp. I, Pág. 21-70, Agust.

I 49 Informe de la Vicerrectoría Académica, Noviembre $200 \mathrm{I}$-Noviembre 2003 - Bucaramanga, sin fecha, Mod. I, Est. 3, Caj. 64, Carp. 8, Fol. I15-Iı6, Agust.

I50 Informe de la Vicerrectoría Académica, noviembre 200 - noviembre 2003, Bucaramanga, sin fecha, Mod. I, Est. 3, Caj. 64, Carp. 8, Fol. I43, Agust.

I5I Grupo de investigaciones de la Maestría en Administración de Empresas, Grupo de investigaciones de la Facultad de Arquitectura de la Universidad Santo Tomás, Seccional Bucaramanga, Grupo de Investigación y Desarrollo en Simulación y Control Numérico, Salud Integral y Bienestar del Adulto Mayor y Convenio Interinstitucional para el estudio del Medio Ambiente y el Hábitat (сімна). En: Informe de la Vicerrectoría Académica, noviembre $200 I$ - noviembre 2003, Bucaramanga, sin fecha, Mod. I, Est. 3 , Caj. 64, Carp. 8, Fol. I47, Agust.

I52 Informe de revisoría fiscal de Jorge Armando Porras para José Antonio Balaguera, decano de División, ro de abril de I997, Mod. I, Est. 4 , Caj. 96, Carp. 3, Fol. 40-42, Agust. Hasta el día de hoy las sedes continúan funcionando administrativamente como decanaturas de división, con órganos semejantes a los de la sede principal.

I53 Decreto no. 4 de agosto II de I999 del Consejo de Fundadores, II de agosto de 1999, Mod. I, Est. 2, Caj. 46, Carp. 2, Fol. 23-24, Agust.

I54 Informe de gestión institucional Tunja 1996-2003, sin fecha, Mod. I, Est. 4, Caj. 8o, Carp. 4, Pág. 5-6, Agust.

I55 Informe de gestión institucional Tunja 1996-2003, sin fecha, Mod. I, Est. 4, Caj. 80, Carp. 4, Pág. 5, Agust.

I56 Informe de Gestión de la Decanatura de División de la Us TA Tunja durante el periodo comprendido entre 1996 y 1999. Resumen ejecutivo, 28 de abril del 2000, Mod. I, Est. 3, Caj. 48, Carp. I, Pag. 4, Agust.

I57 Informe de gestión institucional Tunja 1996-2003, sin fecha, Mod. I, Est. 4, Caj. 80, Carp. 4, Pág. 77, Agust.

I58 Informe de gestión institucional Tunja 1996-2003, sin fecha, Mod. I, Est. 4, Caj. 8o, Carp. 4, Pág. 5, Agust.

I59 Informe de gestión institucional Tunja 1996-2003, sin fecha, Mod. I, Est. 4, Caj. 80, Carp. 4, Pág. 77, Agust.

I60 Informe de gestión institucional Tunja 1996-2003, sin fecha, Mod. I, Est. 4, Caj. 80, Carp. 4, Pág. 84, Agust.

I6I Universidad Santo Tomás, Boletín Estadístico n. ${ }^{0} 3$ I997-2002, 48 y 98.

I62 Informe de gestión 2000-2002. Decanatura de División Sede Medellin, 20 de febrero de 2002, Mod. I, Est. 3, Caj. 59, Carp. I. Fol. I2, Agust.

I63 Análisis sobre el estado actual y futuro de la Universidad Santo Tomás, Sede Medellin, sin fecha, Mod. I, Est. 3, Caj. 59, Carp. I, Fol. 60-6r, Agust.

I64 Adecuamiento e instalación de la infraestructura de voz, datos y potencia regulada para el edificio san Alberto Magno de la Universidad 


\section{4}

\section{Madurez institucional I995-20I8}

Santo Tomás Sede Medellin, sin fecha, Mod. I, Est. 3, Caj. 59, Carp. I, Fol. 223, Agust.

I65 Informe de gestión, Medellin - junio r.o a diciembre I6 de 2002, sin fecha, Mod. I, Est. 3, Caj. 59, Carp. I, Fol. 75, Agust.

I66 Estado de la gestión de la Universidad Santo Tomás presentado por el rector general Eduardo González Gil al rector general electo José Antonio Balaguera, II de julio de 2003 , Mod. I, Est. 2, Caj. 47, Carp. 8, Fol. 45, Agust; Informe rectoral 1999-200I, sin fecha, Mod.I, Est. 3, Caj. 70, Carp. Io, Pág. II, Agust. Mediante Acuerdo del Consejo Superior n. ${ }^{\circ}$ I2 del io de mayo de 2000 : Informe de gestión académica 1999-200I, por Orlando Rueda Acevedo, vicerrector académico general, sin fecha, Mod. I, Est. 4, Caj. 85, Carp. 3, Fol. 15-16, Agust.

I67 Plan General de Desarrollo 1999-2003 "La Universidad comprometida con el saber, su enseñanza y el servicio", septiembre del 2009 , Mod. I, Est. 3, Caj. 57, Carp. 9, Fol. 228, Agust.

I68 Plan General de Desarrollo 1999-2003 "La Universidad comprometida con el saber, su enseñanza y el servicio", septiembre del 2009 , Mod. I, Est. 3, Caj. 57, Carp. 9, Fol. 232, Agust.

I69 Plan General de Desarrollo 1999-2003 "La Universidad comprometida con el saber, su enseñanza y el servicio", septiembre del 2009, Mod. I, Est. 3, Caj. 57, Carp. 9, Fol. 226, Agust.

I70 Plan General de Desarrollo 1999-2003 "La Universidad comprometida con el saber, su enseñanza y el servicio", septiembre del 2009, Mod. I, Est. 3, Caj. 57, Carp. 9, Fol. 235, Agust.

I7I Entrevista con Eduardo González Gil, II de noviembre de 20I6, Archivo Ieshraz, Universidad Santo Tomás.

I72 González, Memorias de gestión rectoral, 49-50.

${ }_{173}$ Informe rectoral 1999-200I, sin fecha, Mod.I, Est. 3, Caj. 70, Carp. Io, Pág. I5, Agust.

I74 Informe sobre el estado de los posgrados a 21 de febrero de 200I. Por Vicerrectoría Académica General, Unidad de Investigación y Posgrados. Informe ejecutivo, 2I de febrero de 20or, Mod. I, Est. 3, Caj. 5I, Carp. 8, Fol. I2, Agust.

I75 Informe sobre el estado de los posgrados a 2 I de febrero de $200 \mathrm{O}$. Por Vicerrectoría Académica General, Unidad de Investigación y Posgrados. Informe ejecutivo, 2I de febrero de 200I, Mod. I, Est. 3, Caj. 5I, Carp. 8, Fol. I3, Agust.

I76 Proyecto Investigativo Institucional Proin (documento inicial). Por Dr. Omar Parra Rozo, director Unidad de Investigación y Posgrados, septiembre del 2000 , Mod. I, Est. 4, Caj. 86, Carp. ro, Pág. 69, Agust.

177 Proyecto Investigativo Institucional Proin (documento inicial). Por Dr. Omar Parra Rozo, director Unidad de Investigación y Posgrados, septiembre del 2000, Mod. I, Est. 4, Caj. 86, Carp. Io, Pág. 78, Agust.

178 Proyecto Investigativo Institucional PROIN (documento inicial). Por Dr. Omar Parra Rozo, director Unidad de Investigación y Posgrados, septiembre del 2000 , Mod. I, Est. 4, Caj. 86, Carp. ro, Pág. 79, Agust.

I79 Proyecto Investigativo Institucional PROIN (documento inicial). Por Dr. Omar Parra Rozo, director Unidad de Investigación y Posgrados, septiembre del 2000, Mod. I, Est. 4, Caj. 86, Carp. ro, Pág. 8o-8I, Agust.

I80 William Mantilla Cárdenas, "Significación compleja de líneas de investigación", Revista Hallazgos (I): 2004, 36 .

I8I Conocida como la Ley General de Educación, entre otras cosas, reglamentaba la obligatoriedad del PEI.

I82 Que reglamentó el sistema de créditos académicos para las instituciones de educación superior.
I83 Estado de la gestión de la Universidad Santo Tomás presentado por el rector general Eduardo González Gil al rector general electo José Antonio Balaguera, II de julio de 2003, Mod. I, Est. 2, Caj. 47, Carp. 8, Fol. 47, Agust; González, Memorias de gestión rectoral, 30. I84 Balaguera, Plan General de Desarrollo 2003-2007, 38.

I8 5 Acta de visita efectuada a la Universidad Santo Tomás, 22 de noviembre de 2001 , Mod. I, Est. 2, Caj. 44, Carp. I2, Fol. 234, Agust. Estas ir facultades eran Ingeniería Civil, Ingeniería Electrónica, Ingeniería Mecánica, Economía y Administración de Empresa, Derecho y Ciencias Políticas, Cultura Física, Deporte y Recreación, Sociología, Comunicación Social, Filosofía y Letras, Contaduría Pública y Psicología.

I86 González, Memorias de gestión rectoral, 48-49.

I87 Universidad Santo Tomás, PEI 2004, 65-66.

I88 Moreno, "Una apuesta por la formación humanística”, I32-I36. I89 Entrevista con Adriana Páez, 28 de noviembre de 2016, Archivo Ieshfaz, Universidad Santo Tomás; Balaguera, Informe de la gestión rectoral 2003-2007, 157 .

I90 Entrevista con Eduardo González Gil, II de noviembre de 2016, Archivo Ieshfaz, Universidad Santo Tomás.

I9I Proyecto de creación del Instituto de Economía y Humanismo Louis Joseph Lebret, octubre de 2000, Mod. I, Est. 5, Caj. 99, Carp. I, Fol. 9, Agust.

192 Proyecto de creación del Instituto de Economía y Humanismo Louis Joseph Lebret, octubre de 2000, Mod. I, Est. 5, Caj. 99, Carp. I, Fol. 75-78, Agust.

193 Proyecto de creación del Instituto de Economía y Humanismo Louis Joseph Lebret, octubre de 2000, Mod. I, Est. 5, Caj. 99, Carp. I, Fol. 90-9I, Agust.

194 Proyecto de creación del Instituto de Economía y Humanismo Louis Joseph Lebret, octubre de 2000, Mod. I, Est. 5, Caj. 99, Carp. I, Fol. 94, Agust.

I95 Universidad Santo Tomás, Informe de autoevaluación con fines de acreditación institucional 20I4-20I5. Decanatura de división de Villavicencio (Bogotá: Universidad Santo Tomás, 2015), I02; Entrevista con Eduardo González Gil, II de noviembre de 2016, Archivo ieshfaz, Universidad Santo Tomás.

I96 Informe rectoral 1999-200I, sin fecha, Mod.I, Est. 3, Caj. 70, Carp. Io, Pág. 47, Agust.

I97 Universidad Santo Tomás, Documento marco. Proyección Social (Bogotá: Ediciones USTA, 20I5), 9.

I98 Entrevista con Eduardo González Gil, II de noviembre de 20I6, Archivo Ieshfaz, Universidad Santo Tomás.

I99 Unidad de Proyección Social - Memoria Histórica, enero de $201 \mathrm{I}$ Archivo Digital Coordinación Centros de Proyección Social, Carp. 20, Subc. 6, Pág. 3.

200 Criterios para la reforma del Estatuto Orgánico. Documento para el Consejo Superior, ig de junio de I996, Mod. I, Est. 4, Caj. 8I, Carp. 6, Fol. 8, Agust.

201 Criterios para la reforma del Estatuto Orgánico. Documento para el Consejo Superior, I9 de junio de I996, Mod. I, Est. 4, Caj. 8I, Carp. 6, Fol. 9, Agust.

202 Universidad Santo Tomás, Estatuto Orgánico 2002 (Bogotá: Universidad Santo Tomás, 2002), I2.

${ }_{20}$ Cronología de la reforma, por Alberto Cárdenas Patiño, secretario general, 26 de agosto de I997, Mod. I, Est. 4, Caj. 8I, Carp. 6, Fol. 156, Agust.

${ }_{20}{ }_{4}$ Criterios para la reforma del Estatuto Orgánico. Documento para el Consejo Superior, I9 de junio de I996, Mod. I, Est. 4, Caj. 8I, Carp. 6, Fol. II, Agust. 


\section{5}

\section{Madurez institucional I995-2018}

205 Criterios para la reforma del Estatuto Orgánico. Documento para el Consejo Superior, I9 de junio de I996, Mod. I, Est. 4, Caj. 8I, Carp. 6, Fol. I2, Agust.

206 Cronología de la reforma, por Alberto Cárdenas Patiño, secretario general, 26 de agosto de I997, Mod. I, Est. 4, Caj. 8I, Carp. 6 Fol. 156, Agust.

${ }_{207}$ Universidad Santo Tomás, Estatuto Orgánico 2002, 35 y 44 Artículos 27 y 42.

208 Universidad Santo Tomás, Estatuto Orgánico 2002, 32. Artículo 24 , numeral I.

209 Universidad Santo Tomás, Estatuto Orgánico 2002, 51-53. Artículos $5 \mathrm{I}-60$.

210 Universidad Santo Tomás, Estatuto Orgánico 2002, 65. Artículo 83 2II Universidad Santo Tomás, Estatuto Orgánico 2002, 88. Artículo I24. Se prohibió ejercer simultáneamente la Vicerrectoría AdministrativaFinanciera General de la Universidad y ser síndico general de la Provincia, ejercer la Revisoría Fiscal y estar emparentado con directivos y personas vinculadas laboralmente a la Universidad, entre otras.

2I2 Gil, Eduardo O.P. Memorias de la gestión rectoral, I999-2003, Consejo Editorial Departamento de Comunicaciones, Bogotá, 2003, 30.

213 González Gil, Eduardo. Memorias de la gestión rectoral, I9992003, I05.

2I 4 Eduardo Alberto Goméz Bello, "Desde la restauración hasta la Usta Colombia”, en De la tomística de Santafé a la Universidad Santo Tomás de Colombia en los últimos 50 años (Bogotá: Ediciones USTA, 20I5), 86

2I5 Decreto no. I7 de junio 6 de 2003 del Consejo de Fundadores, I7 de junio de 2003 , Mod. I, Est. 2, Caj. 46, Carp. 2, Fol. 6o-6I, Agust.

216 Estudio de factibilidad para la creación de la seccional en Tunja, Vol. IV volumen que contiene hojas de vida. directo de la hoja de vida, sin fecha, Mod. I, Est. 3, Caj. 67, Carp. I4, Agust.

2I7 Balaguera, Plan General de Desarrollo 2003-2007, I2. 2I8 Balaguera, Plan General de Desarrollo 2003-2007, 24. 219 Balaguera, Informe de la gestión rectoral, 2003-2007, 2I. 220 Balaguera, Plan General de Desarrollo 2003-2007, 45.

22I Universidad Santo Tomás, Informe de la gestión rectoral, 20032007,37 a 38.

222 Universidad Santo Tomás. Informe de la gestión rectoral, 20032007 , p. $4 \mathrm{I}^{-} 42$.

223 Universidad Santo Tomas. Informe de la gestión rectoral, 20032007, p. 43 a 47 .

224 Balaguera Cepeda, José Antonio, O.P. Resolución Rectoral n. ${ }^{\circ}$ 46 del 15 de agosto de 2006 .

225 Universidad Santo Tomás, PE I 2004, 6.

226 Universidad Santo Tomás, PEI 2004, I7.

227 Universidad Santo Tomás, PEI 2004 , 19.

228 Universidad Santo Tomás, PEI 2004, 3I-32 y 73-79.

229 Universidad Santo Tomás, PEI 2004, 93.

230 Universidad Santo Tomás, PEI 2004, I26-I27.

23I Omar Parra, "Proyecto Investigativo Institucional", Revista Hallazgos I (2004): 9-22; William Mantilla, "Significación compleja de líneas de investigación”, Revista Hallazgos, I (2004): 23-44

232 Omar Parra, Proyecto Investigativo Institucional. Un enfoque para la concepción y el desarrollo de la investigación (Bogotá, Universidad Santo Tomás, 2005).

233 Parra, "Proyecto Investigativo Institucional", 78.
234 Parra, "Proyecto Investigativo Institucional", 30-32.

235 Parra, "Proyecto Investigativo Institucional", 83.

236 Parra, "Proyecto Investigativo Institucional", 84.

237 Parra, "Proyecto Investigativo Institucional", 86-89.

238 Informe ejecutivo de gestión - Vicerrectoría Académica General de junio 2009 a mayo 20I0, sin fecha, Mod. I, Est. 5, Caj. 98, Carp. I4, Pág. Io, Agust.

239 Omar León y Javier Yate, Fundamentación teórica de las Lineas Medulareas de Investigación. Documento de trabajo, 2010.

240 Programa para la formación de competencias investigativas o formación de docentes investigadores, programa de asesorías y consultorías, programa de socialización de la producción investigativa, programa de semillero de investigadores, programa de proyectos de grado, programa de documentación e información y programa de publicaciones y materiales.

24I Parra, "Proyecto Investigativo Institucional", 9I-93.

242 Universidad Santo Tomás, Boletín Estadístico de la Universidad Santo Tomás 2005-2008 (Bogotá: Universidad Santo Tomás, 2009), 38-39.

243 Universidad Santo Tomás, Departamento de Planeación y Desarrollo, Boletín Estadístico 2009-20I0, 82; Informe ejecutivo de gestión - Vicerrectoría Académica General de junio 2009 a mayo 20IO, sin fecha Mod. I, Est. 5, Caj. 98, Carp. I4, Pág. I, Agust. 244 Balaguera, Avance del Plan General de Desarrollo $2008-20 I I, 3$.

245 Entrevista con Eduardo González Gil, II de noviembre de 2016, Archivo Ieshfaz, Universidad Santo Tomás.

246 Entrevista con Eduardo González Gil, II de noviembre de 2016 Archivo Ieshfaz, Universidad Santo Tomás.

247 José Balaguera, Informe de gestión rectoral 2007-20II (Bogotá: Universidad Santo Tomás, 20II), 52-53; José Balaguera, Avance del Plan General de Desarrollo 2008-20II (Bogotá: Universidad Santo Tomás, 2010), 49.

248 Balaguera, Informe de gestión rectoral 2007-20II, I07-IO9 y I37-I42. 249 Balaguera, Informe de la gestión rectoral 2003-2007, 3I.

250 Balaguera, Informe de la gestión rectoral 2003-2007, 88.

25I Invitación para discutir la creación de la Facultad de Teología. De José Gabriel Mesa al rector Balaguera, I8 de mayo de 2004, Mod. I, Est. 2, Caj. 46, Carp. I, Fol. II9, Agust.

252 Poco después se unió con Filosofía dando lugar a la División de Filosofía y Teología.

253 Balaguera, Informe de gestión rectoral 2007-20II, 25.

254 Orlando Rueda, "Restauración de la Facultad de Teología de la Universidad Santo Tomás”, Revista Albertus Magnus, I (2012): I7-I8.

255 Universidad Santo Tomás, Departamento de Planeación y Desarrollo, Boletín Estadístico 2009-20Io (Bogotá: Departamento de Publicaciones, Universidad Santo Tomás, sin fecha), 24.

256 Antolínez, "Semblanza y memoria de Filosofía y Letras", I73. 257 Balaguera, Informe de gestión rectoral 2007-20II, 23. 258 Balaguera, Informe de la gestión rectoral 2003-2007, I57. 259 Balaguera, Avance del Plan General de Desarrollo 2008-20II, 5; Balaguera, Informe de gestión rectoral 2007-20II, 25.

260 Balaguera, Informe de la gestión rectoral 2003-2007, I59. 26I Balaguera, Informe de la gestión rectoral 2003-2007, I6I. 262 Balaguera, Informe de la gestión rectoral 2003-2007, I37 a I42

263 Unidad de Proyección Social - Memoria Histórica, enero de $201 \mathrm{I}$, Archivo Digital Coordinación Centros de Proyección Social, carpeta 20 , subcarpeta 6 . 


\section{6}

\section{Madurez institucional I995-20I8}

${ }_{264}$ Universidad Santo Tomás (Libia Becerra), Proyección social e interacción con el medio (Bogotá: Universidad Santo Tomás: 2010), 63-69.

265 Documentos suministrados por fray Adalmiro Arias.

266"Centro de Proyección social", Universidad Santo Tomás Bucaramanga. Consultado el I2 de diciembre, 20I6, http://www.ustabuca.edu. co/ustabmanga/centro-de-proyeccion-social

${ }_{26} 6$ Universidad Santo Tomás (Libia Becerra), Proyección social e interacción con el medio, $42-43$.

268 Universidad Santo Tomás (Libia Becerra), Proyección social e interacción con el medio, 44.

269 Federación Internacional de Universidades Católicas, Coloquio internacional Asia-América Latina. Comprender los desplazamientos de población. Miradas plurales desde la universidad (Bogotá: Universidad Santo Tomás, 20I2)

270 Acuerdo $n .{ }^{\circ}$ I7, I2 de mayo de $20 I 0$, http://ieshfaz.usta.edu.co/ index.php/documentacion/acuerdo-de-creacion

27I Acuerdo n.0 04, 03 de mayo del 20I2, http://ieshfaz.usta.edu.co/ index.php/documentacion/acuerdo-de-modificacion-de-nombre

272 Algunas de las publicaciones más importantes en las que ha participado el IEshfaz son: Carlos Alzate, Diario de un convento. Santo Domingo de Tunja durante la Independencia (Bogotá: Ediciones USTA, 20I2); Estela Restrepo, Ona Vileikis y Andrés Escobar (ed.), Biblioteca Médica Neogranadina, I775-1833. Vols. I y II (Bogotá: Universidad Nacional de Colombia. Facultad de Ciencias Humanas. Centro de Estudios Sociales, cEs: Universidad Santo Tomás. Vicerrectoría Académica General. Instituto de Estudios Socio-Históricos Fray Alonso de Zamora, O.P., 2013); Carlos Alzate, Fabián Benavides y Andrés Escobar (coord.), Religiosidad e imagen. Aproximaciones a la colección de arte colonial de la Orden de Predicadores de Colombia (Bogotá: Ediciones UsTA, 20I4); Carlos Alzate, Fabián Benavides y Andrés Escobar, La vida cotidiana en el Convento San José de Cartagena de Indias hacia mediados del siglo XVIII y comienzos del XIX (Bogotá: Ediciones USTA, 20I4); Jaime Mancera, Carlos Alzate y Fabián Benavides (ed.), Arquidiócesis de Bogotá, 450 años. Miradas sobre su bistoria (Bogotá: Ediciones USTA, 20I5); Fabián Benavides, Entre la razón y la sinrazón: ¿̨enfermedades mentales o males del alma? (Bogotá: Ediciones UsTA, 2016); fray Eugenio Torrres, Fabián Benavides y Andrés Escobar (ed.), 800 años de la Orden de Predicadores. Vols. I al V (Bogotá: Ediciones UsTA, 20I7).

273 Balaguera, Informe de la gestión rectoral 2003-2007, 55.

274 Universidad Santo Tomás, Boletín Estadístico n. ${ }^{\circ}$ 4: $2003-2004$ (Bogotá: Departamento de Publicaciones, Universidad Santo Tomás, 2006), 47 y 50.

275 Universidad Santo Tomás, Boletín Estadístico de la Universidad Santo Tomás 2005-2008, 36 y 47 .

276 Universidad Santo Tomás, Departamento de Planeación y Desarrollo, Boletin Estadístico 2009-2010, 60.

277 Universidad Santo Tomás, Departamento de Planeación y Desarrollo, Boletín Estadístico 2009-20I0, 67.

278 Universidad Santo Tomás, Departamento de Planeación y Desarrollo, Boletin Estadístico 2009-20I0, 24; Informe ejecutivo de gestión - Vicerrectoría Académica General de junio 2009 a mayo 20ro, sin fecha Mod. I, Est. 5, Caj. 98, Carp. I4, Pág. 31-43, Agust.

279 Universidad Santo Tomás, Informe de autoevaluación Vicerrectoría de Educación Abierta y a Distancia 2014-2015, 44.

280 Universidad Santo Tomás, Informe de autoevaluación Bucaramanga 20I4-20I5, 48 .

28I Universidad Santo Tomás, Informe de autoevaluación Bucaramanga 20I4-20I5, 48 .
282 Universidad Santo Tomás, Informe de autoevaluación Bucaramanga 20I4-20I5, 38.

283 Universidad Santo Tomás, Boletín Estadístico n. ${ }^{4} 4: 2003-2004,45$. ${ }_{284}$ Universidad Santo Tomás, Informe de autoevaluación Bucaramanga 20I4-20I5, 38.

285 Universidad Santo Tomás, Boletín Estadístico n. ${ }^{\circ} 4: 2003-2004,49$. 286 Balaguera, Avance del Plan General de Desarrollo 2008-20II, 5557; Informe ejecutivo de gestión - Vicerrectoría Académica General de junio 2009 a mayo 20I0, sin fecha Mod. I, Est. 5, Caj. 98, Carp. I4, Pág. 31-43.

287 Balaguera, Avance del Plan General de Desarrollo 2008 -20II, 55-57.

288 Universidad Santo Tomás, Informe de autoevaluación Bucaramanga 2014-20I5, 38.

289 Universidad Santo Tomás, Boletín Estadístico n. ${ }^{\circ}$ 3: 1997-2002, 48. 290 Universidad Santo Tomás, Boletín Estadístico n.o 4: 2003-2004, 46. 29I Universidad Santo Tomás, Boletín Estadístico n. ${ }^{\circ} 4: 2003-2004,50$. 292 Vargas, Bautista y Medina, Universidad Santo Tomás. 15 años de presencia en Tunja, I44 y I52-I53.

293 Informe de gestión 2003-2006 - Vicerrectoria Académica Seccional Tunja, 3I de enero de 2006, Mod. I, Est. 3, Caj. 72, Carp. 6, Fol. 37, Agust.

294 Vargas, Bautista y Medina, Universidad Santo Tomás. I5 años de presencia en Tunja, II.

295 Informe de gestión 2003-2006 - Vicerrectoría Académica Seccional Tunja, 3I de enero de 2006, Mod. I, Est. 3, Caj. 72, Carp. 6, Fol. 57, Agust.

296 Informe de gestión 2003-2006 - Vicerrectoría Académica Seccional Tunja, 31 de enero de 2006, Mod. I, Est. 3, Caj. 72, Carp. 6, Fol. 5I, Agust.

297 Informe de gestión 2003-2006 - Vicerrectoría Académica Seccional Tunja, 3I de enero de 2006, Mod. I, Est. 3, Caj. 72, Carp. 6, Fol. 53-54, Agust.

298 Balaguera, Avance del Plan General de Desarrollo 2008-20II, 9I. 299 Universidad Santo Tomás, Informe de autoevaluación con fines de acreditación institucional 20I4-20I5. Seccional Tunja (Bogotá: Universidad Santo Tomás, 20I5), 62. La Corporación Dominicana Opción Vida, Justicia y Paz se constituyó en mayo de 2002 (Invitación a la a samblea de constitución de la Corporación Dominicana Opción Vida, Justicia y Paz, del provincial Carlos Mario Alzate al rector Eduardo González, I2 de marzo de 2002, Mod. I, Est. 3, Caj. 59, Carp. 8, Fol. I-2, Agust) con el objetivo de despertar consciencia sobre la situación de derechos humanos en el país, animar el compromiso de la familia dominicana con su defensa, fortalecer la construcción de una nueva cultura pacífica, generar procesos de organización y brindar análisis para la pedagogía y la cultura de los derechos humanos y la paz: Carta del provincial Carlos Mario Alzate al presidente de la Junta Directiva de Opción Vida, 24 de junio de 2002, Mod. I, Est. 3, Caj. 59, Carp. 8, Fol. 70-71, Agust.

300 Plan de Desarrollo Sede Medellin 2003-2008, sin fecha, Mod. I, Est. 3, Caj. 69, Carp. 18, Fol. I, Agust.

30 Plan de Desarrollo Sede Medellin 2003-2008, sin fecha, Mod. I, Est. 3, Caj. 69, Carp. I8, Fol. I, Agust.

302 Balaguera, Informe de la Gestión Rectoral 2003-2007, I58.

303 Universidad Santo Tomás, Boletín Estadístico n. ${ }^{\circ}$ 4: 2003-2004, 46.

304 Universidad Santo Tomás, Informe de autoevaluación con fines de acreditación institucional 2014-20I5. Decanatura de División Medellin (Bogotá: Universidad Santo Tomás, 20I5), 37. 


\section{7}

\section{Madurez institucional I995-20I8}

305 Plan de Desarrollo Sede Medellin 2003-2008, sin fecha, Mod. I, Est. 3, Caj. 69, Carp. I8, Fol. I, Agust; Estudio para la creación de la Seccional de la Universidad Santo Tomás en Medellín con la asesoría de la seccional Tunja, 28 de septiembre de 2007, Mod. I, Est. 4, Caj. 91, Carp. I7, Fol. 52-54, Agust.

306 Informe de actividades Centro Regional n. ${ }^{\circ} 4$ Villavicencio - Julio I995 a diciembre 1998, sin fecha, Mod. I, Est. 4, Caj. 82, Carp. I5, Fol. I, Agust.

307 Informe de actividades Centro Regional n. ${ }^{\circ} 4$ Villavicencio - Julio I995 a diciembre I998, sin fecha, Mod. I, Est. 4, Caj. 82, Carp. I5, Fol. 2, Agust.

308 Balaguera, Informe de la gestión rectoral 2003-2007, I60-I6I.

309 Universidad Santo Tomás, Informe de autoevaluación Villavicencio 20I4-20I5, 34-35. Reunión del Consejo de Fundadores para discutir la creación de USTA Villavicencio, 29 de septiembre de 2006, Mod. I, Est. 4, Caj. 88, Carp. 8, Fol. 49-54, Agust.

3IO Reunión del Consejo de Fundadores para discutir la creación de USTA Villavicencio, 29 de septiembre de 2006, Mod. I, Est. 4, Caj. 88 Carp. 8, Fol. 50, Agust.

3II Reunión del Consejo de Fundadores para discutir la creación de USTA Villavicencio, 29 de septiembre de 2006, Mod. I, Est. 4, Caj. 88 Carp. 8, Fol. 52, Agust.

3I2 Balaguera, Informe de la gestión rectoral 2003-2007, 42.

3I3 Universidad Santo Tomás, Informe de autoevaluación Villavicencio 20I4-20I5, 35.

3I4 Balaguera, Avance del Plan General de Desarrollo 2008-20II, IIo. 3I5 Balaguera, Avance del Plan General de Desarrollo 2008-20II, Io6.

316 Universidad Santo Tomás. Informe de autoevaluación con fines de renovación de acreditación institucional 20I4-2015. Sede Principal Bogotá, modalidad presencial (Bogotá: Universidad Santo Tomás, 2015), I7.

3I7 Universidad Santo Tomás, Estatuto Orgánico de la Universidad Santo Tomás 2 ого (Bogotá: Universidad Santo Tomás, 20го), I5 Artículo I6, numeral I5.

318 Universidad Santo Tomás, Estatuto Orgánico 20I0, 43. Parágrafo al artículo 53 .

319 Universidad Santo Tomás, Estatuto Orgánico 20IO, 34. Artículo 40. 320 Los rectores seccionales pasaron a hacer parte del Consejo Administrativo-Financiero General (artículo 36, p. 3I); el periodo del Decano de División se amplió de dos a tres años (artículo 75, pág. 5I); los egresados ganaron representación en los consejos de facultad (artículo 79, pág. 53); el requisito de tres años de experiencia en la USTA para ser secretario general se transformó en cinco años de experiencia no necesariamente en el plantel (artículo ro2, pág. 70).

32I"Nuevo rector general de la Universidad Santo Tomás", Centro Virtual de Noticias de la Educación. Consultado el i3 de diciembre, 20I6, http://www.mineducacion.gov.co/cvn/I665/w3-article-276459.html

322 Ortiz, Rostros del centenario de la restauración, 420.

323 Universidad Santo Tomás, Rectoría General, Plan General de Desarrollo 20I2-2015. USTA: excelencia que transforma el país (Bogotá: Universidad Santo Tomás, sin fecha), 27.

324 En este sentido, el Plan retoma el espíritu de armonización entre sedes y seccionales que había caracterizado la administración González Gil. Entrevista con Eduardo González Gil, II de noviembre de 20I6, Archivo IEshfaz, Universidad Santo Tomás.

325 Universidad Santo Tomás, Rectoría General, Plan General de Desarrollo 2OI2-20I5, 27.
326 Universidad Santo Tomás, Rectoría General, Plan General de Desarrollo 2OI2-20I5, 28-29.

327 Universidad Santo Tomás, Rectoría General, Plan General de Desarrollo 20I2-20I5, 32.

328 Universidad Santo Tomás, Rectoría General, Plan General de Desarrollo 20I2-20I5, 34 .

329 Universidad Santo Tomás, Rectoría General, Plan General de Desarrollo 2OI2-20I5, 25-26.

330 Universidad Santo Tomás, Rectoría General, Plan General de Desarrollo 20I2-20I5, 26.

33I Universidad Santo Tomás. Informe de autoevaluación Sede Principal 20I4-20I5, 34

332 Universidad Santo Tomás. Informe de autoevaluación Sede Principal $2014-2015,23$.

333 Universidad Santo Tomás. Informe de autoevaluación Sede Principal $2014-2015,26$

334 Universidad Santo Tomás, Plan de Desarrollo 20I3-20I5 USTA Tunja (sin lugar: Universidad Santo Tomás, sin fecha), 40.

335 Carlos Alzate, usta: excelencia que transforma el país. Gestión 2012-2015 (Bogotá: Universidad Santo Tomás, 20I5), I43.

336 Universidad Santo Tomás, Informe de autoevaluación Sede Principal $2014-2015,163$.

337 Universidad Santo Tomás, Informe de autoevaluación Sede Principal $2014-2015,7$.

338 Universidad Santo Tomás, Informe de autoevaluación Sede Principal $2014-2015, \mathrm{I} 5$

339 Universidad Santo Tomás, Informe de autoevaluación Sede Principal $2014-2015,7^{-8}$.

340 Consejo Nacional de Acreditación, Lineamientos para la acreditación institucional 2015 (Bogotá: Consejo Nacional de Acreditación -Sistema Nacional de Acreditación, 20I4), 25. Consultado el I3 de diciembre, 20I6, http://www.cna.gov.co/I74I/articles-I86359_ Lin_Ins_20I4.pdf

34I Consejo Nacional de Acreditación, Lineamientos para la acreditación institucional $2015,26$.

342 Entrevista con Eduardo González Gil, II de noviembre de 2016, Archivo Ieshfaz, Universidad Santo Tomás.

343 Universidad Santo Tomás. Informe de autoevaluación Sede Principal 20I4-20I5, I24.

344 Entrevista con Eduardo González Gil, II de noviembre de 2016 , Archivo Ieshfaz, Universidad Santo Tomás.

345 Entrevista con Eduardo González Gil, II de noviembre de 2016, Archivo Ieshfaz, Universidad Santo Tomás.

346 Alzate, USTA: excelencia que transforma el país, I 43 .

347 Alzate, USTA: excelencia que transforma el país, I44.

348 Creado en octubre del 20I2, Alzate, UsTA: excelencia que transforma el país, 143 .

349 Universidad Santo Tomás, Informe de autoevaluación Sede Principal $2014-2015,54$.

350 Entrevista con Diana Carolina Godoy Acosta, 20 de octubre de 2oi6, Archivo Ieshfaz, Universidad Santo Tomás.

35I Entrevista con Eduardo González Gil, II de noviembre de 2016, Archivo IEshfaz, Universidad Santo Tomás.

352 Universidad Santo Tomás, Documento marco. Proyección Social, I4.

353 Universidad Santo Tomás, Documento marco. Proyección Social, I5-I7.

354 Universidad Santo Tomás, Informe de autoevaluación Sede Principal $2014-2015$, 100 


\section{8}

\section{Madurez institucional I995-20I8}

355 Universidad Santo Tomás, Informe de autoevaluación Sede Principal 2014-2015, 64-65.

356 Universidad Santo Tomás, Documento marco. Proyección Social, I5-17. 357 Universidad Santo Tomás, Informe de autoevaluación Sede Principal 2014-2015, I09.

358 Universidad Santo Tomás, Informe de autoevaluación Sede Principal 20I4-2015, II3.

359 A saber, el Instituto Católico de París, la Universidad de Montesquieu - Bordeaux IV, la Universidad de Cergy - Pontoise, la Universidad Pontificia Bolivariana de Medellín y la Universidad de La Colima en México; Universidad Santo Tomás, Informe de autoevaluación Sede Principal 2014-20I5, III.

360 Universidad Santo Tomás, Informe de autoevaluación Sede Principal 20I4-20I5, II2.

36I Alzate, USTA: excelencia que transforma el país, 67-76.

362 "Nace el Instituto de Victimología Tomasino", Centro Virtual de Noticias de la Educación, consultado el I4 de diciembre, 20I6, http://www.mineducacion.gov.co/cvn/I665/w3-article-265489. html. E "Instituto de Victimología de la Universidad Santo Tomás de Bucaramanga: investigación al servicio de las víctimas", Ambitojurídico.com, Consultado el i4 de diciembre, 2016, https://www.ambitojuridico.com/BancoConocimiento/Educaciony-Cultura/noti-I20710-o6-instituto-de-victimologia-de-la-universidad-santo-tomas-de-bucaramanga-investigacio

363 "Instituto de Victimología", Universidad Santo Tomás Bucaramanga. Consultado el I4 de diciembre, 20I6, http://www.ustabuca.edu. co/ustabmanga/instituto-de-victimologia

364 “Capacitación victimología”, Universidad Santo Tomás Bucaramanga. Consultado el I4 de diciembre, 20I6, http://www.ustabuca.edu. co/post3729336/capacitacion-victimologia-

365 "Maestría en Reconciliación y Convivencia con énfasis en Derechos Humanos y Victimología", Universidad Santo Tomás Bucaramanga. Consultado el I4 de diciembre, 20I6, http://www. ustabuca.edu.co/gpresenzia/vista/tpl/ustabmanga/maestria-en-reconciliacion-y-convivencia.html

366 Entrevista con Héctor Fabio Jaramillo, 2 de septiembre de 20I6, Archivo Ieshraz, Universidad Santo Tomás.

367 Alzate, USTA: excelencia que transforma el país, I 47 .

368 "Presentación Instituto de Victimología Fr. Bartolomé de las Casas, O. P.", Centro de Estudios para la Paz, Fray Bartolomé de las Casas, O.P. Consultado el 23 de noviembre, 20I6. http://www. ustatunja.edu.co/ustatunja/index.php/quienes-somos-victimologia

369 Reconciliación Colombia y Prodepaz son dos casos paradigmáticos. Entrevista con Juan José Gómez, 25 de octubre de 2016, Archivo Ieshraz, Universidad Santo Tomás.

370 Alzate, USTA: excelencia que transforma el país, 4I-48.

37I Alzate, USTA: excelencia que transforma el país, 46.

372 Universidad Santo Tomás, Informe de autoevaluación Sede Principal 20I4-20I5, 86.

373 Universidad Santo Tomás, Informe de autoevaluación Sede Principal 20I4-20I5, 83 .

374 Universidad Santo Tomás, Informe de autoevaluación Sede Principal 20I4-20I5, 90.

375 Entrevista con Carlos Eduardo Marcucci, I6 de septiembre de 20I6, Archivo Ieshfaz, Universidad Santo Tomás.

376 Alzate, USTA: excelencia que transforma el país, I44.

377 Alzate, USTA: excelencia que transforma el país, 30.

378 Universidad Santo Tomás, Informe de autoevaluación Sede Orincipal 20I4-2015, 38 .
379 Universidad Santo Tomás, Informe de autoevaluación Sede Principal 20I4-20I5, 44.

380 Universidad Santo Tomás, Informe de autoevaluación Sede Principal 20I4-20I5, 40.

38I Universidad Santo Tomás, Informe de autoevaluación Vicerrectoría de Educación Abierta y a Distancia 20I4-20I5, 49.

382 Erico Macchi, O. P., Informe de gestión 20II-II - 20I4-I. Vicerrectoría de Universidad Abierta y a Distancia (Bogotá: Universidad Santo Tomás, 20I4), 56

$383 \mathrm{Macchi}$, O. P., Informe de gestión $20 I I-I I-20 I 4-I$. Vicerrectoría de Universidad Abierta y a Distancia, 75.

384 Universidad Santo Tomás, Informe de autoevaluación Vicerrectoría de Educación Abierta y a Distancia 20I4-2015, 62.

385 Universidad Santo Tomás, Informe de autoevaluación Vicerrectoría de Educación Abierta y a Distancia 20I4-20I5, 55.

386 Universidad Santo Tomás, Informe de autoevaluación Bucaramanga 2014-20I5, 48.

387 Alzate, USTA: excelencia que transforma el país, I44.

388 Universidad Santo Tomás, Informe de autoevaluación Bucaramanga 2014-20I5, 39 .

389 Universidad Santo Tomás, Informe de autoevaluación Bucaramanga 20I4-20I5, 94 y 97 .

390 Universidad Santo Tomás, Informe de autoevaluación Bucaramanga 2014-2015, 49.

39I Universidad Santo Tomás, Informe de autoevaluación Bucaramanga 2014-20I5, II 2 .

392 Universidad Santo Tomás, Informe de autoevaluación con fines de acreditación institucional 20I4-2015. Seccional Tunja, 62.

393 Universidad Santo Tomás, Informe de autoevaluación con fines de acreditación institucional 20I4-20I5. Seccional Tunja, 63.

394 Universidad Santo Tomás, Informe de autoevaluación con fines de acreditación institucional 20I4-20I5. Seccional Tunja, 63.

395 “Diplomado de Reconciliación y Paz", Universidad Ssanto Tomás Tunja, Consultado el I4 de diciembre, 20I6, http://www.ustatunja.edu.co/ustatunja/index.php/departamento-de-humanidades/ eventos-humanidades/item/2619-diplomado-reconciliacion-paz

396 Universidad Santo Tomás, Informe de autoevaluación con fines de acreditación institucional 20I4-20I5. Seccional Tunja, 66.

397 Universidad Santo Tomás, Informe de autoevaluación con fines de acreditación institucional 20I4-20I5. Seccional Tunja, Ioo.

398 Universidad Santo Tomás, Informe de autoevaluación con fines de acreditación institucional 20I4-2015. Decanatura de división Medellin, 38 .

399 Universidad Santo Tomás, Informe de autoevaluación con fines de acreditación institucional 20I4-20I5. Decanatura de división Medellin, 45-46.

400 Universidad Santo Tomás, Informe de autoevaluación Villavicencio 20I4-20I5, 35 .

40I Universidad Santo Tomás, Informe de autoevaluación Villavicencio 2014-2015, 78.

402 Universidad Santo Tomás, Informe de autoevaluación Villavicencio 20I4-2015, 82.

403 Universidad Santo Tomás, Informe de autoevaluación Villavicencio 2014-20I5, 35 .

404 Universidad Santo Tomás, Informe de autoevaluación Villavicencio 2014-2015, 36.

405 "Fray Juan Ubaldo López Salamanca, O. P., nuevo rector general", Historial Tomás Noticias. Consultado el I4 de diciembre, 


\section{9}

\section{Madurez institucional I995-20I8}

20I6, http://antiguotomasnoticias.usta.edu.co/index.php/2014-09I8-22-37-35/884-fray-juan-ubaldo-lopez-salamanca-o-p-nuevorector-general

406"Nuevo rector del Primer Claustro Universitario de Colombia", Universidad Santo Tomás Medellín, Consultado el I4 de diciembre, 2or6, http://www.ustamed.edu.co/index.php/noticias/218-nuevo-rector-general-del-primer-claustro-universitario-de-colombia

407 Juan Ubaldo López Salamanca, Wálter Yesid Rivera Flórez y Wilmar Yesid Ruiz Cortés, Economía y bumanismo: actualidad de una propuesta dominicana (Editorial Universidad Santo Tomás: Bogotá, 20Io). http://scienti.colciencias.gov.co:808I/cvlac/visualizador/generarCurriculoCv.do?cod_rh $=0000512737$

408 Alzate, USTA: excelencia que transforma el país, I55.

409 Fray Juan Ubaldo López Salamanca, Discurso de posesión, I7 de julio de 2015 .

4IO Fray Juan Ubaldo López Salamanca, Discurso de posesión, I7 de julio de 2015 .

4II José Antonio Balaguera, "Palabras de ceremonia de acreditación", en Aquino's Cuentan. Boletin Informativo de Sedes y Seccionales (Ediciones USTA: Bogotá, octubre de 2016), 44-50.

4I2 Ministerio de Educación Nacional, Resolución n. o 1456.29 de enero de 2016

4I3 Ministerio de Educación Nacional Resolución n.o OI 456.29 de enero de 2016.

4I4 Consejo Nacional de Acreditación, Informe de evaluación externa con fines de acreditación - Informe institucional, Fol. 5. Archivo IESHFAZ.

4I5 Entrevista con Héctor Fabio Jaramillo, 2 de septiembre de 20I6, Archivo IEshfaz, Universidad Santo Tomás.

4I6 Consejo Nacional de Acreditación, Informe de evaluación externa con fines de acreditación - Informe institucional, Fol. 79-83. Archivo IEshraz.

4I7 Consejo Nacional de Acreditación, Informe de evaluación externa con fines de acreditación - Informe institucional, Fol. 4. Archivo IESHFAZ.

4I8 Universidad Santo Tomás, Documento Sintesis Plan Integral Multicampus 2016-2027 - Plan General de Desarrollo 2016-2019 (Bogotá: Universidad Santo Tomás, 2017), 35-37.

4I9 Universidad Santo Tomás, Documento sintesis Plan Integral Multicampus 2016-2027 - Plan General de Desarrollo 2016-20I9 (Bogotá: Universidad Santo Tomás, 20I7), 7. Consultado el 28 de junio, 20I8. http://planeacion.usta.edu.co/index.php/publicaciones/ documentos-institucionales

420 Universidad Santo Tomás, Documento sintesis Plan Integral Multicampus 20I6-2027 - Plan General de Desarrollo 20I6-20I9 (Bogotá: Universidad Santo Tomás, 20I7), 3.

42I Universidad Santo Tomás, Departamento de Planeación y Desarrollo, Diccionario Plan Integral Multicampus. Consultado el 28 de junio de 2018 , http://planeacion.usta.edu.co/index.php/planeacion-en-la-usta/planeacion-integral-multicampus-pim-2016-2017/ diccionario-pim

422 Universidad Santo Tomás, Documento sintesis Plan Integral Multicampus 2016-2027 - Plan General de Desarrollo 20I6-20I9 (Bogotá: Universidad Santo Tomás, 20I7), 43.

423 Juan Ubaldo López Salamanca, "Informe de Gestión, Junio 2015-2017" (Bogotá: Universidad Santo Tomás, 2017), 9.

424 Universidad Santo Tomás, Documento sintesis Plan Integral Multicampus 2016-2027 - Plan General de Desarrollo 2016-2019 (Bogotá: Universidad Santo Tomás, 2017), 53.

425 Ibíd., 54-55.
426 Ibíd., 56-57.

427 Ibíd., 58-59.

428 Ibíd., 6o-6r.

429 Ibíd., 62-64.

430 Entrevista con fray Juan Ubaldo López Salamanca, O. P., I4 y I8 de junio de 2018.

43I Universidad Santo Tomás, "Directivos usta Colombia iniciaron jornadas de trabajo con relación a la primera línea del Plan General de Desarrollo (PGD) 20I6-20I9", Aquino's Cuentan. Boletín informativo de sedes y seccionales. 20I7-I (Ediciones Usta: Bogotá, noviembre de 20I7), 42-43.

432 López Salamanca, O. P., Informe de Gestión, Junio 20I5-20I7 (Bogotá: Universidad Santo Tomás, 2017), I2-I3.

433 Entrevista con fray Juan Ubaldo López Salamanca, O. P., I4 y I8 de junio de 2018 .

434 Entrevista con fray Juan Ubaldo López Salamanca, O. P., I4 y I8 de junio de 2018 .

435 Centro de Evangelización y Cultura, Plan de Evangelización Permanente Multicampus - USTA Colombia 2027, Fol. 2. Documento facilitado por el Centro de Evangelización y Cultura.

436 http://www.srg.com.co/ascsapiens.php

437 López Salamanca, O. P., Informe de Gestión, Junio 2015-20I7, 30-31.

438 Universidad Santo Tomás, "II revistas indexadas de la Universidad en una de las bases de datos mundiales más importantes", Aquino's Cuentan. Boletín informativo de sedes y seccionales. 20I6-II (Ediciones USTA: Bogotá, noviembre de 20I7), 2I.

439 Entrevista con fray Juan Ubaldo López Salamanca, O. P., I4 y I8 de junio de 2018.

440Ascún, "Consejo Nacional de Rectores se reunió en Bogotá". Consultado el i4 de diciembre, 20I6, https://www.ascun.org.co/ noticias/detalle/consejo-nacional-de-rectores-se-reunio-en-bogota

44I Entrevista con fray Juan Ubaldo López Salamanca, O. P., I4 y I8 de junio de 2018.

442 Universidad Santo Tomás, "El Ministerio de Educación Nacional entregó a la Universidad Santo Tomás la Orden a la Acreditación Institucional de Alta Calidad de la Educación Superior Francisco José de Caldas", Aquino's Cuentan. Boletín informativo de sedes y seccionales. 20I6-II (Ediciones UsTA: Bogotá, noviembre de 2017), I5-16.

443 Entrevista con fray Juan Ubaldo López Salamanca, O. P., I4 y I8 de junio de 2018 .

444 Universidad Santo Tomás, "II Encuentro de Radios Dominicas de Latinoamérica y el Caribe", Tomás Noticias. Disponible: http:// www.usta.edu.co/index.php/tomas-noticias/noticias-de-la-sema$\mathrm{na} /$ item/828-ii-encuentro-de-radios-dominicas-de-latinoamerica-y-el-caribe

445 Orden de Predicadores, "Declaración Final del Congreso Salamanca sobre los derechos humanos de 2016 ". Disponible: http://www. op.org/es/content/declaracion-final-del-congreso-salamanca-sobre-los-derechos-humanos-de-20I6

446 Orden de Predicadores, Congreso Internacional para la Misión de la Orden - Roma, 2017

447 Juan Ubaldo López Salamanca, "Visita del maestro de la Orden de Predicadores a la Universidad Santo Tomás", Aquino's Cuentan. Boletin informativo de sedes y seccionales (Ediciones USTA: Bogotá, 20I7), IO-II.

448 Revista Time, "Colombia. On the verge of securing peace," Time, diciembre I9 de 2016 , pág. S5. 


\section{0}

\section{Madurez institucional I995-20I8}

449 Universidad Santo Tomás, "Universidad Santo Tomás se sumó al ranking mundial de investigación Scimago", Aquino's Cuentan. Boletín informativo de sedes y seccionales. 20I7-I (Ediciones USTA: Bogotá, noviembre de 2017), I7-19.

450 Universidad Santo Tomás, "Rector general de la Universidad Santo Tomás participó en encuentro franco-colombiano", Tomás Noticias, 4 de julio de 20I7. Disponible en: http://www.usta.edu. co/index.php/tomas-noticias/el-rector-nos-cuenta/item/r677-rector-general-de-la-universidad-santo-tomas-participa-en-encuentro-franco-colombiano

45I Universidad Santo Tomás, "Rector general participó en capacitación sobre rankings de educación superior". Tomás Noticias, 2I de julio de 20I7. Disponible en: http://www.usta.edu.co/index.php/ tomas-noticias/el-rector-nos-cuenta/item/r960-rector-general-participo-en-capacitacion-sobre-rankings-de-educacion-superior

452 Entrevista con fray Juan Ubaldo López Salamanca, O. P., I4 y I8 de junio de 2018.

453 Universidad Santo Tomás, Informe del rector general al Capitulo Provincial 20I8. Bogotá, 2018.

454 Revista The Business Year, "Give peace a chance [entrevista con fray Juan Ubaldo López Salamanca, O. P.]”, The Business Year. Colombia, 20I7, pág. I63.

455 Revista Semana, "Educación Humanista", Revista Semana - Esta Bogotá Promete, noviembre de 20I7, pág. 26-27.

456 Véase: IFC, https://disclosures.ifc.org/\#/projectDetail/SII/4042I e IFC, https://disclosures.ifc.org/\#/projectDetail/ESRS/4042I

457 Universidad Santo Tomás, "Culmina la Cres 2018 con el compromiso de transformar la educación superior", Tomás Noticias. Disponible en: http://www.usta.edu.co/index.php/tomas-noticias/ educacion/item/4572-culmina-la-cres-20I8-con-el-compromisode-transformar-la-educacion-superior

458 Universidad Santo Tomás, Documento sintesis Plan Integral Multicampus 2016-2027 - Plan General de Desarrollo 2016-2019 (Bogotá: Universidad Santo Tomás, 20I7), 59.

459 Universidad Santo Tomás, "La Universidad de Lanús y el Cedlac visitaron la Universidad Santo Tomás con el fin de afianzar la internacionalización de los posgrados", Universidad Santo
Tomás, Aquino's Cuentan. Boletin informativo de sedes y seccionales. 20I6-II, pp. 22-23. Ediciones Usta: Bogotá, noviembre de 2017.

460 Entrevista con fray Juan Ubaldo López Salamanca, O. P., I4 y I8 de junio de 2018 .

46I Universidad Santo Tomás, "I." de octubre de 20r6: inicio de la construcción del edificio Santo Domingo", Aquino's Cuentan. Boletin informativo de sedes y seccionales. 2016-II (Ediciones USTA: Bogotá, noviembre de 20I7), 96-97.

462 Universidad Santo Tomás, "Sede Medellín le apuesta al crecimiento y a la calidad con la nueva sede de posgrados en E1 Poblado", Aquino's Cuentan. Boletín informativo de sedes y seccionales. 20I7-I (Ediciones USTA: Bogotá, noviembre de 20I7), II2.

463 Entrevista con fray Juan Ubaldo López Salamanca, O. P., I4 y I8 de junio de 2018.

${ }_{464}$ Las Normas Internacionales de Información Financiera (NIIF) o "International Financial Reporting Standards" (IFRS) son un conjunto de normas contables emitidas por el Comité de Normas Internacionales de Contabilidad (International Accounting Standards Board, IASB) con sede en Londres. Estas normas establecen parámetros de reconocimiento, medición y presentación de información financiera a revelar sobre las transacciones y hechos económicos que afectan a una organización.

465 Universidad Santo Tomás, Boletin Estadístico 20I8-I (Bogotá: Universidad Santo Tomás, 2018).

466 Universidad Santo Tomás, Boletín Estadístico 20I6-II, I8. (Bogotá: Universidad Santo Tomás, 20I7)

467 Universidad Santo Tomás, Boletín Estadístico 20I6-II, I9.

468 Usme, Cazucá, Chapinero, Suba Gaitana, en Bogotá; Comuneros, en Bucaramanga; Altamira, en Tunja; Aguas Claras y Comuna 3 , en Villavicencio; Bello Horizonte, en Medellín. Universidad Santo Tomás, Boletin Estadístico 20I6-II, 20-2I.

469 Universidad Santo Tomás, Boletín Estadístico 20I6-II, 22.

470 Universidad Santo Tomás, Tomás Noticias. "Universidad Santo Tomás celebró su fiesta patronal”, 7 de marzo de 20I8. Disponible: http://www.usta.edu.co/index.php/tomas-noticias/comunidad-tomasina/item/2449-con-nuevas-esculturas-de-san-alberto-y-su-discipulo-tomas-celebramos-nuestra-fiesta-patronal 


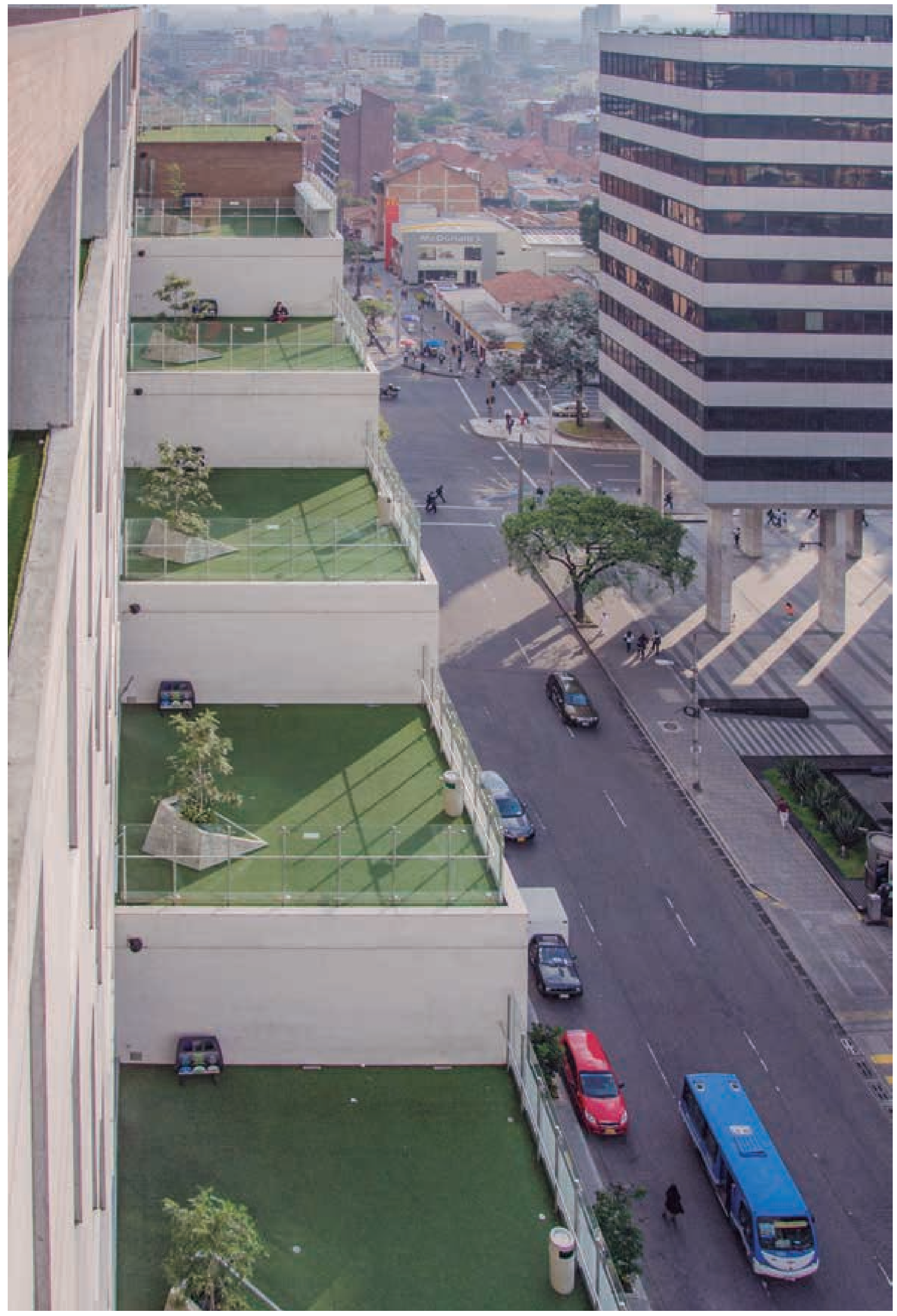




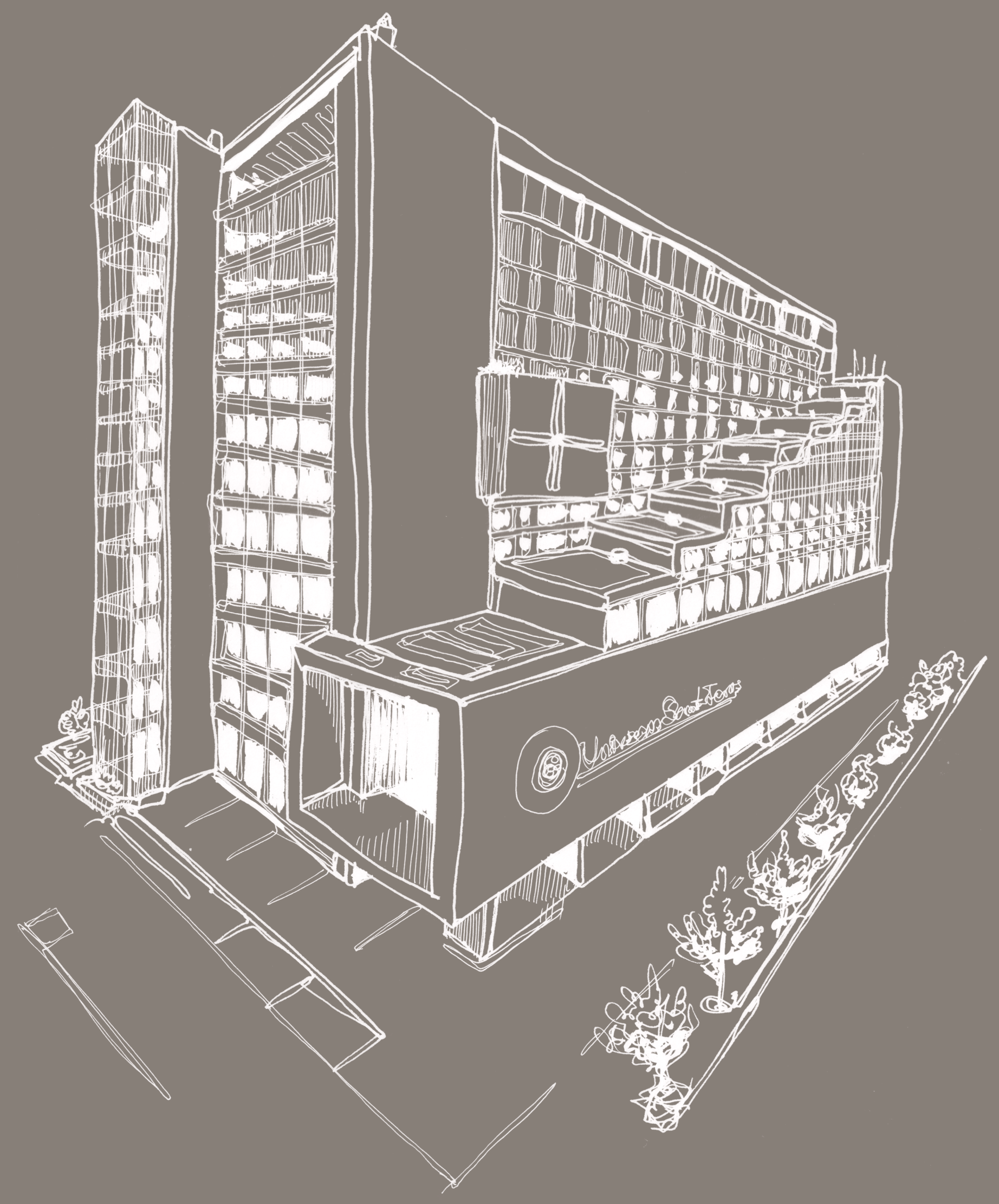

